\title{
A LATENT GROWTH ANALYSIS OF UNDERGRADUATE DEGREE PRODUCTION
}

\author{
A Dissertation \\ Presented to \\ The Faculty of the Curry School of Education \\ University of Virginia \\ In Partial Fulfillment \\ of the Requirements for the Degree \\ Doctor of Philosophy \\ by \\ Rebecca D. Blanchard, B.S., M.Ed.
}

August, 2010 
(C) Copyright by

Rebecca D. Blanchard

All Rights Reserved

August 2010 
ABSTRACT

Dr. Timothy Konold

A theoretical framework based on prestige-maximization is used to identify four time-varying inputs in the production of undergraduate degrees at non-profit colleges and universities. The longitudinal relationship between these inputs (academic expenditures, research funding, faculty quality, and student quality) and the output (undergraduate degrees per FTE) was estimated at the institutional level between 1997 and 2007 with latent growth modeling. Separate models were estimated for institutions producing social science degrees $(n=1,145)$ and physical science degrees $(n=1,114)$. Collinearity diagnostics mandated the exclusion of academic expenditures; thus, interpretations of results were limited. The remaining three inputs were significantly related $(\mathrm{p}<.05)$ to degree production in both models, but an increase in each of these prestige-maximizing inputs did not uniformly produce increased degree rates. 
Leadership, Foundations, and Policy

Curry School of Education

University of Virginia

Charlottesville, Virginia

\section{APPROVAL OF THE DISSERTATION}

This dissertation, "A Latent Growth Analysis of Undergraduate Degree Production," has been approved by the Graduate Faculty of the Curry School of Education in partial fulfillment of the requirements for the degree of Doctor of Philosophy.

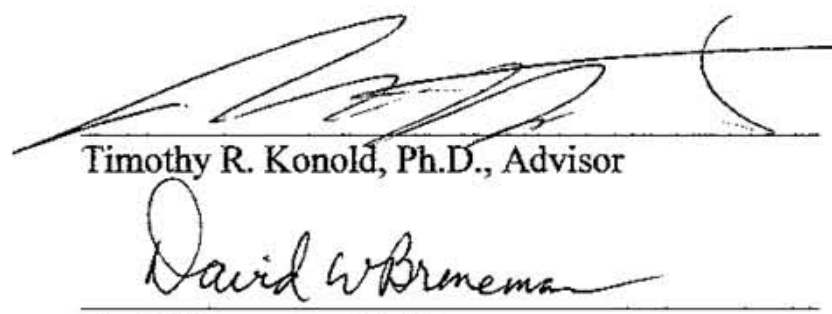

David Breneman, Ph.D.

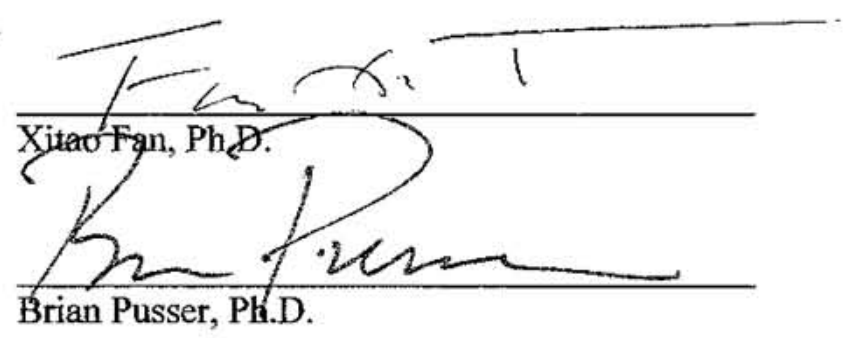




\section{ACKNOWLEDGEMENTS}

I am pleased to thank the members of my committee including Dr. Brian Pusser, Dr. David Breneman, and Dr. Xitao Fan whose comments and guidance consistently made this work better and whose patience and support made this process successful. It is especially a pleasure to thank my chair and advisor, Dr. Timothy Konold, for patiently and frequently keeping me sane. His academic guidance was invaluable, and his humor was always well timed. Dr. Konold's encouragement largely contributed to the success of this process.

Indeed, the journey of writing this dissertation succeeded because of the support from many special people. I thank my good friends and Charlottesville support staff, Barbara Schmertz and Amy Swan, for always knowing what I mean and for helping me laugh when I needed to. For encouraging me with the same amount of love, advice, and friendship that they have given me since the fifth grade, I thank my best friends of 23 (23!) years; Robin Erlandsen, Molly Nace, Kelli McAlister, and Nora Grenager.

I am sincerely overwhelmed and especially blessed to have enjoyed the unending encouragement of my family members who often changed their lives to give the time and support I needed in this journey. I truly appreciate Ed Blanchard for being so proud and

so encouraging. I am indebted to Carol Blanchard for always doing too much for me, and am grateful for the fun, relief, and decorations that came with each of her visits. I especially thank my parents, Rich and Judy Seldow for making education a priority in my 
life and for exemplifying the values of hard work and love of family. While they have always encouraged me to reach my potential, in the past four years they provided an overwhelming amount of time, effort, and encouragement so that I could.

I thank my big brother, Adam Seldow, for being my role model. Perhaps more than he knows, I rely on his sympathetic humor, educated perspective, and infinite support. I am also grateful for my beautiful sisters-in-law, Gayle Ryan and Barbara Beaudoin, who took time from their hectic lives to be here when I needed them. I am in awe of their strength, humor, and compassion and am so proud to have them as friends and sisters. I also cherish the humor, support, and love that I got in countless ways from Kathy Seldow, Danny Beaudoin, and Tim Ryan during this journey. Special thanks to Gabe Seldow, Naomi Seldow, Ben Ryan, Ansley Ryan, and Bruce Ryan for supporting their Auntie Becca.

I am also eternally grateful for my husband, Dano, who gave up four seasons of ice fishing to champion this adventure with his love, laughter, and patience. So much of this accomplishment is the result of his fortitude, and I am forever aware of how lucky I am.

Lastly, I am beyond thankful for our funny, handsome, and loving son, Cal, for so often being the sunshine that lights my way.

This work is dedicated to my guys: no one loves you more than me. 


\section{TABLE OF CONTENTS}

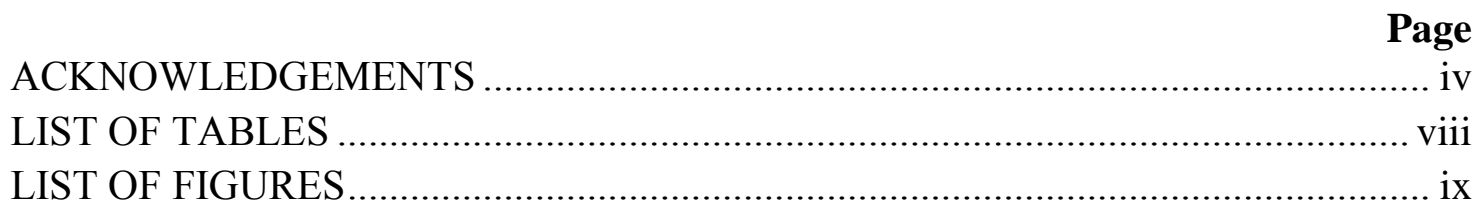

\section{CHAPTER}

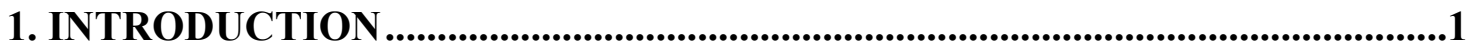

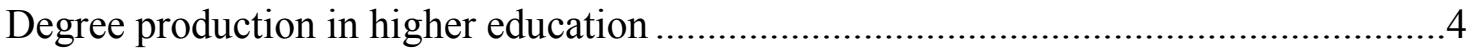

Prestige and degree production ......................................................................

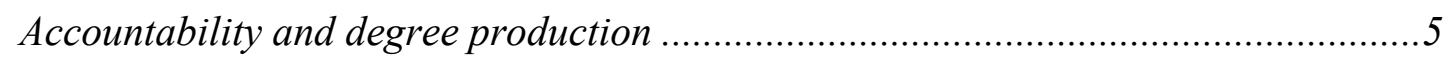

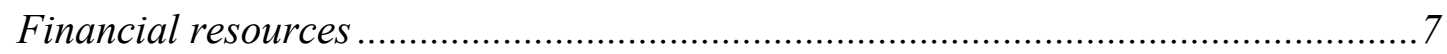

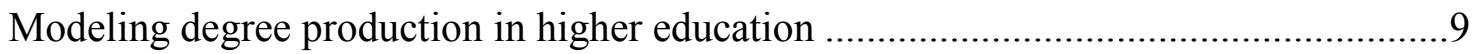

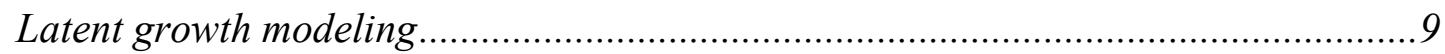

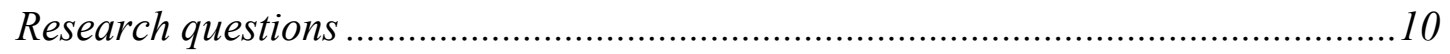

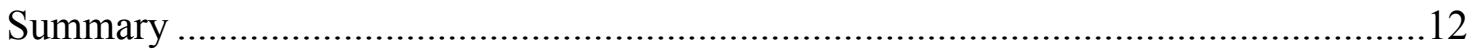

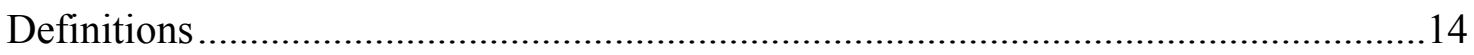

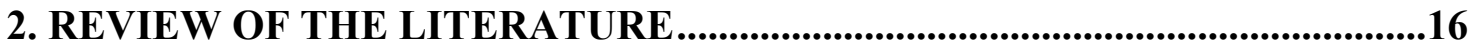

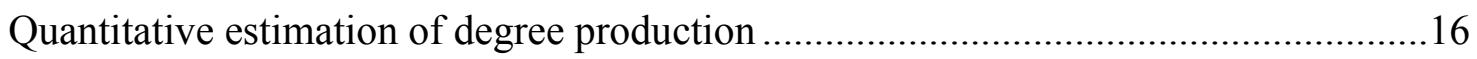

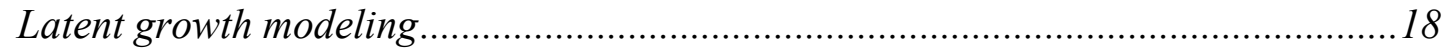

Specifying a model of undergraduate degree production............................................21

Degree production in the social sciences and physical sciences ..............................22

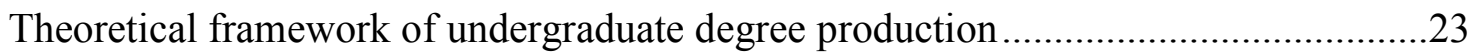

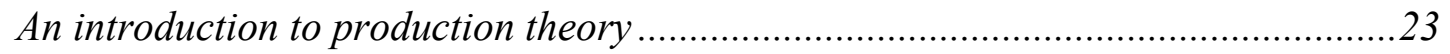

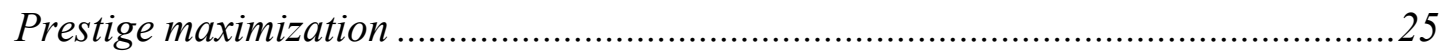

Resources contributing to the production of undergraduate degrees ............................32

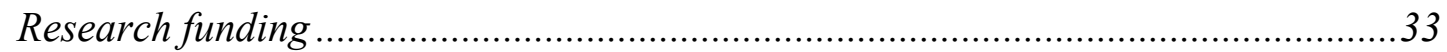

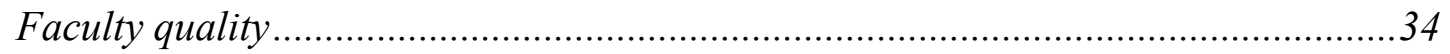

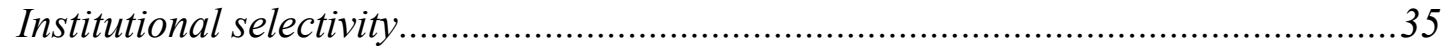

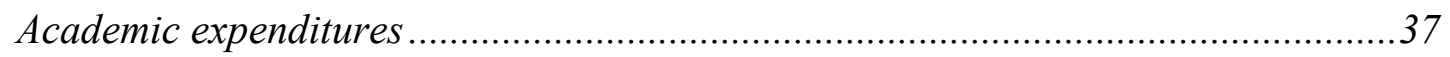

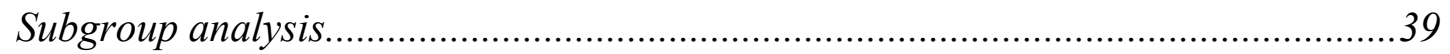

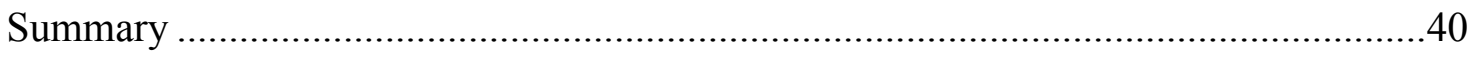

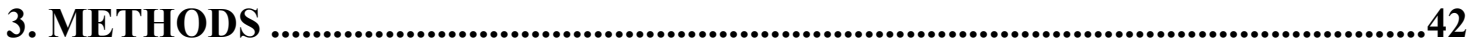

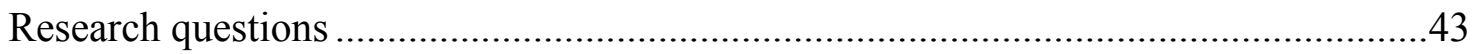




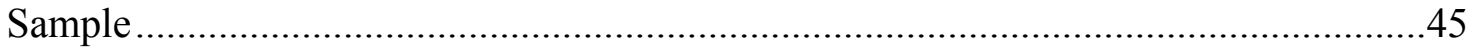

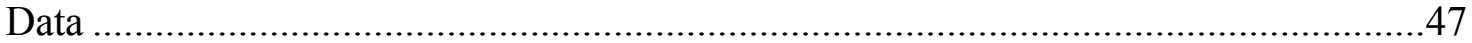

Social sciences and physical sciences ................................................................ 48

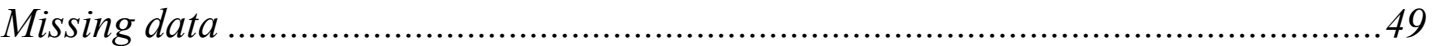

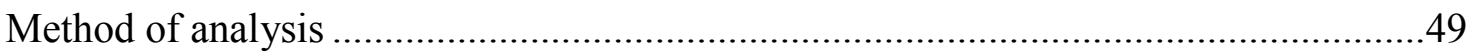

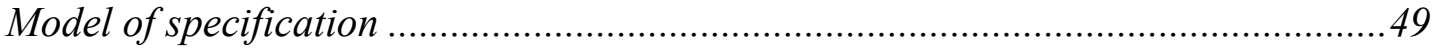

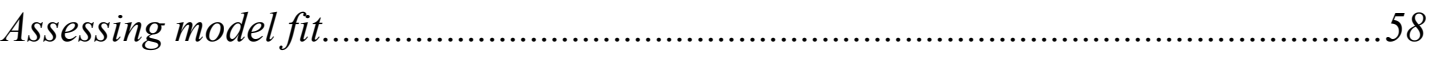

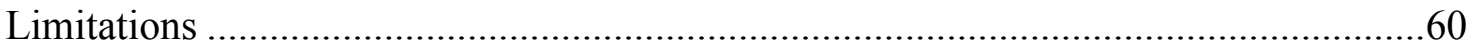

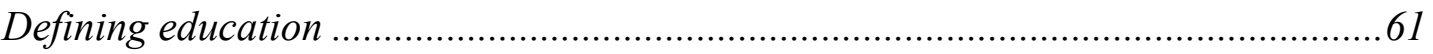

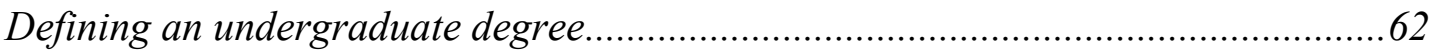

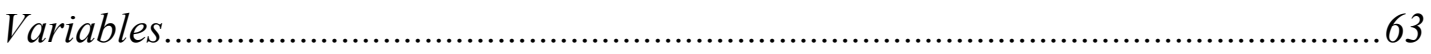

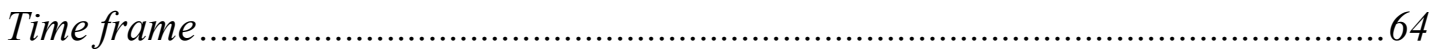

Interpretation of a production function for higher education .................................65

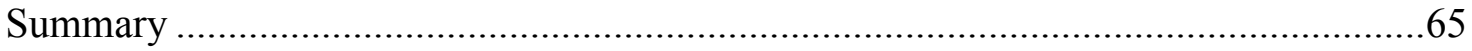

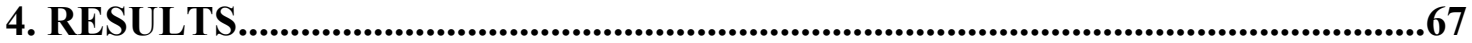

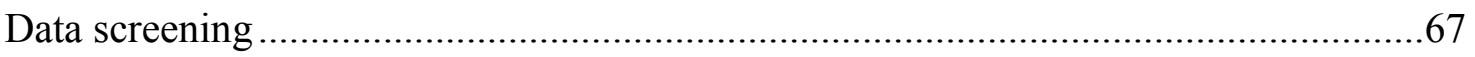

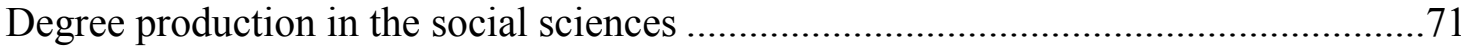

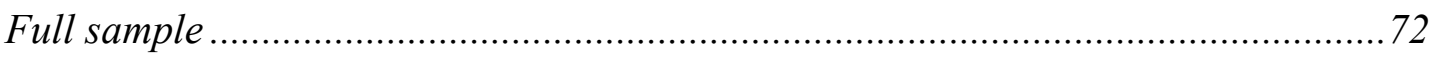

Subgroup analysis: public vs. private institutions................................................. 76

Subgroup analysis: institutions with and without medical schools .........................80

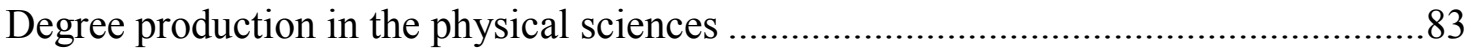

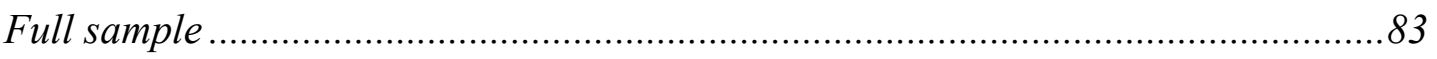

Subgroup analysis: public vs. private institutions............................................... 87

Subgroup analysis: institutions with and without medical schools ..........................89

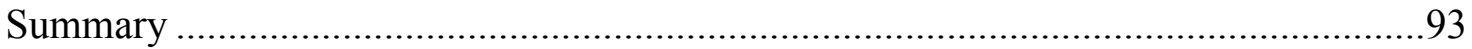

5. DISCUSSION

Interpretation of results ...........................................................................................95

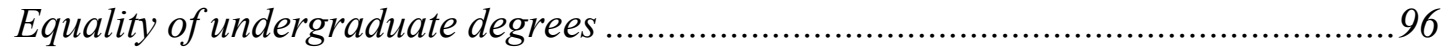

Prestige and degree production .......................................................................96

Latent growth modeling at the institutional level ................................................. 104

Recommendations for future research............................................................ 106

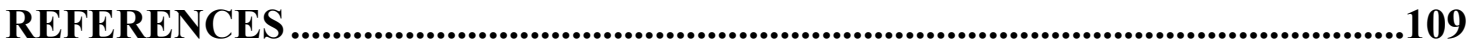

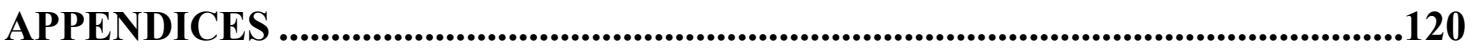




\section{LIST OF TABLES}

$\begin{array}{lll}\text { TABLE } & \text { Page }\end{array}$

1. Descriptive statistics for outcome variables........................................................69

2. Descriptive statistics for schools producing social science degrees …………...........70

3. Descriptive statistics for schools producing physical science degrees .......................70

4. Standardized growth curve estimates: degrees in the social sciences ........................82

5. Standardized growth curve estimates: degrees in the physical sciences ....................92 


\section{LIST OF FIGURES}

FIGURE $\quad$ Page

1. Unconditional latent growth model for undergraduate degrees per FTE ..................53

2. Conditional latent growth model with time-varying predictors ............................56

3. Conditional model without academic expenditures .........................................68

4. Unconditional model of social sciences degrees per FTE at public institutions with

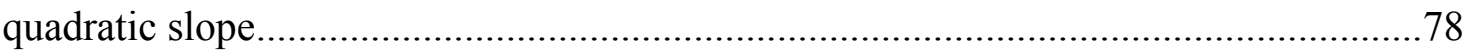




\section{CHAPTER 1}

\section{INTRODUCTION}

In the midst of a national discourse regarding the productivity of higher education institutions was President Barack Obama's address to the Joint Session of Congress in which he promised that "by 2020, America will once again have the highest proportion of college graduates in the world," (Obama, 2009, II 66). With high expectation for degree production and harsh economic realities, universities are being challenged - by many stakeholders - to do more with less. Clearly, the need for answers in this area is being met with greater urgency than ever before, and researchers must meet this demand.

In the context of higher education, productivity can be defined as the relationship between a set of inputs, or resources, and a certain amount of outputs. Generally, researchers have examined the ability of colleges and universities or their faculty to produce student outputs, such as degrees, with the lowest level of inputs possible. In this way, productivity growth can be achieved by increasing the quantity or quality of outputs produced by a consistent quantity of inputs, or by maintaining output levels with a lower quantity or quality of inputs. To this end, examination of the production of undergraduate degrees would be a helpful window into one aspect of the very large discussion on productivity in higher education.

Calls for productivity research in higher education have always been on the academic stage, but recent economic struggles have moved them into the spotlight. In 
2009, an article by William Massy appeared in The Chronicle of Higher Education which called for an investigation into academic productivity. He wrote "we simply can't afford to dodge the hard questions of academic productivity any longer. Continuing to do so will lead to an accelerating decline in educational quality, not to mention dereliction-of-duty charges by our critics,” (Massy, 2009, \3). Six months later, the Delta Cost Project published a report by Patrick Kelly which ranked states by the productivity of their public higher education institutions. The report listed the states that produced the most and fewest degrees per dollar and suggested that less-costly degrees provided greater economic value to the state (Kelly, 2009). This report was the most recent in a series of articles and publications either documenting or addressing the need for research on degree production in higher education.

Campus leaders attempting to improve their university's productivity have often focused on either increasing outputs or improving their quality. However, these targets are ineffective if considered alone. Increasing institutional outputs requires that managerial decisions rely on some assumptions about the outputs and the production process of those outputs (Cohn \& Geske, 1990). Many campus and state leaders use graduation rates as their sole measure of output, but "a $100 \%$ graduation rate is neither likely nor socially optimal...Universities could achieve a higher graduation rate by lowering curricular standards or by encouraging more grade inflation," (Archibald \& Feldman, 2008, p. 81). Thus, tracking this measure by itself gives little indication of resources - financial or human - available to the institution.

Study of educational production processes provides some sense of the process by which outputs are generated. If a university president wants to see an increase in 
graduation rates, she would benefit from an understanding of the influences of various resources on the production of graduates. After all, the exploration of institutional output is worth little if it is not couched in an understanding of institutional resources. Kelly (2009) argues this point by noting:

For example, a 60 percent graduation rate at an institution that serves high proportions of low-income and minority students probably deserves more applause than an institution with an 80 percent graduation rate that is highly selective and serves students from predominately privileged families. (p. 6)

In short, there exists a need for some indication of value-added measures. Thus, evaluation of student graduation rate must consider the quality of incoming students. A productivity ratio - in which the output is considered in light of the resources - allows some investigation into the relative nature of production.

The specification of this type of production function in higher education is necessary for management decisions, statistic interpretations, and effective policy writing. To be sure, the basis of many decisions about higher education processes rests on the assumptions of higher education degree production. Examination of institutional productivity is more relevant for institutional leaders than simply tracking output measures or relying on quality indicators. Estimating the process of degree production at institutions is not only worthwhile but is necessary before an investigation can explore the change in production over time, which allows some grounds for understanding the impact of management decisions and institutional processes. 


\section{Degree Production in Higher Education}

The main incentives for colleges and universities to increase degree production are prestige, accountability, and funding considerations. However, emphasizing the demands of one consideration may also hamper progress towards another, as the mechanisms for increasing prestige do not always favor the standards of legislative accountability. Often, institutions must prove that they are cutting costs and increasing productivity to satisfy restricted funding and/or accountability standards while also proving that they are increasing prestige - a status often positively correlated with institutional spending. However difficult they are to maintain simultaneously, prestige, accountability, and funding are three primary factors influencing the production of degrees.

\section{Prestige and Degree Production}

The relative performance of institutions with regard to degree production can be viewed from the position and performance of peer institutions. Increasing degree production is helpful for improving institutional ranking (Porter \& Toutkoushian, 2006), and institutions are driven to improve their reputations in a perpetual cycle of competition for prestige. Frank and Cook (1995) described the higher education environment as a "positional arms race" (p. 131), in which institutions must invest in their production processes in order to maximize their prestige. Indicative of this perpetual prestige cycle is the popularity of commercial rankings. In the absence of alternative mechanisms for institutional quality assessment, reputation rankings, such as those published by Barron's or US News and World Report, have driven the public's

opinion of institutions. Some of the "prizes" at stake for institutions with better 
rankings in this arms race include access to better students, better faculty, and larger alumni donations. These "inputs" are necessary to produce the outputs, including undergraduate degrees as well as quality alumni and faculty research which, in turn, attract grant money and additional high quality faculty. Improving degree production processes, or producing more and/or better quality outputs with the same or fewer inputs, can result in better quality inputs for the future.

\section{Accountability and Degree Production}

The accountability movement has also spearheaded the call for productivity growth. After all, accountability and productivity are closely related. Productivity is a ratio of outcomes to resources, and accountability is the obligation to ensure that this ratio is maximized (Bowen, 1980). The influence of both concepts gained traction in the political forum with the increase in popularity of higher education. Legislators and campus leaders began to respond to public concerns about university matters as college became a more universal experience. Higher education enrollment in the United States in both public and private universities more than doubled between 1970 and 2007 (National Center for Education Statistics [NCES], 2009). This "massification" of college attendance made college and university matters a priority for the public and, thus, a priority for state policymakers (Alexander, 2000).

However, government support was increasingly scarce: as a percentage of total revenue to public institutions, state government support declined from $45.6 \%$ in 1980 to $35.6 \%$ in 2000 (NCES, 2009). ${ }^{1}$ Private institutions saw their third most important

\footnotetext{
${ }^{1}$ Longanecker (2006) wrote that the relationship between state appropriations and tuition is interpreted differently by the stakeholders involved. By relying on different statistics, blame for increased tuition can
} 
revenue source, federal grants and contracts, decline as well (Blasdell, McPherson, \& Schapiro, 1993). Moreover, rising college costs in the 1990s coincided with a financial recession and "brought new urgency to state demands for campus accountability" (Burke, 2002, p. 6). Consequently, both public and private higher education institutions were being questioned on their efficient use of public funds (McClendon, Hearn, \& Deaton, 2006).

This ensuing accountability movement in the 1990s was "premised on the perception that traditional measures of institutional performance and effectiveness such as peer review and market choice were not sufficient indicators of institutional value" (Alexander, 2000, p. 414). The emphasis on accountability motivated scholars in higher education assessment to author a groundbreaking report holding states responsible for the quality of higher education performance. In 2000, the National Center for Public Policy in Higher Education (NCPPHE) published the first "report card" of the US higher education system. The Measuring Up report, a state-by-state review of higher education across six dimensions, gave "state leaders, policy makers, researchers and others ... the capacity to compare any state with the best performing state in each performance category" (NCPPHE, 2000).

In addition to national reports such as Measuring $U p$, state policies designed to assess institutional quality and improve their production processes were also developed

be placed on either the state or the institution. Higher education institutions can demonstrate that they have "less to spend today because of a big drop in the share of public appropriations" (p. 17). However, state lawmakers argue that "tuition was raised not to replace disappearing state dollars but to increase the price of the product being offered" (p. 21). While the nature of their relationship is outside the scope of this paper, both decreased state appropriations and increased tuition contributed to the demand for increased accountability. 
in response to the national accountability movement in higher education.

Accountability policies were born from the concerns of taxpayers who "through their legislative agents, are interested in whether the benefits of a higher education are worth the substantial investment of scarce societal resources," (DesJardins, 2003, p. 175). State lawmakers hoped accountability policies would serve as incentives for institutional improvement (Banta, Rudolph, Van Dyke, \& Fisher, 1996; Deaton, 2004) and as mechanisms for comparing institutional efficiency and productivity across colleges and universities (Alexander, 2000). In 1995, California lawmakers explicitly required "productivity improvements" by their public university systems following concerns of increasing enrollment demand (Gates \& Stone, 1997). Writing in the midst of this accountability movement, Alexander (2000) aptly noted that "the entire nature of the traditional relationship between government and higher education is in the process of significant change in stretching the public dollar to serve more students in attempting to maximize economic returns" (p. 413). As noted, the accountability movement in higher education often has reflected two conflicting goals upon universities. Lawmakers ask simultaneously for proof of institutional quality worthy of its cost and for institutional cost-cutting strategies. In other words, policies now demand proof that institutions are producing more or better graduates with the same or fewer resources.

\section{Financial Resources}

Another reason that improving institutional productivity has gained interest among campus leaders is the growing concern over diminishing financial resources. This interest has become even more pronounced in this period of economic recession; a time when many institutions examine ways to increase productivity with the same or 
fewer funds (Breneman, 1993). Consequently, earlier this year institutional leaders met to discuss ways to respond "to the array of technological, demographic and budgetary changes that are combining to increase the pressure on colleges and universities to perform" (Lederman, 2009, II 4). University leaders have realized that the economy has narrowed the focus on productivity and that their institutions must take heed. According to Kelly (2009), many public postsecondary institutions convince state leaders that they need more state support so they do not have to raise tuition and fees. Kelly notes that this " is an argument that couples a plea with an ultimatum, and contains the underlying assumption that resources are directly associated with performance. Often absent from this assertion is...how well their institutions are performing with the resources they already have," (p. 5). Toward this end, investigations of productivity are relevant and necessary for both campus leaders and state legislators.

Public institutions, whose operating revenues have largely depended on state appropriations, have primarily been concerned with the decrease in government funding, but private institutions have also become vulnerable during these times. Most notably, private institutions have experienced decreases in endowment values. Further, both private and public universities have enrolled students whose abilities to pay require federal financial assistance. Thus, a decrease in government funding has affected the inputs of every higher education institution in the country. This fact has made the challenge to examine institutional processes, goals, and initiatives toward improving degree production a universally relevant concern. 


\section{Modeling Degree Production in Higher Education}

Policy considerations, public demand, and financial concerns necessitate an exploration into degree production in higher education. A review of the literature, however, demonstrates that few studies have considered the production of undergraduate degrees in the context of institutional prestige-maximization and even fewer have examined this production over time.

Recent studies on education production functions have modeled the relationship between a series of inputs and a single output using cross-sectional data. In the present study, higher education production is examined over time and driven by a framework of economic theory of productivity and prestige-maximization. I argue that an emphasis on institutional reputation and prestige affects the decision-making processes of institutions and, inevitably, the production of undergraduates. This emphasis on prestige translates in the present study as the selection criteria for inputs which can be manipulated and are most prominent in the calculation of reputation rankings.

\section{Latent Growth Modeling}

Several cross-sectional studies have been conducted to compare peer institutions on degree production. However, few have examined this outcome over time. Crosssectional studies are helpful for management decisions and for identifying the comparative productivity of institutions relative to peers. Yet in the midst of the quest for consistently increasing institutional reputation and recent calls for accountability, institutional leaders would benefit from an understanding of how productive institutions have become relative to their pasts. Indeed no studies have examined degree production 
such that the variation in growth trajectories could be examined. Toward this end, this study relies on latent growth modeling.

Latent growth modeling (LGM) is a type of statistical method which can evaluate the change in outcome variables over time as well as the variation between individual institutions. To do this, LGM estimates the average starting points and growth rates over time for the whole group of institutions, as well as the pattern of growth in the outcome variables. More importantly, perhaps, is that LGM allows estimation of how much institutions differ from these estimated values. This detail is important for purposes of this study where institutions, which are known to vary on several of the variables, are included in the sample and indeed their variation about these values is of great interest. The purpose of latent growth analysis in this study is to account for this variation with a set of input resources. The degree to which this is possible provides some context for understanding the degree to which various levels of input resources explain the different levels of degree production at the set of universities over the ten-year time period.

\section{Research Questions}

The unique contribution of this study to the current literature on degree production is the application of latent growth modeling to the examination of prestigemaximizing behavior in the production of undergraduate degrees. Given the capabilities of LGM as a tool for investigation and the substantive focus of the study, the present study addresses the following research questions for the production of undergraduate degrees: 
1. What pattern of growth best explains the production of undergraduate degrees for the whole group of institutions?

2. What are the average starting values for undergraduate degrees across the entire sample of institutions in $1997 ?$

3. How much do these starting values of institutions vary around the average value?

4. What are the average growth rates for undergraduate degrees over time across all institutions in the sample?

5. How much do the growth rates of individual institutions differ across the sample?

6. Do the input resources, including academic expenditures, faculty salaries, yield rate and research funding, account for any of this difference in starting values or growth rate for undergraduate degrees?

7. What is the direct relationship between the input resources of academic expenditures, faculty salaries, yield rate and research funding and undergraduate degrees?

8. How, if at all, does the final model, which includes the input resources of academic expenditures, faculty salaries, yield rate and research funding, indicate that production of undergraduate degrees at these higher education institutions has grown between 1997 and 2007?

9. How do these final models vary by institutional control or presence of a medical school? 
This study examines a sample of doctoral, master's, and baccalaureate colleges and universities, as defined by their 2005 Carnegie Classification ${ }^{2}$. A sample of institutions in which the influence of reputation-influencing inputs can be analyzed allows some investigation into the variation in degree output levels. Therefore, the sample will be drawn by purposefully selecting non-profit institutions which produce undergraduates. Institutional characteristics will be modeled by subgroup analysis to gain an understanding of degree production across institutional control types and across institutions with and without a medical school.

\section{Summary}

Campus and state leaders seek an increase in degree production to satisfy demands of prestige, accountability, and financial considerations. To that end, effective policy writing and institutional decision-making rely on some investigation into the higher education degree production process. The relative nature of degree production requires some benchmark and, in the face of diminishing funds, that benchmark must be progress. Therefore, while researchers have long relied upon peer group comparisons to make conclusions about the relative productivity of institutions, the need exists for a study that also compares institutions to their own past performance.

The present study examines the degree production of four-year colleges and universities over ten years. The results of this study will not only provide a mechanism for understanding this process in higher education, but will also present an evaluation of

\footnotetext{
${ }^{2}$ While Carnegie Classifications have been updated in 2008, the data source for this study, the Integrated Postsecondary Education Data System (IPEDS), relies on the 2005 Classifications.

${ }^{3}$ The Higher Education Act of 1992 declared that reporting to IPEDS is mandatory for all institutions who
} 
degree production in higher education over time. These results are beneficial for policymakers and campus leaders as well as educational researchers expanding their methodological toolboxes in the study of degree production in higher education.

Chapter two of this paper includes a review of the literature regarding latent growth modeling and degree production in higher education. The theoretical framework is introduced in which institutional prestige is hypothesized to drive institutional decision-making. The need is demonstrated for a study in which the degree production of higher education is estimated over time. The resources used to produce undergraduates are specified in this chapter, and the components of latent growth modeling are introduced.

Chapter three outlines the methods for the present study. The chapter begins with a description of the sample of institutions selected. This is followed by a description of the data source, the Integrated Postsecondary Education Data System, and an explanation of the model specification for analysis. The chapter concludes with a list of limitations associated with the study. These limitations speak to the limited availability of data and, more broadly, to the difficulty associated with estimating the elusive nature of the education process. Chapter four presents descriptive statistics of the samples and results of analysis. In chapter five, the results of the study are expounded, and avenues for future research are suggested. 


\section{Definitions}

Some definitions are helpful in moving forward with this study. The following terms are defined according to their use in this research.

Academic expenditures per FTE - the total amount spent on instruction, academic support, and student services in an academic year, divided by the institution's total FTE value.

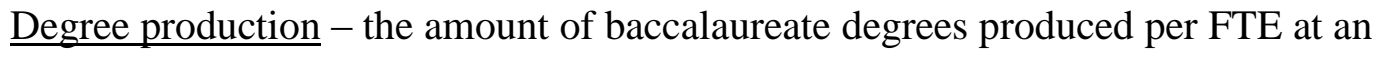
institution controlling for the institution's level of input resources.

Efficiency - increasing the undergraduate degrees per FTE produced at an institution without increasing its input resources.

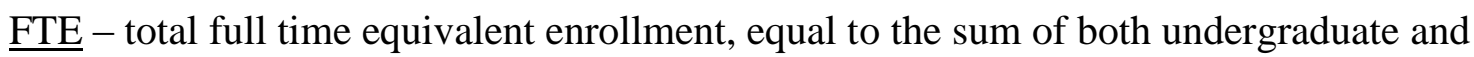
graduate (if applicable) FTE. FTE is calculated as the total number of instructional credit hours divided by the average annual credits per degree-seeking student, as defined by IPEDS. For institutions with a semester, trimester, continuous enrollment, or 4-1-4 plan, the undergraduate denominator is 30 and the graduate denominator is 24 . For institutions with a quarter plan, the undergraduate denominator is 45 and the graduate denominator is 36 .

Faculty salaries per FTE - the total amount of faculty salaries for all employed faculty on a campus in an academic year, divided by the institution's FTE value.

$\underline{\text { Input resources }}$-the group of covariates hypothesized to contribute to the production of undergraduate degrees per FTE. Input resources in this study include: research 
dollars per FTE, faculty salaries per FTE, academic expenditures per FTE, and yield rate.

$\underline{\text { IPEDS }}$ - the Integrated Postsecondary Education Data System, maintained by the National Center for Education Statistics.

Output - the amount of baccalaureate degrees produced at an institution divided by the institution's FTE value.

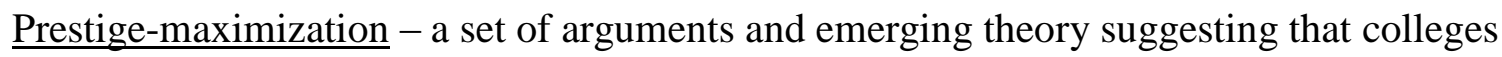
and universities operate with the competitive goal of improving their reputational position among peer institutions in order to obtain higher quality faculty, better students, and more alumni donations.

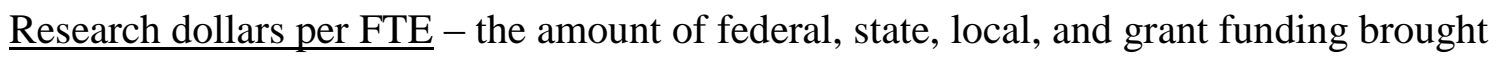
onto a campus in a given academic year, divided by the institution's FTE value.

Yield rate - a measure of student selectivity, equal to the number of students who enroll in an institution divided by the number of students who were admitted. 


\section{CHAPTER 2}

\section{REVIEW OF THE LITERATURE}

The present study relies on latent growth modeling to understand the growth in the production of undergraduate degrees at a group of institutions over a ten-year period as well as the variation around that growth. To contextualize this study, a review of relevant literature is helpful. This chapter begins with an examination of latent growth modeling as it is used in the present study and as it will be adapted to understand the production of undergraduate degrees. The chapter then focuses on the theoretical framework guiding the selection of the output variable and input variables that will be used in the analysis. The selection of these variables is guided by a theoretical framework composed of both elements from a classic economic theory of production and emerging theory, emphasizing prestige and reputation in higher education.

\section{Quantitative Estimation of Degree Production}

The investigation into a production process requires some understanding of the relationship between outputs and inputs. In a similar study of institutional productivity, Porter and Toutkoushian (2006) modeled a production function of university reputation with a regression model in which the dependent variable was an academic reputation score from $U S N W R$. For analysis, the authors specified three related equations. First, the primary equation of interest suggested that institutional reputation was a function of faculty and student quality and institutional characteristics. Second, research productivity was expressed as a function of student quality, institutional reputation, faculty human 
capital, and institutional characteristics. Finally, the authors defined student quality as a function of an institution's reputation and other characteristics. Given that the dependent variables were interrelated and that maximum likelihood would fail to converge on a solution with correlated error estimates, Porter and Toutkoushian used three stage least squares (TSLS) to estimate model parameters.

While Porter and Toutkoushian's (2006) research demonstrated the relationship between quality and reputation, their methodology and method cannot be extended to the present study because the researchers' did not include a consideration of time. The present study is investigating the production of undergraduate degrees over a period of ten years. While cross-sectional studies are helpful for estimating a production function, the utility of the current productivity analysis is derived from its ability to estimate the growth or decline in productivity after internal process changes or reallocation of resources. Indeed the research investigating longitudinal modeling of productivity growth in higher education is limited. The dearth of information is likely the result of data limitations (Kelly, 2009) and measurement difficulties associated with measuring the intangible variables in education (Hopkins \& Massy, 1981).

Despite the difficulties, some researchers have examined productivity over time in higher education. Worthington and Lee (2008) used Malmquist indices to measure productivity growth over a five year period. This non-parametric method captures the productivity growth (or decline) between two time points for a group of institutions with a particular emphasis on defining the inefficiency of an institution based on a production frontier. Besides the limitation that comes with non-inferential statistics (such that the results cannot be generalized to a larger population), this method does not allow for any 
estimation of a non-linear growth trajectory between the two time points. Further, the specification of the present study is not to define a production frontier, but rather to examine the productivity of institutions relative to their pasts.

Some researchers have extended the Cobb-Douglas Function (Guellec \& Van Pottelsberghe de la Potterie, 2004) or the Mincer model (Krueger \& Lindahl, 2001) to include a time component. However, in these equations, the dependent variable must be transformed into a natural logarithm. This process makes the specification and interpretation of results quite complex.

One method which not only allows estimation of institutional growth over time, but allows investigation of the variation in individual growth trajectories is latent growth modeling (LGM). LGM allows all relationships between inputs and outputs to be statistically estimated with a much more straightforward interpretation than that involved with Cobb-Douglas functions or Mincer models. Further, LGM allows the researcher to estimate the relationship between multiple inputs and multiple outputs. These benefits, coupled with the weaknesses of alternative methods, make LGM an appropriate method for specifying production of undergraduate degree production in higher education.

\section{Latent Growth Modeling}

LGM is a type of structural equation model which allows the researcher to specify relationships over time between observed or measured variables and latent variables (Loehlin, 2004). In other words, several observations are used to "get a more parsimonious estimate of the underlying trajectory that gave rise to the repeated measures" (Bollen \& Curran, 2006, p. 3). Due to its flexibility for use with many 
studies, LGM has grown in popularity among researchers (Fan \& Konold, in press; Heck \& Takahashi, 2006). According to Bollen \& Curran (2006), LGM addresses the following unknowns: the growth trajectory for the entire group of institutions and the effectiveness of certain covariates or predictors that sufficiently explain the individual institutional trajectories.

Similar to the general linear model, an institution's outcome variable in LGM can be expressed in the following equation (Fan, 2003; Fan \& Konold, in press):

$$
\begin{aligned}
Y_{i} \overline{\bar{t}} a_{i}+\beta_{i} \lambda_{i}+\varepsilon_{i}, \text { where: } & \\
a & =\text { intercept for institution's growth trajectory } \\
\beta & =\text { slope for institution's growth trajectory } \\
\lambda & =\text { repeated measurement time points } \\
\varepsilon & =\text { the institution's residual term }
\end{aligned}
$$

The inclusion of the repeated measures for each institution makes this model different from the linear statistical model in OLS regression. Bollen and Curran (2006) note how equation (1) further expands to include a time-varying covariate, $\omega_{i t}$, such that:

$$
Y_{i t}=a_{i}+\beta_{i} \lambda_{i}+\gamma_{t} \omega_{i t}+\varepsilon_{i t}
$$

Equation (2) is the level-1 model of growth. This equation demonstrates that the predicted value of the outcome variable at a specific time point is a function of the intercept, the pattern of growth over the specified time period, the value of the timevarying covariate at that time point, and a measure of individual error at that time point. 
Note that time-invariant covariates can also be added in the level-2 equations by expanding the slope and intercept terms. The intercept and slope designated in equation (2) expand to include these time-invariant covariates, $x_{1}$, such that:

$$
\begin{aligned}
& a_{i}=\mu_{a}+\gamma_{a i} x_{1 i}+\zeta_{a i} \\
& \beta_{i}=\mu_{\beta}+\gamma_{\beta 1} x_{1 i}+\zeta_{\beta i}
\end{aligned}
$$

Equations (3) and (4) have covariates that directly affect the intercept and slope parameters, where equation (2) demonstrates that the covariate directly influences the outcome variable which is simultaneously being predicted by the growth parameters. These models are referred to as conditional latent curve models (Bollen \& Curran, 2006).

Many researchers have used LGM as a method to explore educational phenomena. Indeed, this method has grown in popularity among educational researchers over the past decade (Marsh \& Hau, 2007). Due to its flexibility for being applied in various situations and the variety of questions that LGM can answer, the method is appropriate for research in policy analysis (Heck \& Takahashi, 2006) and student achievement and development (Konold \& Pianta, 2007). The present study contributes to this body of research by extending LGM into institutional-level analysis in higher education. Marsh and Hau (2007) note the importance of "synergistic papers" (p. 152) that are both methodologically advanced and substantively focused. The authors highlight LGM as a new methodological approach used in many synergistic papers and argue that such studies shed new light on substantive issues by developing and extending these methodological solutions. The goals of the present study are in line with those expressed in the synergistic papers described by Marsh and Hau. While the substantive issue of 
degree production in higher education is the main focus of this research, the extension of LGM into this type of analysis is undoubtedly an important element.

\section{Specifying a Model of Undergraduate Degree Production}

This study empirically investigates the production of undergraduate degrees by a group of inputs specified through prestige maximization. Baccalaureate degrees are among the largest products of American higher education, and researchers have often used the undergraduate full-time equivalent (FTE) enrollment as an output to operationalize undergraduate degrees (de Groot, McMahon, \& Volkwein, 1991; Salerno, 2003). In their study of the efficiency of institutions of higher education, Cohn et al. (1989) noted that the choice of undergraduate FTE for an output variable may have been questionable by some, but it seems to be "the best available measure of teaching output," (p. 284). The authors defend their choice of output measure by accepting that the troubles with undergraduate FTE enrollment were less than those associated with other output measures.

One of those other commonly used outcome variables is graduation rate (Kelly, 2009). Gates and Stone (1997) noted that effectiveness of higher education for productivity analysis could be conceptualized as it is in the service industry. They suggest that graduation rate is a measure of service accomplishment, or how many customers were served in a specific and meaningful way. Since many institutional missions refer to the goal of student learning, graduation rates proxy for the "product" of higher education (Gilmore, 1990) in the absence of achievement tests.

Despite its popularity, however, there exist problems with relying on graduation rate as an appropriate metric for educational output. First, this measure does not 
account for the few years that students were enrolled at the institution prior to transferring or dropping out (Cohn, Rhine, \& Santos, 1989; Salerno, 2003). Further, the maximization of this output does not make logical sense, as a $100 \%$ graduation rate is neither likely nor preferred (Archibald \& Feldman, 2008), and the rate is biased towards institutions which enroll higher quality students, as these institutions should see higher graduation rates than institutions with more at-risk student enrollment (Gilmore \& To, 1992). A final issue arising from the use of graduation rates in a production function is that six-year graduation rates are cumulative measures of six years of production processes (Cohn et al., 1989). The specification of a model in which the graduation rate is being appropriately matched with six years of inputs is difficult. Therefore, undergraduate FTE is accepted as a reasonable measure of the amount of teaching being conducted at the undergraduate level for an institution, and the amount of degrees awarded normalized by this amount of teaching represents the appropriate outcome variable for this study.

\section{Degree Production in the Social Sciences and Physical Sciences}

The nature of productivity analysis involving undergraduate degrees is limited by one particular assumption; the model assumes that the nature of the degrees being produced is similar. Given the breadth of academic disciplines on the campuses of colleges and universities, there are indeed some which demand considerable differences in the translation of resources into outputs. More specifically, the production of a social science graduate involves expenses and quantities of research different than those required in the production of a physical science graduates. Overall, the resources vary (Breneman, 1978). To account for this variation, two separate models of degree 
production will be estimated. The production of degrees in the arts, humanities, mathematics and social sciences ("social sciences") will be estimated separately from the production of biological, life, and physical science degrees ("physical sciences").

\section{Theoretical Framework of Undergraduate Degree Production}

In order to understand how undergraduate degrees are being produced, we must estimate the relationship between the production of undergraduate degrees and the inputs used to create them. A theoretical framework guides a purposeful selection of these inputs. This study adopts a model of non-profit organizational behavior which argues that the production of degrees is one tangible output of institutions which maximize prestige. Drawing on the work of Garvin (1980), prestige maximization is helpful for viewing the process of institutional decision-making by suggesting that institutions seek to maximize prestige much like private sector businesses maximize profits. Prestige maximization guides the specification of inputs in the production of undergraduate degrees explored in the current study. However, before prestige maximization is discussed, an introduction to production theory is helpful for understanding the view on undergraduate degree production being employed in this study.

\section{An Introduction to Production Theory}

While the present study does not attempt to specify a true production function for higher education, an introduction to production theory is helpful for understanding the lens through which this analysis of undergraduate degrees is being viewed. Productivity theory provides this economic lens through which to view the processes of higher education. The theory states that inputs relate to outputs in a systematic way 
such that the relationship can be modeled with a production function. Though the ultimate goal of this research is not to build a production function for higher education, the theory of economic productivity is helpful to understand interpretation of this study of undergraduate degree production.

Production theory states that institutions will transform a given set of inputs into specific outputs. This theory recognizes the variation in input combinations which yield similar outputs. Analyzing productivity allows a greater understanding of the education production process and offers new production possibilities for long-term university growth and efficiency in production (Hoenack, 1990).

Critics of productivity research have suggested that omitting intangible variables leaves a production function which only accounts for differences in quantity of outputs, not quality (Gilmore, 1990). Further, many scholars criticized the ability of researchers to specify the transformation process involved with converting inputs to outputs in higher education (Gilmore, 1990). However, even in the absence of perfectly defined input and output metrics, productivity literature continues to produce empirical estimations of the inherently enigmatic production of education.

Peterson (2007) argued that productivity analysis in higher education regained popularity in the late 1990s in response to demands for accountability, especially on the part of state lawmakers. The benefits of productivity research were becoming clearer. Deller and Rudnicki (1993) noted that the education production function benefits policymakers, as it "lends itself to the straightforward testing of many policy related hypotheses such as the influences of school spending and school size on student achievement," (p. 47). Indeed, in his review of empirical literature using the education 
production theory framework, Hanushek (1986) found that results from educational productivity research have supported many policy discussions and debates. Bowles (1970) noted that the "knowledge of the educational production function is essential to efficient resource allocation" for both policy and planning (p. 12). Productivity analysis has also been helpful for evaluating the relative importance of various inputs in the production of outcomes (Schapiro, 1993).

As mentioned, this study is not investigating a true production function. Rather, it seeks to investigate the changing nature of the relationship between inputs and outputs. The benefits of this exercise are similarly effective and necessary, however, for three main reasons. First, universities produce multiple outputs so a true production function of just undergraduate degree production would be difficult to isolate. Second, the micro-level of degree production - including individual decision-making - is difficult to capture with quantitative metrics. Third, estimating the relative importance of the same variables used to calculate reputation rank in the production of undergraduate degrees gives a macro perspective on the relationship between reputational rankings and production of undergraduate degrees. Therefore, the present study focuses on the changing relationship of four inputs into the production of undergraduate degrees.

\section{Prestige Maximization}

In order to specify the four inputs included in this study, a model of organizational behavior called prestige maximization is identified which drives the inclusion of inputs as well as the interpretation of their relationship. This model suggests that institutions make decisions under a goal of maximizing institutional reputation. 
The argument that institutions maximize prestige emerged in productivity analysis literature to define and explain the goal of increasing institutional reputation (James, 1990). Melguizo and Strober (2007) note that prestige maximization is indicative of the "emerging economic theory in higher education" (p. 635). Garvin (1980) developed a model of prestige maximization arguing that prestige greatly influenced institutional decision-making. In other words, the prestige maximization argument is that, in non-profit institutions of higher education, internal decisions are made with the goal of maximizing prestige similar to the way that private sector firms may work to maximize profits (Solomon, 1984).

Prestige maximization has become more pronounced in higher education over the past twenty years. As described by Ehrenberg (2000), institutions were, for many years, grouped by broad categories such as highly selective, selective, and non-selective and enjoyed "roughly the same 'prestige' as all other institutions in the group," (p.51). However, Ehrenberg argued that "with the advent of the [US News and World Report] rankings, [administrators, faculty, students, and alumni] must now worry about how their institution is numerically ranked relative to its close competitors," (p. 52). This concern developed even more in the 1990s (Ehrenberg, 2000). After all, prestige maximization is serious business for institutions. An increase in reputation rankings or prestige can influence most aspects of the institution. Namely, an increase in prestige can improve the quality of student applicants (and the probability that accepted students will enroll), attract better quality faculty, and encourage alumni donations (Ehrenberg, 2000). Winston (1999) argued the theoretical link between prestige and student learning. Winston argued that the influence of prestige on the admissions process enhances the 
peer effects "where, to a significant degree, students educate both themselves and each other, and the quality of the education any student gets from college depends in good measure on the quality of that student's peers" (p. 17). Indeed, the influences of prestige permeate the higher education institution.

Frank and Cook (1995) described the system of prestige maximization in higher education as a "winner-take-all" market (p. 2), suggesting that the few, highly prestigious institutions define the competitive higher education market and thus get the best students, faculty, and administrators. Consequently, Frank and Cook noted that higher education is engaged in a "positional arms race" (p. 131) whereby institutions invest excessively to secure a better ranking position relative to their peers. The result of such an arms race is that no institution is willing to cap its spending lest it forego its position relative to its peers (Ehrenberg, 2000). Consider the following argument by Ehrenberg (2000):

Moreover, the selective private institutions do not have the option of banding together and voluntarily agreeing to limit spending. Similarly, they do not have the option of voluntarily agreeing to limit the fraction of their classes that they admit through an early decision process. Doing either probably would be viewed as an attempt to reduce competition and thus be considered a violation of the consent decree. Even if the most selective members of the group reduced their spending on activities such as student recruiting, the lesser selective institutions have an incentive to continue such spending to gain a competitive advantage and increase their attractiveness to students. So attempts to obtain agreement on spending limitations would be highly unlikely to prove effective. (p. 278)

In his paper, Solomon (1984) defined prestige as "how closely a particular institution (or department) resembles Harvard, Berkeley, or Amherst (or the corresponding department there)," (p. 25-26). Solomon challenged the prestige maximization model by asserting that this goal varies with the institution's place in the 
hierarchy of prestige; the goal of survival is sometimes in conflict with prestige maximization for those at the bottom of the hierarchy. In other words, some colleges have so little prestige that increasing it is an unrealistic prospect; for these institutions, the main goals are survival or revenue maximization. However, as demonstrated by Ehrenberg's (2000) argument above, the decisions of the most selective institutions ripple down the pecking order. In addition, Winston (1999) also argues that the competition for prestige is based on the position of an institution in the hierarchy of reputation, and that institutions generally compete with those schools closest above and below them in position and that even schools in the bottom of the hierarchy compete for students.

Prestige maximization has gained some attention from researchers who seek to empirically understand the role that competition and reputation play in the performance of higher education institutions. Though not mentioned by name, the tenets of a model of prestige maximization have been accepted by several researchers writing on the role and behavior of American universities and university departments (Breneman, 1976; Clotfelter, 1996; Cole, 1993; Marginson, 2006). James (1990) noted that a model of prestige maximization encapsulates the institutional quest for quality as well. Indeed quality is an important component of prestige and, some would argue, synonymous with it. Alpert (1985) argued that the quality of an academic department can be measured by its prestige among peers. Prestige has been used as a measure of quality at the university level as well. According to Massy (1996), "prestige provides professional fulfillment for faculty and administrators; it enhances the value of the degree, thus improving application and acceptance rates; and, it improves the prospects for obtaining 
gifts and sponsored research support," (p. 60). Prestige maximization suggests that universities advance institutional reputation for the benefit of several other outputs which contribute to increased university quality.

\section{Empirically investigating prestige maximization.}

Researchers have empirically linked reputation and productivity in the public sector (Morgan, Meier, Kearney, Hays, \& Birch, 1981) and in university academic departments (Hagstrom, 1971). A study by Garfunkel, Ulshen, Hamrick, and Lawson (1994) tested the influence of institutional prestige in the publication rate of manuscripts and brief reports. The authors found no significant relationship between institutional prestige and manuscript publication but they did find a significant, positive relationship between the prestige of an institution and the rate that brief reports are selected for publication. Prestige and productivity have been tested by other researchers as well.

In their study of university productivity, Porter and Toutkoushian (2006) posited that institutions became more geared towards prestige maximization in response to the increasing popularity of ranking publications such as those by US News and World Report (USNWR). The authors noted that the rising costs of college forced stakeholders to evaluate the benefits of institutions through prestige rankings. According to Melguizo and Strober (2007), 70\% of reputational rankings are comprised of institutional performance on retention and graduation rate, faculty resources, selectivity and financial resources. The remaining $30 \%$ is comprised of alumni satisfaction and opinions of other college leaders.

Positing that institutional reputation, research, and student quality were jointly produced on college campuses, Porter and Toutkoushian (2006) measured institutional 
prestige with an academic institutional reputation score from USNWR. The reputation score was derived from a survey to campus presidents, provosts and deans on which respondents were asked to rate peer institutions on a scale from 1 to 4 . Relying on a sample of 203 national universities and 143 national liberal arts universities - a sample defined by the USNWR 1996 rankings - the researchers found that their models explained $88 \%$ of the variance in institution reputation and over $70 \%$ of the variance in student quality and faculty quality. In addition, the researchers found that student quality, defined by the midpoint between the $25^{\text {th }}$ and $75^{\text {th }}$ percentile SAT score, and faculty quality, defined by publications per full-time faculty, were significant influences on the reputation of national universities. Finally, Porter and Toutkoushian (2006) found that a higher university reputation contributed to a higher quality student body. This finding supports the applicability of prestige maximization to higher education.

\section{Extending empirical investigation of prestige maximization.}

Limitations to existing studies demand that research be extended with this theoretical framework. First, Porter and Toutkoushian (2006) did not examine the growth in productivity over time. In fact, the change in productivity growth demonstrates how institutions react and adapt to the internal and external demands for accountability. Thus, any model proposed for examining productivity, must be one that relates that productivity growth to the institution's previous performance. This leads to the second reason for which the work of Porter and Toutkoushian must be extended which is that the statistical method used to model their production function is not amenable to the exploration of institutions' individual growth trajectories over time. Porter and Toutkoushian relied on three-stage least squares regression to model their 
three interrelated equations. However, the interrelatedness of the variables can be modeled in a more parsimonious way through latent growth modeling. Latent growth modeling allows the relationships between inputs and outputs to be examined. As the name suggests, this method allows estimation of the growth of these relationships. This type of method would serve the exploration of productivity in higher education by presenting a much more parsimonious estimation of the production process.

While their research should be extended, Porter and Toutkoushian (2006) did provide an appropriate frame for sample selection. The researchers applied their model to "national universities" and "national liberal arts colleges" as defined by USNWR. The authors noted that their first group of institutions offered a mix of baccalaureate, master's and doctoral degrees and that "many are heavily engaged in research" (p. 608). Their second group of institutions primarily included undergraduate schools. While the emphasis on reputation and the quest for prestige is greatest at doctoral research institutions (Zemsky, Shaman, \& Iannozzi, 1997), it influences institutions at every level to some degree (Solomon, 1984). Thus, a model of undergraduate degree production driven by the theoretical framework of prestige maximization should focus on many different kinds of universities. The Carnegie Classification system is a helpful way to capture the sample of universities.

The Carnegie Classifications of Institutions of Higher Education is a system of grouping similar institutions along a set framework. The Basic Classification framework groups institutions according to three main considerations: what is taught, who are the students, and what is the setting (Carnegie Foundation for the Advancement of Teaching, 2009). Doctoral research universities are further broken down by their 
research activity, as measured by their research and development (R\&D) expenditures, research staff, and doctoral conferrals by program (Carnegie Foundation for the Advancement of Teaching, 2009). Principal components analysis applied to this data revealed two indices, including level of research activity and per-capita research activity. Doctoral institutions are then categorized by their position along those two dimensions, creating three classifications; institutions rating very highly to either index, institutions rating only highly to either index, and institutions not rated highly or very highly on either index. These three groups are labeled "Research Universities (very high research activity)", "Research Universities (high research activity) and "Doctoral/Research Universities". As discussed, the selection of these three Carnegie Classification categories, as well as the Master's colleges and universities and the Baccalaureate colleges (arts \& sciences) create the appropriate sample of institutions to be consistent with the application of prestige maximization to the production of undergraduate degrees.

\section{Resources Contributing to the Production of Undergraduate Degrees}

The prestige maximization behavior of non-profit institutions is couched in an understanding of productivity analysis in higher education. The theoretical framework for this study helps guide selection of the four inputs that are posited to produce undergraduate degrees. The quest for prestige in higher education suggests that this study will demonstrate the manipulation of inputs involved with the calculation of institutional reputation, including faculty and financial resources and institutional selectivity (Melguizo \& Strober, 2007). Inputs are included in the present model if they are primary to the advancing of institutional reputation and if they are manipulatable. 
The inputs chosen for the present study include measures of research funding, faculty quality, student selectivity, and academic expenditures. Further, the current model includes the consideration of undergraduate degree production by subgroups of institutions. A discussion of the selected inputs and subgroups are defined below.

\section{Research Funding}

The amount of research funding streaming into a university is included in the model to provide a perspective on the academic climate. The amount of research funding can be conceptualized as a level of the amount of research being done and, thus, the distraction of faculty away from teaching. Nerlove (1972) argued that graduate education and undergraduate educational services were jointly produced and that research and graduate education were "inextricably combined" (p. S199). More specifically, according to Nerlove (1972):

That basic research and graduate training and the provision of undergraduate educational services are carried on within the same institution and frequently by the same individuals,... suggests that the two activities are complementary in production in the sense that fewer scarce resources are needed to produce given amounts of the two goods if they are produced together rather than separately. (p. S204)

Though he did not empirically investigate his conceptual argument, Nerlove (1972) posited that many institutional leaders probably had a sense of the production function for their institutions but that the production function for a sector of higher education was inconclusive.

The present study accepts the argument presented by Nerlove (1972) with some modifications. To begin, research is indeed an input to be considered in the production of undergraduate degrees. In a chastising evaluation of American universities, Thorstein 
Veblen criticized much of the academy. While his critique was largely penned under the guise of simply reflecting societal views (Raines \& Leathers, 2003), his message was no doubt colored by his own faculty experiences. Underneath the scathing criticism however, Veblen (1918) did manage to present a theory of the economic functioning of universities. Specifically, Veblen (1918) noted the link between undergraduate teaching and research. He noted that the synergy between teaching and conducting research was necessary for faculty members and that the relationship between the two activities was essential, such that an instructor could only "do the work of a teacher as it should be done only so long as he continues to take an investigator's interest in the subject in which he is called on to teach," (Veblen, 1918, p. 80 as quoted in Raines \& Leathers, 2003, p. 105). Research funding has often been included in empirical studies as a proxy for faculty or institutional quality (Grunig, 1997). Grunig (1997) found that the amount of research conducted at an institution significantly correlated with the selectivity of the undergraduate education program. The amount of research funding can also be indicative of the emphasis on research in the institutional mission (Porter \& Toutkoushian, 2006). In this study, research is operationalized as the amount of research funding per FTE and is included as a measure of emphasis placed on research at the institution compared to other universities in the sample.

\section{Faculty Quality}

Melguizo and Strober (2007) considered the influence of prestige maximization on faculty quality. They operationalized the quality of faculty through the amount of faculty salaries at an institution. While faculty salaries have most often been examined through human capital theory, the authors maintained that the new perspective of 
prestige maximization should be considered. They argued that the combination of experience and research productivity driving faculty salaries was often calculated so that activities which do not support the goal of prestige maximization were slighted (Melguizo \& Strober, 2007). In other words, faculty members contribute to the emphasis on prestige and this contribution is rewarded via salary. The findings by Melguizo and Strober (2007) were consistent with their theory that "faculty members are financially rewarded for enhancing the prestige of their institutions" (p. 657). Further, they found that time spent on teaching was not financially rewarded. Thus, as a metric of the influence of prestige maximization on faculty, faculty salaries are an appropriate input to university production.

Faculty salaries give some indication of the type of faculty at an institution in that these salaries increase with years of experience and amount of research. In addition, normalizing those salaries by the full-time equivalent enrollment, or number of teaching hours, captures the quantity of the faculty at an institution. The present study includes faculty salaries per FTE as a measure of faculty input to the production of undergraduates.

\section{Institutional Selectivity}

On average, the least selective institutions across the country still compete for students (Winston, 1999). While they sometimes scramble to fill the empty seats from excess capacity (Breneman, 1993), these institutions still are employing some form of the customer-input technology which represents a key property of higher education economics (Winston, 1999). Winston (1999) posits that the result of selective admissions, peer quality, is a primary input to education production. Indeed, the 
selectivity of colleges and universities provides some understanding of the type of student that is at the university. According to Ehrenberg (2000), "the ranking of an institution's undergraduate program influences the quantity and academic quality of the applicants, as well as the likelihood that high-quality applicants who are accepted will enroll," (p. 50). In other words, the yield rate is largely influenced by the reputation of the school and the quality of students.

Researchers have considered alternative measures of student quality such as the high school rank of entering freshmen (Archibald \& Feldman, 2008) and SAT scores of entering freshmen (Dolan \& Schmidt, 1994; Porter \& Toutkoushian, 2006). However, the high school rank of entering freshman fails to control for the variation in high school quality, and standardized test scores themselves are wrought with criticism (Schapiro, 1993). At best, standardized test scores offer a value-added assessment of student knowledge. At worst, they measure very specific set of constructs and neglect vast areas of student improvement. Further, Astin (1999) points out that student quality is a limited resource such that an increase in the quality of students at one school decreases the availability of quality for another school. Thus, an absolute measure of student quality, such as SAT scores or high school rank, inevitably reduces the availability of resources across all colleges and universities.

An appropriate proxy for student quality is institutional selectivity (Lam, 2008; Schmitz, 1993). In his translation of selectivity, Gilmore (1990) used the ratio of applications received to institutional size. In defense of this metric, Gilmore noted that the decision to apply to an institution is often swayed by institutional research and academic quality. After all, institutional selectivity not only ensures ample amounts of 
student quality coming in the door but also lining up to apply to the institution in future years (Winston, 1999). The measure of selectivity used in the present study is yield rate, defined as the percent of students who enrolled at an institution relative to the number that were admitted. It is a measure of student quality at the institution relative to other institutions in the sample. The yield rate included in this study is the only input captured for a different year than the outcome variable. The yield rate included in the present exploration of undergraduate degree production is the rate for four years prior to the year of the outcome variable. Because both measures are examining the students of an institution, it is important that they capture the same group of students. Only by examining the yield rate for the graduating students can we examine the effect of that yield rate on the quantity of degrees produced for that class.

\section{Academic Expenditures}

The financial resources enjoyed by an institution affect many parts of the educational production function and its success in garnering prestige. Because the present study examines student graduates and research activity, expenditures that are spent on instruction and education will be examined. Many researchers have found that educational expenditures are significantly positively linked with student achievement (Card \& Krueger, 1996) and graduation rates (Ryan, 2004). Many have debated the inclusion of expenditures in production function research. In a meta-analysis of education production studies at the primary and secondary school level, Hanushek (1997) showed that the effects of financial resources on student achievement were largely unclear. Indeed, the author concludes, this finding suggests that the importance of 
financial resources on student achievement, measured by standardized test scores, may be less than hypothesized by many policymakers and researchers.

The financial processes of K-12 education, however, are different than those occurring at the university level. Indeed, financial resources have been linked with student success at the postsecondary level. Gansemer-Topf and Schuh (2006) found that institutional expenditures, particularly those related to academics, significantly and positively contributed to the retention and graduation rates of students. Archibald and Feldman (2008) included cost variables in their model under the category of "institutional effort." The authors argued that institutions committed to their students by maximizing investments which support their success and selected cost per undergraduate student and percent of full-time faculty to represent campus educational expenditures.

Further, Kelly (2009) noted that institutional revenues or expenditures should yield similar results in productivity models. Because both public and private institutions are being examined in the present study and because their revenue streams are different, expenditures, rather than revenues, are included. In the present model, educational expenditures, normalized by FTE, will be examined through the amount universities spent on instruction, academic support, and student services for the fiscal year.

The selection of inputs in the present study is driven by a theoretical framework which emphasizes the institutional quest for prestige. While the theoretical framework drove the types of inputs relevant to the model of degree production, previous research was used to define student, faculty, and financial inputs for the analysis. 


\section{Subgroup Analysis}

The theoretical framework for this study relates the inputs to undergraduate degree production, but the production process is notably influenced by certain characteristics of institutions. These characteristics are outside the control of decision makers and, thus, should not be considered part of the production model. However, these variables can have an exogenous influence on the degree production of higher education institutions, and thus they must be considered. To this end, analysis will be conducted for subgroups of the sample of institutions determined by institutional control and presence of a medical school. The production of undergraduate degrees will be estimated and compared for an understanding of the varying relationship between subgroups.

\section{Institutional control.}

The research on the effect of institutional control on productivity has not been consistent. Some research has shown that institutional control is not a significant influence on productivity (de Groot, McMahon, \& Volkwein, 1991; Dundar \& Lewis, 1998; Porter \& Toutkoushian, 2006). However, in analyzing the influence, Dundar and Lewis (1998) noted that private universities may provide different incentives and organizational structures which increase faculty publication productivity. Because it is possible that the production of undergraduate degrees varies across public and private institutions, separate production models will be estimated for these groups.

\section{Presence of a medical school.}

In a study examining the cost structure of American research universities, de Groot et al. (1991) found that the dummy variable for the presence of a medical school 
was positive and significant, suggesting a pricier cost structure at universities with a medical school. Following the argument that the organizational processes at a medical school affect various measures of institutional productivity, Gander (1999) posits that the presence of a medical school will "significantly affect [the institution's] research and teaching technology and the estimates of the production function" (p. 174). Other researchers have found that including a variable to indicate the presence of a medical school can control for variations in the research productivity of faculty since faculty in medical schools had lower publication frequencies and slower rank advancement than their peers in other schools (Ahern \& Scott, 1981; Long, Allison, \& McGinnis, 1993). Thus, models of degree production will be estimated separately for institutions with and without medical schools to understand differences in the relationships between the inputs and output.

\section{Summary}

Models of undergraduate degree production in both the social sciences and physical sciences are estimated using latent growth modeling. LGM allows a mechanism for estimating the relationship between multiple inputs and this output over time. In addition, LGM provides the researcher opportunity to examine individual institutional growth trajectories.

The production model itself is specified through a theoretical framework couched in an understanding of productivity theory and prestige maximization, which suggests that institutions operate to maximize reputation. Inputs are specified in accordance with the theoretical framework, and this model of undergraduate degree production covers aspects of institutional selectivity, faculty quality, and financial 
resources. In addition, subgroup analysis is conducted to investigate differences in the production of undergraduate degrees associated with institutional control and with the presence of a medical school.

This study fills a gap in the literature by framing a longitudinal model of degree production for higher education influenced by the quest for prestige. Through LGM, this study not only provides information and perspective on the degree production of higher education institutions over ten years but also offers some utility on the distribution of various resources in this process. 


\section{CHAPTER 3}

\section{METHODS}

Previous studies which have examined the productivity of higher education institutions have done so by comparing cross-sectional data (Dolan \& Schmidt, 1994) or by ranking institutions on their level of productivity (Grunig, 1997; Porter \& Toutkoushian, 2006). Studies which have examined change in productivity over time have done so with econometric change indices (Worthington \& Lee, 2006). However, these studies failed to consider at least one of the following; a) the variation in growth over time across institutions or b) a theoretical framework considering the maximization of prestige. Cross-sectional studies are helpful for management decisions and for identifying the comparative productivity of institutions relative to peers. Yet institutional leaders would also benefit from an understanding of how productive institutions have been relative to their pasts. Further, appropriate specification of the production function necessitates that inputs are selected based on the goal of increasing institutional reputation.

Examining the productivity of higher education institutions is a difficult task. Discussing the merits and complications of an educational production function, Bowles (1970) wrote that:

In statistical investigation using non-experimental data, the most we can expect is to discover some relationship among measurable dimensions of the process, based on the particular configuration of the data in our sample. In this, we are limited both by the preconceptions of the researchers who selected the sample and 
obtained the data and by the patterns of variation which school decision-making processes have brought about in the sample of schools chosen. (p. 15)

To mitigate such limitations, the production function expressed in the current study relies on a theoretical framework to guide the selection of input variables and applies that function to a set of institutions which are hypothesized to exhibit, though to different degrees, the prestige-maximizing behavior outlined by that framework.

In this paper I estimate models for a sample of institutions to examine the longitudinal change in the production of undergraduates in both the social sciences and the physical sciences. This analysis relies on latent growth modeling (LGM) to model the educational production function of doctoral research universities, master's universities, and baccalaureate colleges over time. In addition to shedding light on the research questions, this study is intended to develop a mechanism for the analysis of productivity growth, which may then be extended to additional institutions as well as additional inputs and outputs. LGM is the appropriate method for this goal, as it offers flexibility for investigating time-varying relationships in the data which are hypothesized to exist. Following are the research questions for this study as well as explanations and detail of the sample, data, and latent growth models appropriate to answer these questions. The chapter concludes with an outline of some limitations associated with this research.

\section{Research Questions}

While higher education most appropriately subscribes to a production function that includes multiple outputs, a review of the literature demonstrates that few studies have modeled the productivity of higher education in this manner. This study contributes to current production function research by specifying the production 
function with influence from prestige-maximization theory and by modeling this function over time through latent growth modeling. Towards this end, the research questions for the current study are addressed through a series of six models for each of two groups of undergraduate degrees: those granted in the social sciences, arts, mathematics, and humanities ("social sciences") and those granted in the physical, life, and biological sciences ("physical sciences"). Each model will address one or more of the research questions. An unconditional latent growth model addresses the first five research questions for both groups:

1. What pattern of growth best explains the production of undergraduate degrees for the whole group of institutions?

2. What are the average starting values for undergraduate degrees across the entire sample of institutions in $1997 ?$

3. How much do these starting values of institutions vary around the average value?

4. What are the average growth rates for undergraduate degrees over time across all institutions in the sample?

5. How much do the growth rates of individual institutions differ across the sample?

The four time-varying input resources are added to the unconditional model for both groups to answer the next research questions:

6. Do the input resources, including academic expenditures, faculty salaries, yield rate and research funding, account for any of this difference in starting values or growth rate for undergraduate degrees? 
7. What is the direct relationship between the input resources of academic expenditures, faculty salaries, yield rate and research funding and undergraduate degrees?

8. How, if at all, does the final model, which includes the input resources of academic expenditures, faculty salaries, yield rate and research funding, indicate that production of undergraduate degrees at these higher education institutions has grown between 1997 and $2007 ?$

Finally, the full conditional model will be used to answer the final research question for both sub-groups.

9. How do these final models vary by institutional control or presence of a medical school?

\section{Sample}

The model of undergraduate degree production being developed in the current study seeks to identify and explain the production process in higher education relative to the influence of prestige-maximization. Therefore, selecting a sample of institutions in which this influence varies makes more plausible the exercise of appropriately distinguishing the differences in relative importance of the inputs within higher education. Including this variation in the sample has both theoretical and statistical importance.

Theoretically, the prestige-maximization argument suggests that all institutions exhibit some degree of reputation-maximizing behavior. By including institutions with varying missions, we should still be able to test the importance of the prestige-driven inputs on the production of undergraduates. An institution's qualities affect its distribution of resources (Volkwein \& Sweitzer, 2006), which affects its productivity. By 
relying on a group of institutions with various qualities, patterns of resource distribution can be detected in light of these differences.

Statistically, the inclusion of various classifications of institutions increases the statistical variation in the latent growth model. This increase in variation through sample selection increases what may be explained by input predictors. With this consideration, the sample for the current study is defended as a purposeful group of four-year, not-forprofit institutions that produce undergraduates in the social sciences, the physical sciences, or both.

Following the theoretical framework for this study, the sample chosen for analysis includes institutions in which the quest for prestige is apparent to varying degrees. Using the Carnegie Classification system, non-profit institutions which produce undergraduates in the social sciences, physical sciences or both are selected. The Carnegie Classification system provides a way to select groups of institutions with similar missions. Ryan (2004) notes that a sample with reasonable homogeneity such as among those institutions found using Carnegie Classifications "reduces the confounding effects of expenditures at institutions with [different types of] enrollments" by focusing on similarly populated student bodies (p. 104). To build the sample of institutions, I relied on the Integrated Postsecondary Education Data System (IPEDS). IPEDS is a federally maintained database to which all postsecondary institutions receiving federal aid must report ${ }^{3}$. The Carnegie Classifications used by IPEDS are from the 2005 system of classifications.

\footnotetext{
${ }^{3}$ The Higher Education Act of 1992 declared that reporting to IPEDS is mandatory for all institutions who participate in federal student financial assistance programs (NCES, n.d.), and currently, over 3,000 public and private higher education institutions report annual data to IPEDs.
} 
Seven classification categories were selected to compose the sample of institutions for this study. These categories included; research universities (very high research activity), research universities (high research activity), doctoral/research universities, master's colleges and universities (larger programs), master's colleges and universities (medium programs), master's colleges and universities (smaller programs), and baccalaureate colleges - arts \& sciences. By further limiting the sample to include only non-profit institutions, the final number of colleges and universities considered for inclusion in the analysis was 1,161 . However, not all of these institutions produced both social sciences and physical sciences undergraduate degrees. Therefore, the sample for each group was slightly smaller based on that consideration. For analysis, the final group of institutions producing undergraduate degrees in the social sciences was 1,145, and the final number of institutions producing undergraduate degrees in the physical sciences was 1,114 (see Appendix A). Further details on the samples can be found in the Results chapter.

\section{Data}

Data for this study was obtained from the existing national dataset IPEDS published by the National Center for Education Statistics (NCES). While my study was based on longitudinal data, the time frame for the study was purposefully delineated based on data availability. The maximum time frame in which there existed reliable data in IPEDS on each variable in the study was between 1997 and 2007. Reporting to IPEDs is conducted every fall for the current academic year (July through June) on most variables. Further, financial information is only available for the previous academic year. Therefore, the most current financial resources information available was for the 2007- 
2008 academic year. Therefore, to ensure accuracy, data for this study is modeled from the fall of each of the following three years: 1997, 2002, and $2007^{4}$.

One input variable is limited by the availability of data in IPEDS. Yield rate data is only available for the class described by the final time point. This is because students earning undergraduate degrees in the 2007-2008 academic year were described by admissions data for the 2003-2004 academic year (and subsequently enrolled in the 20042005 year as freshmen). Admissions data is not available on IPEDS for the students receiving degrees in 1997 or 2002 . Therefore, yield rate is only included as an input at the final time point.

\section{Social Sciences and Physical Sciences}

Because the production of social science graduates requires different amounts of expenditures and, arguably, different pedagogical strategies that might be reflected in the four predictors, degree data was grouped from IPEDS into one of these two program areas (see Appendix B) and the production of undergraduates was analyzed independently for each. Two separate sets of analyses were run in this study to independently investigate the production of social science and physical science degrees. The following description of this study's analyses was therefore applied to both the models for social science and physical science degrees. The similarities and differences of these models are discussed in subsequent chapters.

\footnotetext{
${ }^{4}$ To be consistent, academic years are designated in this study by the year they begin, or by the time point in the analysis models. For example, academic year 1997 through 1998 is referred to as both "1997" and "Year 1".
} 


\section{Missing Data}

The dataset was analyzed to ensure that missing data was missing completely at random (MCAR) and not associated with a specific variable value by comparing the distributions of respondents and non-respondents on each variable (Little \& Schenker, 1995). Given that missing data was found, full information maximum likelihood (FIML) was employed.

\section{Method of Analysis}

Production functions have most often been evaluated through regression analysis or other methods evaluating cross-sectional data. However, the present study relied upon an alternative mechanism for investigating the relationships between inputs and outputs in higher education. Latent growth modeling allowed the relationship between the inputs and outputs to be examined longitudinally. By examining productivity over time, a clearer idea of the production process was obtained since the model captured variation in the relationship between inputs and outputs over time.

Following the theoretical framework, the production of higher education is specified through one output variable, undergraduate degrees normalized by the full time equivalent enrollment (FTE) at the institution.

\section{Model Specification}

LGM is a type of structural equation model which allows estimation of individual growth trajectories and estimates average growth parameters for groups. Other statistical processes for examining change, such as repeated measures ANOVA, assume that individuals change or grow in the same way (Chan, 1998) and fail to capture individual variation. However, especially in the case of something as complex 
as production at universities, this may not be the case. Thus, LGM offers a way to uncover distinct group growth trajectories. Specifically, according to Bollen and Curran (2006), LGM estimates the following; the growth trajectory for the entire group and whether the predictors added to the model sufficiently explain the variation in individual trajectories.

LGM analyzes the variance-covariance matrix and the mean structure of observed variables to define the intercept and slope (Fan \& Konold, In press; Heck \& Takahashi, 2006). Thus, assumptions exist for appropriate LGM analysis. These assumptions include the following: the error of the latent variables (disturbance) has a mean of 0 , the slope and intercept are uncorrelated with the residuals of the predictors, intercepts and slopes for each institution are not correlated with the intercepts and slopes of another institution and, finally, that the errors for different institutions are uncorrelated (Bollen \& Curran, 2006, p. 20). Violation of these assumptions requires modification of the model. If the assumption of multivariate normality is violated, model parameters can still be obtained by estimation methods that are generally robust to this violation (Bollen \& Curran, 2006). Another assumption mandated by LGM analysis is that data is collected on a minimum of three time points (Bollen \& Curran, 2006; Fan \& Konold, in press).

\section{Unconditional model.}

Model specification for this study was guided by the research questions. To begin, the first research question asked: is an unconditional model of growth in undergraduates best explained by linear or spline growth? In order to build the growth model for undergraduate and graduate degrees per FTE, an unconditional model was specified for the sample of institutions. The unconditional model is the basic general linear model 
with no predictors or covariates. This level-1 unconditional model for undergraduate degrees per FTE (UNDERGRAD) can be expressed as follows:

$$
U N D E R G R A D_{i t}=a_{i U}+\beta_{i U} \lambda_{i U}+\varepsilon_{i t U}, \text { where: }
$$

$U N D E R G R A D_{i t}=$ undergraduate degrees per FTE for each institution $i$ at each time point $t$

$a_{i U}=$ intercept for growth trajectory of undergraduate degrees for institution $i$

$$
\begin{aligned}
& \beta_{i U}=\text { slope for growth trajectory of undergraduate degrees for institution } i \\
& \lambda_{i U}=\text { vector of coefficients for repeated measurement time points } \\
& \varepsilon_{i t U}=\text { residual term for institution } i \text { at time } t
\end{aligned}
$$

Further, equation (5) expands to include the parameters that define individual intercept and slope values in terms of a group mean and institutional error. Thus, the level-2 equations, which define the growth parameters for the unconditional model for undergraduate degrees per FTE, are as follows:

$$
\begin{aligned}
& a_{i U}=\mu_{a U}+\zeta_{a i U} \\
& \beta_{i U}=\mu_{\beta U}+\zeta_{\beta i U}
\end{aligned}
$$

These level-2 equations demonstrate the estimation of the intercept and slope parameters. AMOS software was used to analyze the latent growth models. Full information maximum likelihood (FIML) estimation was used to obtain model parameters. FIML defines the population parameters in the model such that they reflect as accurately as possible the mean and covariance matrix of the sample of institutions (Bollen \& Curran, 2006). 
The latent growth model for equation (5) is graphically represented in Figure 1. This unconditional model depicts growth estimation of undergraduate degrees over the ten-year time frame. The intercept and slope parameters were estimated for the output variable. Consistent with AMOS specification, the figure reflects that observed variables are indicated by boxes and latent, or unobserved, variables are designated with circles or ovals. Single-headed arrows indicate causal relationships, or factor loadings, and doubleheaded arrows (such as that seen between the intercept and slope below) represent correlations.

In AMOS, intercept parameters were set to 1 to reflect that growth from the first year was being estimated. The slope parameter was set to 0 for 1997 to reflect that this was the first year. Growth parameters for years 2002 and 2007 were set to 5, and 10, respectively, to reflect that data points were five and ten years from the intercept year. This parameterization reflected that growth was specified in five-year increments. Residual values for undergraduate degrees per FTE at each time point reflected the unexplained error for these variables not captured by the growth parameters. Further, observed variable means were set equal to zero and residual values were set to one for each time point. 
Figure 1. Unconditional latent growth model for undergraduate degrees per

FTE

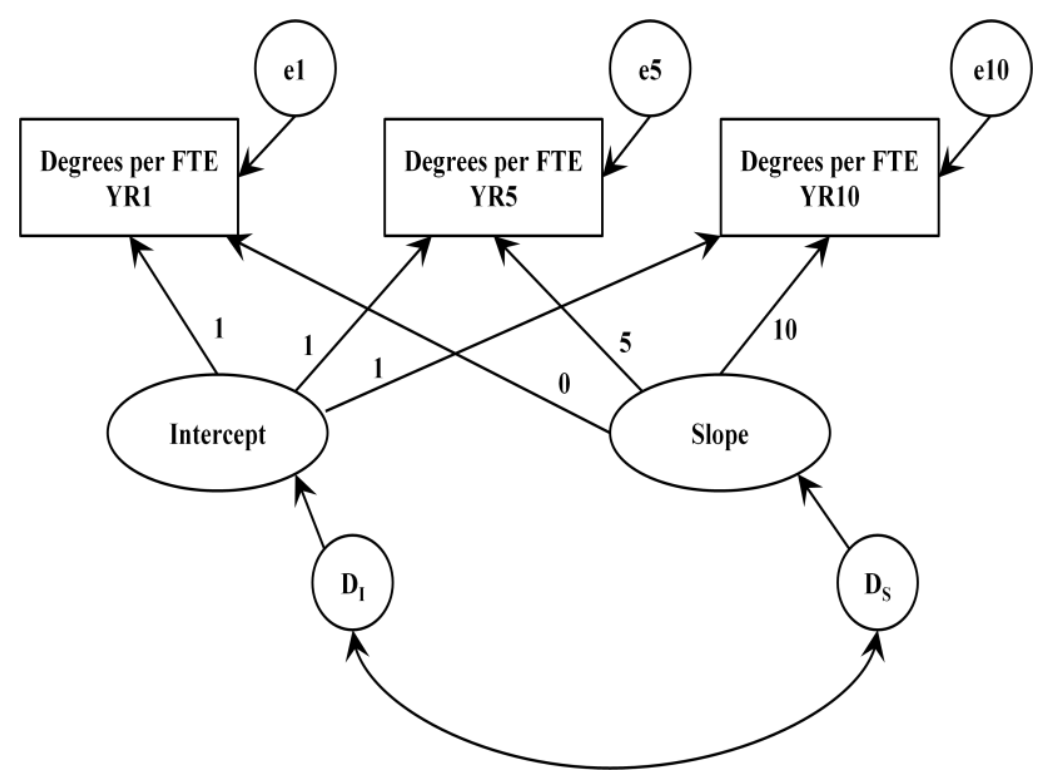

This unconditional model allowed a response to the first five research questions.

Specifically, the shape of the growth trajectory for undergraduate degrees was determined for both the social sciences and the physical sciences. Constraining or freely estimating the slope parameters for undergraduate degrees tested the linearity or non-linearity of the growth curve. By constraining the slope parameters to 5 and 10 for both of the outputs, the model tested a linear growth between time points. The fit of this model was compared to a spline growth model. Spline growth was estimated by anchoring the first and last time points, and allowing the middle time point to be freely estimated (Bollen \& Curran, 2006). In Figure 1, the slope parameters for undergraduate degrees were set to 0 for 1997 and 10 for 2007, but the slope factor loading for year 2002 were freely estimated from the data. This spline method allowed non-linear growth to be modeled more parsimoniously than polynomial growth due to fewer parameters being estimated (Bollen 
\& Curran, 2006). The fit of this spline model was compared to the fit of the linear model to determine whether linear or nonlinear growth fit the data best.

This unconditional model was also used to answer subsequent research questions. Specifically, the average intercepts for undergraduate degrees per FTE across the entire sample of institutions in 1997 were recorded. Also available from this model were the model-implied variances of the intercepts that indicated how much the intercepts of individual institutions varied around the group intercepts for undergraduate degrees.

The unconditional growth model was also used to examine the growth pattern across institutions. The model-implied mean values of the slope parameters for undergraduate degrees addressed the research question asking for the average slopes for undergraduate degrees over time across all institutions. The model-implied variances of these average slope parameters further indicated how much slopes of individual institutions varied around the two slope parameters over the three time points.

\section{Conditional model.}

In order to investigate the effect of time-varying covariates on the slope variation and the direct relationship of these covariates with the dependent variables, the unconditional model was advanced to include several predictors that were hypothesized to translate into the output of undergraduate degrees. From the economic perspective of productivity, these predictors were the resources that institutions manipulated to produce their undergraduate degrees. Because these resources varied across time, they were included in the model as time-varying predictors. The inclusion of one time-varying covariate to the LGM is shown below: 
$\left(U N D E R G R A D_{i t}\right)=\left(\Lambda_{U \eta} \mu_{\eta_{U}}+\Lambda_{U \eta} \xi_{U_{i}}+\varepsilon_{i_{U}}\right)+\Gamma z_{i t}$, where:

$z=$ time-varying covariate of both undergraduate degrees for each time point

$\Gamma=$ vector of coefficients for time-varying covariate, $z$

The inputs included in the model were measures of research, academic expenditures, and measures of student and faculty quality. These predictors were included in the model with the following variables; faculty salaries per FTE, yield rate, research dollars per FTE, and academic expenditures per FTE. The resulting conditional model is shown in Figure 2. At each time point, undergraduate degrees were concurrently produced by the input variables as demonstrated by the factor loadings. Because yield rate data was not available for the first two time points, that variable was only added as a covariate in the third time point. The residuals for the time-varying predictors, between each year, were correlated. In other words, the presumption existed that the faculty salaries per FTE at a university for one year were likely correlated with the faculty salaries per FTE for the following year.

This model (shown in Figure 2) was used to address the influence of covariates on both the variation around the slope of undergraduate degrees over the ten-year time period and the direct effect of the covariates on these dependent variables. By assessing the model-implied slope and intercept variance values, it was determined to what degree the time-varying inputs explained any of the variance in the average slope in undergraduate degrees per FTE. Further, the significance of each of the factor loadings of the inputs was considered. Significant factor loadings suggested that their inclusion in the model was appropriate given the sample data. 
Figure 2. Conditional latent growth model with time-varying predictors

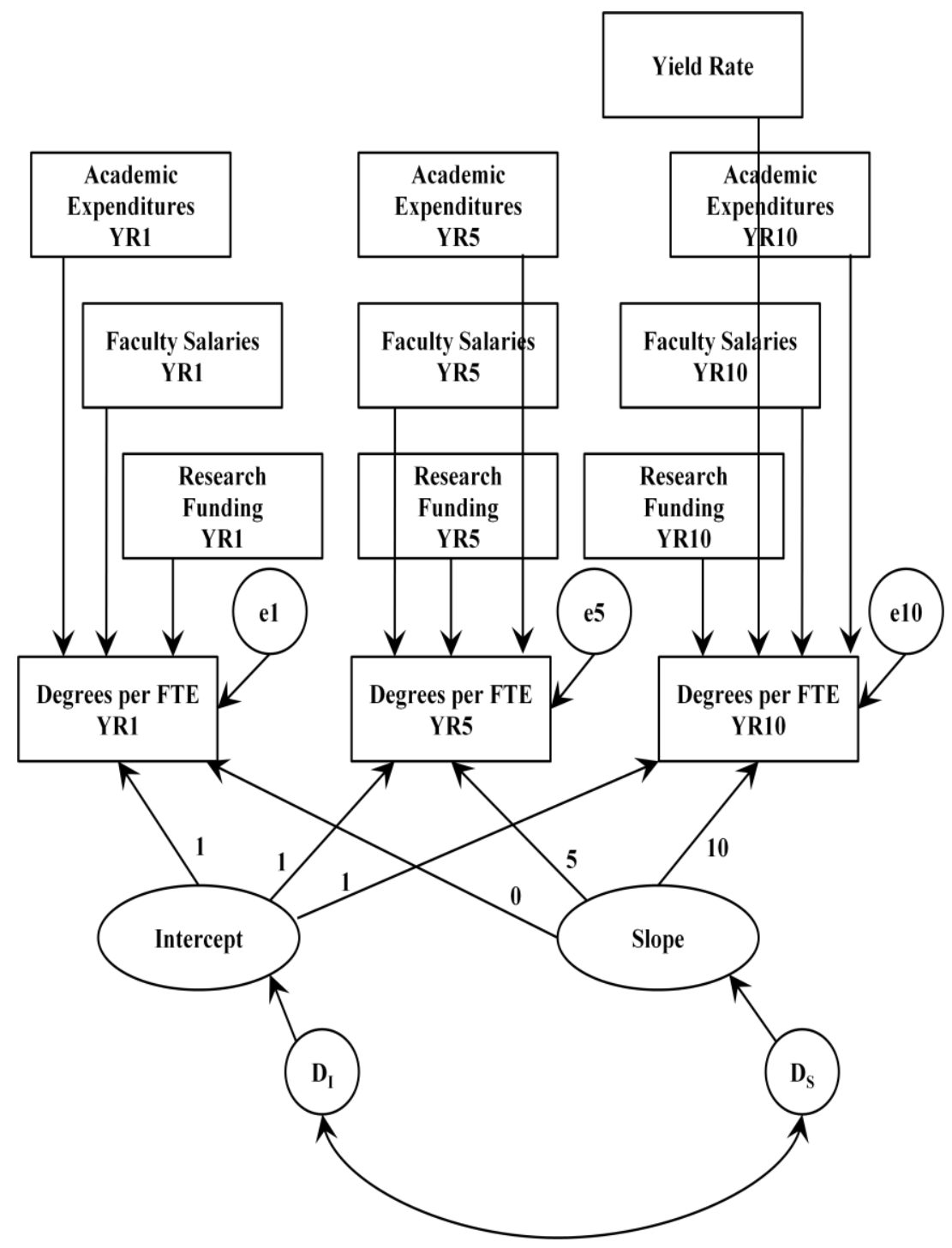

NOTE: In order to preserve clarity, correlations that were specified between all timevarying predictors are not shown in above figure.

All time-varying predictors were examined using a nested model structure. This means that the conditional model was evaluated in several iterations. First, the model was estimated with all time-varying predictors included in the model. Next, three of the factor loadings of the predictors were set to zero and one of the loadings was estimated at 
a time. This series of model estimates allowed a chi-square test to determine the significance with which each of these iterations improved the fit of the model to the sample data. The most parsimonious model resulting from this series of chi-square tests was retained.

The conditional model was used to answer three more research questions. It addressed whether the inclusion of time-varying covariates explained any of the variance in the average slopes or intercepts for undergraduates, the direct relationship between the inputs and the outputs, and how, if at all, the final conditional model indicated that production of undergraduates at these higher education institutions had grown between 1997 and 2007. The answer to this final question was determined by evaluating the intercept and slope parameter values for undergraduate degrees per FTE. Further, the factor loadings of time-varying covariates onto undergraduate degrees per FTE were examined. The magnitude of direct effects reflected the relationship between the four inputs and the outputs of undergraduate degrees per FTE over time.

\section{Conditional model by groups.}

The conditional model (shown in Figure 2) was examined for specific groups to answer the final research question. This question asked how the conditional models of production varied by institutional control or by presence of a medical school for undergraduates in both the social sciences and physical sciences. Doing so allowed several components of the model to be compared across groups. Specifically, the model fit was compared, fixed and random effects components of the models were compared and the relationships between the inputs and the outputs were compared across groups. 


\section{Assessing Model Fit}

The research questions were answered by a series of model fit indices that tested how well each model fit the data. While AMOS computed many indices of model fit, only the most commonly accepted (Duncan et al., 2006) were considered to ultimately assess model fit. GOF indices were reported for both the unconditional and conditional models. Chi-square, a popular and widely used test statistic, tested the hypothesis that the model did not differ significantly from the relationships observed in the data. Therefore, a nonsignificant chi-square statistic indicated adequate fit (Duncan et al., 2006). However, chi-square is sensitive to sample size; a sample size that is too small could lead to retaining a false hypothesis (type II error; MacCallum, Browne, \& Sugawara, 1996). Therefore, chi-square was one of several fit indices evaluated to determine goodness of model fit.

Two fit indices that were used were baseline fit indices. Both the Tucker-Lewis Index (TLI) and the comparative fit index (CFI) compared the hypothesized model to a baseline model. Degrees of freedom were used by both these indices to account for the complexity of the hypothesized models (Bollen \& Curran, 2006). Values for both TLI and CFI range between 0 and 1, but CFI values cannot exceed 1 . A TLI or CFI value of 1 suggested a perfect model fit (Bollen \& Curran, 2006). Hu \& Bentler $(1998,1999)$ demonstrated that values of TLI and CFI that were greater than .95 indicated good model fit however, more recent research suggests that the cutoff values for GOF indices should be relaxed in light of other considerations, including small sample sizes $(\mathrm{N} \leq 250)$ and behavior of the GOF index (Marsh, Hau \& Wen, 2004). 
A stand-alone metric of model fit, the root-mean-square error of approximation (RMSEA), was also used. This index took into consideration both the sample size and the degrees of freedom, such that a "penalty" was placed on saturated models (Bollen \& Curran, 2006, p. 47). While RMSEA values have no upper limit, values close to zero indicate good model fit. Specifically, RMSEA values of .05 or lower indicated a very good model fit, where values greater than .10 indicated poor model fit (Bollen \& Curran, 2006).

The final GOF index was used to evaluate the parsimony of the model. This final statistics was Akaike's (1974) information criterion (AIC). This measure was not interpreted alone; rather, it was intended to compare models for goodness of fit. This measures was used to evaluate various iterations of the previously described models. AMOS software computed all of the GOF statistics. Model fit was ultimately determined by aggregate consideration of these fit indices.

\section{Effect of sample size on model fit indices.}

A final consideration for model identification is the sample size. Power analysis in latent growth modeling have been conducted though Monte Carlo simulations. The moderate sample size for some of the groups in the present study (including those institutions with medical schools) indicated that some potential existed for type II error, or retaining a model that should be rejected. Fan et al. (1999) found that sample size and estimation method influenced several structural equation modeling fit indices. However, the least influenced by sample size were two being used in this study, RMSEA and CFI. In a slightly misspecified model, the authors found that, with maximum likelihood estimation, a sample size of 200 produced an RMSEA of .077, where a sample size of 
500 produced an RMSEA $=.075$. Fan et al. concluded that these two GOF indices were the least sensitive to model misspecification.

In another study on the effects of sample size on fit indices, Sivo, Fan, Witta, and Willse (2006) found that optimal values of GOF indices varied by sample size. The authors found that a smaller sample size $(\mathrm{N}=150)$ resulted in lower cut-off values for not rejecting correct models. Among the GOF tested for N=150, optimal cut-off values for selected indices included RMSEA=.06 and CFI=.95. Thus, while the sample size for some groups in this study were moderately small, some consideration of sample size effect on GOF indices assured appropriate conclusions were made regarding model fit.

\section{Limitations}

While this study relies on previous studies for guidance on variable selection and specification, measuring productivity in higher education is still an elusive concept. Making relative conclusions about the results is even more difficult. The demand for exploration into higher education productivity has grown in recent years even though there remain several limitations with the exercise. Extension of the concept of productivity away from the private sector and into education requires an emphasis on tangible resources other than cost and price. As noted by Smith (1990), "the absence of market prices for the various outputs of the organization precludes the existence, let alone measurement, of a single performance measure such as profitability," (p. 56). More broadly, the two major problems with capturing and measuring productivity in education are that 1) the multiple resources and objectives of education are difficult to measure with quantifiable inputs and outputs, and 2) the degree to which any of the chosen inputs and outputs is invalid and unreliable is unknown (Lindsay, 1982). The following explains 
more specifically issues with defining education, educational outputs and quality as well as limitations associated with data availability.

\section{Defining Education}

Baumol and Blackman (1995) proposed that educational services were a "handicraft activity," difficult to reduce through technology, and difficult to capture quantitatively. Any discussion of capturing, measuring, and evaluating the educational process must explicitly submit to the intangible and unspecified process of education. So great is this consideration that several researchers find the application of productivity in education altogether unfitting (Carter, 1972; Hoos, 1975). However, the failure to completely define the educational process in the search for a relative evaluation is a predicament shadowed impressively by the ignorance of suggesting that the moveable pieces of the process cannot be modeled quantitatively for relative comparison. Thus, as suggested by Lindsay (1982);

...it must be recognized that the application of a quantitative approach in an area as complex and intangible as education, in which the underlying processes are not fully understood and in which the development of adequate measures of the conceptual constructs has made only limited progress, means that convenience in analysis is purchased at the price of completeness. As a consequence, [such analysis] is best thought of as a technique for providing preliminary or exploratory assessments, (p. 178).

While the statistical exploration into higher education productivity for this study is intended to examine - as thoroughly as possible - the relative performance of institutions, it is nonetheless subject to the theoretical disagreements of scholarly discourse. 


\section{Defining an Undergraduate Degree}

There are a variety of institutions included in the present study in order to get an understanding of the variation associated with the production of undergraduate degrees in both the social and physical sciences. While the institutions vary by both size and sector, they certainly also vary greatly in resources, including peer quality and faculty quality. Therefore, one primary consideration when reviewing this work is the limitation that an undergraduate degree at one institution is equivalent to an undergraduate degree at any other institution. The definition of an undergraduate degree as an accumulation of institutional credits is the definition being employed in this study. No qualifier was available which distinguishes a degree obtained from Harvard University from a degree obtained from Kutztown University. In this study, the two are both seen as outputs of undergraduate degrees. Thus, while it is acknowledged that these two degrees are intuitively different, the present study considers them simultaneously.

\section{Specifying quality.}

On particular issue associated with the difficulty of distinguishing among undergraduate degrees is the lack of appropriate measures of quality in higher education output. In his review of education production function studies, Hanushek (1986) argued that the emphasis on quantity rather than quality measures ignores the fact that "the differential effectiveness of schools is the heart of production function studies," (p. 1151). However, Hanushek found much of the empirical research incorporating "quality" measures - such as student and school characteristics - into production functions "inconclusive" (p. 1151). The inclusion of these variables, he argued, was 
based on researchers' subjective assumptions of how these variables affected the quality of student learning (Hanushek, 1986). Hubbell (2007) identified several reasons why quality in the higher education "market" was difficult to define. One such reason, she wrote, is that "quality is undefined or defined in dramatically differing ways by the purchaser and the producer - and further, because the quality of the customer is a key ingredient in production, output quality varies by purchaser" (p. 5). Indeed the reputation of the institution, or its perceived quality, varies not just by student and institution, but often by departments and faculty members within the institution (Schapiro, 1993).

Overall, higher education suffers from a lack of quality metrics. Several researchers (Hopkins, 1990; Hopkins \& Massy, 1981) have highlighted measures of quality omitted from their studies as "intangible" variables for consideration. However, while both the omission of quality metrics in studies of education productivity and the inclusion of them encounter criticism, this empirical study relies on previously specified measures of quality for input variables. However, for the output variable of undergraduate degrees produced, this study accepts the same limitation that plagues other models of degree production in education; namely, an appropriate metric for crossinstitutional comparison of degree quality does not exist.

\section{Variables}

Related to the lack of quality metrics is the overall abbreviated supply of data in higher education. Indeed, the availability of data has often driven how researchers empirically define productivity measures (Deller \& Rudnicki, 1993; Hopkins, 1990). In 
his report on productivity in public postsecondary education (2009), Patrick Kelly of

NCHEMS wrote:

The most difficult barrier to conducting sound productivity analyses in postsecondary education, however, is the lack of available data on the institutional costs of producing college degrees. Expenditure data for institutions, by degree program and degree level, are not available in public databases. Therefore, the analytic capabilities associated with calculating costs of producing college graduates across institutions - and programs within them have never been present. (p. 6)

Variables detailing institutional expenditures are among many seemingly absent from public databases. The lack of available data is not particularly the fault of an organization or institution. The aforementioned lack of understanding about how to define and measure intangible educational characteristics is the main culprit. However, even the tangible descriptive characteristics of universities pose problems when researching panel data. Thus, like any longitudinal study, this research is bound by the collected variables and by the availability of data in those variables over time for each institution.

\section{Time Frame}

The time frame of interest in this study is also limited by the availability of data. Given the sample size and data requirements for institution-level variables, the time frame for this study includes the maximum number of years that can be examined through available data. The primary data source for this study is the Integrated Postsecondary Educational Data System (IPEDS) into which, under Title IV, all institutions receiving federal funds must report. This data file is maintained by the National Center for Education Statistics (NCES) and is the most comprehensive data file available for the analysis. Given that the primary emphasis of this study is to specify a 
model of degree production for higher education, the time frame, though limited, does not preclude the importance of the current investigation.

\section{Interpretation of a Production Function for Higher Education}

The interpretation of standardized regression coefficients estimated through LGM yielded some understanding of the relationship between the time-varying inputs and the output variables of degrees per FTE. It must be noted that these coefficients estimate one aspect of the relationships between the variables. Indeed, faculty members are not exchangeable or replaceable and so their value cannot strictly be measured by quantity. Therefore, the limitation exists that a quantified model of degree production estimating the relationships between variables with intangible benefits must consider those benefits before more local interpretations of the production model can be extrapolated.

Specific to the production model specified in this study, I acknowledge that higher education institutions produce more than undergraduates. Among these other outputs are research and graduate students. Therefore, while faculty salaries were related to the production of undergraduate degrees, the value of faculty a college campus extends beyond the production of undergraduate degrees. The focus of this study was not to estimate the relationships between the inputs and these other outputs, but the fact that these other variables exist and relate to the selected inputs is acknowledged.

\section{Summary}

This study modeled the undergraduate degree production for a group of universities by examining the relationships between input resources and degree output over a ten-year period for both social science and physical science degrees. Productivity studies of higher education have largely relied on cross-sectional data or measures of 
productivity which consider only one university output. To extend the research on higher education degree production, this study used latent growth modeling to estimate a longitudinal production of undergraduate degrees with multiple inputs. Further, estimation of intercept and slope means and variances were examined to shed light on the change in degree production over ten years. While limitations of this type of analysis exist, it was the goal of this study to build a model of higher education degree production that could be extended over time and applied to various groups of colleges and universities for the continued investigation into the production of undergraduates. 


\section{CHAPTER 4}

\section{RESULTS}

The purpose of this study was to model the production of undergraduate degrees in a sample of four-year, non-profit colleges and universities. In addition to shedding light on the research questions, this study was intended to develop a mechanism for analysis of productivity growth that could be used to investigate additional institutions as well as additional inputs and outputs. LGM was an appropriate method for this goal, as it offered flexibility for investigating time-varying relationships in the data which were hypothesized to exist. Therefore, latent growth modeling (LGM) was applied to undergraduate degree rates measured at three time points over ten years. Inputs selected through a framework of prestige-maximization were selected to understand their influence in the production process. The current chapter presents descriptive information about the data and results of LGM analysis.

\section{Data Screening}

All undergraduate degrees awarded by institutions were categorized into one of two groups, labeled "Social Sciences" and "Physical Sciences", as shown in Appendix B, and downloaded from IPEDS. Applications of LGM to the complete set of variables yielded inadmissible results and required detailed screening of the data. Multicollinearity analysis demonstrated that the covariance between Academic Expenditures per FTE and the other three inputs was high. Therefore, this variable was deleted from the analysis to 
preserve a low level of multicollinearity. The resulting model analyzed by AMOS is shown in Figure 3.

Figure 3. Conditional model without academic expenditures

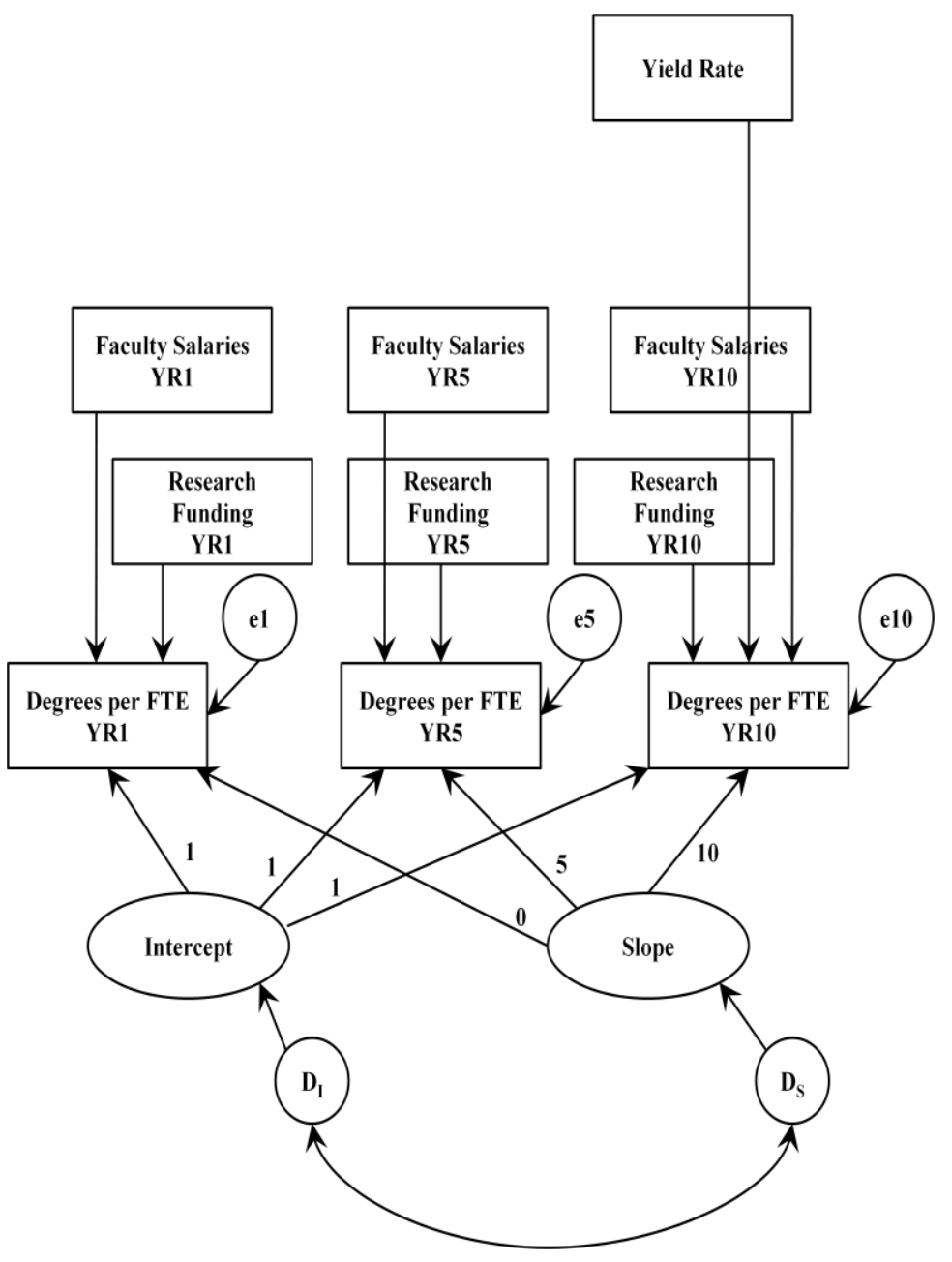

NOTE: In order to preserve clarity, correlations between time-varying predictors not shown in above figure.

Further, outlier analysis was conducted separately for the social sciences data and physical sciences data. Multivariate outliers were ranked by Mahalanobis distances. When an outlier was deleted, new Mahalanobis distances were calculated. Outlier 
analysis was completed when LGM yielded admissible solutions for all models. A total of three outliers were removed from the physical sciences dataset and three cases from the social sciences dataset prior to analyses.

Descriptive statistics for the final datasets, including means and standard deviations of undergraduate degrees (UD) in both disciplines, appear in Table 1.

Table 1. Descriptive statistics for outcome variables

\begin{tabular}{|l|c|c|}
\hline \multicolumn{1}{|c|}{ Output Variables (Year) } & Mean & Std. Deviation \\
\hline Social Sciences UD1 (97) & .1605 & .0628 \\
\hline Social Sciences UD2 (02) & .1865 & .1047 \\
\hline Social Sciences UD3 (07) & .1745 & .0745 \\
\hline Physical Sciences UD1 (97) & .0415 & .0307 \\
\hline Physical Sciences UD2 (02) & .0402 & .0975 \\
\hline Physical Sciences UD3 (07) & .0415 & .0304 \\
\hline
\end{tabular}

The total number of institutions in the sample that produced social science degrees was 1,145 schools. Of these, 681 were private institutions and 464 were public. Further, 108 of these institutions had a medical school while the remaining 1,037 did not. Institutions ranged from small, private institutions like Amherst College (MA) and Lindenwood University (MO) to large, public institutions like Pennsylvania State University and the University of Texas. The variety of institutions is demonstrated in the descriptive statistics including the mean, standard deviation, and range for the input variables found in Table 2. 
Table 2. Descriptive statistics for schools producing social science degrees

\begin{tabular}{|l|r|r|r|}
\hline Input Resource (Year) & \multicolumn{1}{|c|}{ Mean } & \multicolumn{1}{c|}{ Std. Deviation } & \multicolumn{1}{c|}{ Range } \\
\hline Research Dollars per FTE (98) & $2,439.21$ & $6,044.38$ & $84,770.37$ \\
\hline Research Dollars per FTE (03) & $3,184.06$ & $7,585.84$ & $106,956.78$ \\
\hline Research Dollars per FTE (08) & $3,613.51$ & 10.670 .06 & $166,351.27$ \\
\hline Academic Expenditures per FTE (98) & $9,316.79$ & $9,503.82$ & $106,460.00$ \\
\hline Academic Expenditures per FTE (03) & $12,348.02$ & $20,188.61$ & $534,894.48$ \\
\hline Academic Expenditures per FTE (08) & $14,906.78$ & $18,337.13$ & $240,299.15$ \\
\hline Faculty Salaries per FTE (98) & $2,483.30$ & $1,915.97$ & $27,990.02$ \\
\hline Faculty Salaries per FTE (03) & $3,122.18$ & $4,224.65$ & $116,742.62$ \\
\hline Faculty Salaries per FTE (08) & $3,513.14$ & $3,046.04$ & $56,925.44$ \\
\hline Yield Rate (04) & 0.4266 & 0.1635 & .9231 \\
\hline
\end{tabular}

Physical sciences degrees were produced by 1,114 institutions, in which 656 were private and 458 were public. In this group, 107 institutions had medical schools while 1,007 did not. This group also had a diverse mix of institutions, ranging from small, private institutions like Morehouse College (GA) to small public institutions like Kutztown University (PA). Descriptive statistics, including the mean, standard deviation and range, for the input variables associated with this sample are shown in Table 3.

Table 3. Descriptive statistics for schools producing physical science degrees

\begin{tabular}{|l|r|r|r|}
\hline Input Resource (Year) & \multicolumn{1}{c|}{ Mean } & \multicolumn{1}{c|}{ Std. Deviation } & \multicolumn{1}{c|}{ Range } \\
\hline Research Dollars per FTE (98) & $2,276.81$ & $4,615.17$ & $53,442.73$ \\
\hline Research Dollars per FTE (03) & $3,109.99$ & $6,927.97$ & $107,016.83$ \\
\hline Research Dollars per FTE (08) & $3,354.58$ & $8,170.59$ & $98,133.11$ \\
\hline Academic Expenditures per FTE (98) & $9,201.40$ & $8,877.68$ & $106,460.00$ \\
\hline Academic Expenditures per FTE (03) & $11,981.69$ & $14,684.60$ & $295,836.76$ \\
\hline Academic Expenditures per FTE (08) & $14,641.95$ & $17,050.10$ & $240,299.15$ \\
\hline Faculty Salaries per FTE (98) & $2,461.57$ & $1,760.71$ & $27,990.02$ \\
\hline Faculty Salaries per FTE (03) & $3,037.09$ & $2,708.45$ & $42,247.63$ \\
\hline Faculty Salaries per FTE (08) & $3,465.70$ & $2,884.13$ & $56,925.44$ \\
\hline Yield Rate (04) & 0.4232 & 0.1607 & .9231 \\
\hline
\end{tabular}


While the variety of institutions included in this study is large, the goal of the study's statistical analysis is to account for this variation. If all institutions were the same, or if institutions did not vary on any of the measures, than there would be no way to distinguish their performance on the output variable. Therefore, including a variety of institutions is a necessary starting point for providing some understanding of the difference between institutions in the production of social and physical science degrees. The research questions for this study address the production of social science and physical science degrees.

\section{Degree Production in the Social Sciences}

The research questions for this study were addressed for two groups; the production of undergraduate degrees in the social sciences and the production of undergraduate degrees in the physical sciences. Results for all the research questions are

first presented as they relate to degrees in the social sciences before they are presented for the production of degrees in the physical sciences.

LGM for the production of undergraduate degrees in the social sciences began with an unconditional model for the full sample of institutions. Model fit statistics were favorable, and these are shown in Table 4. Also in Table 4 are the following estimates from the full sample of institutions and the subgroup analyses; parameter estimates, estimates of the fixed and random effects, intercept-slope correlations, and squared multiple correlations for the dependent variables. 


\section{Full Sample}

\section{Unconditional model.}

The unconditional model of undergraduate degree rates per FTE for the social sciences addressed the first five research questions of the study. The first research question asked what pattern of growth best explains the production of undergraduate degrees for the sample. The unconditional model was best explained by a spline growth model, rather than a linear growth model. The linear unconditional model for the social sciences data produced a non-positive definite (NPD) covariance matrix and, thus, the results were inadmissible.

The next two research questions asked what the average starting values for undergraduate degrees were across the entire sample of institutions in 1997 and how much these starting values of institutions varied around the average value. To that end, the average value for the starting point for all institutions in 1997 was .163, with statistically significant variation equal to .002 around that value.

The last two research questions for this unconditional model of undergraduate degrees per FTE in the social sciences asked what the average slopes for undergraduate degrees over time were across all institutions in the sample and how much the slopes of individual institutions varied around the average slope parameter. The rate of growth for this group was significant at .001 degrees per FTE, and, though the variation estimate around this parameter was statistically significant, it was negligible $\left(\sigma_{\text {Slope }}^{2}<.001\right)$.

Overall, average growth for undergraduate social science degrees for this set of institutions over the ten-year period was .010 degrees per FTE $\left(10^{*} .001=.010\right)$. Further, 
the growth parameter for the estimated time point indicated non-linear growth. From 1997 to 2002, undergraduate growth was .033 degrees per FTE $(32.723 * .001=.0327)$. Growth from 2002 to 2007 for undergraduate degrees was $(10-32.723) * .001=-.0227$. In other words, the number of undergraduate degrees produced decreased from 2002 to 2007 by .023 degrees per FTE. Most of the growth in undergraduate degrees produced per FTE occurred in the first five years of the selected time period $(.0327 / .010=3.27)$. Growth then decreased in the last five years $(-.023 / .010=-2.3)$. This resulted in the overall increase of $1 \%$ in undergraduate degrees in the social sciences per FTE between 1997 and 2007.

\section{Conditional model.}

Time-varying covariates were then added to the model to answer the final research questions. First, the research question asked if the inclusion of inputs explained any of the variation in starting values or growth for undergraduate degrees. While inclusion of these covariates did not account for any of the variation around the fixed effects parameters of the model, they did influence the model in other ways. Model fit statistics improved slightly over the unconditional model (see Table 4). The improved fit of the model was further supported by a chi-square difference test between the full estimated conditional model and the model with the effects of the covariates on the outcome variables set equal to zero $\left.\left(\chi_{D}^{2}(8)=120.112, \mathrm{p}<.001\right)\right)$. In addition, squared multiple correlations for the outcome variables were high, suggesting that the full conditional model explained a significant portion of the variation in degrees in the social sciences per FTE for this set of institutions. 
Standardized regression weights, or direct effect estimates, for the three input variables on the undergraduate degrees per FTE were significant across all time points (see Table 4). The inclusion of these covariates decreased the average intercept value for the set of institutions to .151 degrees per FTE but did not change the statistically significant estimated growth over the ten-year period. Further, correlation between the intercept and slope value in this model was equivalent to the unconditional model, demonstrating that institutions with high starting values grew at a higher rate over the ten-year period. The covariates only slightly decreased the estimated pattern coefficient for 2002 from 32.723 in the unconditional model to 32.683 in the conditional model.

The next research question asked about the direct relationship between the inputs and the output of undergraduate degrees. The interpretation of coefficients for timevarying covariates is conceptualized as "the time-specific prediction of the repeated measure after controlling the influence of the underlying growth process," (Bollen \& Curran, 2006, p. 194). The conditional model simultaneously controls for the influence of the time-varying covariates, or input resources, on the production of undergraduate degrees and estimates the growth parameters of undergraduate degrees per FTE. In other words, the effect of each TVC is interpreted as the influence on the production of undergraduate degrees per FTE above and beyond what would be expected as the normal growth in the production of undergraduate degrees per FTE captured by the model.

The influence of faculty salaries had a significant and positive direct effect on the production of undergraduate degrees across all three time points, while research dollars had a significant and negative effect on the outcome variable across all three time points. The effect of yield rate on the outcome variable was also significant on the final time 
point, suggesting that, all other factors remaining consistent, an increase in yield rate would have a small but positive influence on the number of degrees produced per FTE. Indeed these results, including the change in intercept value and the statistical significance of the effects of the covariates, are interesting considerations across all the models of the study.

The last research question for the full social sciences model asked how, if at all, this final conditional model indicated that production of undergraduates at these higher education institutions had grown between 1997 and 2007. In the social sciences, the full final conditional model demonstrated that production had changed through the relative importance of various inputs in the production of degrees. Standardized regression weights for all three covariates were lower in 2007 than in 1997. This would suggest that a one standard deviation increase in these areas in 2007 resulted in a lower number of social science degrees than it did ten years earlier. While this demonstrated that, overall, productivity of social science degrees decreased in the ten-year time period, a closer look at the model told a different story.

Faculty salaries had a large increase in standardized regression weight for undergraduates in 2002 from 1997 which then fell again five years later. Faculty salaries, therefore, peaked with regards to their "payoff" in the production of undergraduates in 2002. The investment in faculty salaries in 2007 declined from 2002, and yielded fewer undergraduate degrees than it did in 1997. Similarly, the attainment of research funding resulted in a decrease in undergraduates, but that relationship was lowest in 2002. The value of this standardized regression weight suggested that a one standard deviation increase in the amount of research funding brought onto campus decreased the number of 
undergraduate degrees in the social sciences holding other covariates constant. An increase in research dollars per FTE in 2002 related to a decrease in undergraduate degrees per FTE produced, but this inverse relationship was lower in magnitude than it was in both 1997 and in 2007, further supporting a peak in undergraduate degree production in 2002 .

Finally, an increase in yield rate (or selectivity) for the admissions year of 2004 resulted in an increase in undergraduate degrees for those students in 2007. This increase was smaller relative to the influence of faculty salaries, but did demonstrate the positive relationship between student selectivity and degree production.

Overall, production of undergraduate degrees in the social sciences peaked in 2002 as demonstrated by 1) the same investment in faculty salaries in 2002 yielded more undergraduate degrees than in 1997 or in 2007, and 2) the inverse relationship between research dollars and undergraduate degrees was lowest in 2002.

\section{Subgroup Analysis: Public vs. Private Institutions}

The final research question asked how the conditional models of undergraduate degree production varied across public and private institutions and across institutions with and without medical schools. Therefore, subgroups were investigated in order to understand how the effect of being a public or private institution or an institution with a medical school may have moderated the findings we see in analysis of the full sample.

\section{Unconditional models.}

The production of undergraduate degrees in the social sciences was first compared by institutional control, and the results are included in Table 4. While model fit statistics for the unconditional models of degree production fit the data reasonably 
well for both groups, the analysis of public institutions was best fit with inclusion of a quadratic slope (see Figure 4). Significant intercepts for both groups in their unconditional models demonstrated that private institutions started with more degrees per FTE in the social sciences in 1997 (Intercept $_{\text {private }}=.172$ ) than did public institutions (Intercept $\mathrm{public}=.146)$. In addition, public institutions demonstrated slightly more variation around their average intercept $\left(\sigma_{I n t e}^{2}=.003\right)$ than did private institutions $\left(\sigma_{I n t_{e}}^{2}=.002\right)$.

Overall, private institutions grew at a lower rate $\left(\right.$ Slope $\left._{\text {private }}=.001\right)$ than public institutions (Lin-Slope public $_{\text {.003; }}$ Quad-Slope public $_{\text {.000). While public institutions }}$ demonstrated a significant linear slope, this value was not interpreted in light of the fact that the model best fit with a quadratic slope. The value of the quadratic slope, however, was negligible. Overall, average growth for undergraduate social science degrees for private institutions over the ten-year period was .10 degrees per FTE $\left(10^{*} .001=.010\right)$. Further, the growth parameter for the estimated time point indicated non-linear growth. From 1997 to 2002, undergraduate growth was .033 degrees per FTE (32.6*.001=.0326). Growth from 2002 to 2007 for undergraduate degrees was $(10-32.6) * .001=-.0226$. In other words, the number of undergraduate degrees produced decreased from 2002 to 2007 by .023 degrees per FTE. Most of the growth in undergraduate degrees produced per FTE occurred in the first five years of the selected time period $(.0326 / .010=3.26)$. Growth then decreased in the last five years $(-.0226 / .010=-2.26)$. This resulted in the overall increase of $1 \%$ in undergraduate degrees in the social sciences per FTE at private institutions between 1997 and 2007. 
Figure 4. Unconditional model of social sciences degrees per FTE at public institutions with quadratic slope

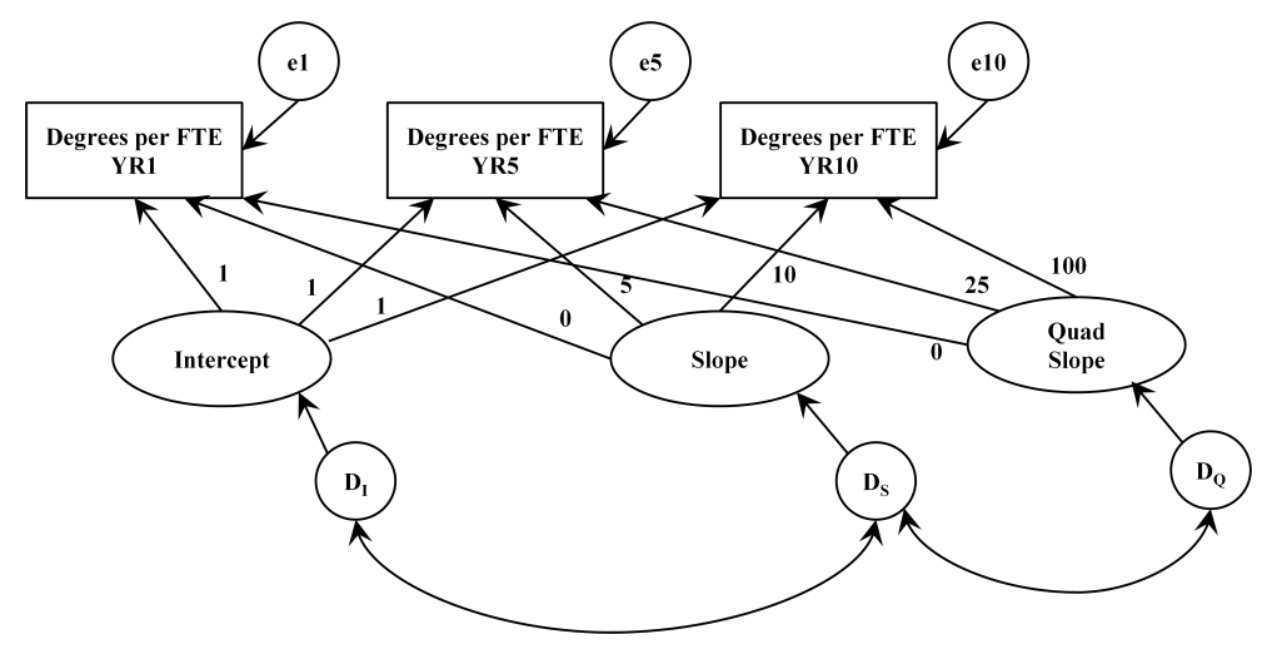

\section{Conditional models.}

The time-varying covariates were then added to both models. Model fit statistics for private schools demonstrated better fit to the data than demonstrated in public institutions (see Table 4). Inclusion of the covariates did not account for any of the variation around the growth parameters however they did decrease the estimates of the intercept parameters. Similar to the unconditional models, significant intercepts in the conditional models demonstrated that private institutions started with more degrees per FTE in the social sciences in 1997 (Intercept $_{\text {private }}=.162$ ) than did public institutions $($ Intercept $\mathrm{public}=.103)$. Conditional models also demonstrated that private institutions demonstrated the same significant growth over the ten-year period as they did in the unconditional model but that public institutions did not demonstrate measureable growth after controlling for the covariates. 
An interesting influence of the subgroup analysis by institutional control was demonstrated by the significant direct effects of the time-varying inputs included in the conditional models of undergraduate degree growth. Faculty salaries per FTE were significant in the production of undergraduate degrees at both public and private institutions. However, research dollars per FTE and yield rate were also significant in the production of undergraduate degrees per FTE at private institutions. The direction of their influence was similar such that faculty salaries contributed positively to the production of undergraduate degrees in the social sciences for both groups. Research dollars was a negative influence on the production of undergraduate degrees in the social sciences at private institutions and yield rate demonstrated a small positive influence.

The most interesting result of this analysis was that the magnitude of the direct effects demonstrated different results in the productivity between the two groups. To wit, coefficients of faculty salaries per FTE at public institutions demonstrated that the relationship between faculty salaries and undergraduate degree per FTE decreased in magnitude at each time point. This suggests that a similar investment in faculty salaries resulted in a decreased number of undergraduate degrees per FTE over the ten years. The production of undergraduate degrees per FTE in the social sciences at private institutions more closely resembled the full sample model, such that the relationship between faculty salaries and undergraduate degrees peaked in 2002 and fell in 2007. Finally, the yield rate of students was a significant and positive influence in the production of social science degrees at private institutions but not at public institutions. 


\section{Subgroup Analysis: Institutions With vs. Institutions Without Medical Schools}

\section{Unconditional models.}

Institutions were also grouped by whether or not there existed a medical school on their campus. Results from comparing the schools with ("med") and without ("non-med") medical schools are also included in Table 4. Model fit statistics for the unconditional models demonstrated reasonable fit to the data, though fit was slightly better for non-med schools. Further, linear growth fit the data better for med schools while non-med schools required a spline growth model to produce reasonable model fit. Significant intercepts for both groups in their unconditional models demonstrated that non-med institutions started with more social sciences degrees per FTE in 1997 (Intercept non-med $=.165)$ than did med institutions (Intercept $\left.{ }_{\text {med }}=.146\right)$ but grew at the same rate $\left(\right.$ Slope $_{\text {non-med }}=$

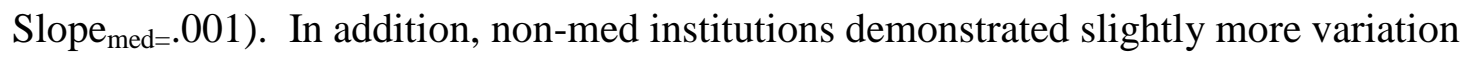
around their average intercept $\left(\sigma_{I n t e}^{2}=.002\right)$ than did med institutions $\left(\sigma_{I n_{t e}}^{2}=.001\right)$. Neither group had measurable variation around their slope estimates. Interestingly, however, the correlation between intercept and growth in social science degrees was positive for non-med schools and negative for med schools. This suggests that med schools with a lower number of social science degrees in 1997 grew at a higher rate over the ten year time period, while high growth in non-med schools was experienced by those that started with a higher number of social science degrees in 1997.

\section{Conditional models.}

The addition of the time-varying covariates to both models demonstrated improved model fit for both groups (see Table 4). Because there was little measurable 
variation in the growth parameters for the unconditional model, it is not surprising that none of this variation could be accounted for by the inclusion of the covariates; however the estimates of the growth parameters did change for both groups. To begin, the intercept for non-med institutions ( Intercept $\left._{\text {non-med }}=.152\right)$ was again higher than for med institutions (Intercept $\mathrm{med}_{\mathrm{m}}=.123$ ). Further, while non-med school growth was similar in the conditional model to its value in the unconditional model $\left(\right.$ Slope $\left._{\text {non-med }}=.001\right)$, the inclusion of covariates for med schools increased the estimated slope parameter $\left(\right.$ Slope $\left._{\text {med }}=.002\right)$ from the unconditional model. Overall, average growth in undergraduate social science degrees per FTE for med institutions over the ten-year period was .20 degrees per FTE $(10 * .002=.020)$. Further, growth was linear over the tenyear time period, so growth between 1997 to 2002 was.01 degrees per FTE $\left(5^{*} .002=.01\right)$ and growth from 2002 to 2007 for undergraduate degrees was also .01 degrees per FTE $\left[(10-5)^{*} .002=.01\right]$

The presence of a medical school did influence the direct effect estimates between the covariates and the output variables. For both groups, faculty salaries per FTE were significant and positive in the production of undergraduate degrees but their influence was consistently greater for med schools than for non-med schools. In addition, for nonmed institutions, yield rate was also positive and significant. Finally, squared multiple correlations for the outcome variables were consistently higher for med institutions than for non-med institutions at each of the three time points, though all values were greater than .5 for both groups. 


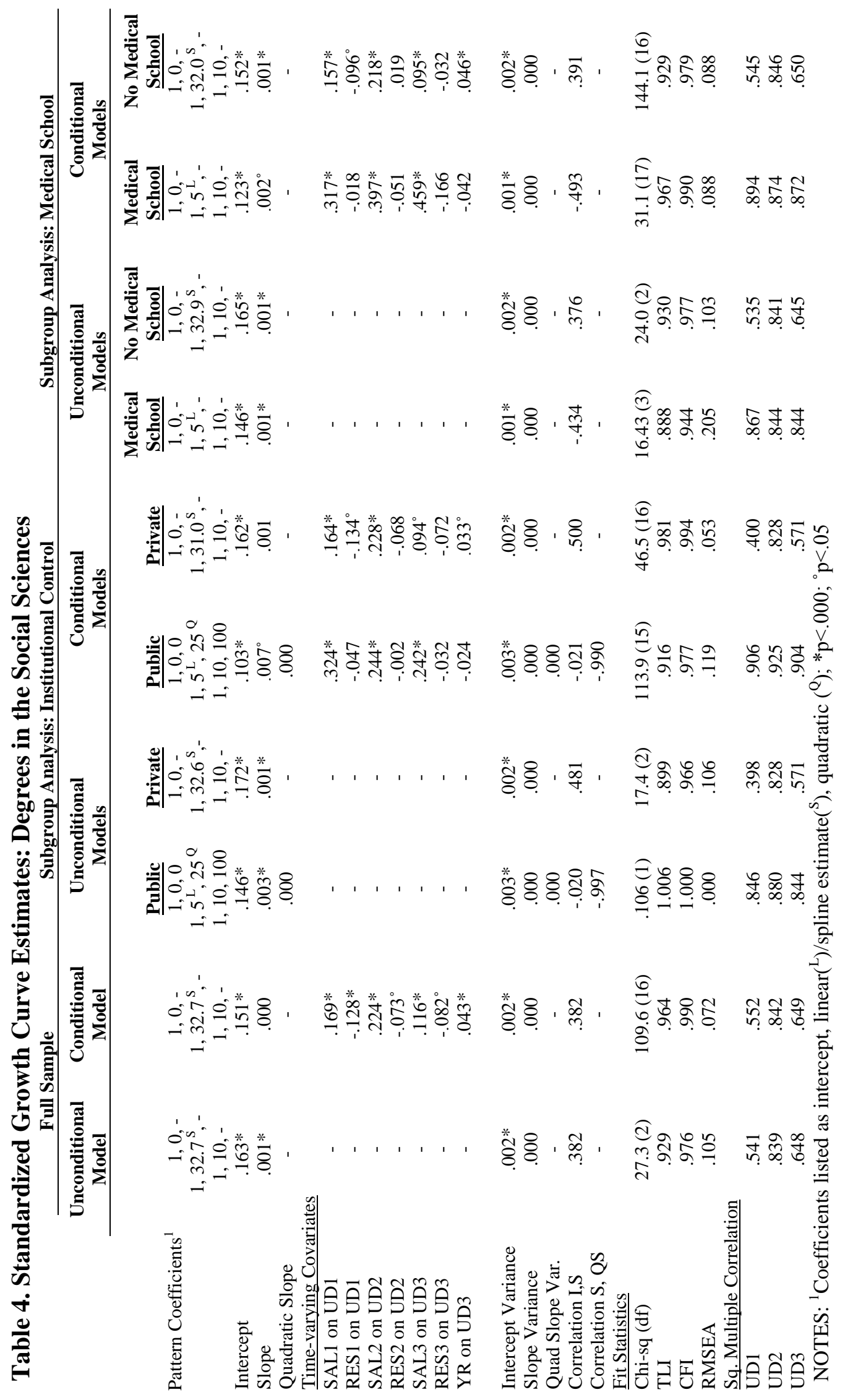




\section{Degree Production in the Physical Sciences}

LGM for the production of undergraduate degrees in the physical sciences also began with an unconditional model for the full sample of institutions. Model fit statistics for most groups were favorable, and these are shown in Table 5. Similar to the analysis for social science degrees, the following statistics are also shown for the full sample of institutions and for the two subgroup analyses; parameter estimates, estimates of the fixed and random effects, intercept-slope correlations, and squared multiple correlations for the dependent variables.

\section{Full Sample}

\section{Unconditional model.}

The unconditional model of physical sciences degrees per FTE addressed the first five research questions of the study. The first research question asked what pattern of growth best explained the production of undergraduate degrees in the physical sciences

for the sample. The unconditional model was best explained by a spline growth pattern, rather than a linear growth model, as specifying a linear model produced an NPD covariance matrix.

The next two research questions asked what the average starting values for undergraduate degrees were across the entire sample of institutions in 1997 and how much these starting values of institutions varied around the average value. To that end, the average intercept for all institutions in 1997 was .041, with statistically significant variation equal to .001 around that value. The intercept for physical science degrees was statistically significant and considerably smaller for this sample of institutions than for the social sciences degree group. The variation around this intercept was also larger for 
the social sciences group than the physical sciences group. Both of these comparisons were largely explained by the fact that fewer disciplines were considered "physical science" for the purposes of this study and, thus, those that were considered remained fairly consistent and homogenous over the ten-year period.

The last two research questions for this unconditional model of undergraduate degrees per FTE in the physical sciences asked what the average slopes for undergraduate degrees over time were across all institutions in the sample and how much the slopes of individual institutions varied around the average slope parameter. However, the number of physical sciences degrees per FTE did not grow over the ten-year period, nor was there significant variation $\left(\sigma_{\text {Slope }}^{2}=.000\right)$. The negligible rate of growth and small intercept value also produced unusually dramatic pattern coefficients when estimated through spline estimation procedures. These values were more reasonable when considered in context. In other words, multiplying a large, negative pattern coefficient by an incredibly small rate of growth (estimated as less than .001 for both the unconditional and conditional models) demonstrated that physical science degrees declined slightly over the ten-year time period. While the pattern coefficient values were unusual, the study still sought to understand the relationship between the covariates on the outcome variable of physical science degrees and, therefore, the conditional model and subgroup analyses were estimated.

\section{Conditional model.}

For the conditional model of growth, time-varying covariates were added to the unconditional model to answer the next research question which asked if the inclusion of 
inputs explained any of the variation in starting values or growth for undergraduate degrees. While inclusion of these covariates did not account for any of the variation around the fixed effects parameters of the model, they did influence the model in other ways. Model fit statistics improved remarkably over the unconditional model (see Table 5). Further, a chi-square difference test $\left(\chi_{D}^{2}(8)=108.67, \mathrm{p}<.001\right)$ also indicated that a conditional model with estimated direct effects better fit the data than a conditional model in which these effects were set equal to zero. The inclusion of these covariates also decreased the average intercept value for the set of institutions to .031 degrees per FTE. While no measureable growth over the ten-year period was detected, the estimated pattern coefficient increased slightly in the conditional model. This suggested that the inclusion of covariates accounted for some of the decline demonstrated by the sample during the time period of interest. Correlation between the intercept and slope values in this model was negative, which demonstrated that institutions with higher starting values grew at a lower rate over the ten-year period. Finally, squared multiple correlations for the outcome variables were high for both the unconditional and conditional models, suggesting that these models each explained a significant portion of the variation in degrees per FTE in the physical sciences for this set of institutions.

The next research question asked about the direct relationship between the inputs and outputs in this model. Direct effect estimates for faculty salaries and research dollars per FTE were positive and significant in the production of undergraduate physical science degrees for 1997 and 2007 but not for 2002 (see Table 5). Further, both of these estimates declined slightly between the two time points. The positive influence of 
research dollars per FTE on physical science degrees contrasts the negative influence estimated in the production model for social sciences degrees. This may suggest that faculty research and degree attainment may be a more symbiotic relationship for undergraduates in the physical sciences than for those in the social sciences. In other words, it might suggest that undergraduate students have the ability to participate in research and that participation contributes to student success. However, the estimated coefficient could also be reflecting a relationship between faculty quality and student degree attainment. Because physical sciences faculty might receive more funding from grants than social sciences faculty, the relationship demonstrated in this model might be reflecting the same positive coefficient demonstrated in both models between faculty salaries and student success. Finally, yield rate was also a significant and positive influence suggesting that an institution's selectivity was a large portion of the success of undergraduates focused in the physical sciences.

Finally, the last research question for the full sample asked how, if at all, this conditional model indicated that production of undergraduate physical sciences degrees at these higher education institutions had grown between 1997 and 2007. The conditional model demonstrated that production declined slightly over the ten-year time period when assessed by the relative importance of faculty salaries and research dollars. Standardized regression weights of the covariates declined slightly from 1997 to 2007, and were not significant in 2002. In other words, a one standard deviation increase in each of the covariates in 2007 resulted in a slight decrease in degrees compared to 1997. Overall, then, productivity of physical science degrees did not follow the same pattern as did the production of social science degrees though the relative importance of the inputs were 
different during the time period. Indeed, I conclude that the production of undergraduate degrees in the physical sciences declined slightly over the ten-year time period given that the relative importance of faculty salaries and research dollars decreased in 2007 from their influence in 1997. In addition, the influence of yield rate on the production of physical sciences was .021 in 2007 suggesting that student selectivity accounted for a positive increase in undergraduate physical science degrees above and beyond the growth in degrees captured by the model and after controlling for faculty salaries and research funding.

\section{Subgroup Analysis: Public vs. Private Institutions}

\section{Unconditional models.}

The full sample of institutions was subsequently broken into subgroups to address the final research question which asked if productivity changed based on institutional control or presence of a medical school. Results for analysis by institutional control are included in Table 5. Model fit statistics for the unconditional models of degree production demonstrated reasonable fit for both groups. Though estimates for intercepts were much lower for public and private institutions in the production of physical sciences degrees than for social science degrees, intercept values for the physical sciences still demonstrated that private institutions started with slightly more degrees per FTE in 1997 (Intercept private $=.042)$ than did public institutions (Intercept public $=.040)$, though the estimates were quite close. Estimates of variation around these intercepts were equal across both groups $\left(\sigma_{I n t e}^{2}=.001\right)$ and neither group demonstrated significant or measureable growth over the ten-year period. The only significant difference between 
the two groups was in the estimated correlation between the intercept and slope values. Public institutions demonstrated a much greater negative correlation (-.342) than private institutions (-.070), such that a public institution with a low number of physical science degrees per FTE in 1997 would have shown a larger rate of growth in degrees per FTE over the ten-year time period.

\section{Conditional models.}

Model fit statistics remarkably improved for both public and private institutions with the inclusion of time-varying covariates (see Table 5). Inclusion of the covariates did not account for any of the variation around the intercept parameter for private institutions, but did account for all the variation around this parameter for public institutions. Further, statistically significant intercept values for both groups decreased in the conditional models but still demonstrated that private institutions started with more degrees per FTE in the physical sciences in 1997 (Intercept private $=.034)$ than did public institutions $\left(\right.$ Intercept $\left._{\text {public }}=.014\right)$. The correlations for the growth parameters increased in magnitude from the unconditional model but still demonstrated that public institutions that started with these lower values of physical science degrees per FTE grew at a higher rate over time.

Indeed, the conditional model for public institutions was the only model to demonstrate growth in physical sciences degree production over the ten-year period. Overall, average growth for undergraduate physical science degrees for public institutions over the ten-year period was $1 \%$, or .010 degrees per FTE $(10 * .001=.01)$. Further, the growth parameter for the estimated time point indicated small, but non-linear growth. From 1997 to 2002, undergraduate growth increased by .00098 degrees per FTE 
(.982*.001=.000982). Growth from 2002 to 2007 for undergraduate degrees was (10$.982)^{*} .001=.009$. In other words, the number of undergraduate degrees in the physical sciences for public institutions increased from 2002 to 2007 by .009 degrees per FTE demonstrating that nearly all of the growth in undergraduate degrees produced per FTE occurred in the last five years of the selected time period $(.009 / .010=.90)$. No measureable growth was estimated for private institutions over the ten-year period.

Indeed the most interesting influence of the subgroup analysis by institutional control was demonstrated by the significant direct effects of the time-varying inputs included in the conditional models of undergraduate degree growth. Both faculty salaries and research dollars per FTE were significant in the production of undergraduate degrees at public institutions (see Table 5). However, faculty salaries had a larger relationship with the output variable for public institutions than for private institutions. This could be interpreted so that a standard deviation increase in faculty salaries at a public institution resulted in a larger increase in physical science degrees than it did at private institutions. Further, the positive relationship demonstrated between research dollars and physical science degrees was only significant for public institutions, and, while it was positive and significant for the full sample, yield rate was not a significant influence for either subgroup in the production of physical sciences degrees.

\section{Subgroup Analysis: Institutions With vs. Institutions Without Medical Schools} Unconditional models.

Similar to the analysis for social science degrees, institutions were also grouped by whether or not there existed a medical school on campus. Results from comparing the schools with ("med") and without ("non-med") medical schools are also included in 
Table 5. Model fit statistics for the unconditional models demonstrated relatively poor model fit to the data for med schools, though linear growth fit the data better for med schools while non-med schools required a spline growth model to produce reasonable model fit. Not surprisingly, significant intercepts for both groups in their unconditional models demonstrated that non-med institutions started with fewer degrees per FTE in the physical sciences in 1997 (Intercept non-med $=.040)$ than did med institutions $($ Intercept $\mathrm{med}=.057)$ though neither demonstrated significant or measurable growth. In addition, non-med institutions demonstrated slightly more variation around their average intercept $\left(\sigma_{I n t e}^{2}=.001\right)$ than did med institutions $\left(\sigma_{I n t e}^{2}<.001\right)$. Neither group had measurable variation around their slope estimates.

\section{Conditional models.}

The addition of the time-varying covariates to both models demonstrated reasonable model fit for both groups (see Table 5). None of the variation around the growth parameters for non-med institutions was accounted for by the inclusion of the covariates however estimates of these growth parameters did change. Statistically significant intercepts for both groups in the conditional models declined and, as expected, non-med institutions started with fewer degrees per FTE in the physical sciences in 1997 $\left(\right.$ Intercept $\left._{\text {non-med }}=.028\right)$ than did med institutions ( Intercept $\left._{\text {med }}=.046\right)$. Again, neither group had statistically significant or measureable growth.

The presence of a medical school did influence the direct effect estimates between the covariates and the output variables. Most notably, direct effect estimates for research dollars were not significant in the production of physical science degrees for med 
institutions. This may have been the result of the small sample size and low variation in this sample, or the fact that the influence of research funding on the production of physical sciences degrees was captured by the significant and positive relationship between faculty salaries and the outcome variable.

Not surprisingly, direct effect estimates in the production of undergraduate degrees in the physical sciences at non-med institutions yielded significant covariates similar to the estimates for the full sample. One noticeable difference was that research dollars per FTE was larger and significant in 2007, suggesting that the majority of the positive influence of faculty research in the physical sciences disciplines in that year was experienced by institutions without a medical school. Finally, yield rate for both groups was a positive and significant influence on the production of physical sciences degrees. 


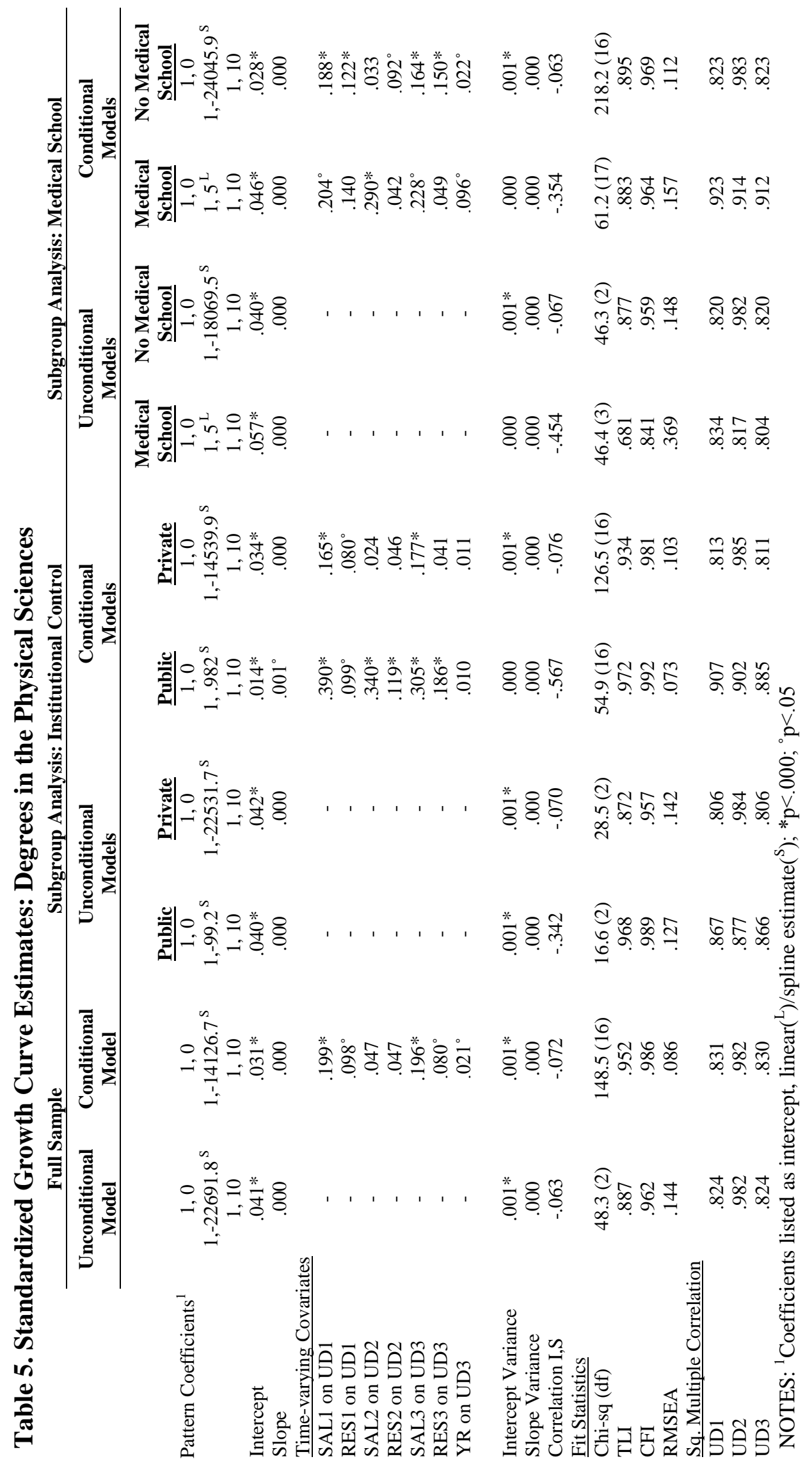




\section{Summary}

The production of undergraduate degrees per FTE in the social and physical sciences was examined through latent growth modeling. While most of the institutions included in this study produced undergraduates in both disciplines, the two datasets were not exactly similar, and results were presented by discipline. Investigation was also done by subgroups in order to understand how membership to a particular group changed the net effects of growth and relationships between the covariates and the outcome variables. While the data did not demonstrate large amounts of growth or variation, analyses did uncover several interesting patterns and relationships.

Overall, model fit statistics demonstrated that the latent growth models for the full samples and subgroups fit the data reasonably well for degree production in both the social sciences and physical sciences. Results of the analysis for social science degree production demonstrated more growth and higher starting values for undergraduate degrees than in the physical sciences. Further, correlations between the intercept and slope values were largely positive for institutions producing undergraduates in the social sciences. Not surprisingly, more variation existed in the data across social science disciplines than for physical science disciplines.

The major finding across both disciplines and across subgroups involved the relationships between the covariates and the production of undergraduate degrees in the conditional models. Across all analyses examining the production of social science degrees, the influence of faculty salaries was positive and significant. Similarly consistent was the significant and negative effect of research dollars on the outcome variable. In the production of physical science degrees, faculty salaries and research 
dollars per FTE remained significant and positive across most of the analyses. Across most models in both disciplines, yield rate was a small but significant influence on the production of undergraduate degrees.

Growth parameters across both disciplines also demonstrated some interesting patterns. Across both disciplines, private institutions began with a higher rate of undergraduates than public institutions. However, contrary to the production of social sciences, public institutions grew at a higher rate in the production of physical sciences degrees. Indeed, for every model except that for public institutions, undergraduate degree production in the physical sciences demonstrated no measurable growth over the ten-year time period. On the other hand, degree production in the social sciences grew at small but different rates across most groups.

Overall, it was demonstrated that productivity in the social sciences peaked in 2002 and decreased in 2007 as demonstrated by the relative importance of the timevarying covariates. Production of the physical science degrees also declined slightly over the ten-year time period but without a peak in 2002, as demonstrated by the low rate of growth and the consistent pattern of relationships between the time-varying covariates and the output variables. 


\section{CHAPTER 5}

\section{DISCUSSION}

By estimating several latent growth models, change in undergraduate degree production among a sample of higher education institutions was assessed from 1997 through 2007. Modeling the production of undergraduate degrees in both the social sciences and physical sciences is a convoluted process and interpretations must be considered in appropriate context. This chapter outlines the results of the study and the context for these findings. More specifically, the relative importance of three major inputs in the production of both social and physical science degrees is detailed and followed by a discussion of the merits of latent growth modeling for the present analysis. The chapter concludes with suggestions for future research in the substantive area.

\section{Interpretation of Results}

The productivity of higher education institutions was modeled for both the social sciences and the physical sciences through latent growth modeling. Overall, production of undergraduate degrees in the physical sciences has declined slightly over the ten-year time period while degree production in the social sciences declined in 2007 after reaching a peak in 2002. However, interpretations of these conclusions are limited, and more accurate conclusions can be extrapolated from the model by examining the specific relationships between undergraduate degree production and the individual inputs at each time point. 


\section{Equality of Undergraduate Degrees}

A consideration in this analysis limits the extent to which findings can be extracted and interpreted in the context of current literature. The sample of institutions included in the analysis produce undergraduate degrees that vary greatly in quality, and no mediator for this quality was included. It is important to note that the inclusion of variation is largely a foundation of the basis for statistics. While a sample is drawn to represent a population, the sample includes variation. The purpose of the current model and many other statistical analyses - is to explain, or model, that variation. Doing so

lends insight to the reasons that units vary. However, while the present analysis sought to understand if institutions varied in their quantity of degrees produced, a variable was not included to account for the variation in the quality of the degrees produced. This omission is the result of the dearth of available data measuring quality across institutions. This consideration certainly affects the production process of undergraduate degrees in both disciplines, and the reader should bear this in mind when considering the interpretation of findings.

\section{Prestige and Degree Production}

Overall, the unique contribution of this study to the current literature on degree production is the application of latent growth modeling to the examination of prestigemaximizing behavior in the production of undergraduate degrees. Analysis of the full sample of institutions demonstrated that all three prestige-driven inputs included in the models were significantly related to the production of undergraduate degrees for at least two of the three time points. These inputs were selected based on their ability to influence the reputation, or prestige, of institutions. Prestige-maximizing behavior would 
suggest that institutions focus on these inputs in an effort to improve their reputations. However, the present study demonstrated that the results of increasing each input are not clear-cut translations into increased degree rates.

For example, research funding largely contributes to the reputation of an institution. The present study demonstrated, however, that an increase in research funding negatively influences the production of social science degrees and positively influences the production of physical science degrees. Indeed this suggests that faculty research has a different effect across disciplines. Results of this study could be demonstrating that campuses which favor research funding also demonstrate larger interest in the production of physical science degrees rather than social science degrees. In other words, research funding may not actually be detrimental to the production of social science degrees; it may simply reflect that the instructional foci of institutions with larger amounts of research funding are in other disciplines. This suggestion would explain the positive relationship between the amount of research funding and the production of physical science degrees.

The favorable relationship between the other two inputs - yield rate and faculty quality - with degree production across the models could reflect that increased institutional prestige is beneficial for student progress. However, the exclusion of other institutional metrics necessitates that interpretations proceed with caution. The effects of student and faculty quality across institutional types and in different disciplines could be mediated by the effects of other, excluded variables. Indeed, the confounding results of the influences of these inputs on the production of degrees prove that the substantive focus on degree production is indeed more nuanced than can be captured by the present 
models. Productivity analyzed at the institutional level can only point to suggestions about process rather than definitive conclusions due to the complex organizational structures and funding schemas of institutions as well as the variation in behaviors of institutional leaders. However, in light of this consideration, a discussion of the specific input-output relationships is warranted.

\section{Faculty salaries and undergraduate degree production.}

Prior to conducting analysis, collinearity diagnostics were performed on the data. During this process, the variable of "Academic expenditures per FTE" was found to be too highly correlated with "Faculty salaries per FTE" to produce an admissible solution to the model. Therefore, the variable was deleted from the analysis. Removing academic expenditures from the model was a statistical specification that had substantive implication. After all, while removing academic expenditures from the model allowed estimates of parameters to be obtained, the overall model now presumed that the production of undergraduate degrees was the result of three, rather than four, inputs. What is more, faculty salaries became the only consideration of student spending on campus represented in the model. Without close examination of this limitation, the findings could be interpreted to support an argument that instructional expenditures lead to increased student persistence, perhaps by demonstrating an avenue for student engagement and integration as argued by Ryan (2004). However, the absence of academic expenditures in the model beyond faculty salaries does not allow this generalization to hold. In other words, this model of undergraduate degree production only examined the expenditure of faculty salaries per FTE, rather than the sum of all perstudent academic expenditures. 
Therefore, rather than examine faculty salaries as the sum of academic spending in the model, interpretation should focus on the significant and positive relationship between the investment in faculty salaries and the production of undergraduate degrees. For example, the models for both physical sciences and social sciences degree production suggest that faculty quality, proxied by faculty salaries, has a positive and significant influence on the number of undergraduate degrees produced. This could be indicative of a spurious relationship demonstrated by results found by Dolan and Schmidt (1994) who found that higher quality students are drawn to universities with higher quality faculty. Thus, this argument would suggest that the higher quality students contribute to the higher degree rate, rather than the higher quality faculty. However, it seems logical to suggest that faculty quality does indeed have some unique contribution on student success, and likely that relationship is captured with this model.

\section{Research funding and undergraduate degree production.}

Unlike faculty salaries, the relationship between research funding per FTE and undergraduate degrees was not consistent across disciplines. In the production of social sciences, this relationship was negative and not significant across subgroup analyses. In fact, examination of this relationship across the three time points suggests that, over the ten year period, institutions with larger amounts of research funding coming on to campus had lower rates of undergraduate degrees produced in the social sciences per FTE. While this finding could be interpreted with some dismay - such that institutions bringing on more research funding graduate fewer students - the results must, as with the results of faculty salaries, be taken with some consideration. 
First, it is worthy to note that the magnitude of the inverse relationship between research funding and undergraduate social sciences degrees was not large. Certainly, for the full sample analysis, this relationship was significant, but it was largely not statistically significant across the subgroup analyses, suggesting that this relationship is not exhibited uniformly by specific groups.

Second, the significant and positive relationship between research funding and the production of physical sciences degrees might suggest that the input is actually acting as a second proxy for faculty quality in that model. This could be because 1) grant funding often contributes largely to the salaries of physical sciences faculty and 2) grant amounts for the physical sciences might be much larger than the social sciences. The research funding is not delineated by disciplines on IPEDS, so the trends of research funding cannot be examined descriptively in this manner. However, the influence of research funding on the production of physical sciences degrees seemed much more stable across subgroup models than it did in the analysis of social sciences degree production.

The relationship between research funding and undergraduate degrees can also be interpreted to reflect the convoluted relationship between institutional reputation and student success. Indeed, literature demonstrates that faculty research activity has small but positive association with student learning outcomes (Feldman, 1987; Grunig, 1997; Volkwein \& Carbone, 1994) and the model for physical sciences degree production supports that argument. However, increased research funding also takes some faculty away from the classroom. As Grunig (1997) explains this situation:

Perhaps students and other members of the public do not always make the mental connection between the process of research (which may often contribute to 
consumer dissatisfaction) and the outcome of the research process (which leads to greater academic reputation and more favorable consumer attitudes). (p. 45)

Therefore, the relationship between research funding and undergraduate degree production can be interpreted as a difficult one for analysis. Methodologically, the tradeoff between research and student success may be negative but substantively, the influence of this research on institutional reputation benefits the student.

\section{Yield rate and undergraduate degree production.}

Discussing the merits of investigation into production processes, I noted that Kelly (2009) observed that:

.... 60 percent graduation rate at an institution that serves high proportions of low-income and minority students probably deserves more applause than an institution with an 80 percent graduation rate that is highly selective and serves students from predominately privileged families. (p. 6)

Kelly (2009) was referring to the consideration of yield rate in the performance of an institution. The yield rate, defined as the number of admitted students who chose to enroll in the university, reflects the prestige of an institution (Ehrenberg, 2000) and the quality of its students. This study found that, in both the social sciences and physical sciences, yield rate had a significant and positive influence in the production of undergraduate degrees, suggesting that higher quality students largely contributes to higher numbers of degrees per FTE. However, due to data limitations, the relationship between yield rate and undergraduate degrees per FTE could only be examined for the final time point. Therefore, the results of the relationship could not be tested or corroborated over time. Certainly the model would benefit from additional data. However, the model does suggest that the quality of students enrolled in a class positively and significantly influenced the amount of degrees produced for that class. 


\section{Distinctions among public and private institutions.}

The models for social sciences and physical sciences were examined for influences attributable to institutional control. In the production of physical sciences degrees, the influence of both faculty salaries and research funding were positive and statistically significant on the campuses of public institutions. On the contrary, faculty salaries at private institutions were only significant in 1997 and 2007, and research funding was significant and positive in 1997. Indeed public institutions also demonstrated measurable growth during the ten-year period, while private institutions did not. The demonstrated $1 \%$ increase in physical science degrees per FTE on the campuses of public institutions over the ten-year period was apparent only after controlling for faculty salaries and research funding.

The large positive and significant influence of faculty salaries and research funding on the degree production at public institutions might be representative of the differences in size and quality among the sample of public institutions. Previous research demonstrated that the size of an institution was associated with its level of research activity and that selectivity of institutions was associated with faculty salaries (Grunig, 1997). Indeed, public institutions produce various levels of research and the differences may contribute to the variation in the quantity of physical science degrees produced. In other words, campuses with faculty that attract more research funding may be more likely to have larger degree programs (with larger classrooms) which produce more undergraduate degrees than public institutions with less research funding. Similarly, public institutions that have higher faculty salaries may be more selective and, thus, graduate more students per FTE. 
The influence of yield rate was not significant in the production of undergraduate degrees in either discipline for public institutions. Statistically, this is interpreted such that the growth of undergraduate degrees per FTE at public institutions in 2007 was not significantly influenced by the quality of enrolled students above and beyond the influence of faculty salaries and research funding and the underlying growth trajectory captured by the model. Now, whether this holds true substantively requires some further consideration.

While it may be the case that public institutions largely demonstrated an influence by yield rate in other years, the dearth of historical admissions data in IPEDS prevents exploration of this. However, the influence of institutional control on student quality was not significant in Porter and Toutkoushian's (2006) study of research productivity, student quality, and institutional reputation. Therefore, the fact that student quality was not significant in the model of public institutions may suggest that public institutions producing more degrees per FTE do not necessarily have success recruiting better students. In other words, larger is not always better. Of course, while this relationship is not significant in the model for public institutions, the coefficient for yield rate is significant in the full model. Therefore, I hesitate to conclude the deficiency of public institutions in recruiting better students with great certainty and, instead, argue that, as a whole, better quality students contribute to more degrees being produced.

In the production of social science degrees per FTE, faculty salaries had a significant and positive influence for both public and private institutions. In addition, private institutions reflected a significant and negative influence of research funding and a significant and positive influence of yield rate. The similarity of significant pattern 
coefficients across both types of institutions for the social sciences suggests that the production of social science degrees is similarly influenced by the inputs at public and private institutions. Model fit statistics were slightly better for the private institutions suggesting that the model of social science degree production explained the growth pattern better for this group than for public institutions.

\section{Distinctions among institutions with and without medical schools.}

The relationships between the inputs and the production of social science and physical science degrees were further examined for institutions with ("med") and without ("non-med") medical schools. Not surprisingly, the non-med school models often reflected the results of the full sample, as the sample size was so large. However, the med school models demonstrated that, in the production of physical sciences, student and faculty quality largely contributed to the degree rate. Further, in both disciplines, research funding did not significantly contribute to the production of degrees. Taken together with the finding by Ahern and Scott (1981) that faculty in medical schools have lower publication frequencies than their peers in other schools, it can be argued that the quality of med schools is largely captured by the personnel inputs rather than research funding. In this respect, increasing the prestige of med schools could simultaneously increase the success of their students.

\section{Latent Growth Modeling at the Institutional Level}

While limitations exist for interpretation of results, some discussion of the methodological side of the present study is helpful. As a tool for the analysis of institutional degree production, latent growth modeling is beneficial but limited. The benefits of this method in the current substantive context are similar to the benefits of 
latent growth modeling as a tool in other substantive areas. The method allows examination of average change over time as well as individual variation in that change. In other words, latent growth modeling is appropriate for analyzing panel data which captures some phenomenon over time for a set of units. In addition, covariates can be added to explain variability among the units. Longitudinal analysis is helpful for investigation into higher education because trends in university data often hold the keys for understanding progress. Further, variation among institutions gives researchers opportunities to identify constructs or variables that explain the variation. Understanding why and how institutions differ is helpful for understanding the experiences of students.

However as previously mentioned, one of the challenges associated with applying this method in the current context was the gap between the statistical appropriateness of the model and the theoretical assumptions of the substantive focus. This gap was largely fed by the lack of longitudinal data available at the institutional level that could have accounted for additional academic expenditures and institutional quality. These complications certainly limited the applicability of the model with respect to definitive conclusions regarding degree production, but they also highlighted the need for more institution-level data for critical examination of undergraduate degree production. Indeed the dearth of quantitative information collected uniformly across institutions makes this level of analysis - with any method - quite difficult. Further, while advances are being made to improve data collection, longitudinal analysis remains difficult. Therefore, this exercise demonstrated that investigation into longitudinal institution-level analysis is possible and often largely beneficial but somewhat limited in the context of more convoluted substantive arenas such as degree production. 
Because the statistical specification of latent growth models required certain modifications to the theoretically designed model, substantive interpretations of the results are limited. For example, while the model still provided a reasonable estimate of the production of undergraduate degrees on college and university campuses, the assumption that faculty salaries are the only academic expenditures contributing to student success is incorrect. The degree to which results can be interpreted within the context of higher education productivity literature is understandably limited. These models estimated the influence of only three inputs in the production of degrees while, in actuality, there exist many more. To that end, some additional research in this area is warranted for a better understanding of the production of undergraduate degrees.

\section{Recommendations for Future Research}

Three recommendations are made to guide future research in undergraduate degree production with consideration of latent growth modeling. First, given the convoluted nature of degree production, future analysis on this topic should extend the present model to consider additional inputs and outputs. While this study identified the relationship between some campus resources and degree attainment, additional inquiry is necessary to understand relationships that exist between additional resources and the production of degrees. This analysis could also investigate the relationship between resources and multiple outputs, given that institutions produce more than just undergraduate degrees. Among the many outputs of universities are graduate students and research. Exploration into the relationship between a larger number of university inputs and their joint outputs would move towards a larger perspective of the production processes of higher education institutions. 
There is caution in this extension, however. While latent growth modeling can certainly be expanded to include multiple outcome variables and more time points, the complexity of the model exponentially increases and, at some point, the researcher may find that an alternative method is more appropriate.

Second, production of undergraduate degrees should be evaluated across all disciplines. The theoretical assumption was adopted for this study that the production of undergraduate degrees in the physical sciences differed from the production of social sciences. Future research would benefit from an investigation into the production of undergraduate degrees across all disciplines. This analysis could further test the relationships between the resources and degree attainment uncovered in the present study. In addition, combining undergraduate degrees of all disciplines into one model benefits the statistical method of this analysis. By increasing the variation present in the latent growth model, the researcher increases the opportunity for covariates to account for this variation.

A third recommendation for researchers is also a challenge. Productivity analysis and policy development would benefit from access to student-level data which could be used to compare institutions. For example, the production of student learning or student engagement across different types of institutions should be assessed. Therefore, the third recommendation is that instruments which measure these difficult constructs be developed and implemented for longitudinal data collection. Doing so ensures that these constructs can be included in production research for an understanding of how more intangible processes contribute to the production of student success. This type of macro- 
level analysis of degree production with student-level variables could point researchers and policymakers toward institutions that have developed ways to "do more with less."

This study shed light on the methodological and substantive benefits and challenges associated with modeling production of undergraduate degrees across disciplines. In doing so, it extended the research of others and sparked new questions about the relationships between inputs and degree production on college campuses as well as the applicability of growth curve analysis in this area. While complications with the analysis limited the extent to which findings could be interpreted, general conclusions regarding the positive influence of faculty and student quality were uncovered. Recommendations for future research identified paths down which researchers may tread to find answers about the larger picture of degree production on college campuses. With the collection of additional data at the institutional level and the continued focus of education researchers, macro-level issues can continued to be investigated with the best methods possible. 


\section{REFERENCES}

Akaike, H. (1974). A new look at the statistical model identification. IEEE Transactions on Automatic Control, AC-19, 6, 716-723.

Alexander, F.K. (2000). The changing face of accountability: Monitoring and assessing institutuional performance in higher education. The Journal of Higher Education, 71(4), p. 411-431.

Alpert, D. (1985). Performance and paralysis: The organizational context of the American research university. The Journal of Higher Education, 56(3), 241-281.

Ahern, N.C., \& Scott, E.L. (1981). Career outcomes in a matched sample of men and women doctorates. Washington, DC: National Academy Press.

Archibald, R.B. \& Feldman, D.H. (2008). Graduation rates and accountability: Regressions versus production frontiers. Research in Higher Education, 49, 80100.

Astin, A.W. (1999). Student involvement: A developmental theory for higher education. Journal of College Student Development, 40(5), 518-529.

Banta, T., Rudolph, L., Van Dyke, J., \& Fisher, H. (1996). Performance funding comes of age in Tennessee, The Journal of Higher Education, 67(1), p. 23-45.

Baumol, W. \& Blackman, S.A. (1995). How to think about rising college costs. Planning for Higher Education, 23(4), p. 1-7.

Bellas, M.L. \& Toutkoushian, R.K. (1999). Faculty time allocations and research productivity: Gender, race and family effects. The Review of Higher Education, 22(4), 367-390.

Bentler, P. M., \& Bonett, D. G. (1980). Significance tests and goodness-of-fit in the analysis of covariance structures. Psychological Bulletin, 88, 588-606.

Berger, J. (2002). The influence of the organizational structures of colleges and universities on college student learning. Peabody Journal of Education, 77(3), 4059.

Blackburn, R.T. \& Lawrence, J.H. (1995). Faculty at work. Motivation, expectation, satisfaction. Baltimore, MD: Johns Hopkins University Press. 
Bland, C.J., Center, B.A., Finstad, D.A., Risbey, K.R., \& Staples, J.G. (2005). A theoretical, practical, predictive model of faculty and department research productivity. Academic Medicine, 80(3), 225-237.

Blasdell, S.W., McPherson, M.S., \& Schapiro, M.O. (1993). Trends in revenues and expenditures in US higher education: Where does the money come from? Where does it go? In McPherson, M.S., Schapiro, M.O., \& Winston, G.C. (eds.) Paying the Piper: Productivity, incentives, and financing in US higher education, 15-36. Ann Arbor, MI: University of Michigan Press.

Bollen, K.A. \& Curran, P.J. (2006). Latent curve models: A structural equation perspective. Hoboken, NJ: Wiley.

Bourdeiu, P. (1987). The forms of capital. In J.G. Richardson (Ed.), Handbook of theory and research for the sociology of education (pp. 241-258). New York:

Greenwood Press.

Bowen, H.R. (1980). The costs of higher education: How much do universities spend per student and how much should they spend? San Francisco: Jossey-Bass.

Bowles, S. (1970). Towards an educational production function. In Hansen, W.L. (Ed.) Education, Income and Human Capital. National Bureau of Economic Research, Conference on Research in Income and Wealth. New York: Columbia University Press, 11-61.

Bozdogan, H. (1987). Model selection and Akaike's Information Criterion (AIC): The general theory and its analytical extensions, Psychometrika, 52(3), 345-370.

Breneman, D.W. (1976). The PhD production process. In Fromkin, J.T., Jamison, D.T., \& Radnor, R. (eds.) Education as an industry. Cambridge, MA: Ballinger.

Breneman, D.W. (1978). Effect of recent trends in graduate education on university research capability in physics, chemistry, and mathematics. In Smith, B.L.R. \& Karlesky, J.J. (Eds.), The State of Academic Science, p. 133-162. New York: Change Magazine Press.

Breneman, D.W. (1993). Higher education on a collision course with new realities. Washington, DC: Association of Governing Boards of Universities and Colleges.

Burke, J.C. (2002). The new accountability. In Burke, J. and Associates (Eds.), Funding public colleges and universities for performance: Popularity, problems and prospects (pp. 1-18). Albany, NY: Rockefeller Institute. 
Burris, V. (2004). The academic caste system: Prestige hierarchies in $\mathrm{PhD}$ exchange networks. American Sociological Review, 69(2), 239-264.

Card, D. \& Krueger, A.B. (1996). School resources and student outcomes: An overview of the literature and new evidence from North and South Carolina. Journal of Economic Perspectives, 10(4), 31-50.

Carnegie Foundation for the Advancement of Teaching (2009). The Carnegie Classification of institutions of higher education. Retrieved from http://www.carnegiefoundation.org/classifications/.

Carter, C.F. (1972). The efficiency of universities. Higher Education, 1(1), 77-90.

Chan, D. (1998). The conceptualization and analysis of change over tie: An integrative approach incorporating longitudinal mean and covariance structure analysis (LMACS) and multiple indicator latent growth modeling (MLGM). Organizational Research Methods, 1, 421-483.

Clotfelter, C.T. (1996). Buying the best: Cost escalation in elite higher education. Princeton, NJ: Princeton University Press.

Cohn, E. \& Geske, T.G. (1990). The economics of education. Third edition. New York: Pergamon Press.

Cohn, E., Rhine, S.L.W., \& Santos, M.C. (1989). Institutions of higher education as multi-product firms: Economies of scale and scope. The Review of Economics and Statistics, 71(2), 284-290.

Cole, J.R. (1993). Balancing acts: Dilemmas of choice facing research universities. Daedalus, 122(4), 1-36.

Coleman, J., et al. (1966). Equality of Educational Opportunity. Washington, DC: US GPO.

de Groot, H., McMahon, W.W., \& Volkwein, J. F. (1991). The cost structure of American research universities. The Review of Economics and Statistics, 73(3), 424-431.

Deaton, R. (2004, May). The funding formula as a higher education policy tool in Tennessee. Paper presented at the Association for Institutional Research conference, Boston, MA. 
Deller, S.C. \& Rudnicki, E. (1993). Production efficiency in elementary education: The case of Maine public schools. Economics of Education Review, 12(1), 45-57.

DesJardins, S. (2003). The monetary returns to instruction. In Lewis, D.R. \& Hearn, J. (Eds.), The Public Research University: Serving the public good in new times, (p. 175-205). Lanham, MD: University Press of America.

Dolan, R.C. \& Schmidt, R.M. (1994). Modeling institutional production of higher education. Economics of Education Review, 13(3), 197-213.

Duncan, T.E., Duncan, S.C., \& Strycker, L.A. (2006). An introduction to latent variable growth curve modeling: Concepts, issues and applications ( $\left.2^{\text {nd }} \mathrm{ed}.\right)$. Mahwah, $\mathrm{NJ}$ : Lawrence Erlbaum Associates.

Dundar, H. \& Lewis, D.R. (1998). Determinants of research productivity in higher education. Research in Higher Education, 39(6), 607-631.

Ehrenberg, R.G. (2000). Tuition rising: Why college costs so much. Cambridge, MA: Harvard University Press.

Ewell, P. (2002). An emerging scholarship: A brief history of assessment. In Banta, T. (ed.) Building a Scholarship of Assessment, (pp. 3-25). San Francisco: JosseyBass.

Fairweather, J.S. (2002). The mythologies of faculty productivity: Implications for institutional policy and decision making. The Journal of Higher Education, 73(1), 26-48.

Fan, X. (2003). Power of latent growth modeling for detecting group difference in linear growth trajectory parameters. Structural Equation Modeling, 10, p. 380-400.

Fan, X. \& Konold, T.K. (in press). Latent growth model analysis in structural equation modeling: Concepts and implementations. In Leo, T. \& Khine, M.S. (Eds.), Structural Equation Modeling in Education Research: Concepts and Applications. Rotterdam, Netherlands: Sense Publisher.

Fan, X., Thompson, B., \& Wang, L. (1999). Effects of sample size, estimation methods, and model specification on structural equation modeling fit indexes. Structural Equation Modeling, 6(1), p. 56-83.

Feldman, K.A. (1987). Research productivity and scholarly accomplishment of college teachers as related to their instructional effectiveness: A review and exploration. Research in Higher Education, 26(3), 227-298. 
Frank, R.H. \& Cook, P.J. (1995). The winner-take-all society: How more and more Americans compete for fewer and bigger prizes, encouraging economic waste, income inequality, and an impoverished cultural life. New York: Free Press.

Gander, J.P. (1999). Faculty gender effects on academic research and teaching. Research in Higher Education, 40(2), 171-184.

Gansemer-Topf, A.M., \& Schuh, J.H. (2006). Institutional selectivity and educational expenditures: Examining organizational factors that contribute to retention and graduation. Research in Higher Education, 47(6), 613-642.

Garfunkel, J.M., Ulshen, M.H., Hamrick, H.J., \& Lawson, E.E. (1994). Effect of institutional prestige on reviewers' recommendations and editorial decisions. Journal of the American Medical Association, 272, 137-138.

Garvin, D.A. (1980). The economics of university behavior. New York: Academic Press.

Gates, S. \& Stone, A. (1997). Understanding productivity in higher education (Report No. DRU-1596-IET). Washington, DC: RAND Corporation.

Gilmore, J.L. (1990). Price and quality in higher education. (ERIC \# ED326146). Washington, DC: Government Printing Office.

Gilmore, J.L. \& To, D. (1992). Evaluating academic productivity and quality. In Terenzini, P.T. \& Chaffee, E.E. (Series Eds.) \& Hollins, C.S. (Vol. Eds.), Containing costs and improving productivity in higher education: Vol 75. New Directions for Institutional Research (p.35-47). San Francisco: Jossey-Bass.

Grunig, S.D. (1997). Research, reputation, and resources: The effect of research activity on perceptions of undergraduate education and institutional resource acquisition. The Journal of Higher Education, 68(1), 17-52.

Guellec, D. \& Van Pottelsberghe de la Potterie, B. (2004). From R\&D to productivity growth: Do the institutional settings and the funds of R\&D matter? Oxford Bulletin of Economics and Statistics, 66(3), 0305-9049.

Hagstrom, W.O. (1971). Inputs, outputs, and prestige of university science departments. Sociology of Education, 44(4), 375-397.

Hanushek, E. (1986). The economics of schooling: Production and efficiency in public schools. Journal of Economic Literature, 24(3), 1141-1177.

Hanushek, E. (1997). Assessing the effects of school resources on student performance: An update. Educational Evaluation and Policy Analysis, 19(2), 141-164. 
Harvey, L. (1998). An assessment of past and current approaches to quality in higher education. Australian Journal of Education, 42(3), p. 237-252.

Heck, R.H. \& Takahashi, R. (2006). Examining the impact of Proposition 48 on graduation rates in Division $1 \mathrm{~A}$ football and program recruiting behavior: Testing a policy change model. Educational Policy, 20, p. 587-614.

Hoenack, S.A. (1990). An economist's perspective on costs within higher education institutions. In Hoenack, S.A. \& Collins, E.L. (eds.). The economics of American universities: management, operations, and fiscal environment (p. 129-154). New York: State University of New York Press.

Hoos, I.R. (1975). The costs of efficiency: Implications of educational technology. The Journal of Higher Education, 46(2), 141-159.

Hopkins, D.S.P. (1990). The higher education production function: Theoretical foundations and empirical findings. In Hoenack, S.A. \& Collins, E.L. (Eds). The Economics of American Universities: Management, Operations, and Fiscal Environment, 11-32. Albany, NY: State University of New York Press.

Hopkins, D. \& Massy, W.F. (1981). Planning models for colleges and universities. Stanford, CA: Stanford University Press.

Hu, L.T. \& Bentler, P.M. (1998). Fit indices in covariance structure modeling: Sensitivity to underparameterized model misspecification. Psychological Methods, 3, 424453.

Hu, L.T. \& Bentler, P.M. (1999). Cutoff criteria for fit indexes in covariance structure analysis: Conventional criteria versus new alternatives. Structural Equation Modeling, 6, 1-55.

Hubbell, L. L. (2007). Quality, efficiency, and accountability: Definitions and applications. In Lapovsky, L. \& Klinger, D. (Series Eds.) \& Kramer, M. \& McLaughlin, J.B. (Vol. Eds.), Strategic Financial Challenges for Higher Education: How to Achieve Quality, Accountability, and Innovation: Vol 140. New Directions for Higher Education (p. 5-13). San Francisco: Jossey-Bass.

James, E. (1990). Decision processes and priorities in higher education. In Hoenack, S.A. \& Collins, E.L. (Eds.), The Economics of American Universities: Management, Operations, and Fiscal Environment, 77-106. Albany, NY: State University of New York Press. 
Johnes, J. (2006). Data envelopment analysis and its application to the measurement efficiency of higher education. Economics of Education Review, 25, 273-288.

Kelly, P.J. (2009, July). The dreaded "P" word: An examination of productivity in public postsecondary education. Washington, DC: Delta Cost Project.

Konold, T.R. \& Pianta, R.C. (2005). Empirically-derived, person-oriented patterns of school readiness in typically developing children: Description and prediction to first grade achievement. Applied Developmental Science, 9, 174-187.

Krueger, A.B. \& Lindahl, M. (2001). Education for growth: Why and for whom? Journal of Economic Literature, 39(4), 1101-1136.

Lam, W. (2008). The impact of environmental and institutional factors on state higher educational performance: A longitudinal study across 50 states (1997- 2006). Dissertation Abstracts International, 70(02), (UMI No. 3347651).

Lederman, D. (2009, June 23). Hazard or opportunity? Article from Inside Higher Ed. Retrieved July 14, 2009 from http://www.insidehighered.com/news/2009/06/23/crisis.

Liefner, I. (2003). Funding, resource allocation, and performance in higher education systems. Higher Education, 46(4), 469-489.

Lindsay, A.W. (1982). Institutional performance in higher education: The efficiency dimension. Review of Educational Research, 52(2), 175-199.

Little, J.R. \& Schenker, N. (1995). Missing data. In Arminger, G., Clogg, C.C., \& Sobel, M.E. (Eds.) Handbook of Statistical Modeling for the Social and Behavioral Sciences (p. 39-75). New York: Plenum.

Loehlin, J.C. (2004). Latent variable models: An introduction to factor, path, and structural equation analysis ( $4^{\text {th }}$ Ed.). Mahwah, NJ: Lawrence Erlbaum Associates.

Long, J.S., Allison, P.D., \& McGinnis, R. (1993). Rank advancement in academic careers: Sex differences and the effects of productivity. American Sociological Review, 58(5), 703-722.

Longanecker, D. (2006). A tale of two pities: The story of public higher education finance in America. Change, 38(1), p. 14-25. 
MacCallum, R.C., Browne, M.W. \& Sugawara, H.M. (1996). Power analysis and determination of sample size for covariance structure modeling. Psychological Methods, 1(2), 130-149.

Marginson, S. (2006). Dynamics of national and global competition in higher education. Higher Education, 52(1), 1-39.

Marsh, H.W. \& Hau, K.T. (2007). Applications of latent-variable models in educational psychology: The need for methodological-substantive synergies. Contemporary Educational Psychology, 32, 151-170.

Marsh, H.W., Hau, K.T., \& Wen, Z. (2004). In search of golden rules: Comment on hypothesis-testing approaches to setting cutoff values for fit indexes and dangers in overgeneralizing Hu and Benter's (1999) findings. Structural Equation Modeling, 11(3), 320-341.

Massy, W.F. (1996). Productivity issues in higher education. In Massy, W.F. (ed.) Resource allocation in higher education (p. 48-86). Ann Arbor, MI: The University of Michigan Press.

Massy, W.F. (2009). It's time to improve academic, not just administrative, productivity. The Chronicle of Higher Education, 55(18), p. A26. (January 9, 2009).

McLendon, M.K., Hearn, J.C., \& Deaton, R. (2006). Called to account: Analyzing the origins and spread of state performance-accountability policies for higher education. Educational Evaluation and Policy Analysis, 28(1), p. 1-24.

Melguizo, T. \& Strober, M.H. (2007). Faculty salaries and the maximization of prestige. Research in Higher Education, 48(6), 633-668.

Morgan, D.R., Meier, K.J., Kearney, R.C., Hays, S.W. \& Birch, H.B. (1981). Reputation and productivity among US public administration and public affairs programs. Public Administration Review, 41(6), 666-673.

National Center for Education Statistics (2009). Digest of Education Statistics, 2008. NCES 2009020.

National Center for Public Policy in Higher Education (2000). Measuring Up 2000: The state-by-state report card for higher education, Retrieved February 24, 2009 from http://measuringup.highereducation.org/2000/. 
Nerlove, M. (1972). On tuition and the costs of higher education: Prolegomena to a conceptual framework. The Journal of Political Economy, 80(3), Part 2: Investment in Education: The Equity Efficiency Quandry. S178-S218.

Obama, B. (2009). Address to Joint Session of Congress. Speech delivered February 24, 2009, Washington, DC. Transcript retrieved August 12, 2009 from http://www.whitehouse.gov/the_press_office/remarks-of-president-barack-obamaaddress-to-joint-session-of-congress/

Perna, L.W. (2005). The benefits of higher education: Sex, racial/ethnic, and socioeconomic group differences. The Review of Higher Education, 29, 23-52.

Peterson, M.W. (2007). The study of colleges and universities as organizations. In Gumport, P. (ed.) Sociology of higher education: contributions and their contexts (p. 147-184). Baltimore, MD: Johns Hopkins University Press.

Porter, S.R. \& Toutkoushian, R.K. (2006). Institutional research productivity and the connection to average student quality and overall reputation. Economics of Education Review, 25, 605-617.

Porter, S.R. \& Umbach, P.D. (2001). Analyzing faculty workload data using multilevel modeling. Research in Higher Education, 42(2), 171-196.

Raines, J.P. \& Leathers, C.G. (2003). The economic institutions of higher education: Economic theories of university behavior. Northampton, MA: Edward Elgar.

Ramsden, P. (1994). Describing and explaining research productivity. Higher Education, 28, 207-226.

Rowan-Kenyon, H., Blanchard, R., Reed, B., \& Swan, A. (2009). Social and cultural capital factors of persistence for low-SES students. Manuscript in preparation for publication.

Ruggiero, J. (1996). Efficiency of educational production: An analysis of New York school districts. The Review of Economics and Statistics, 78(3), 499-509.

Ruppert, S. (1994). Charting higher education accountability: A sourcebook on statelevel performance indicators. Denver, CO: Education Commission of the States.

Ryan, J.F. (2004). The relationship between institutional expenditures and degree attainment at baccalaureate colleges. Research in Higher Education, 45(2), 97114. 
Salerno, C. (2003). What we know about efficiency of higher education institutions: The best evidence. External report for The Center for Higher Education Policy Studies, University of Twente. (ID 47097).

Schmitz, C.C. (1993). Assessing the validity of higher education indicators. The Journal of Higher Education, 64(5), 503-521.

Sax, L.J., Hagedorn, L.S., Arredondo, M., \& Dicrisi III, F.A. (2004). Faculty research productivity: Exploring the role of gender and family-related factors. Research in Higher Education, 43(4), 423-446.

Schapiro, M.O. (1993). The concept of productivity as applied to US higher education. In McPherson, M.S., Schapiro, M.O., \& Winston, G.C. (eds.) Paying the Piper: Productivity, incentives, and financing in US higher education, 37-68. Ann Arbor, MI: University of Michigan Press.

Sivo, S.A., Fan, X., Witta, E.L., \& Willse, J.T. (2006). The search for “optimal” cutoff properties: Fit index criteria in structural equation modeling. The Journal of Experimental Education, 74(3), 267-288.

Sizer, J., Spee, A., \& Bormans, R. (1992). The role of performance indicators in higher education. Higher Education, 24(2), p. 133-155.

Smith, P. (1990). The use of performance indicators in the public sector, Journal of Royal Statistical Society. Series A (Statistics in Society), 153(1), 53-72.

Solomon, L.C. (1984). A theory of innovation in graduate education. In Pelczar, M.J. \& Solomon, L.C. (Series Eds.) \& Kramer, M. (Vol. Ed.), Keeping Graduate Programs Responsive to National Needs: Vol 46. New Directions for Higher Education (p. 21-30). San Francisco: Jossey-Bass.

Tien, F.F. \& Blackburn, R.T. (1996). Faculty rank system, research motivation, and faculty research productivity: Measure refinement and theory testing. The Journal of Higher Education, 67(1), 2-22.

Tinto, V. (1993). Leaving college: Rethinking the cause and cures of student attrition (2nd Ed.). Chicago, IL: University of Chicago Press.

Tinto, V. (1987). Leaving college: Rethinking the causes and cures of student attrition. Chicago, IL: University of Chicago Press.

Toutkoushian, R.K., Porter, S.R., Danielson, C., \& Hollis, P.R. (2003). Using publications counts to measure an institution's research productivity. Research in Higher Education, 44(2), 121-148. 
Volkweirn, J.F. \& Carbone, D.A. (1994). The impact of departmental research and teaching climates on undergraduate growth and satisfaction. Journal of Higher Education, 65(2), 147-167.

Volkwein, J.F. \& Sweitzer, K.V. (2006). Institutional prestige and reputation among research universities and liberal arts colleges. Research in Higher Education, 47(2), 129-148.

Walpole, M. (2008). Emerging from the pipeline: African American students, socioeconomic status, and college experiences and outcomes. Research in Higher Education, 49, 237-255.

Winston, G.C. (1999). Subsidies, hierarchies, and peers: The awkward economics of higher education. Journal of Economic Perspectives, 13(1), 13-36.

Worthington, A.C. \& Lee, B.L. (2006). Efficiency, technology, and productivity change in Australian universities, 1998-2003. Economics of Education Review, 27, 285298.

Zemsky, R., Shaman, S., and Iannozzi, M. (1997). In search of strategic perspective: a tool for mapping the market in postsecondary education. Change, November/December, 23-38. 


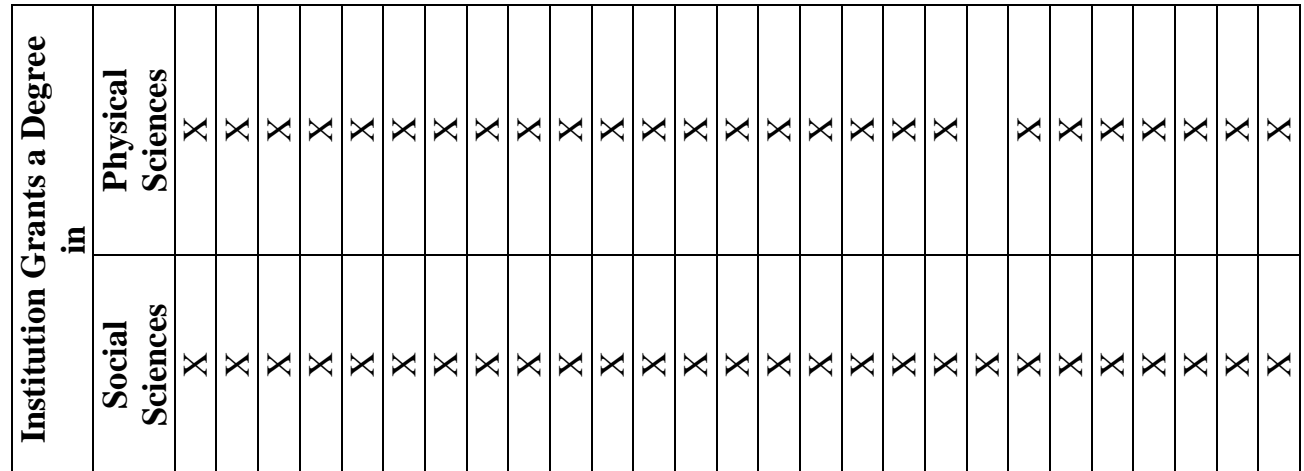

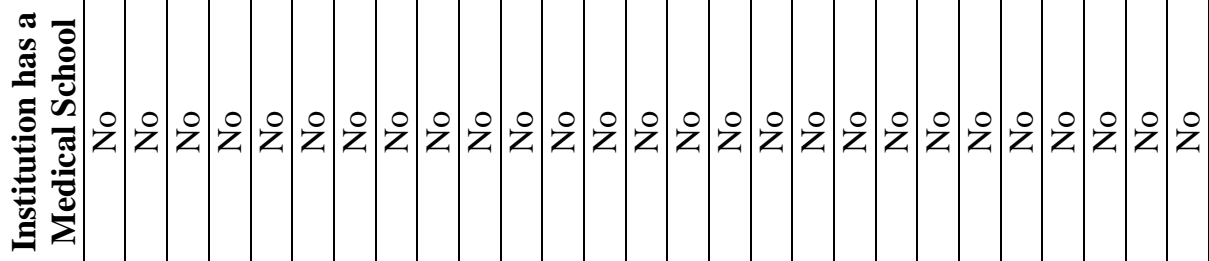
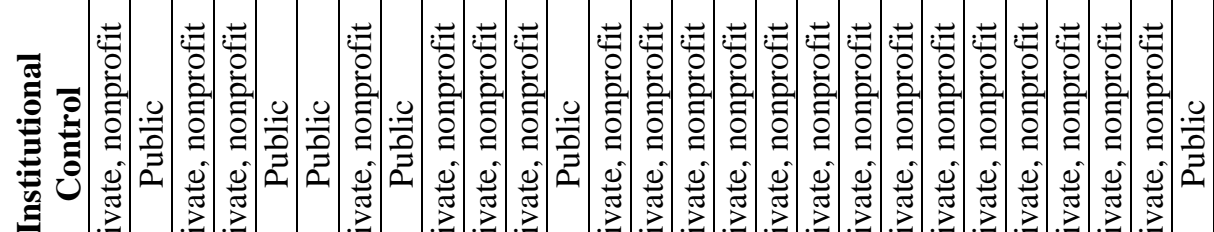

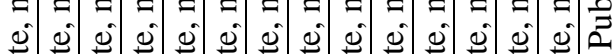

怘 $\vec{m}$

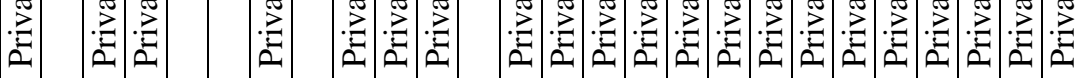

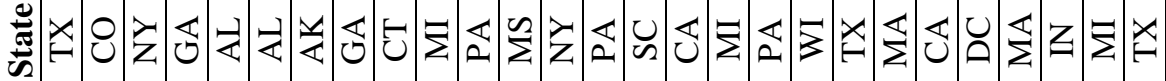

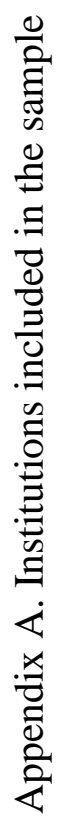




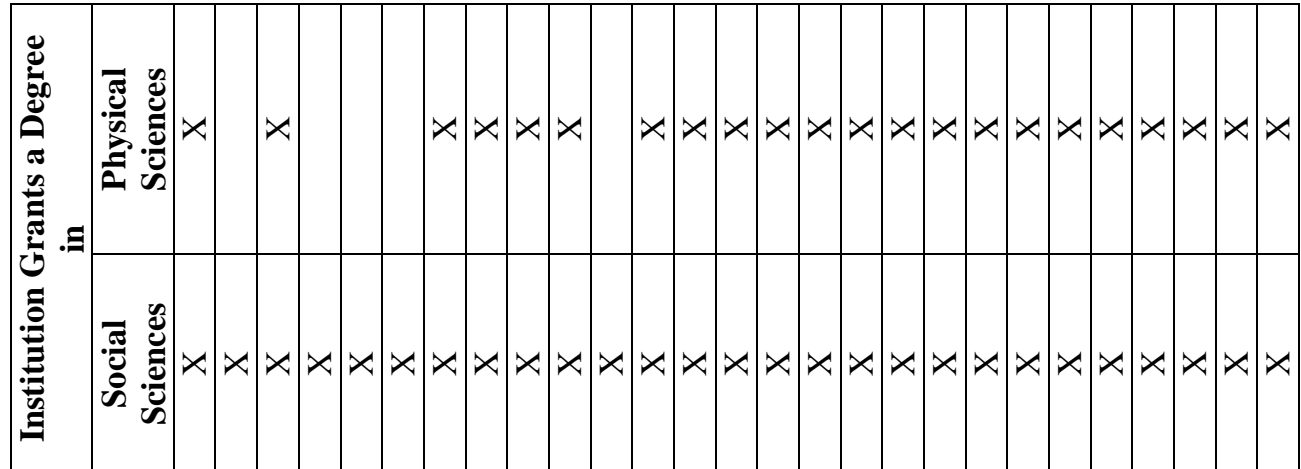

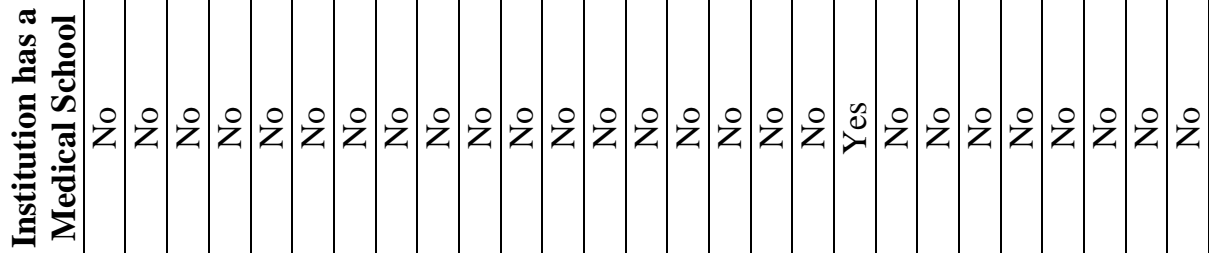

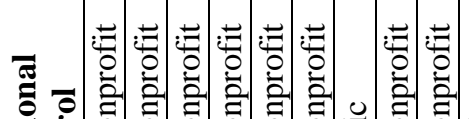

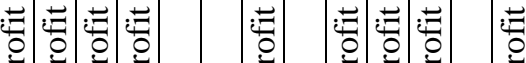

苛

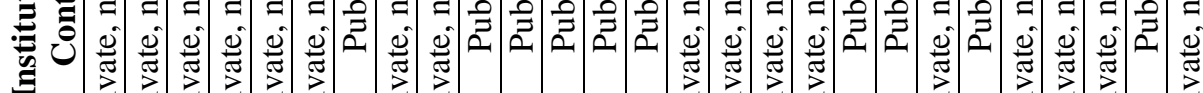

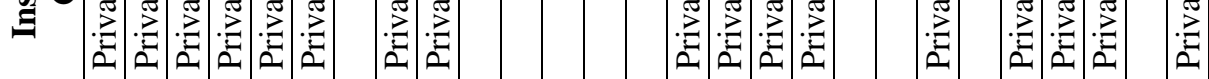

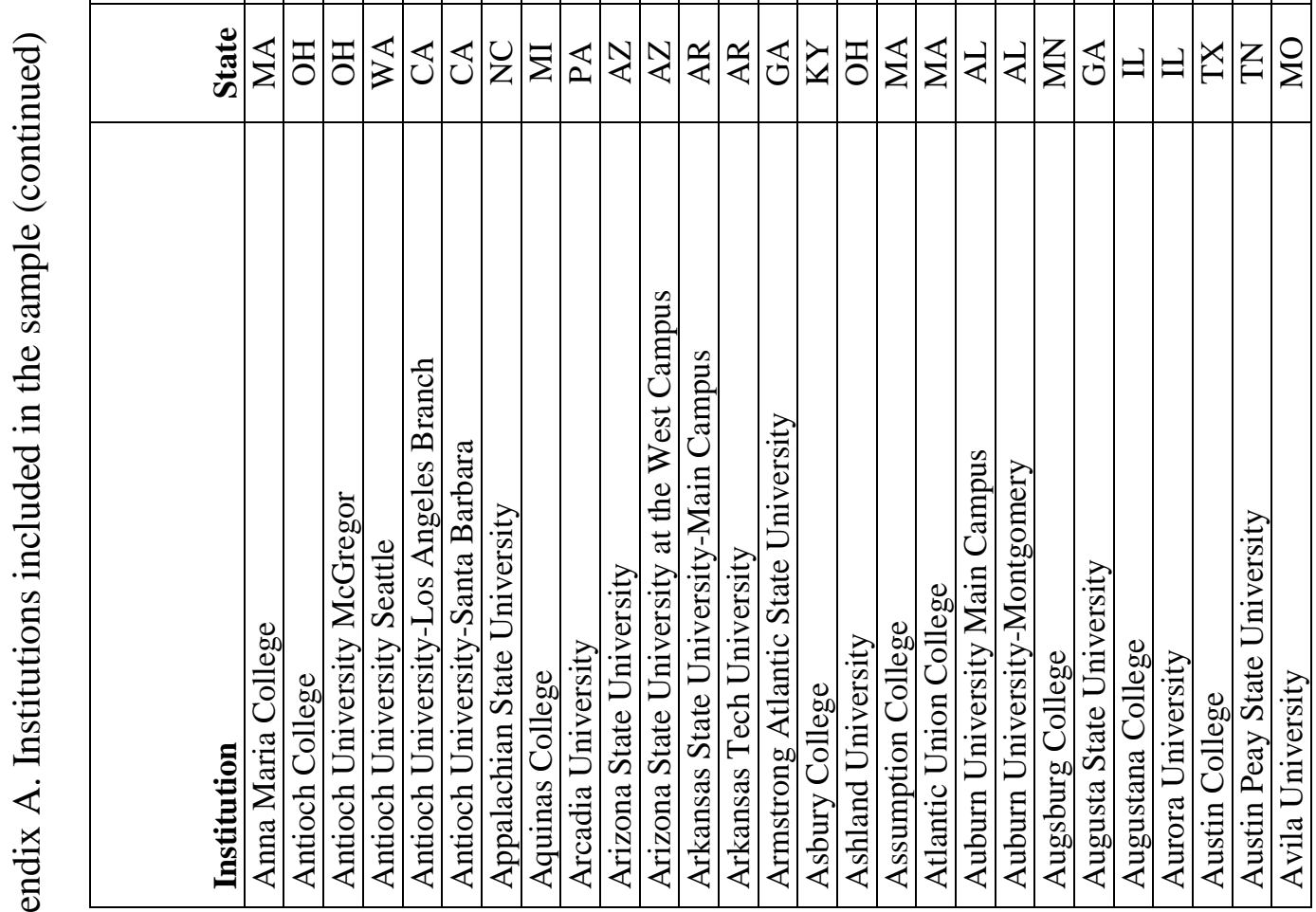

$\frac{2}{2}$ 


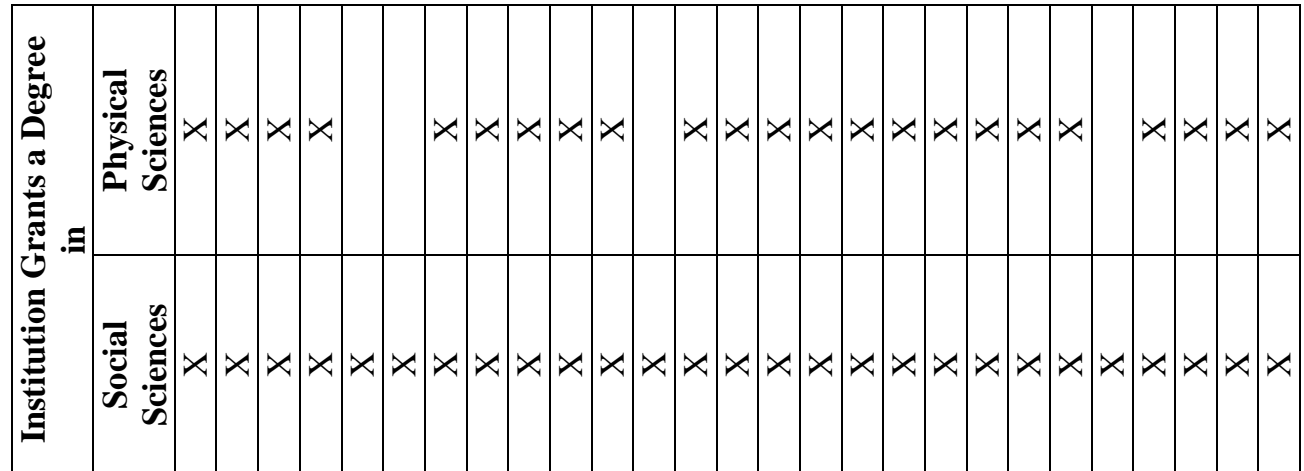

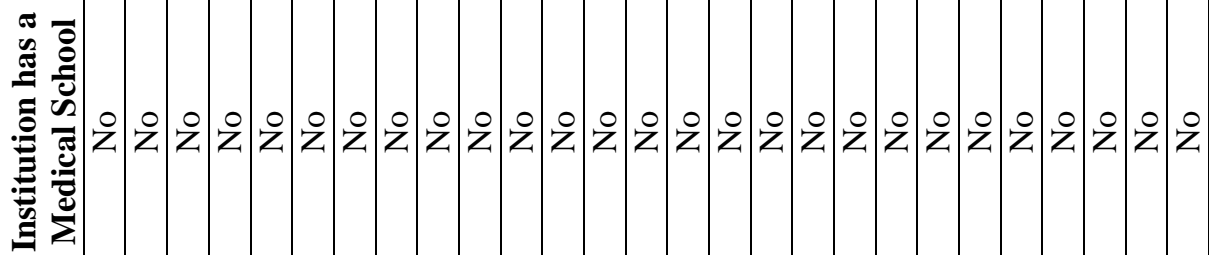

苍

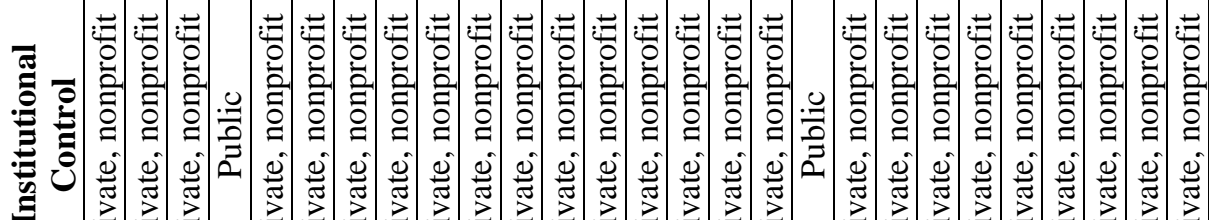

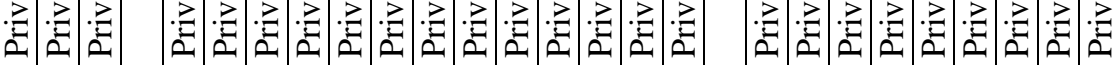

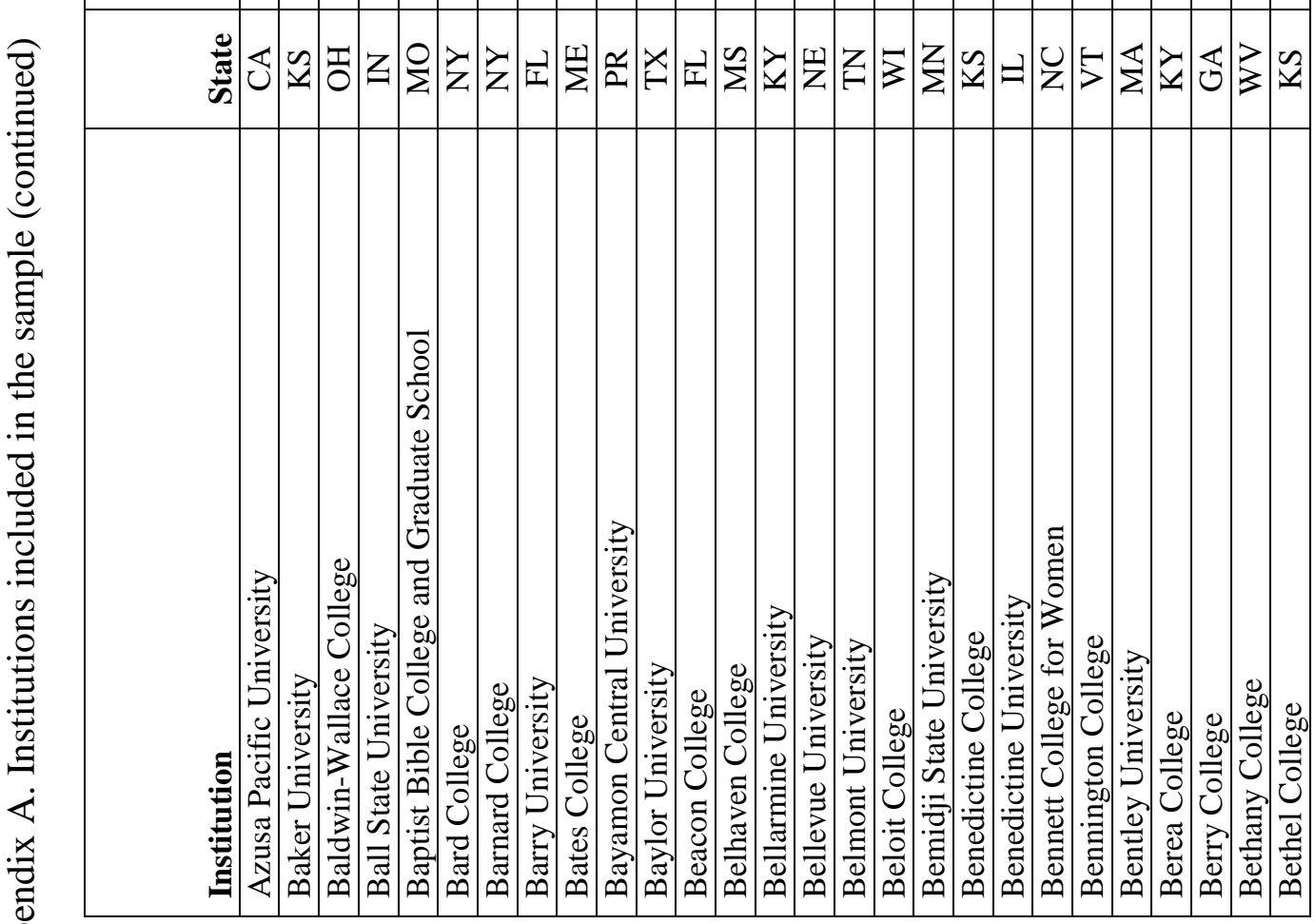

$\frac{\AA}{2}$ 


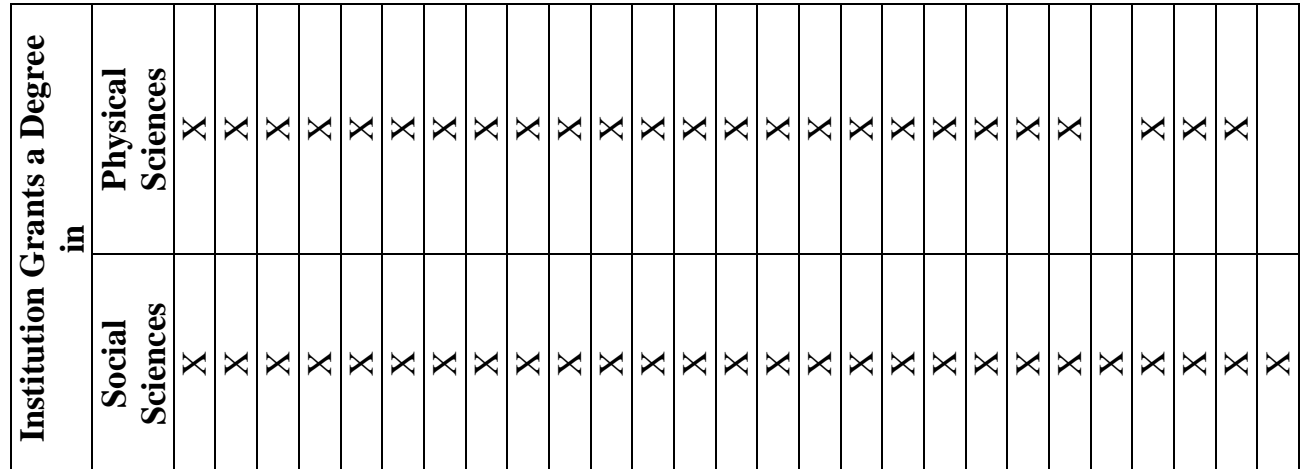

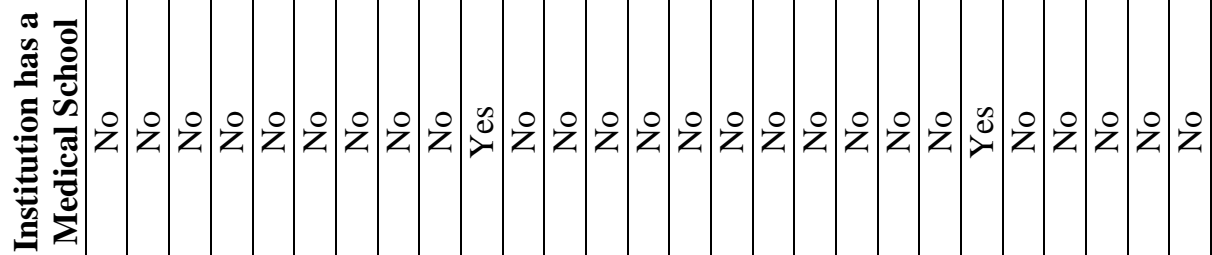

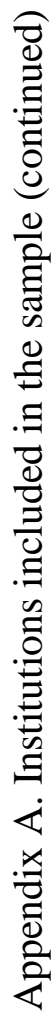

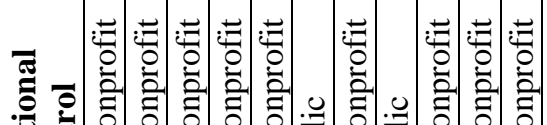

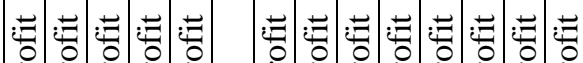

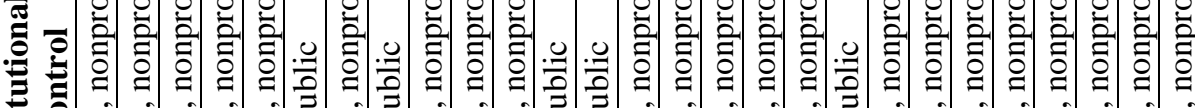

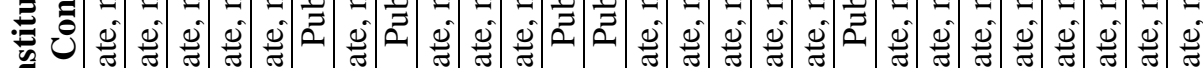

事

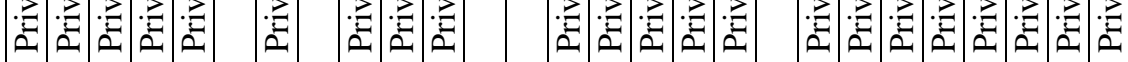

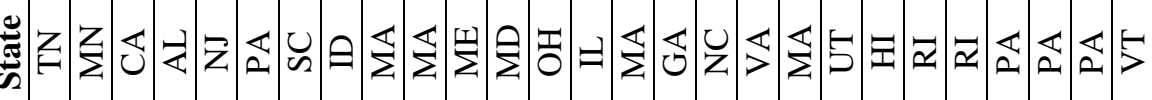

$\frac{\substack{0 \\ 0}}{0}$

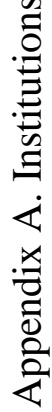

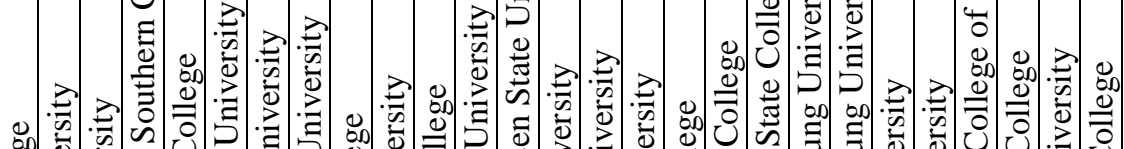

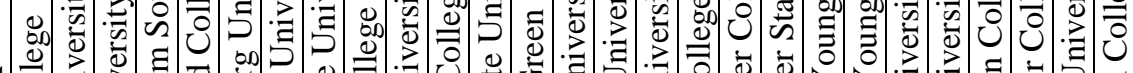
‡

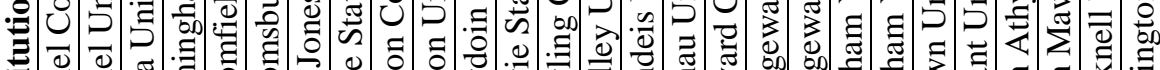

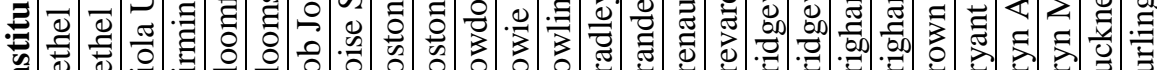

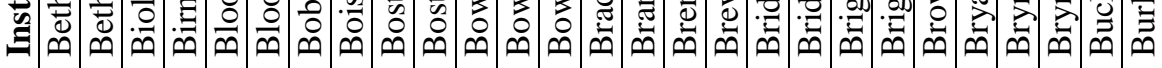

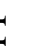




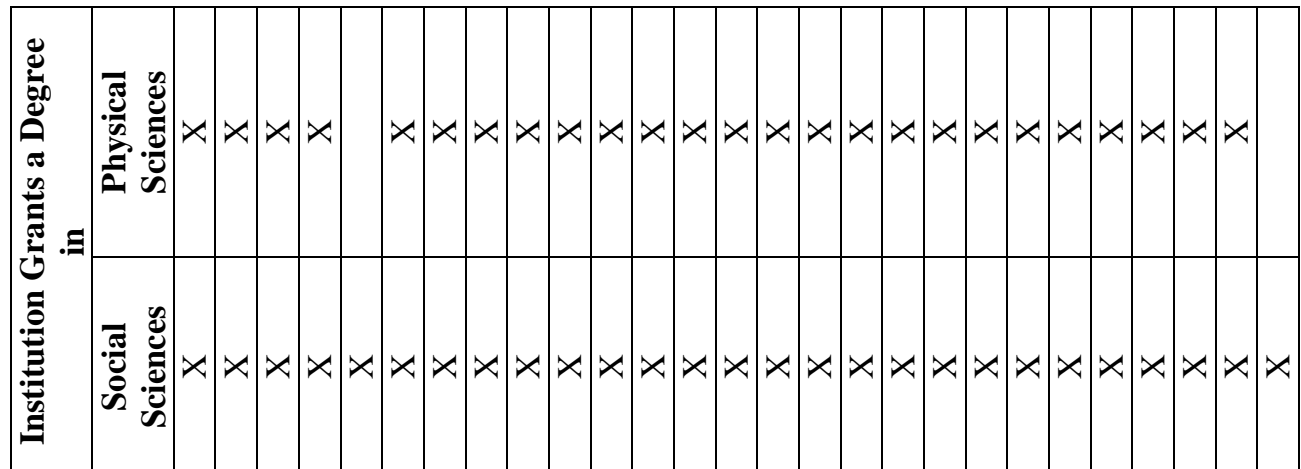

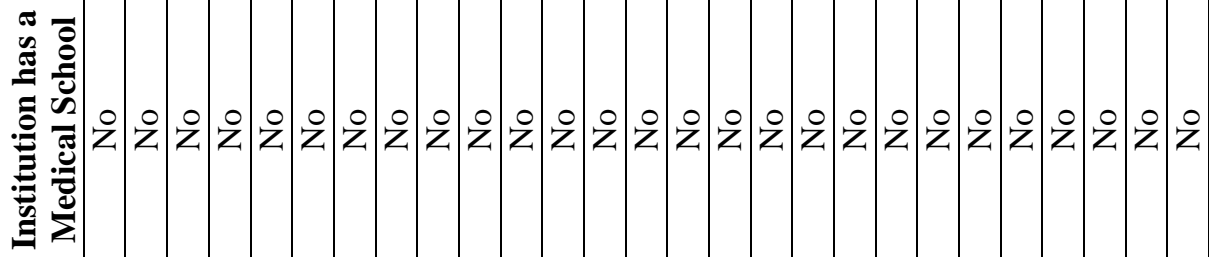

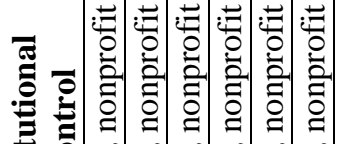

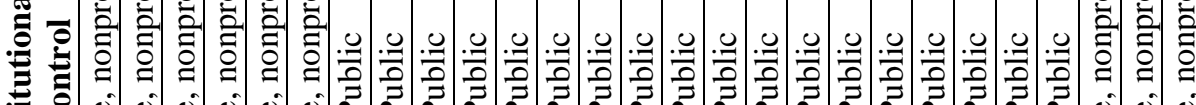

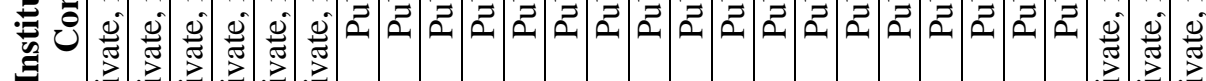

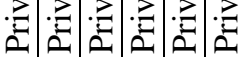

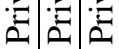

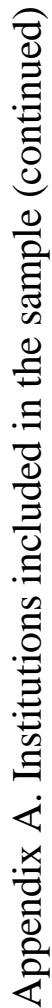

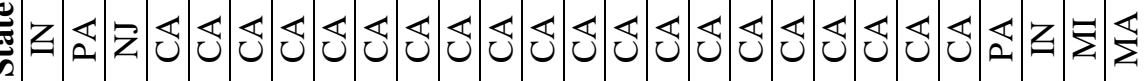

(

๐े

象

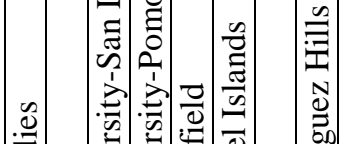

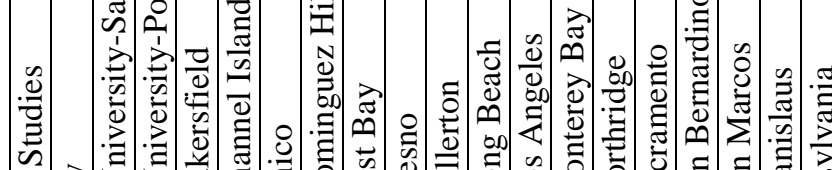

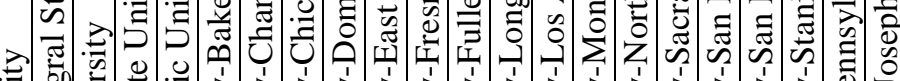

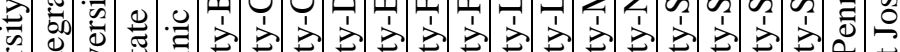

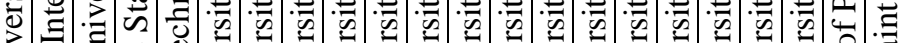

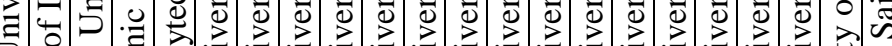
>. . (1) :

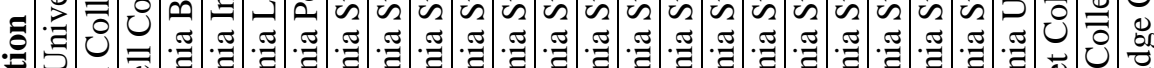
:

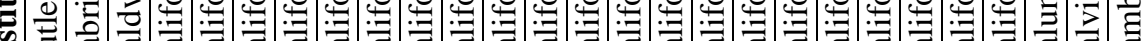

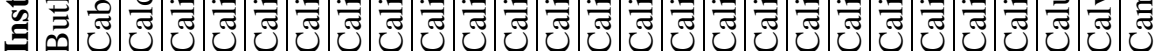




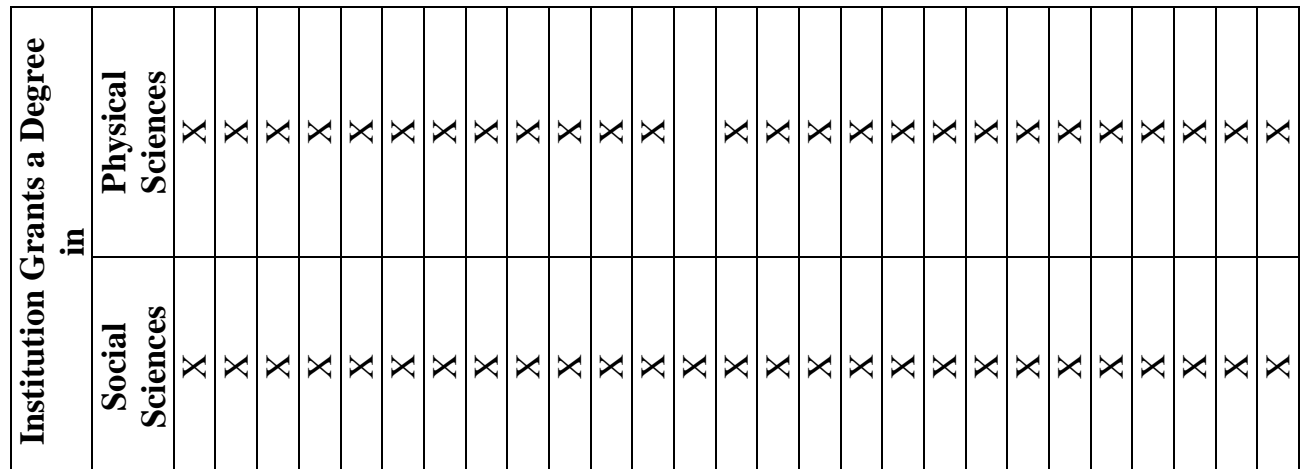

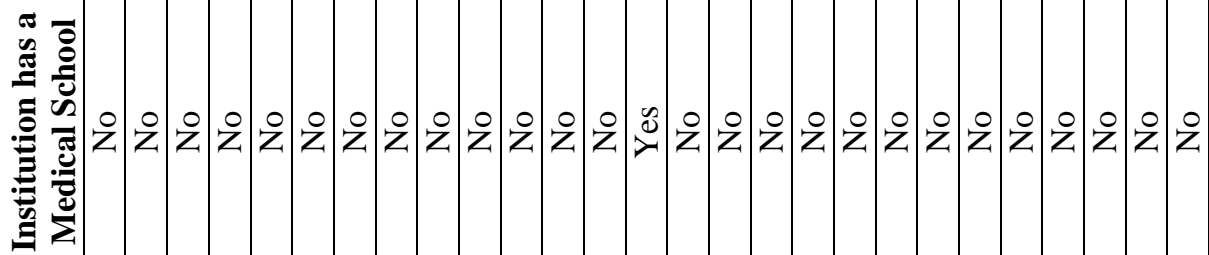

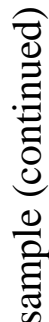

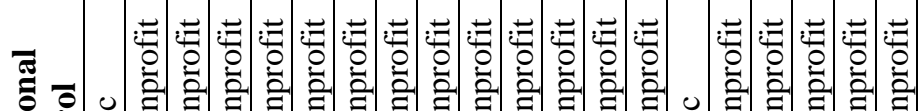

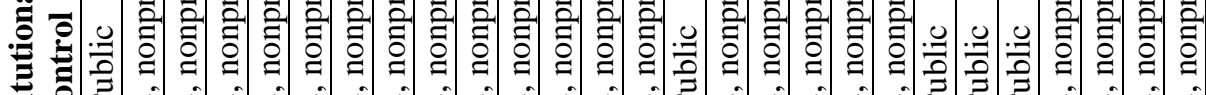

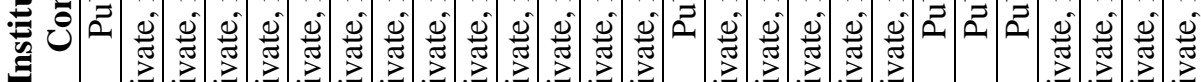

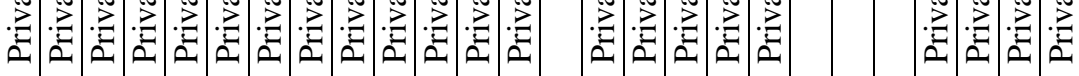

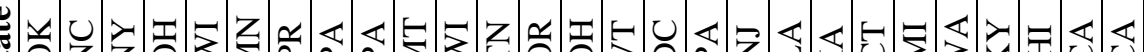

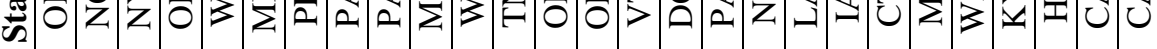

$\frac{0}{0}$

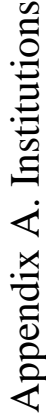

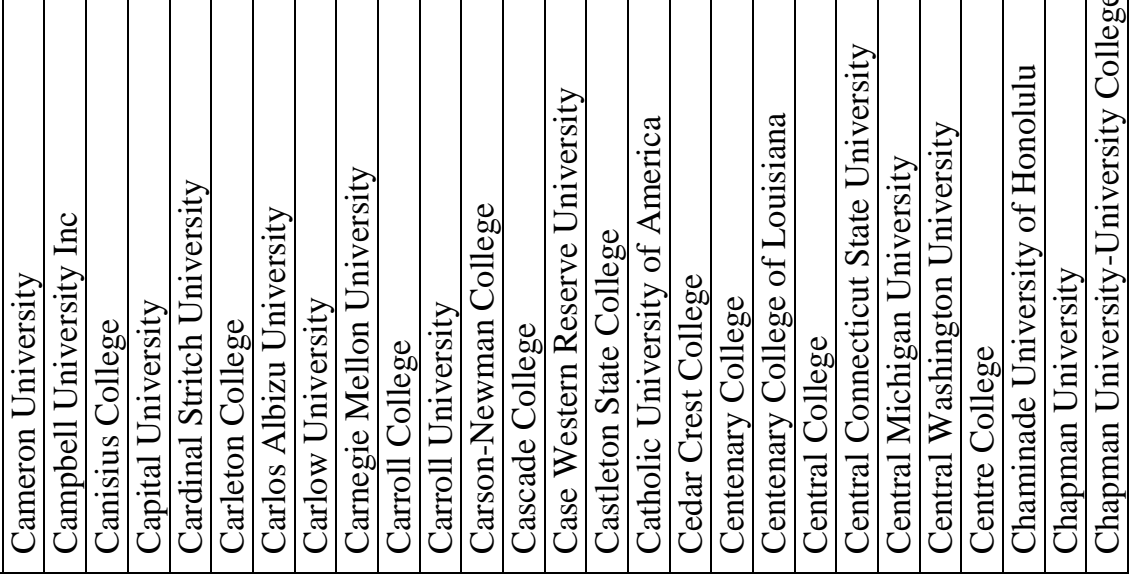

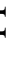




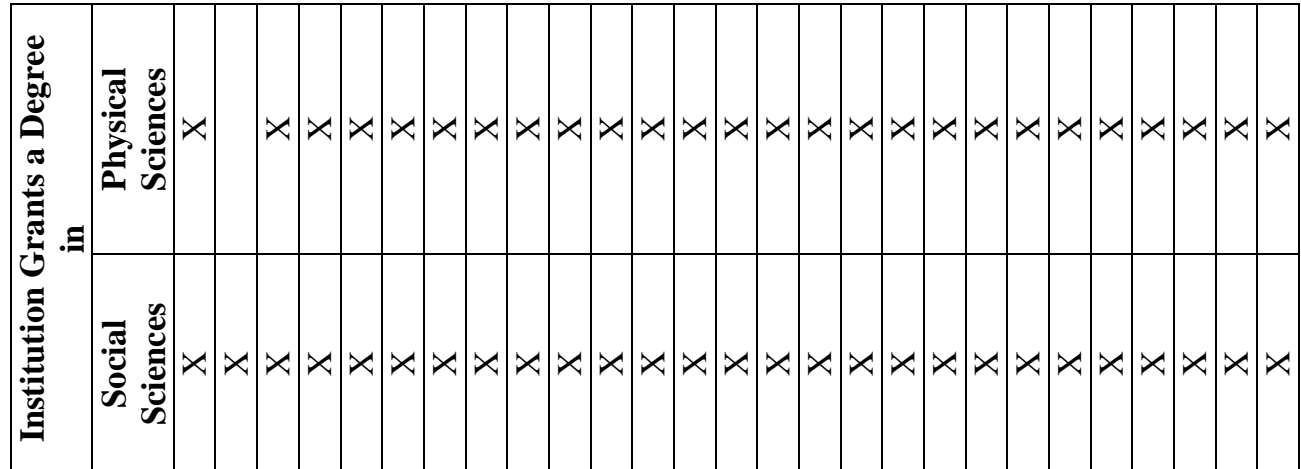

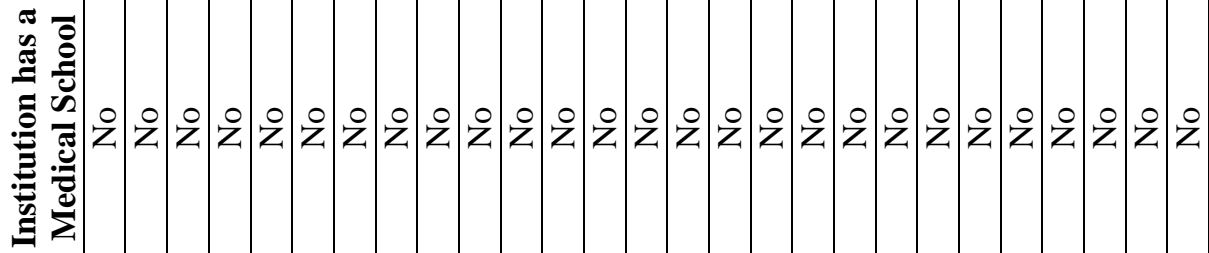

胥

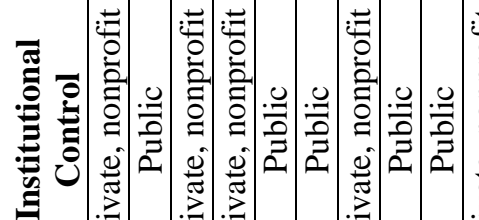

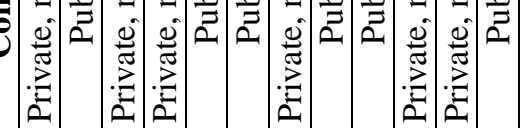

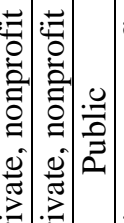

:

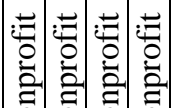

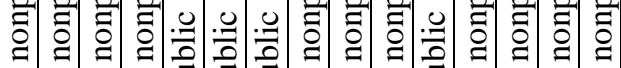

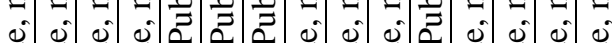

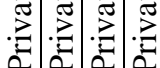
$: \vec{z}: \vec{z}$ $\cdot \vec{z} \cdot \overrightarrow{=} \cdot \vec{z} \cdot \vec{z}$

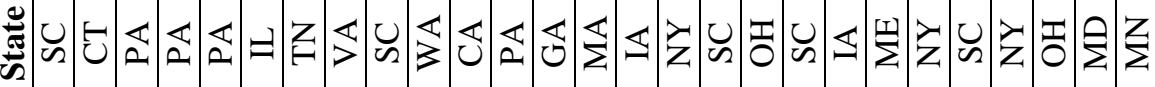




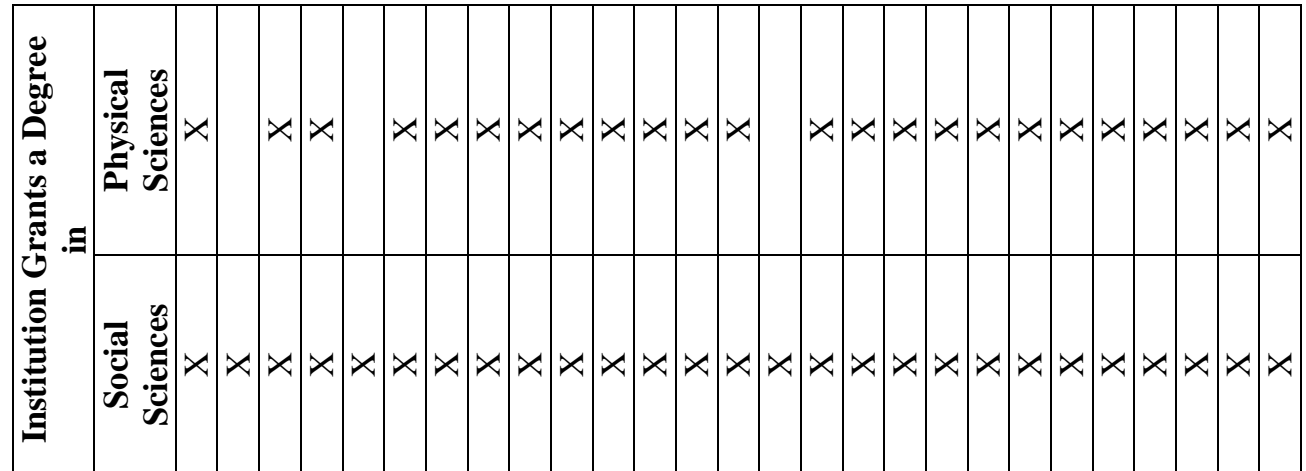

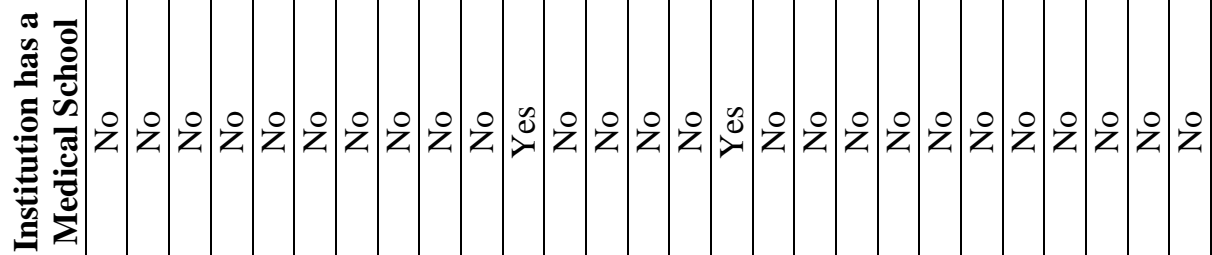

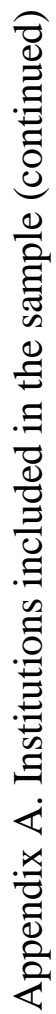

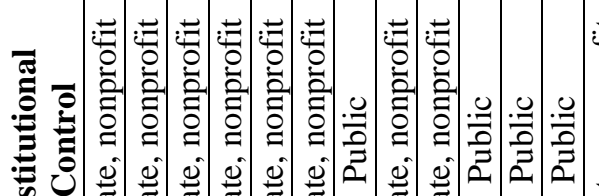

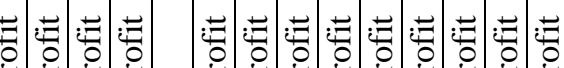

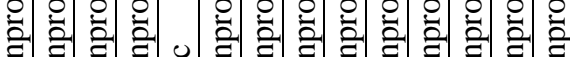

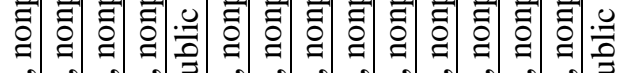

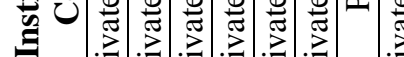

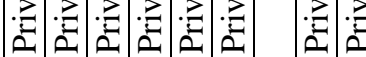

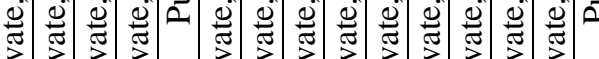

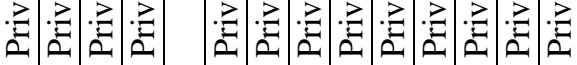

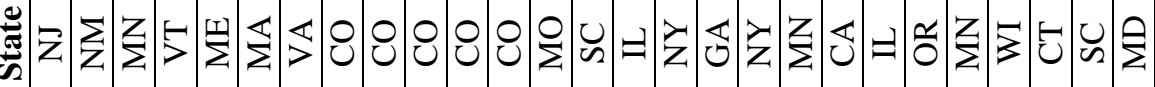

- 글 $\frac{3}{5}$

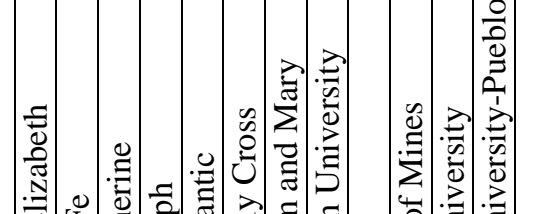

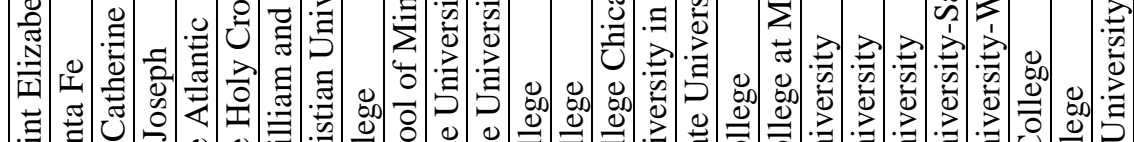
:

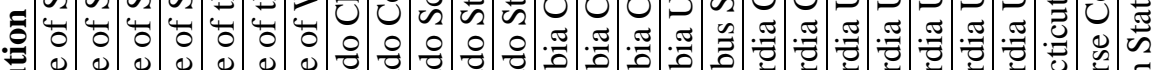

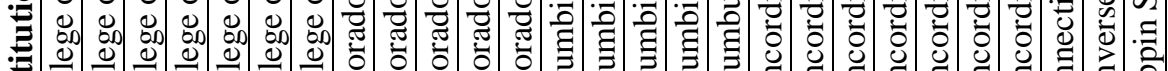
至 


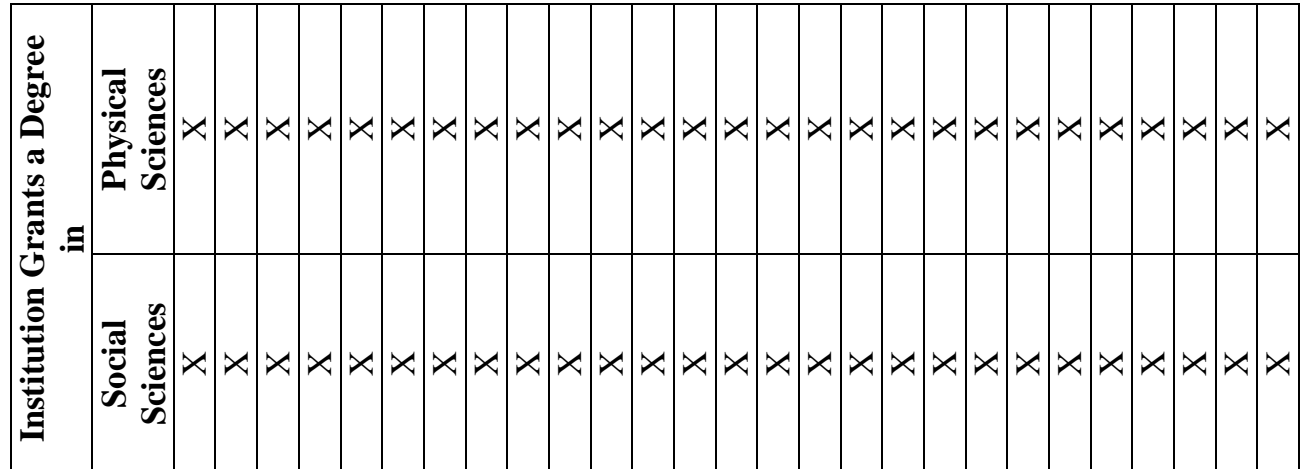

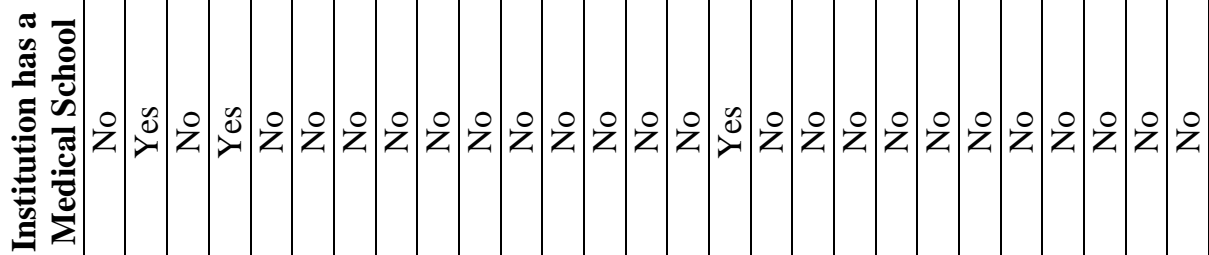

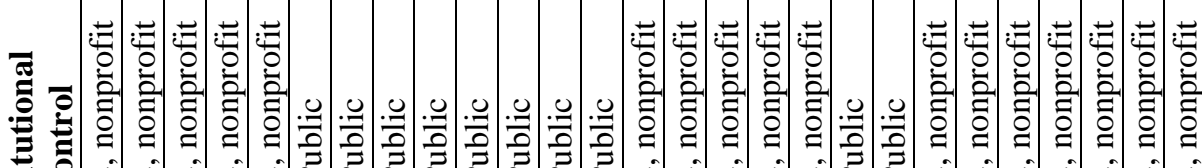

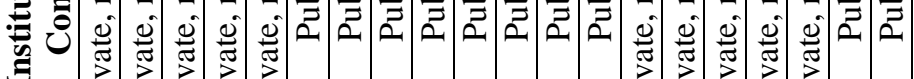

$\Xi$

$: \geq . \geq 2 . \geq$

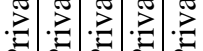

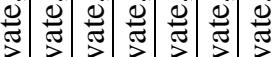

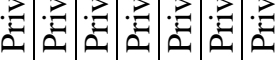

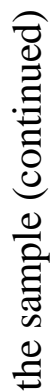

(2)

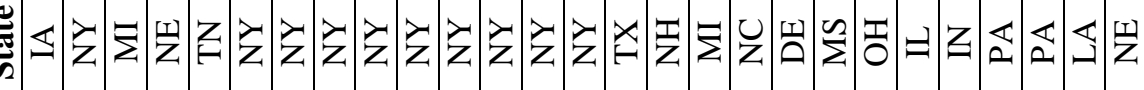

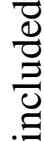

0

:

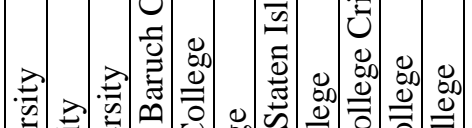

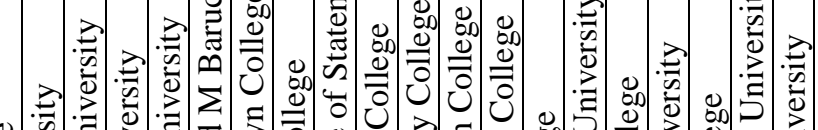

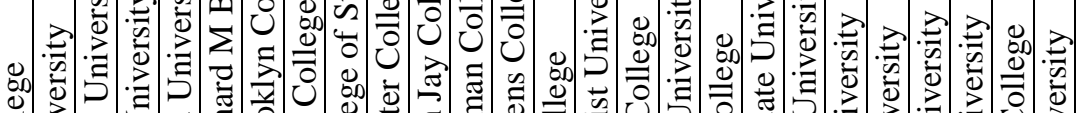

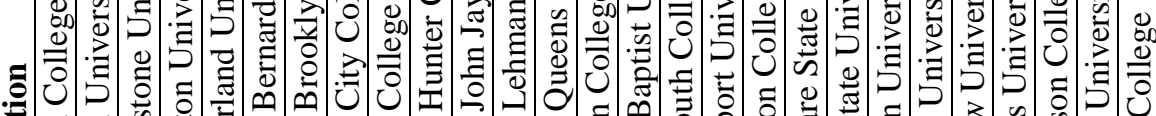

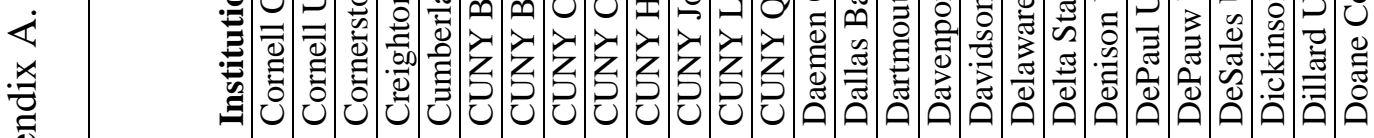

完 


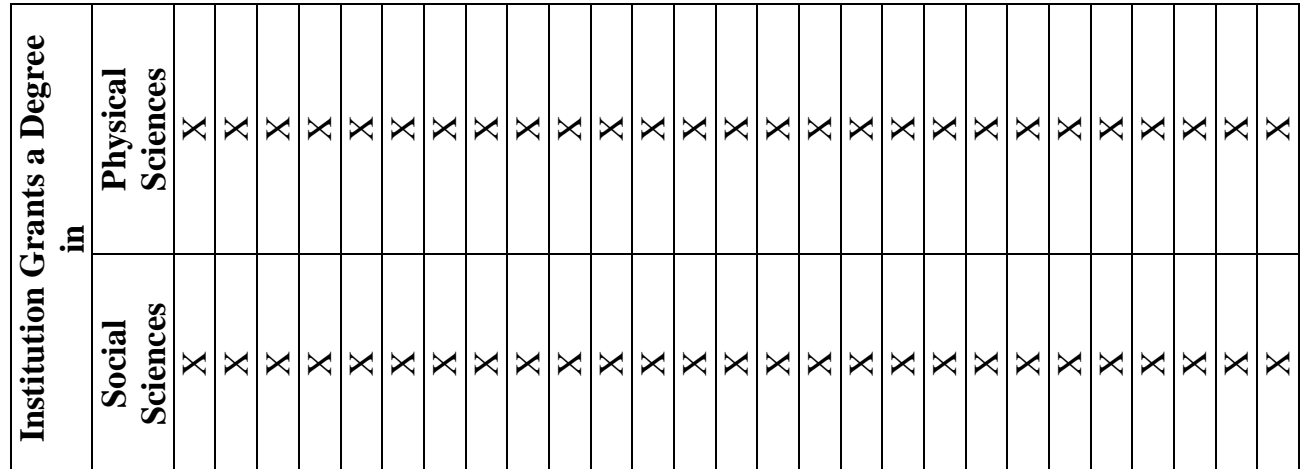

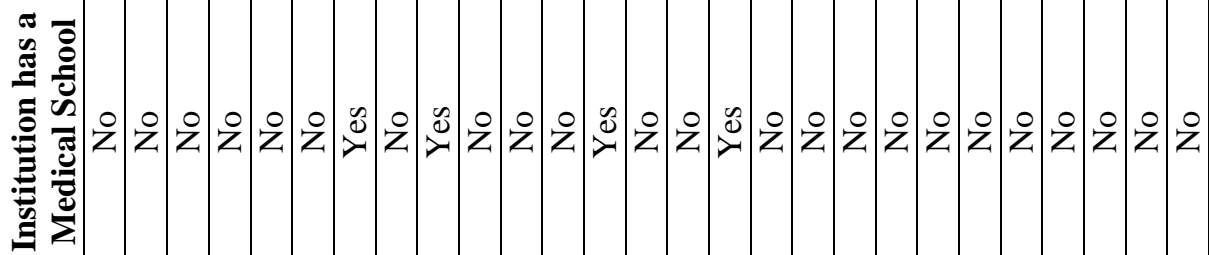

元

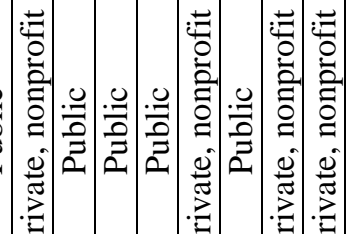

氖

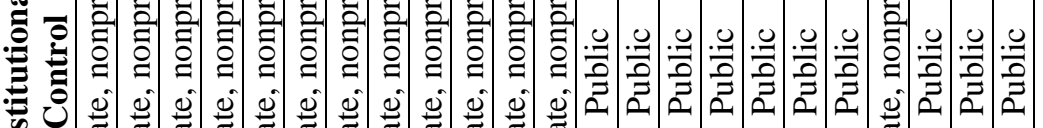

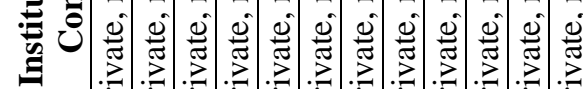

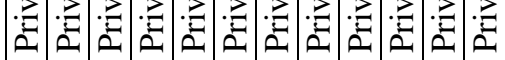

: $\vec{\Xi} \cdot \vec{\Xi}$

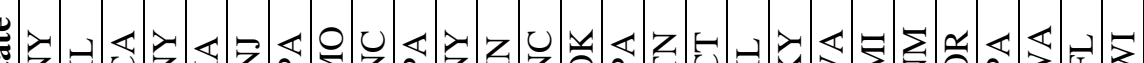

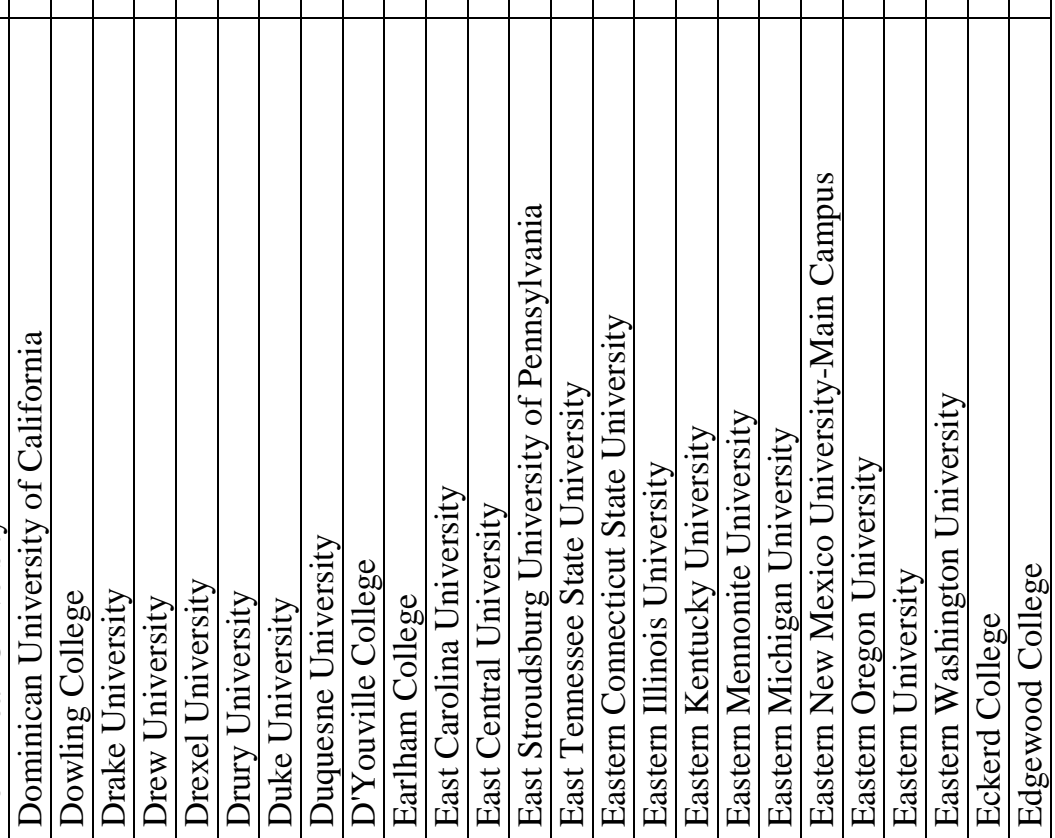

远 


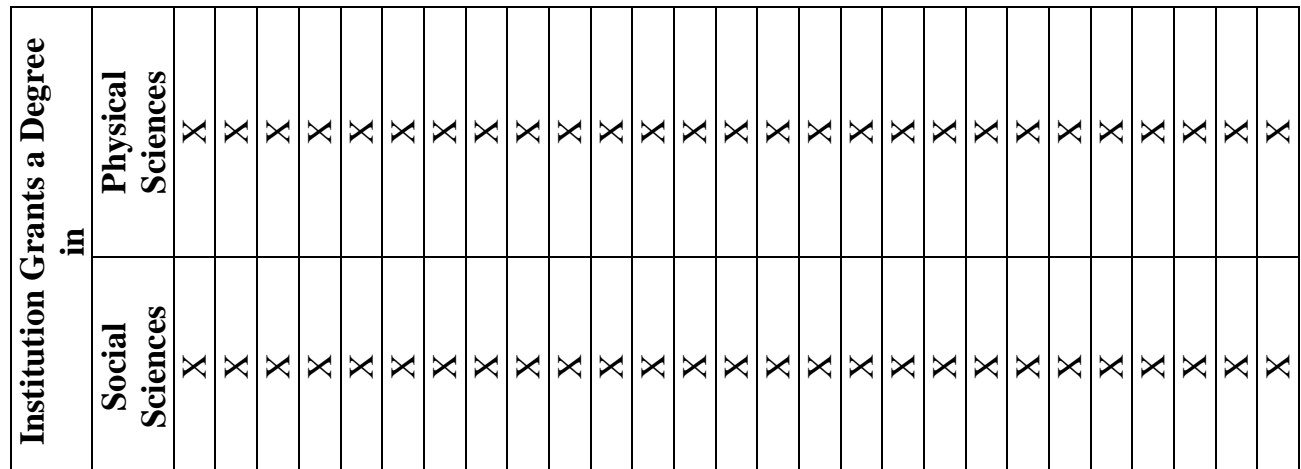

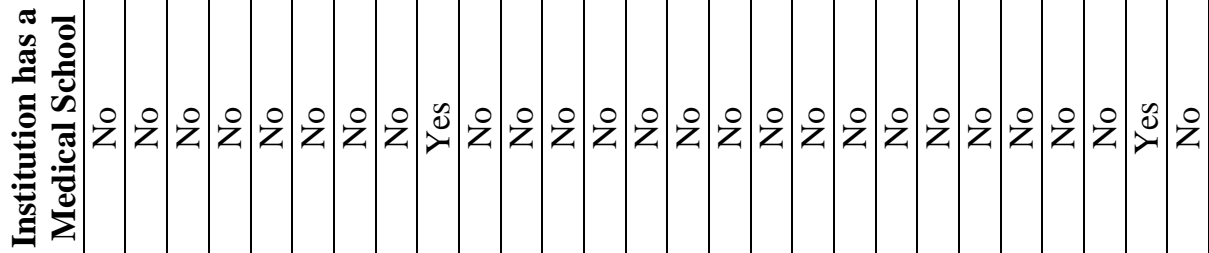

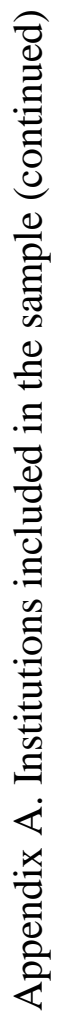

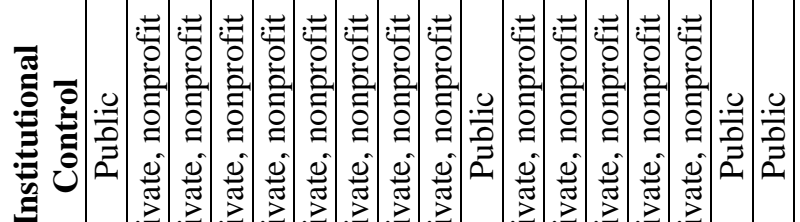

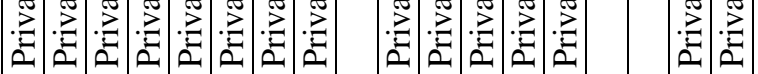

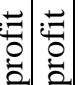

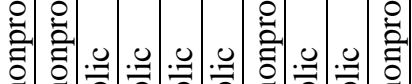

.

$\stackrel{\pi}{2}$

: $\vec{a}$

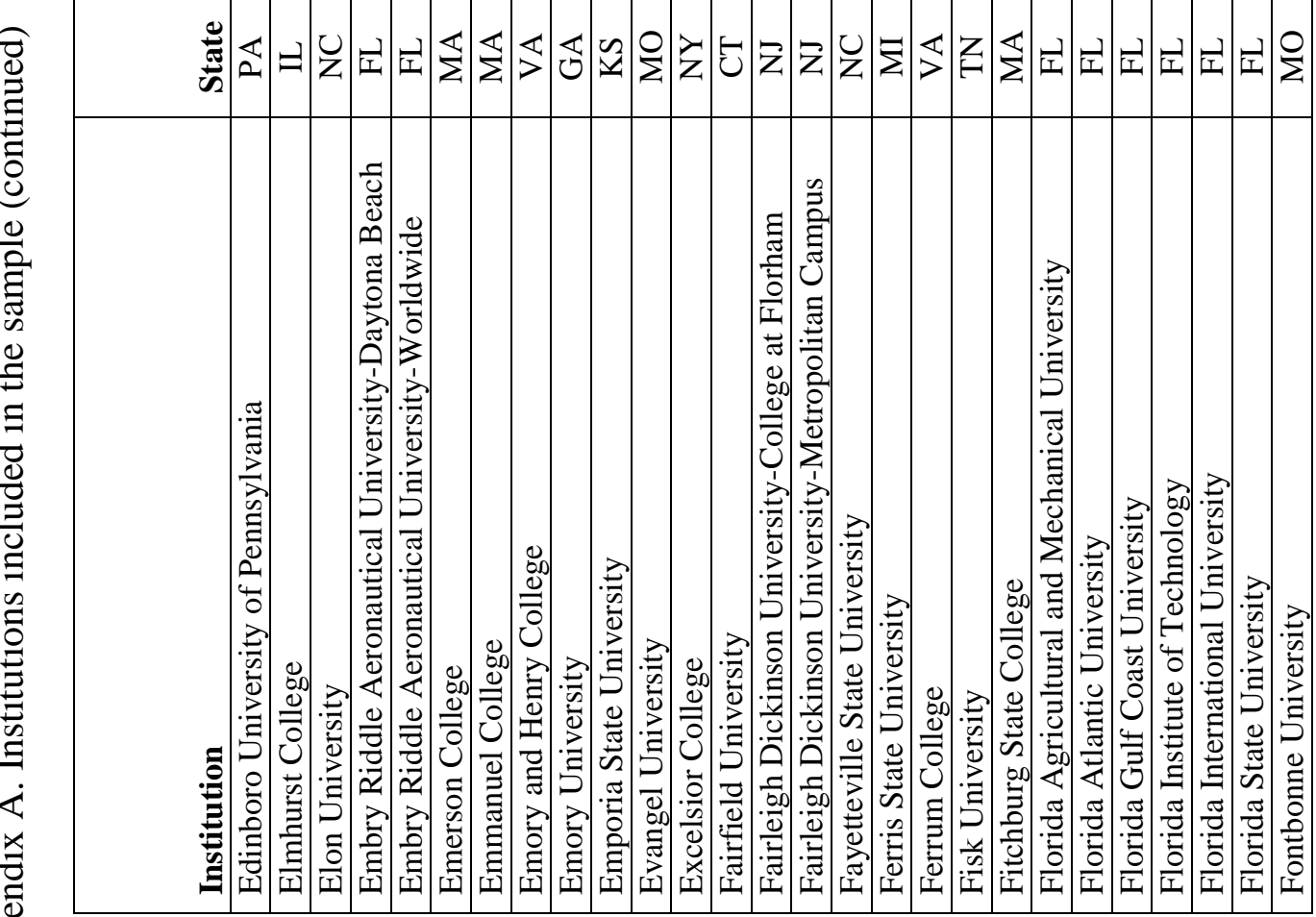




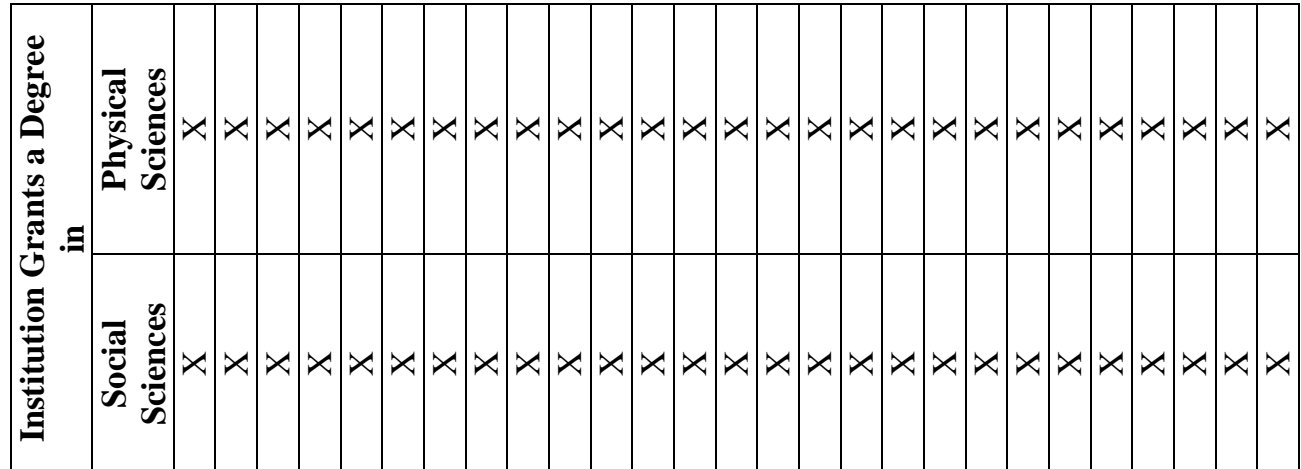

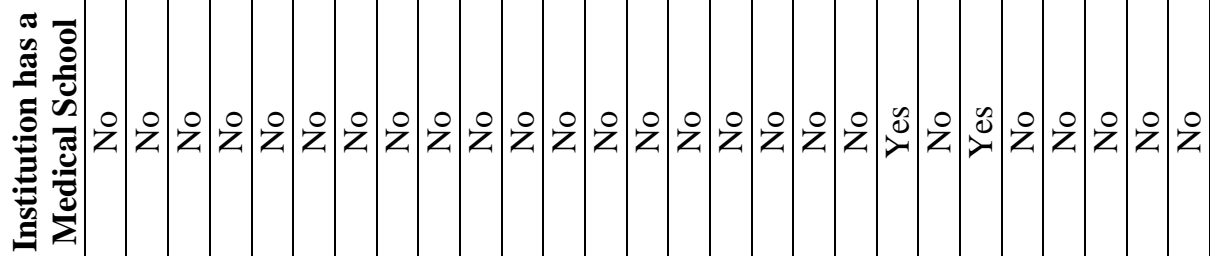

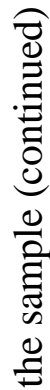

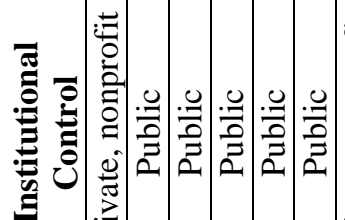

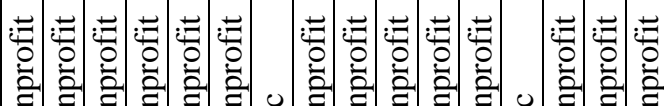

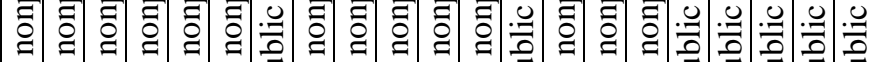

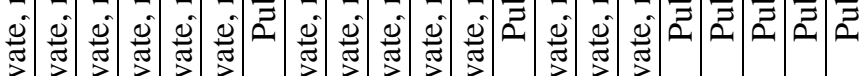

:

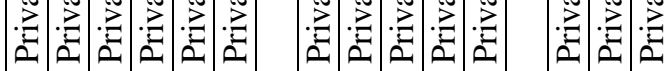

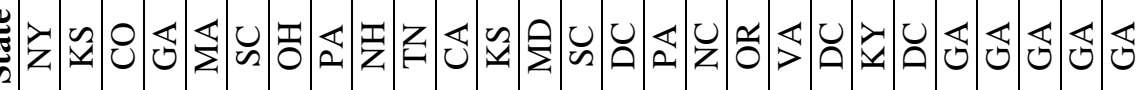

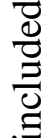

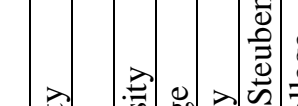

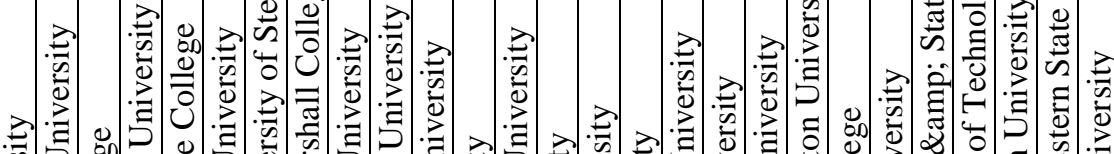

के

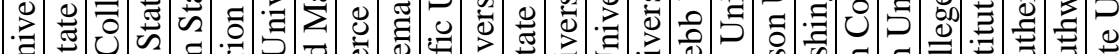

吾

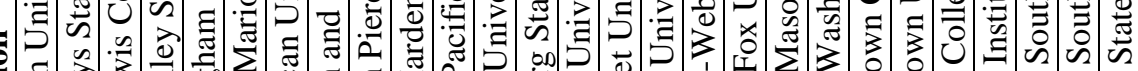

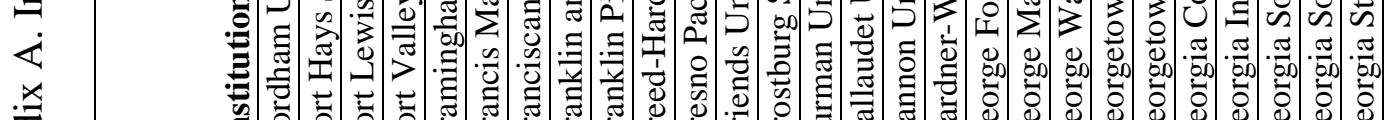

$\stackrel{x}{=}$

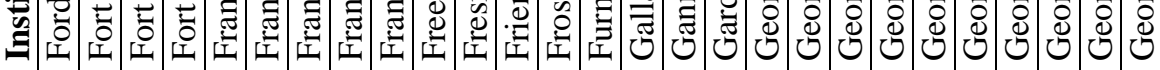

产 


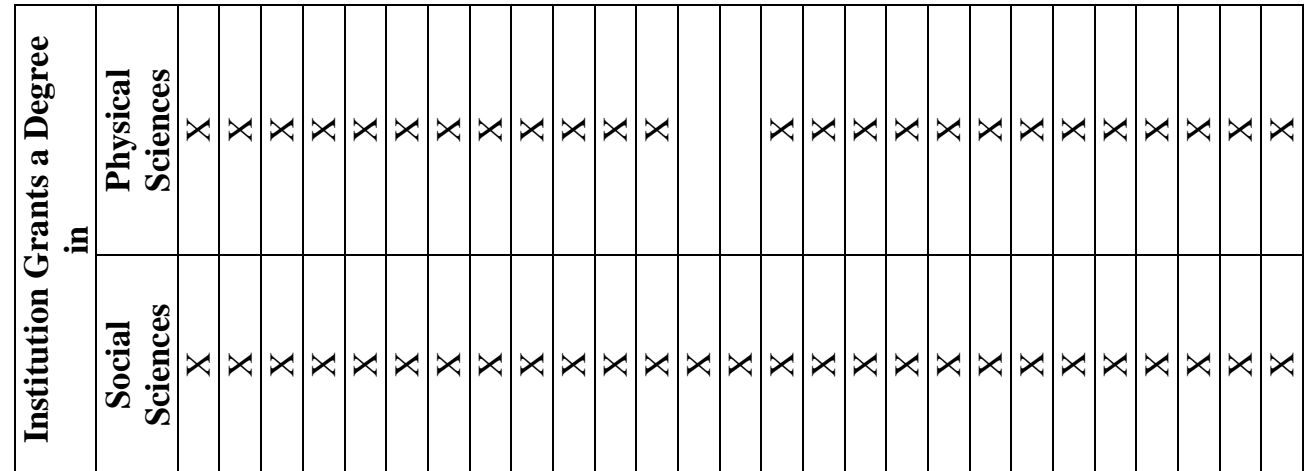

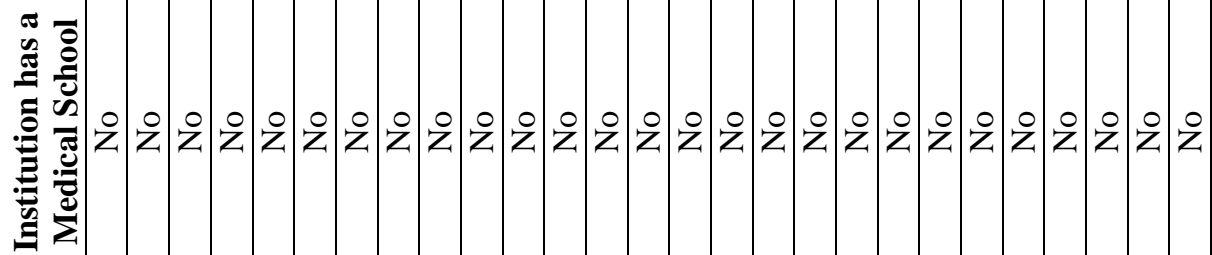

苍

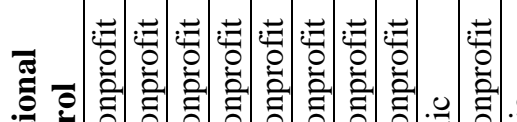

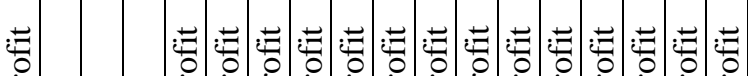

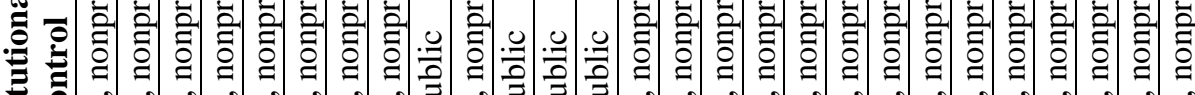

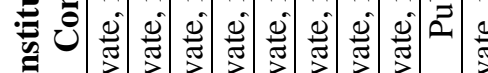

至

$\cdot \vec{z}$

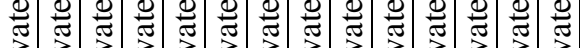

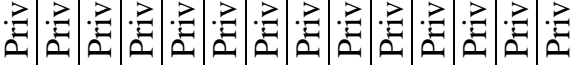

$5<t_{2}$

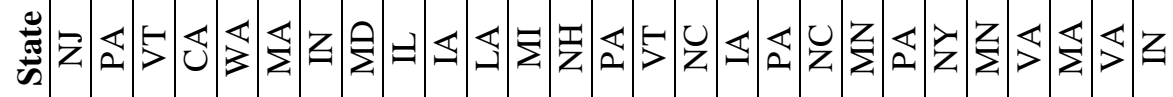




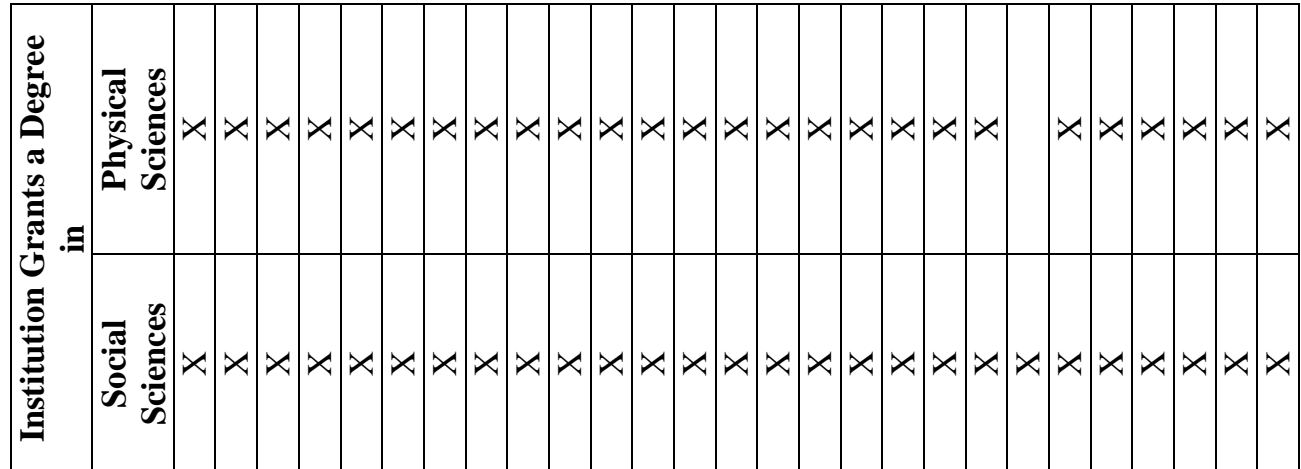

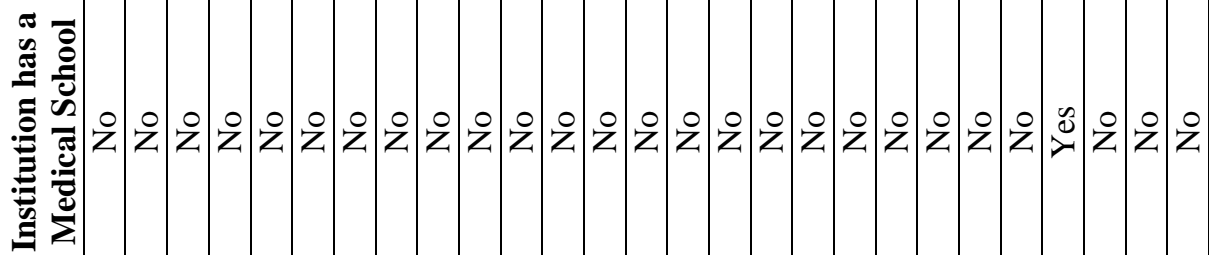

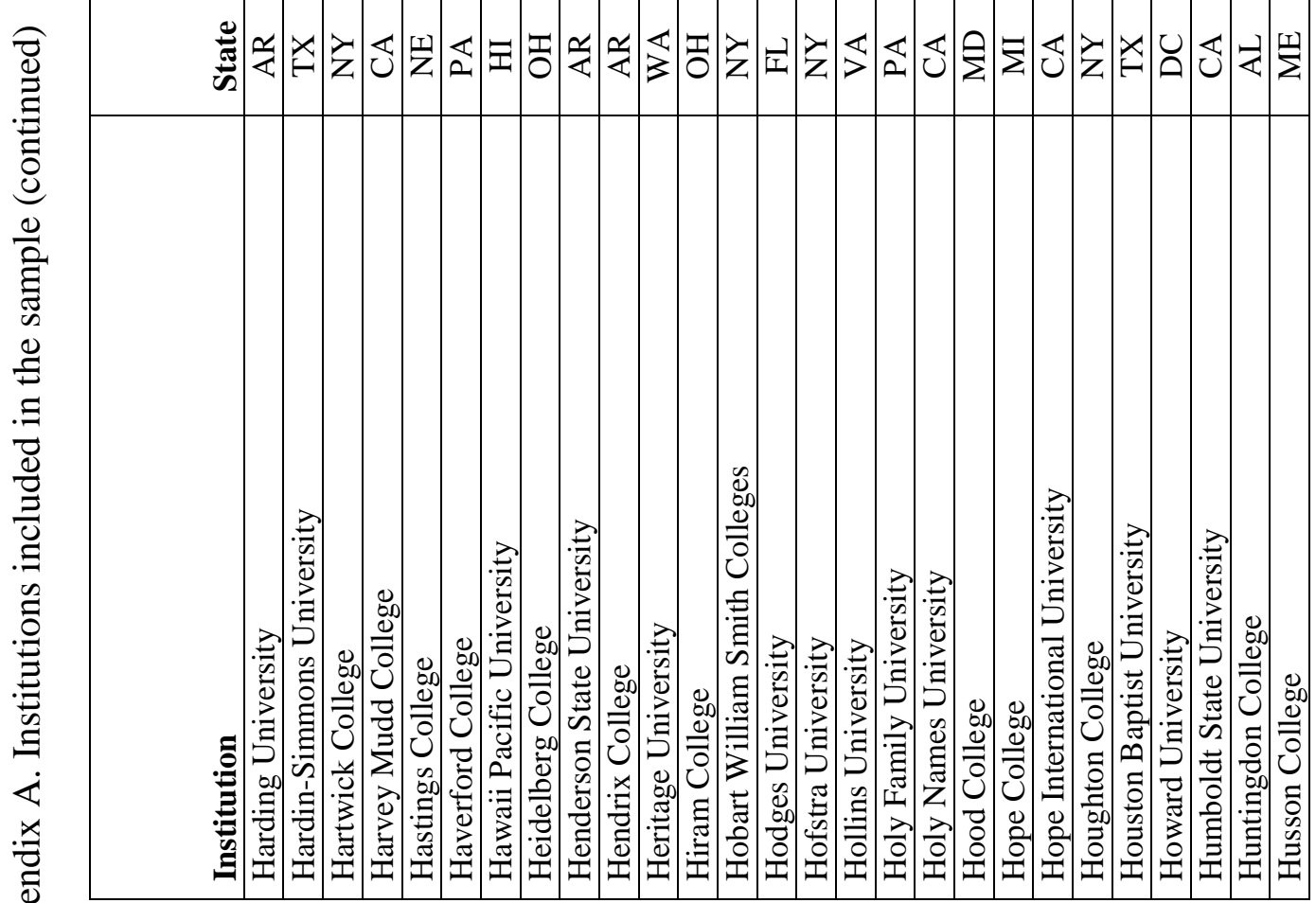

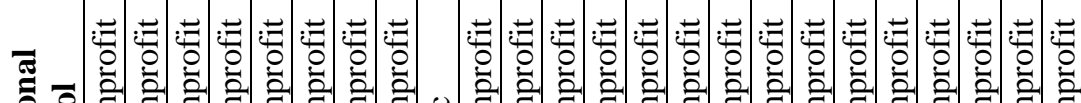

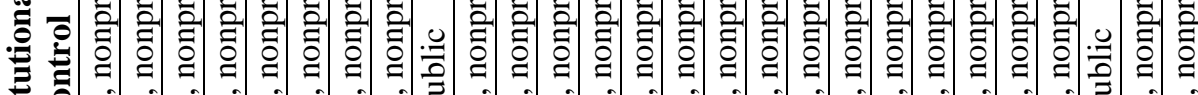

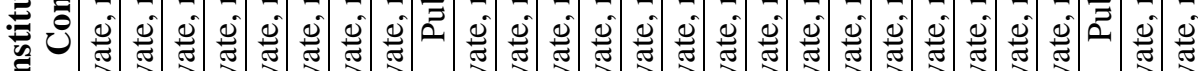

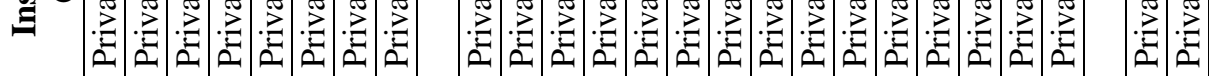

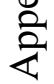




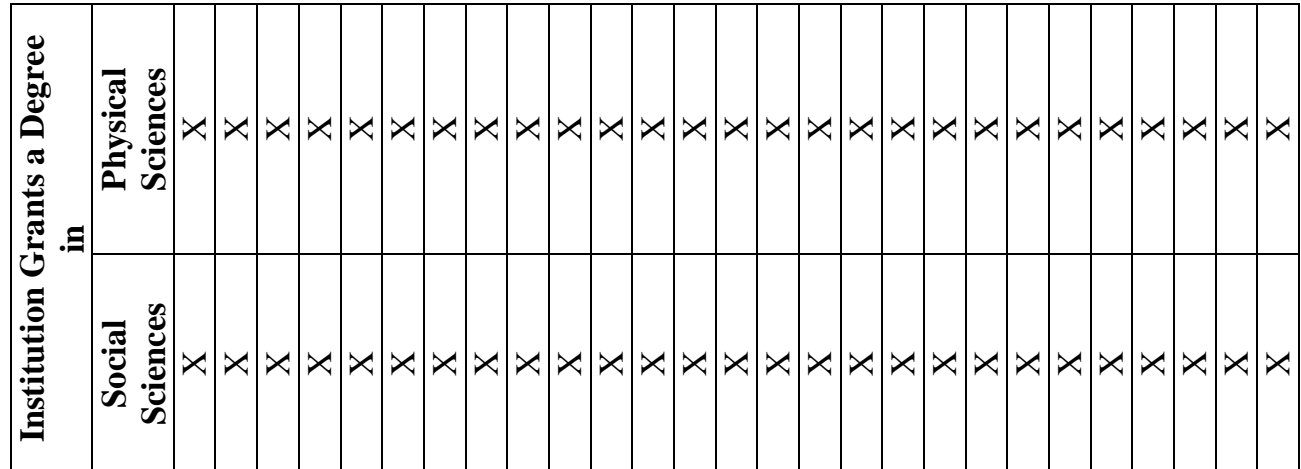

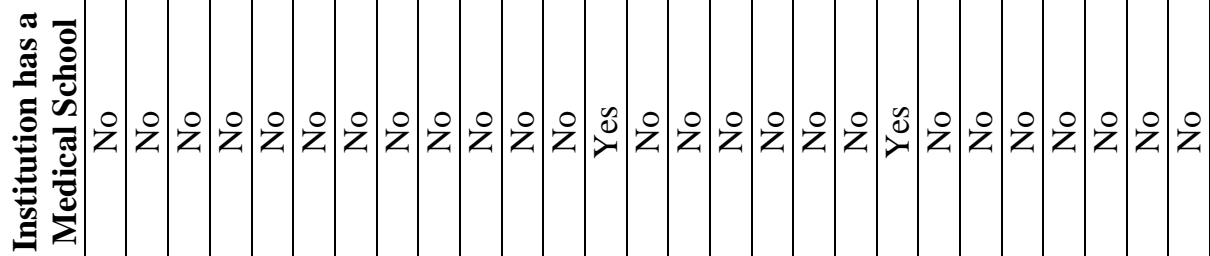

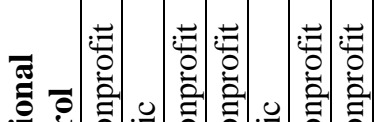

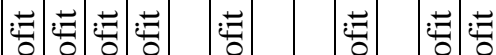

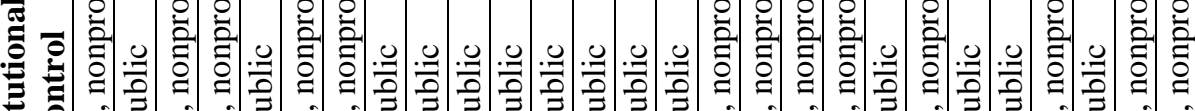

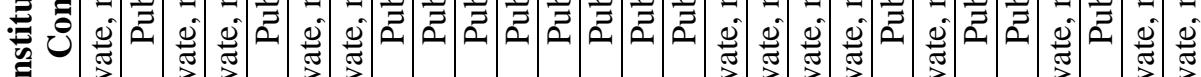

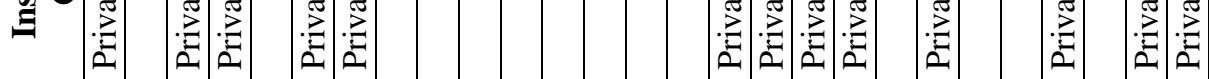

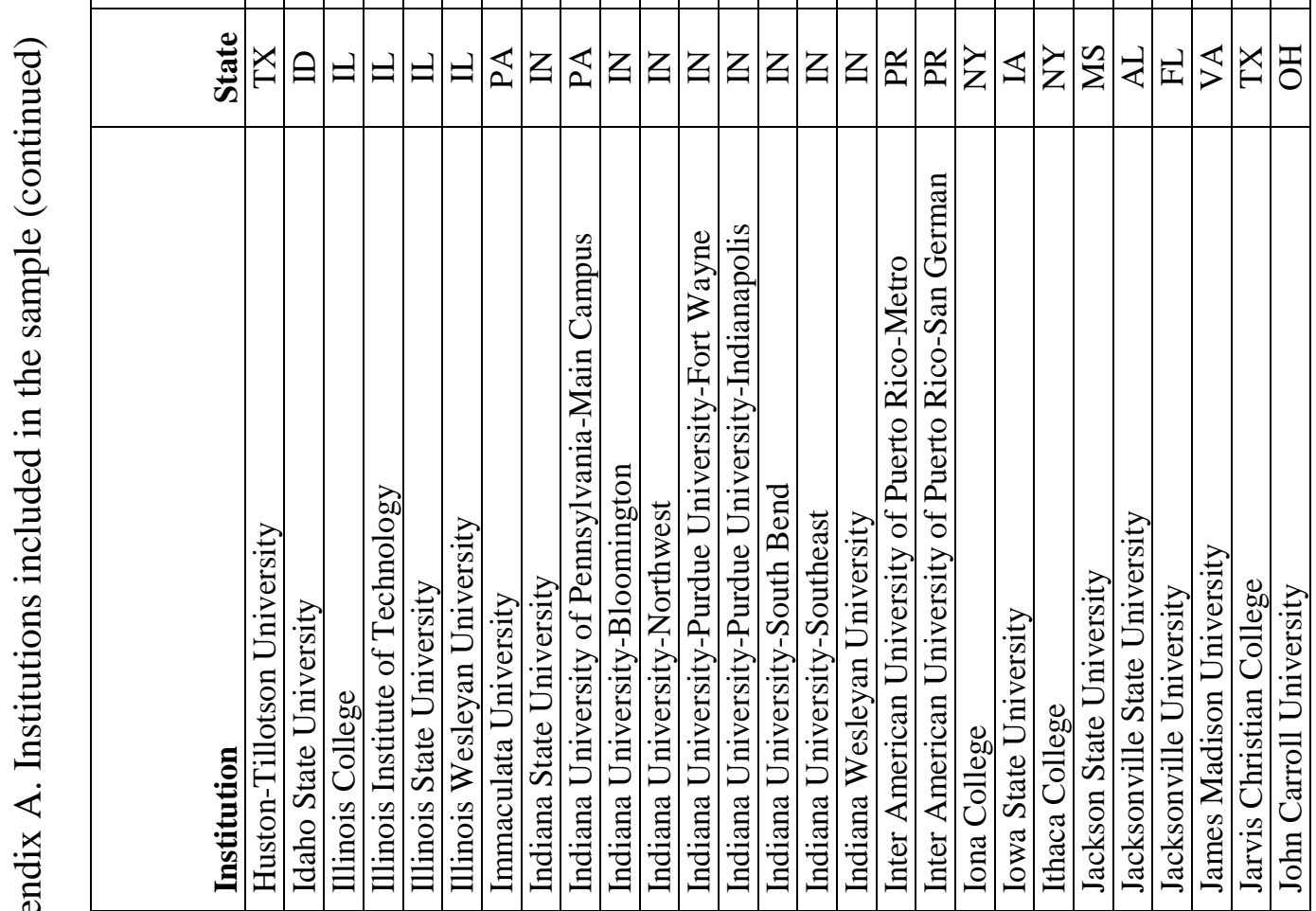

$\frac{2}{2}$ 


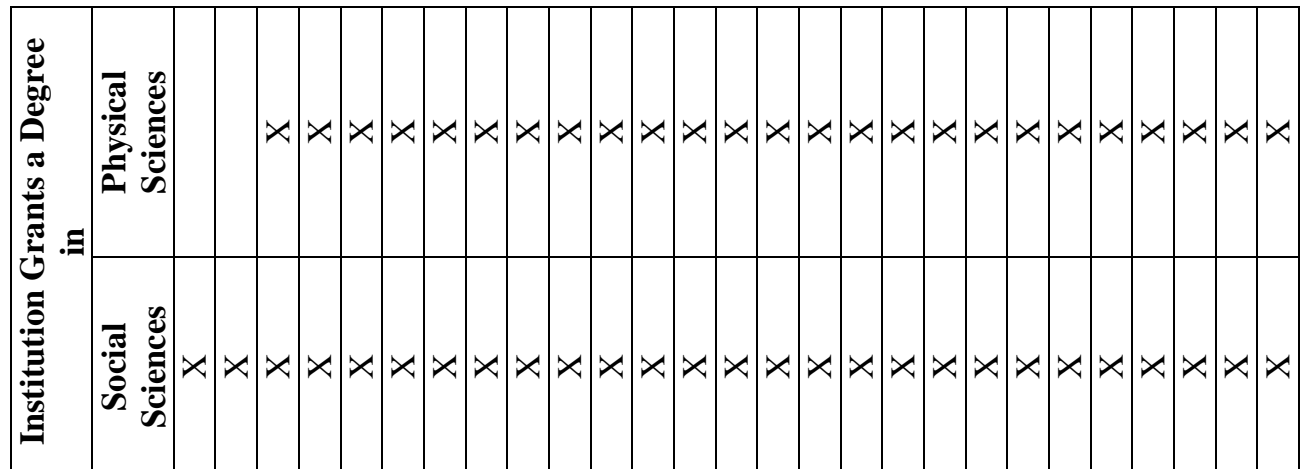

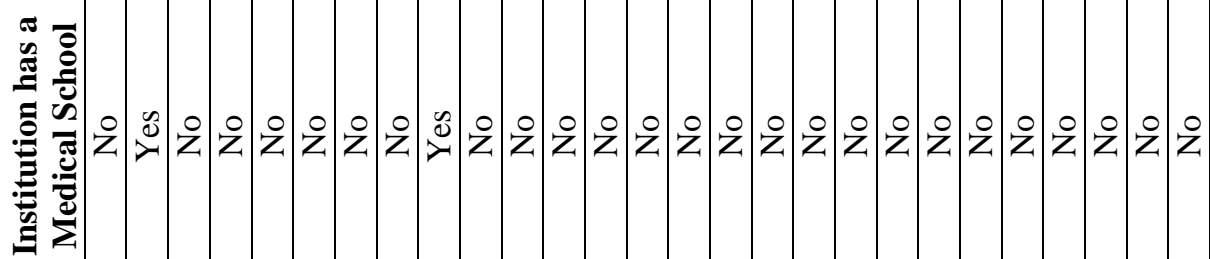

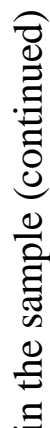

西

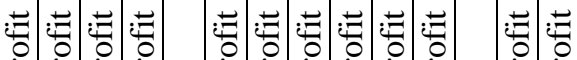

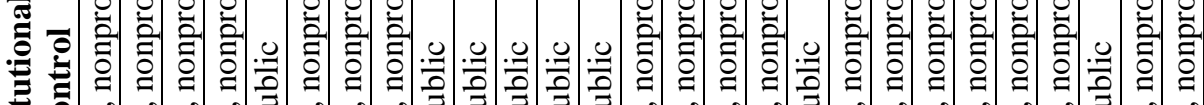

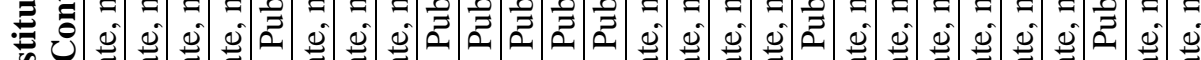

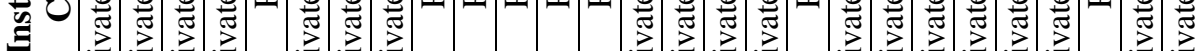

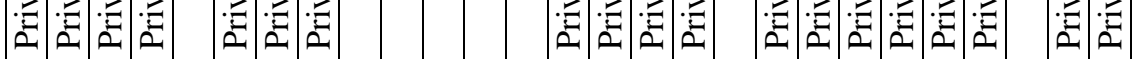

节

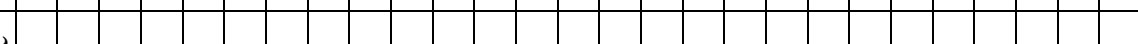

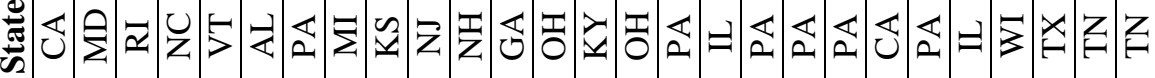

莺

:

:

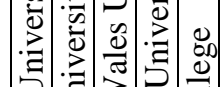

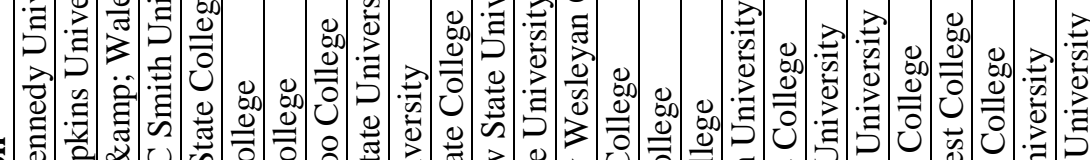



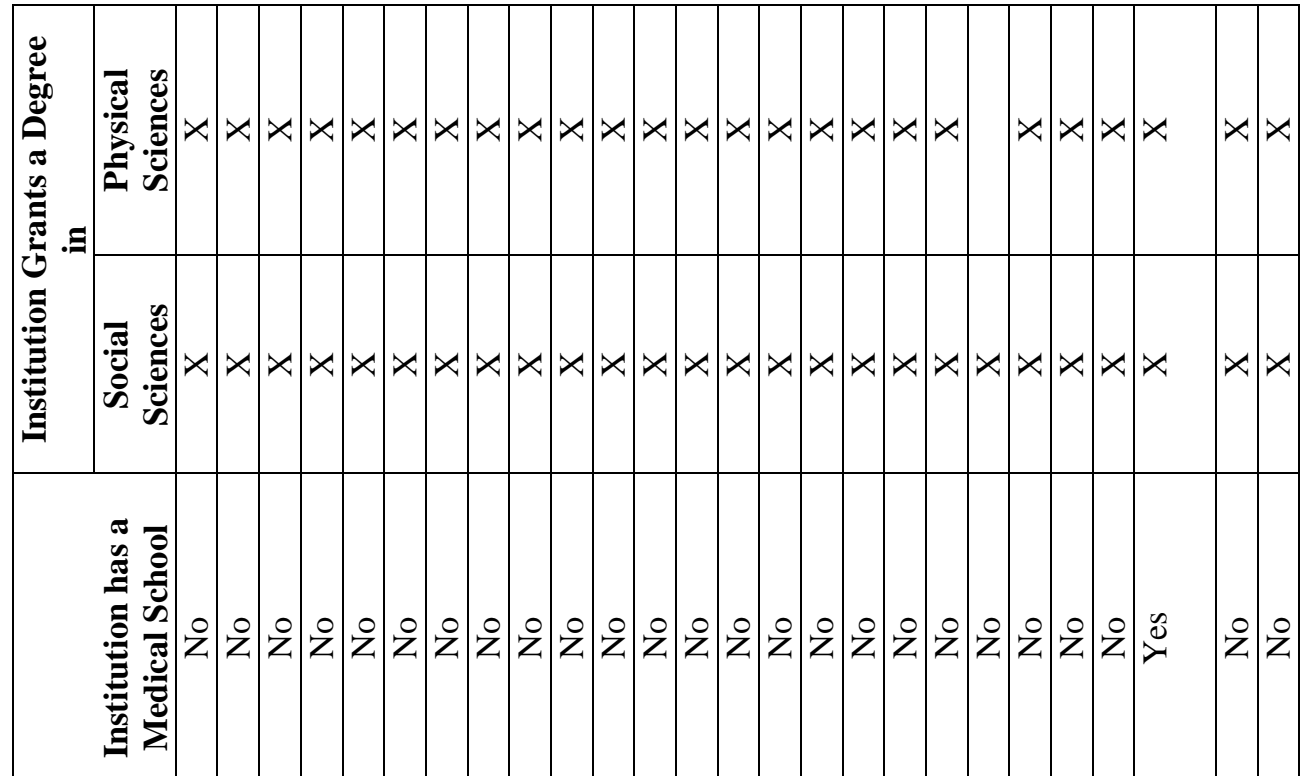

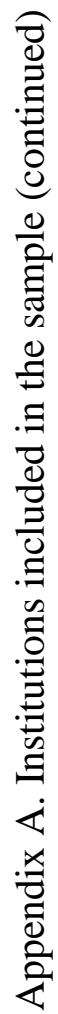

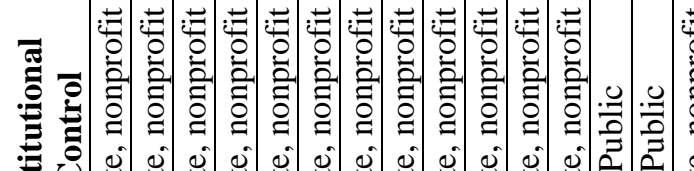

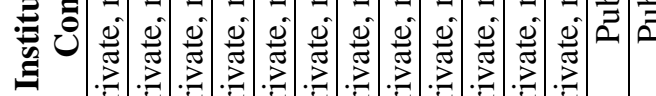

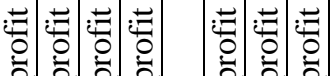

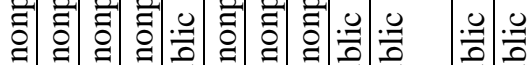

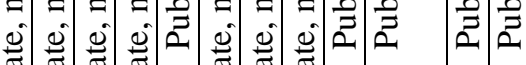

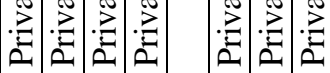

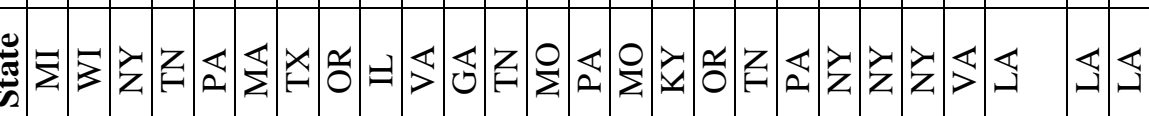

글

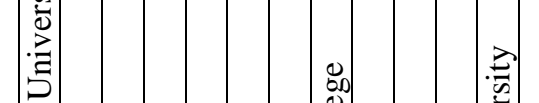

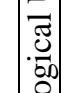

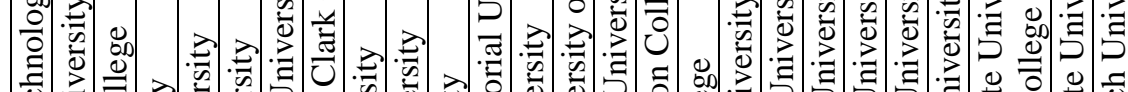

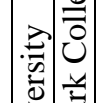

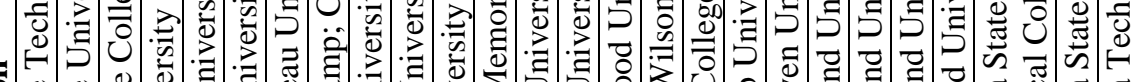

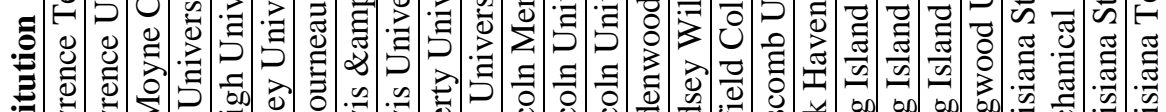
苞苟 


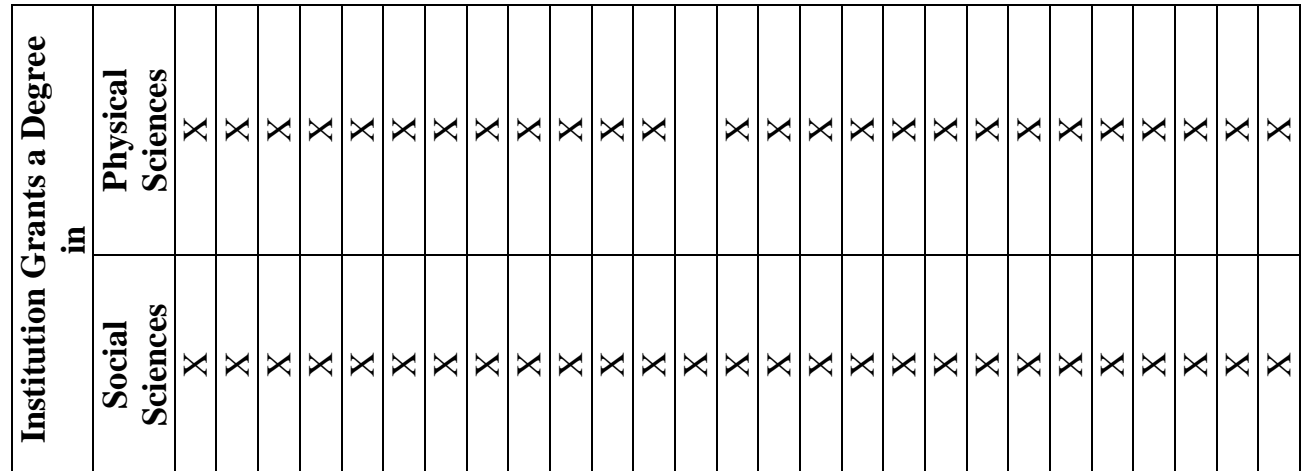

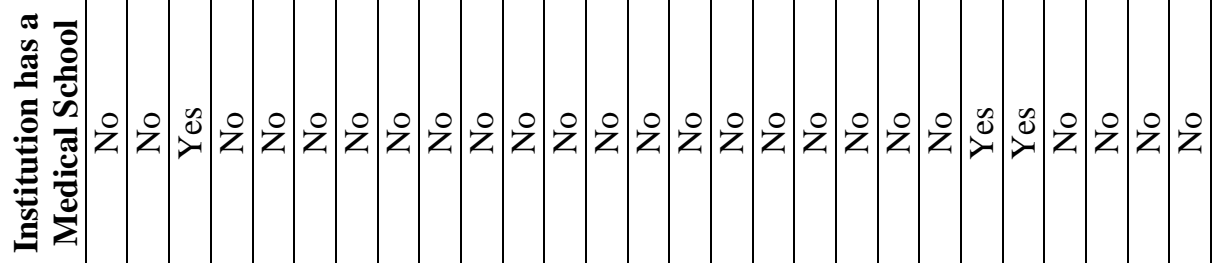

ত્త్ర

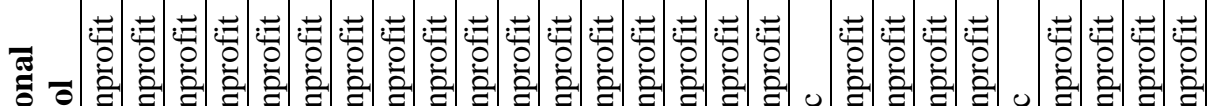

产 홉

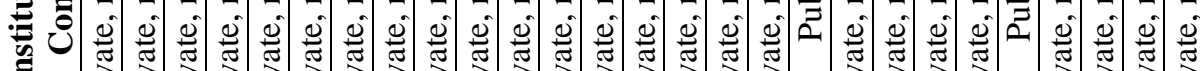

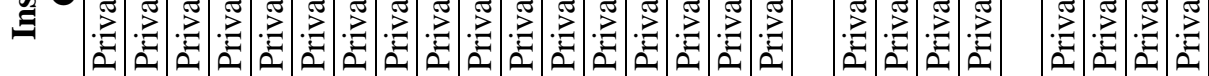

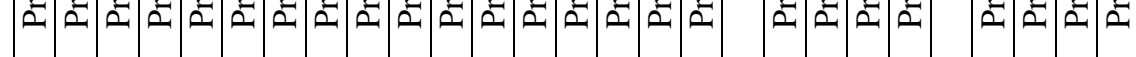

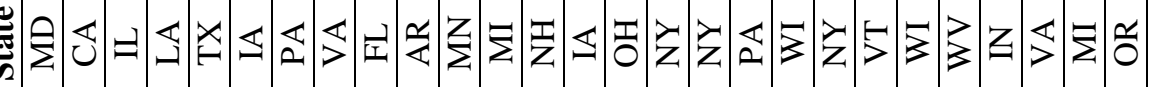

$\frac{7}{\frac{0}{0}}$

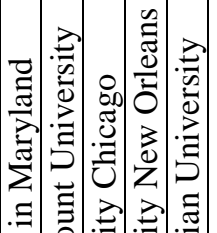

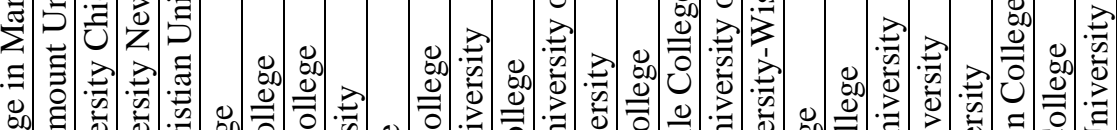

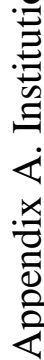

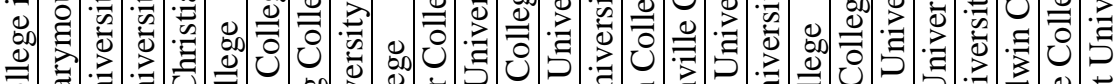
.ี

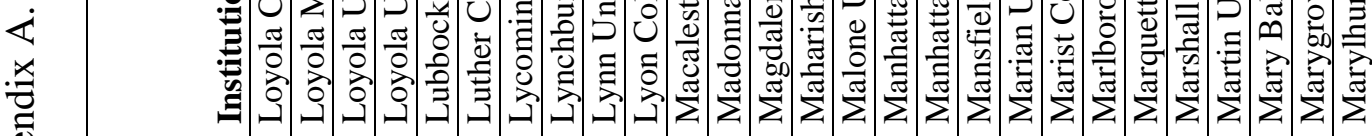

足 


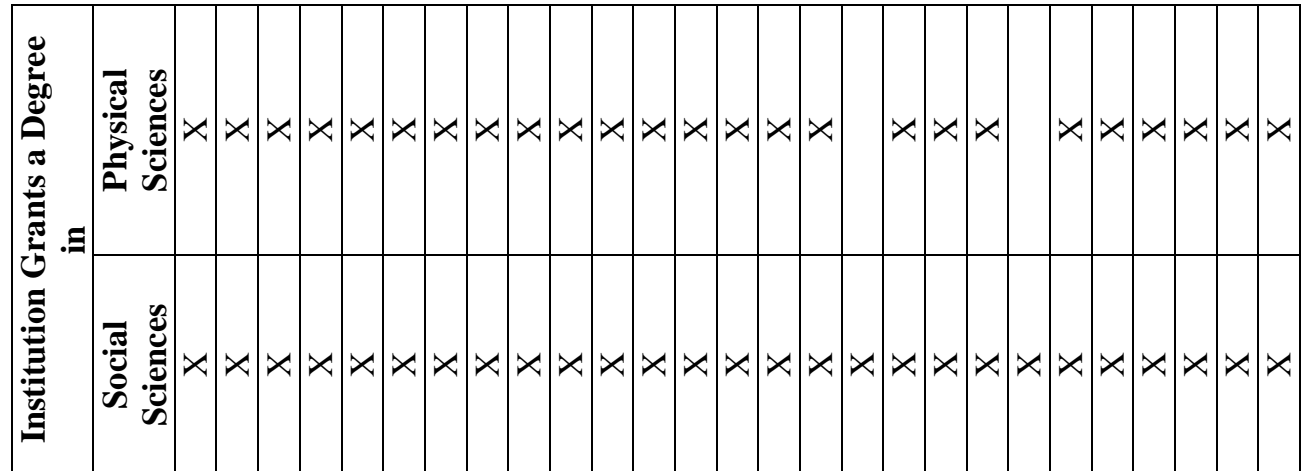

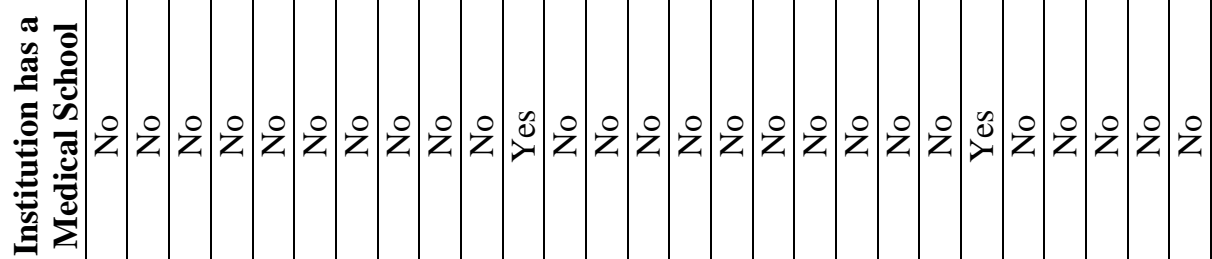

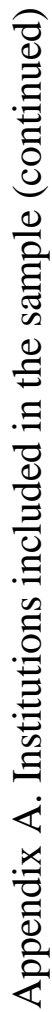

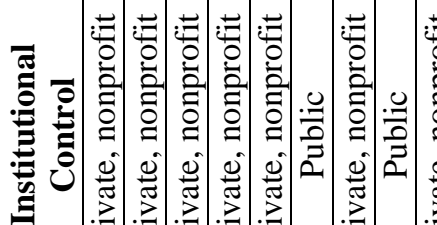
$\cdot \vec{\Xi} \cdot \vec{\Xi} \cdot \vec{z} \cdot \vec{z}$

:

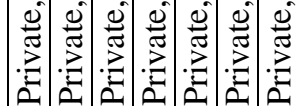

:

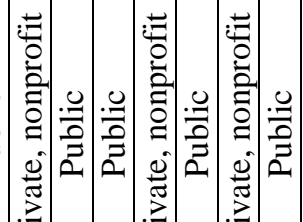

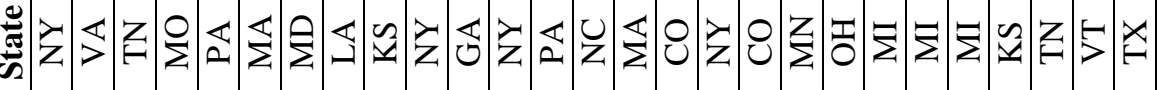

$\frac{7}{\frac{0}{0}}$

|

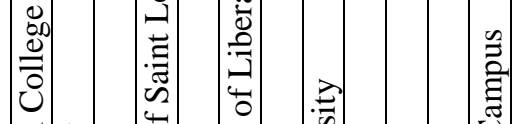

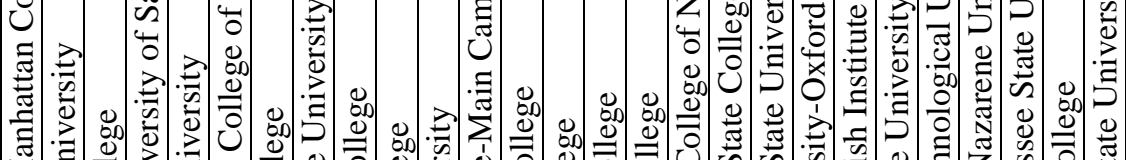

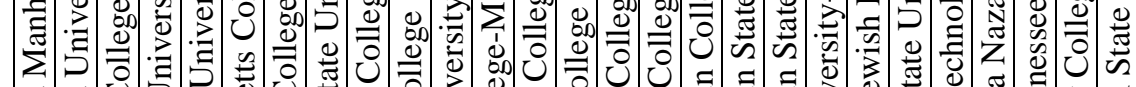
$=$ =

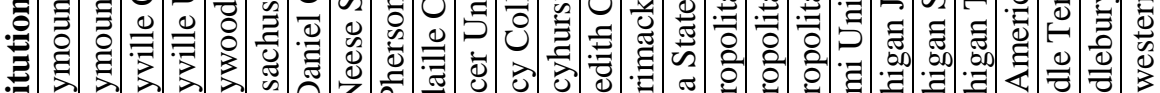

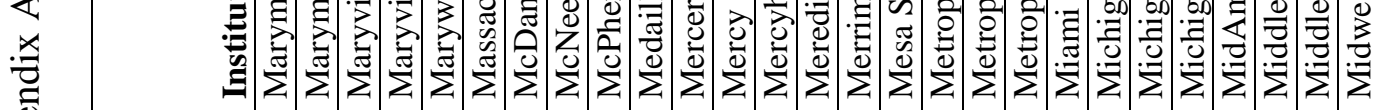

$\frac{2}{2}$ 


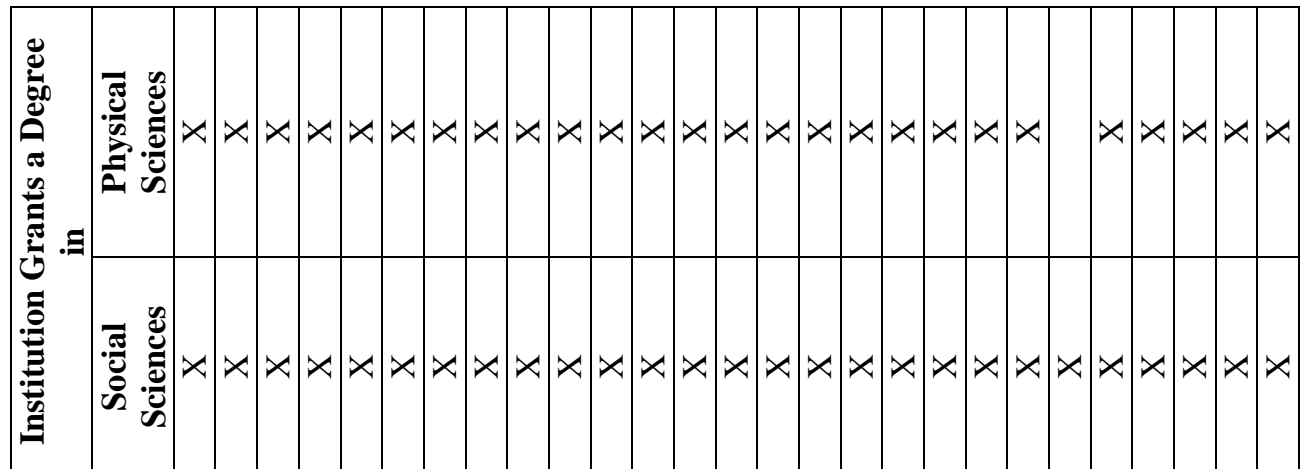

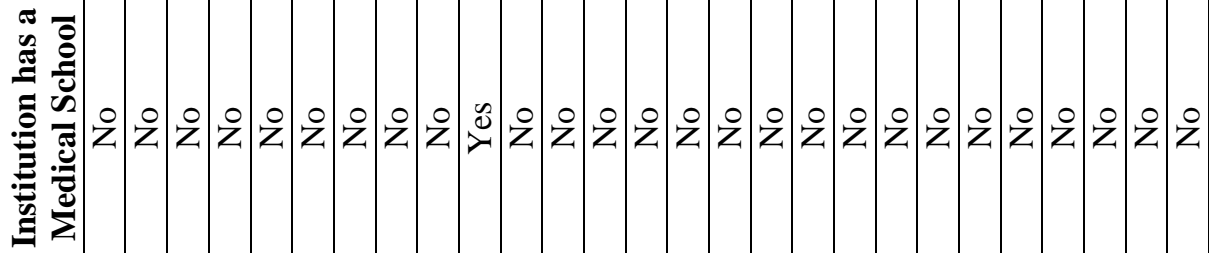

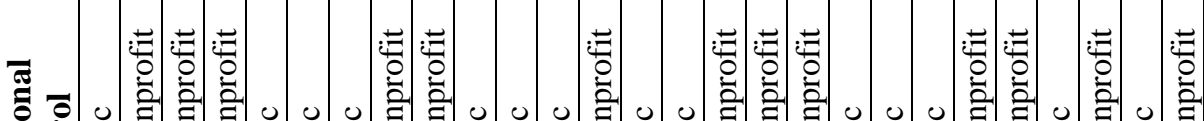

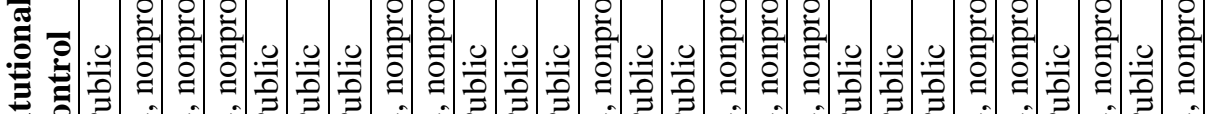

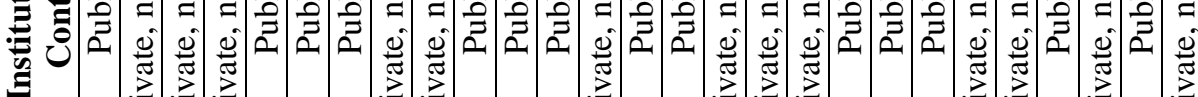

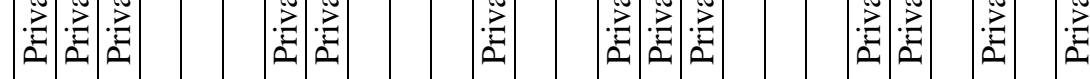

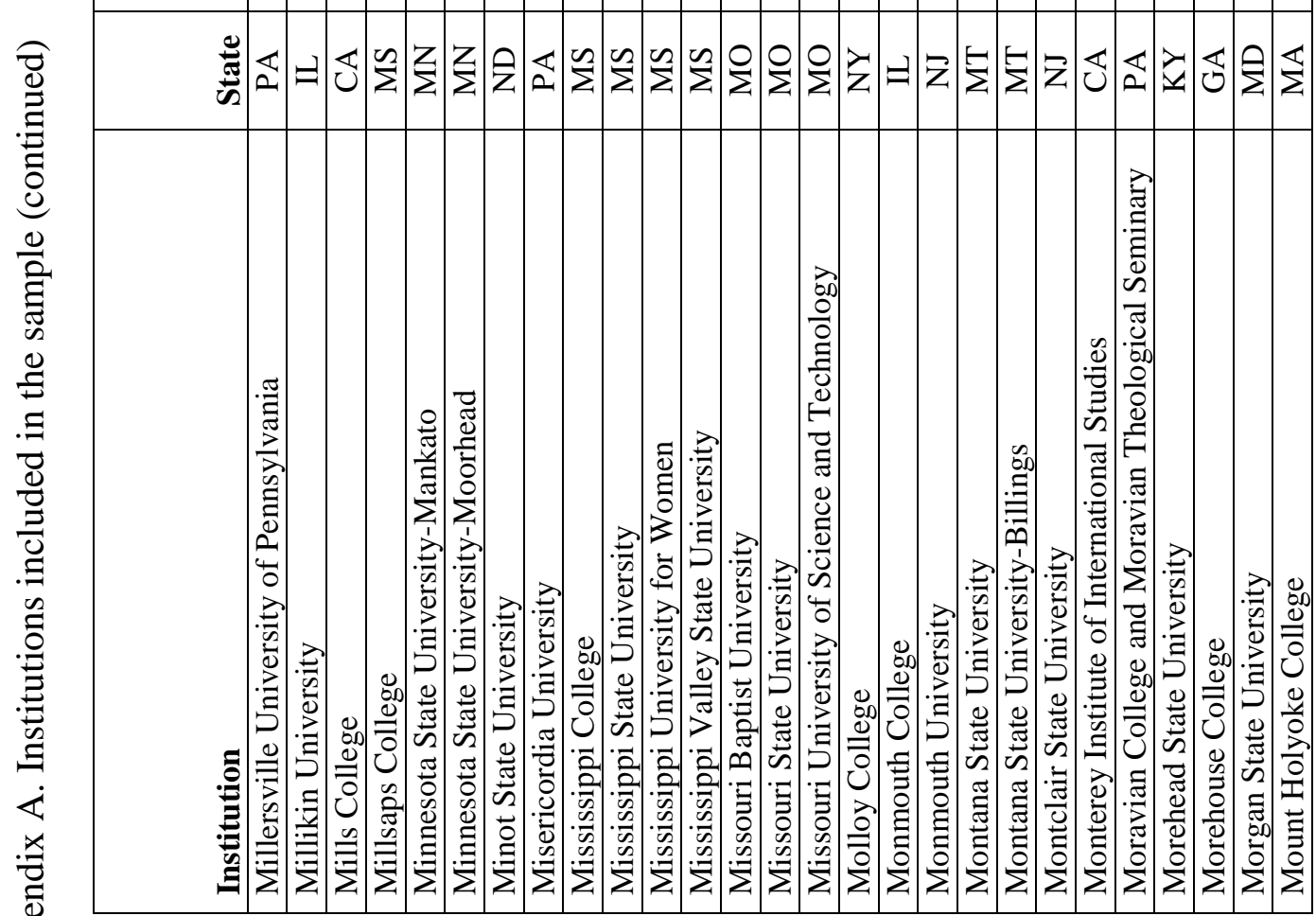
$\frac{\AA}{2}$ 


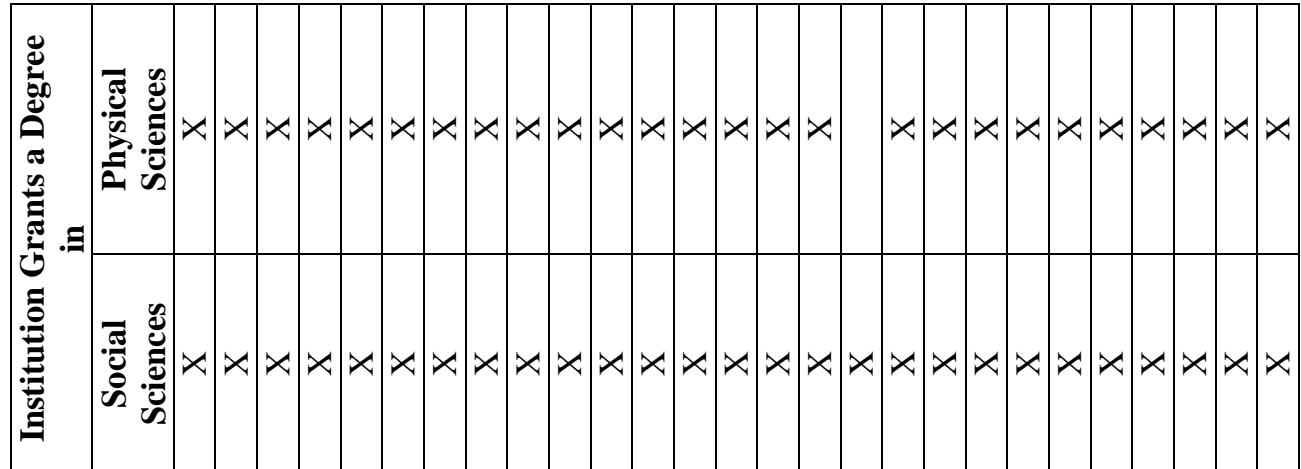

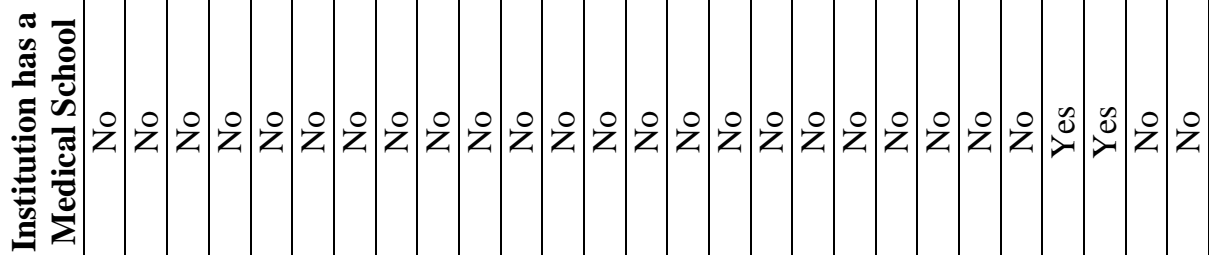

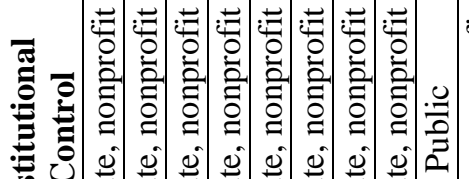

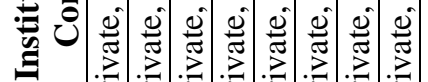
논

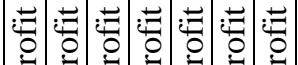

응

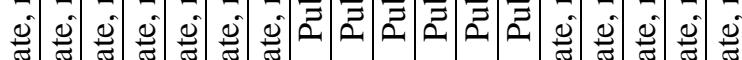

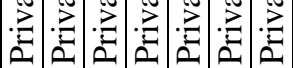

$\cdot \vec{D} \cdot \vec{D} \cdot \vec{D} \cdot \vec{D}$

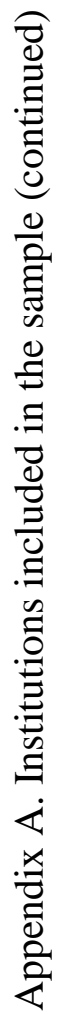

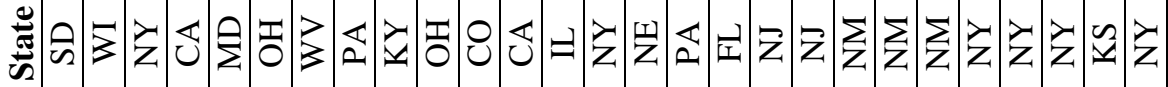

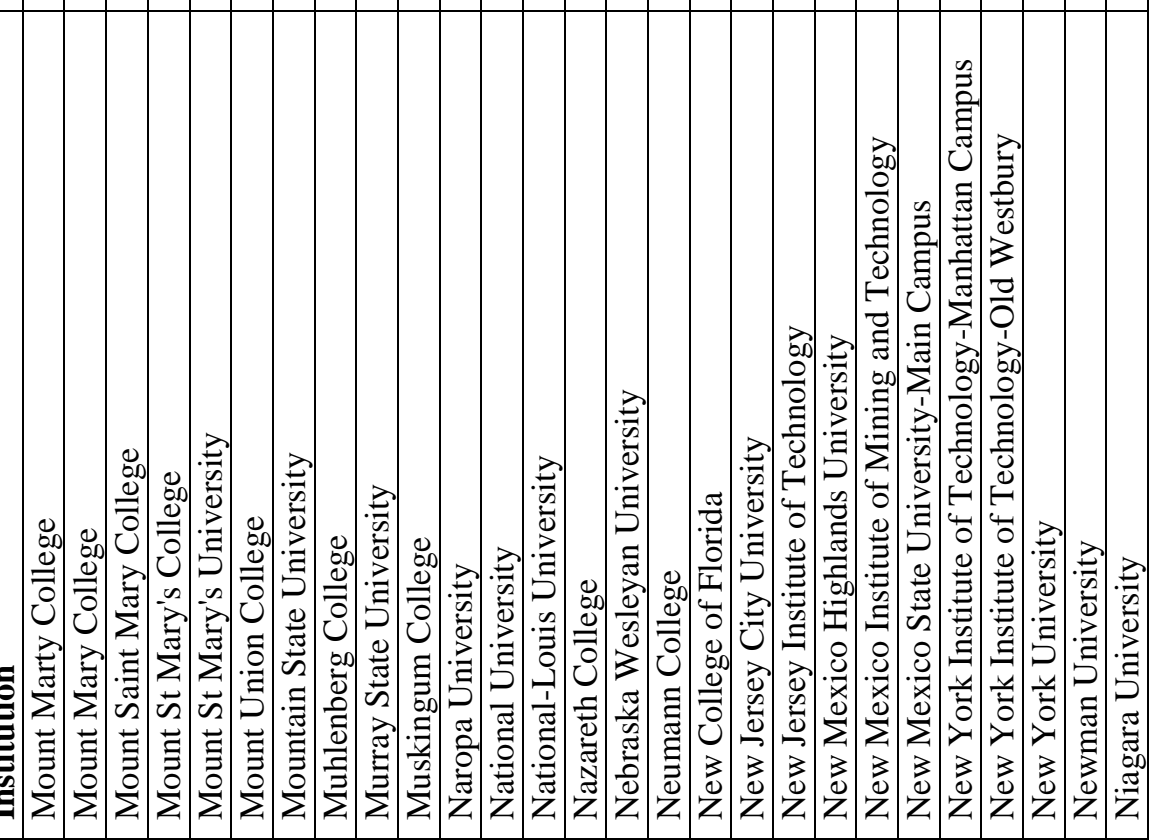




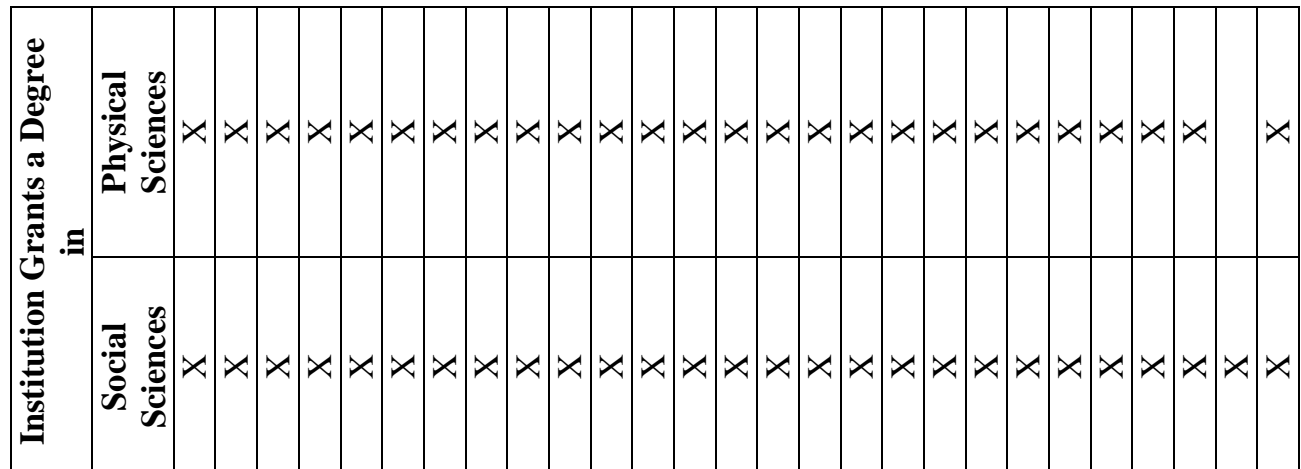

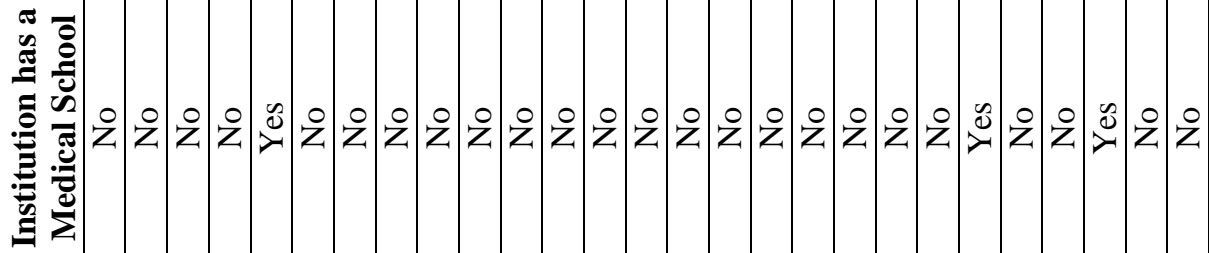

ฮิ

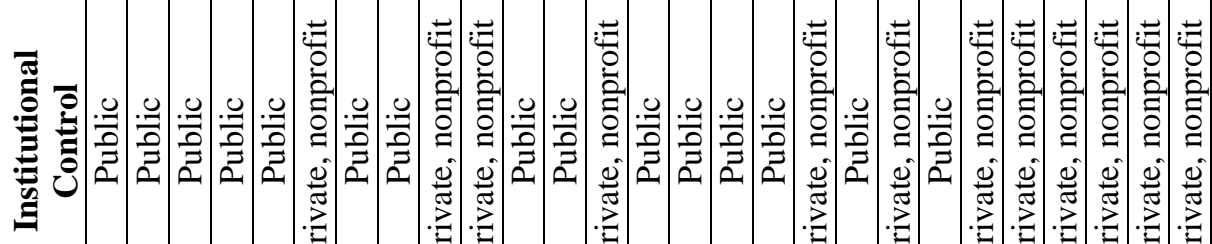

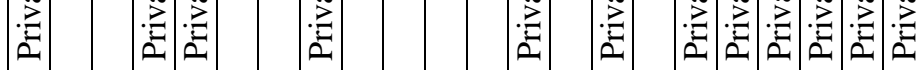

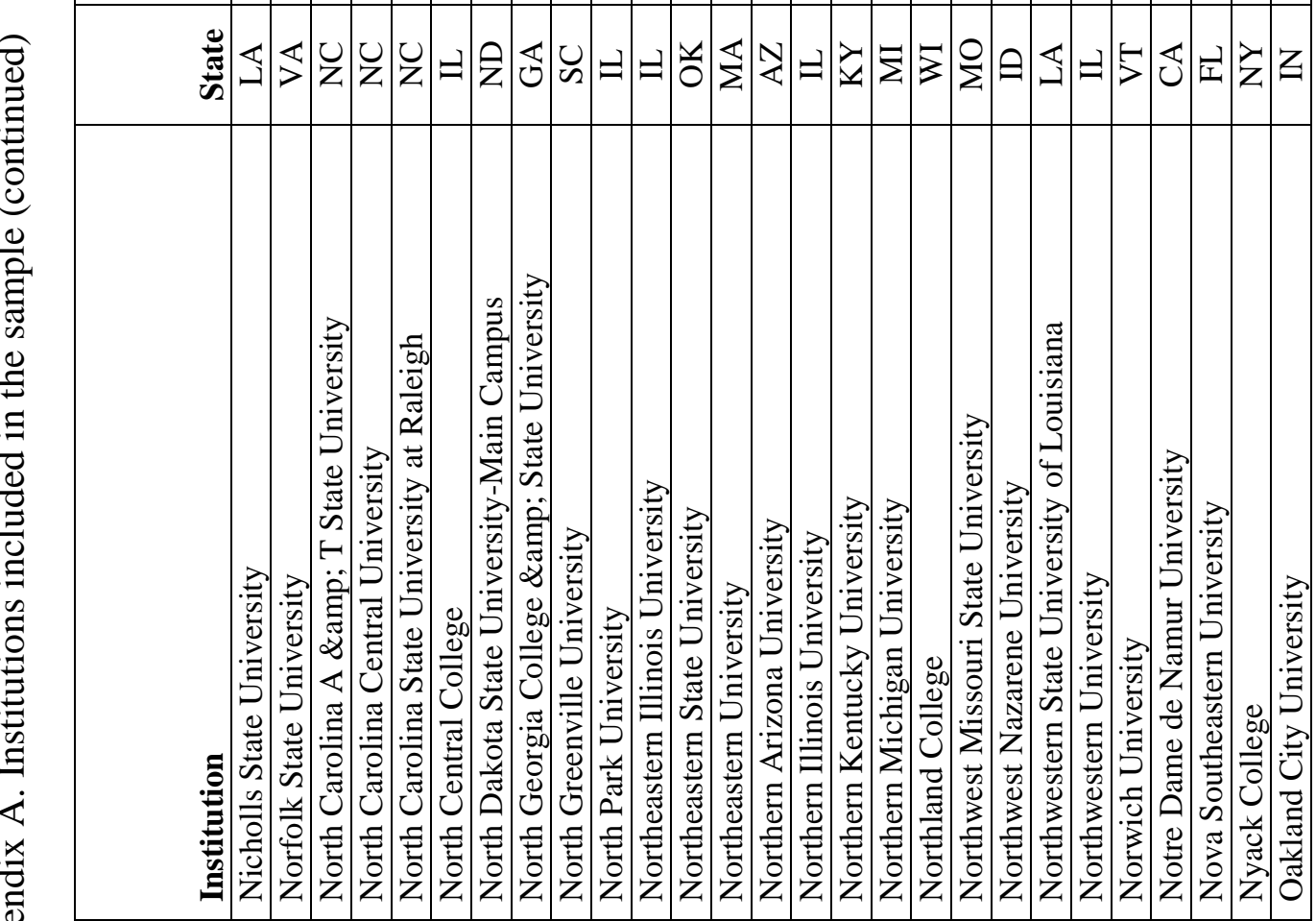

$\frac{\mathbb{2}}{2}$ 


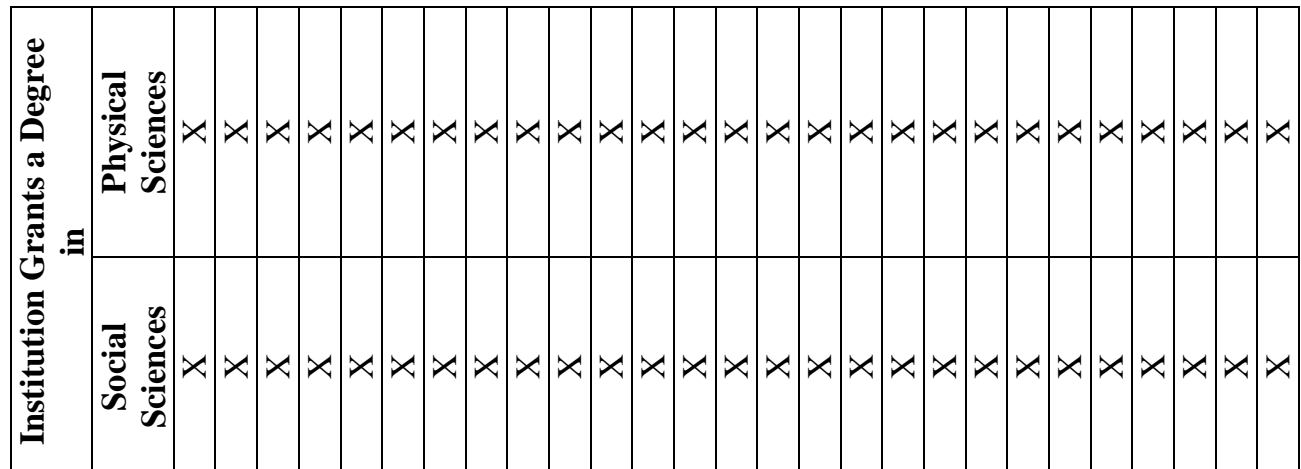

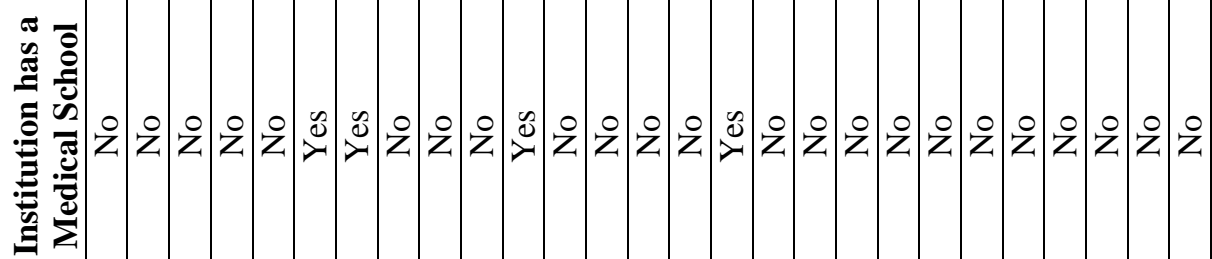

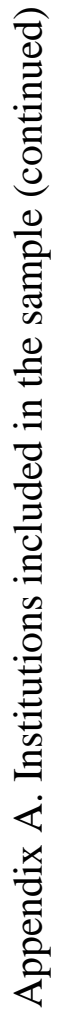

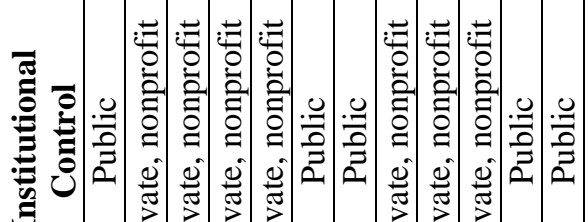

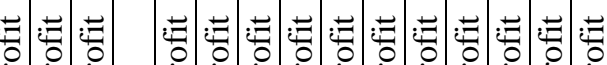

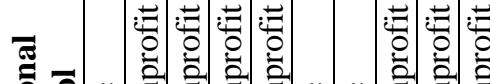

은 0 은

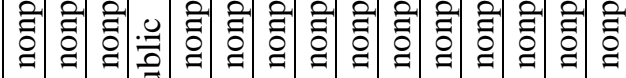
$\because 0$ a

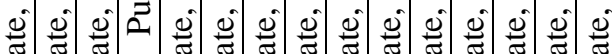

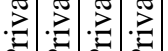

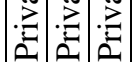

in

a

\section{$-1$}

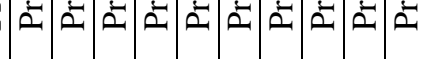




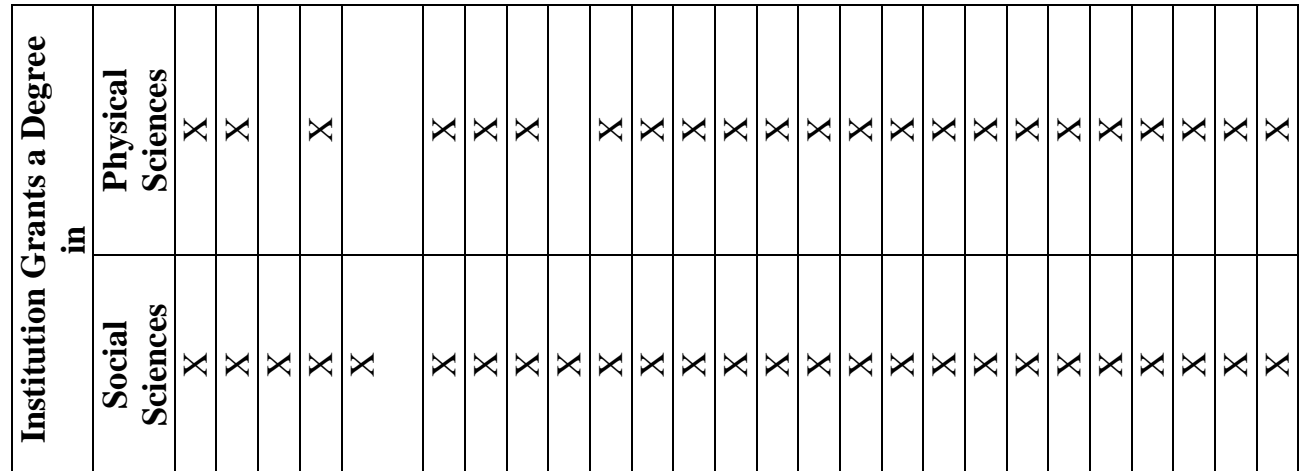

疍

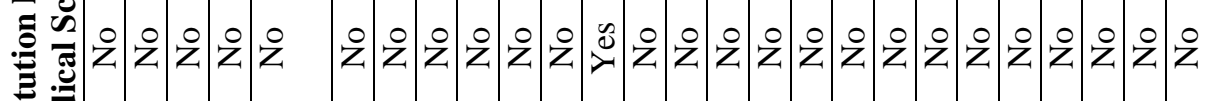
莺

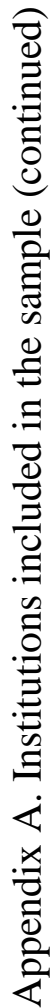

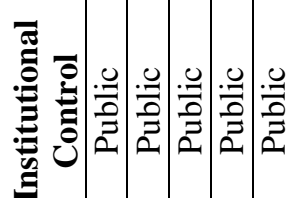

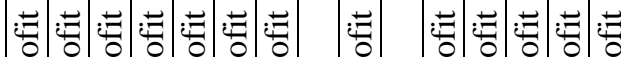

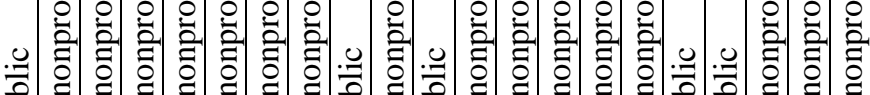

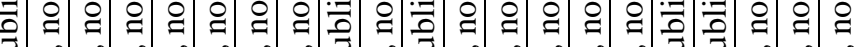

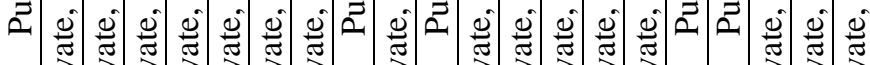

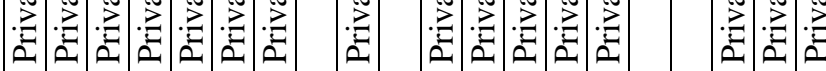

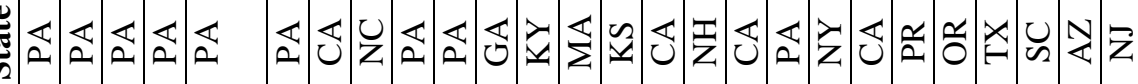

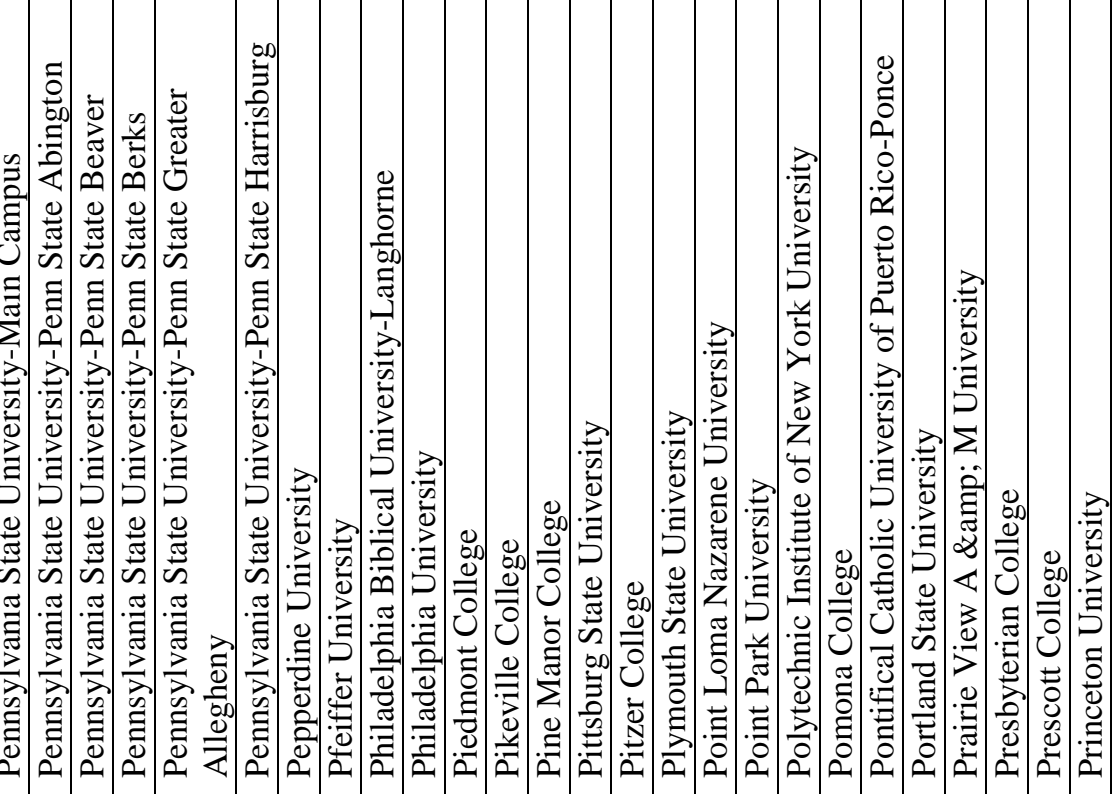




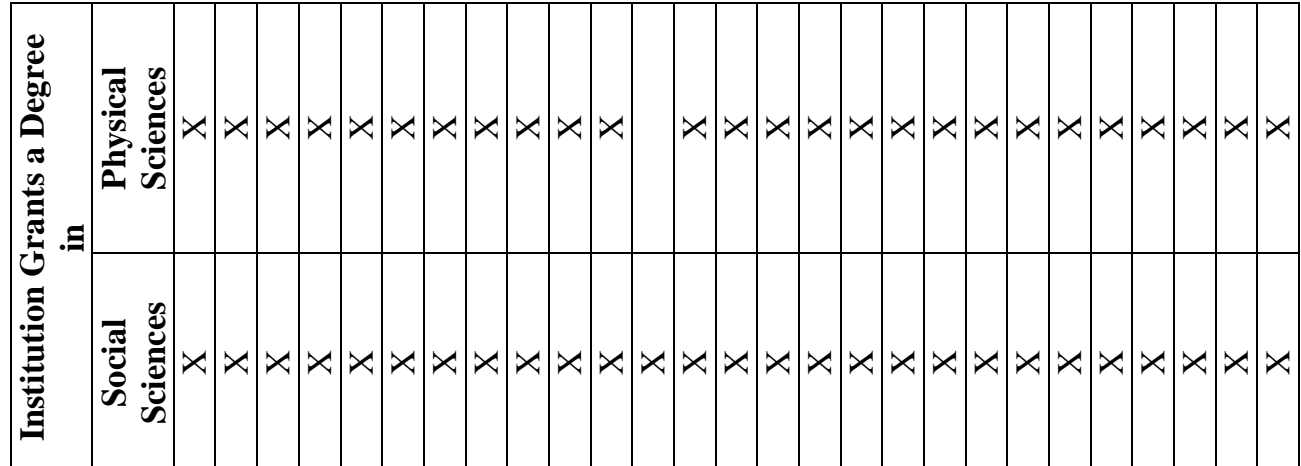

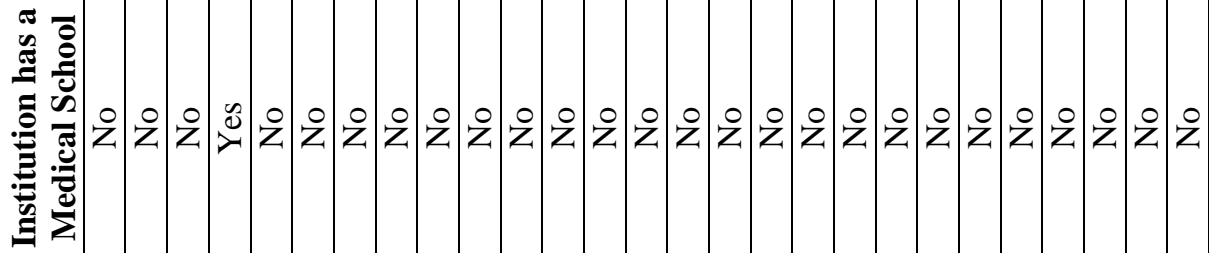

胥

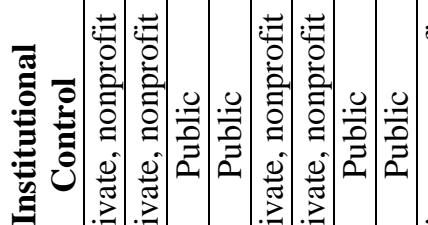

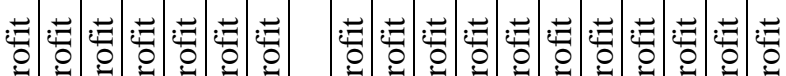

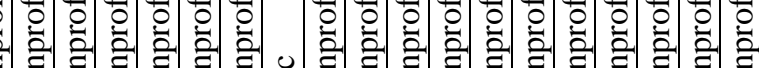

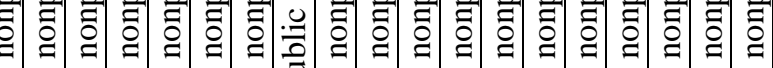

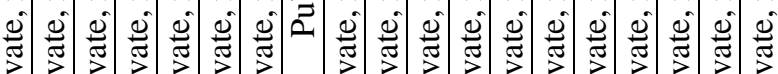

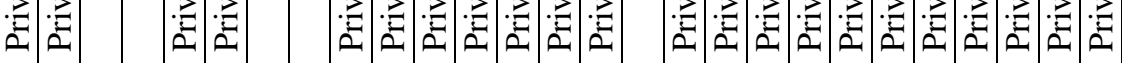

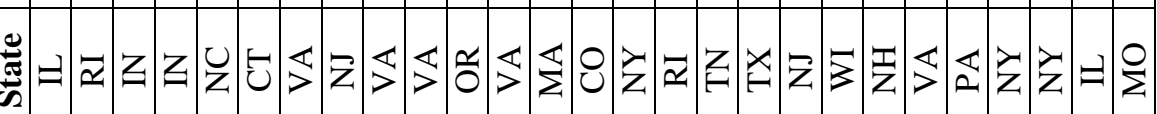

气ิ

$\frac{\frac{8}{3}}{0}$

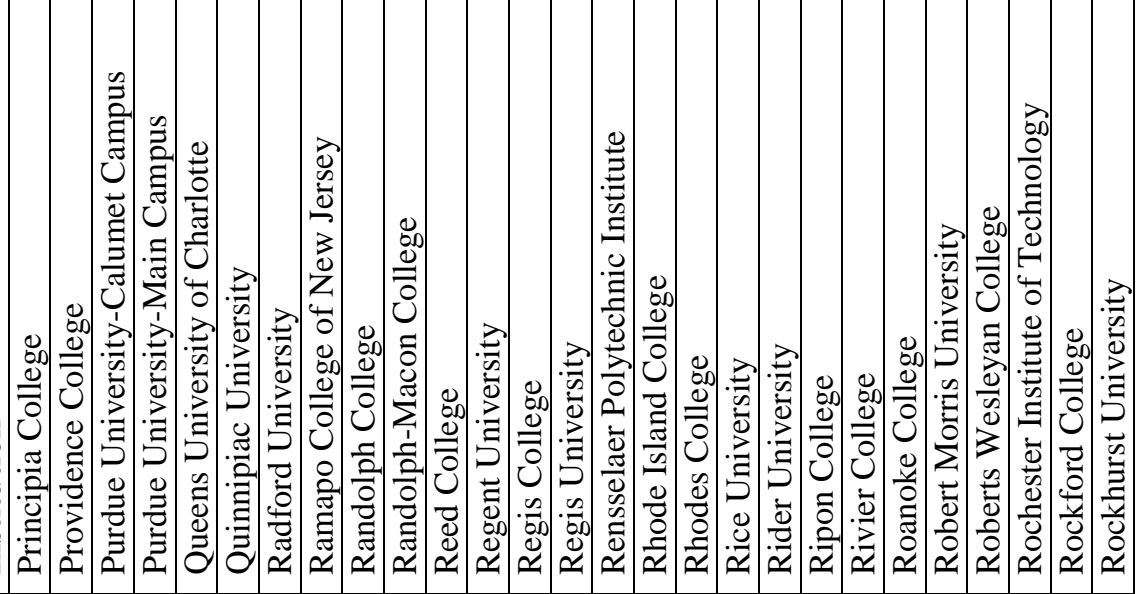

$\frac{2}{2}$ 


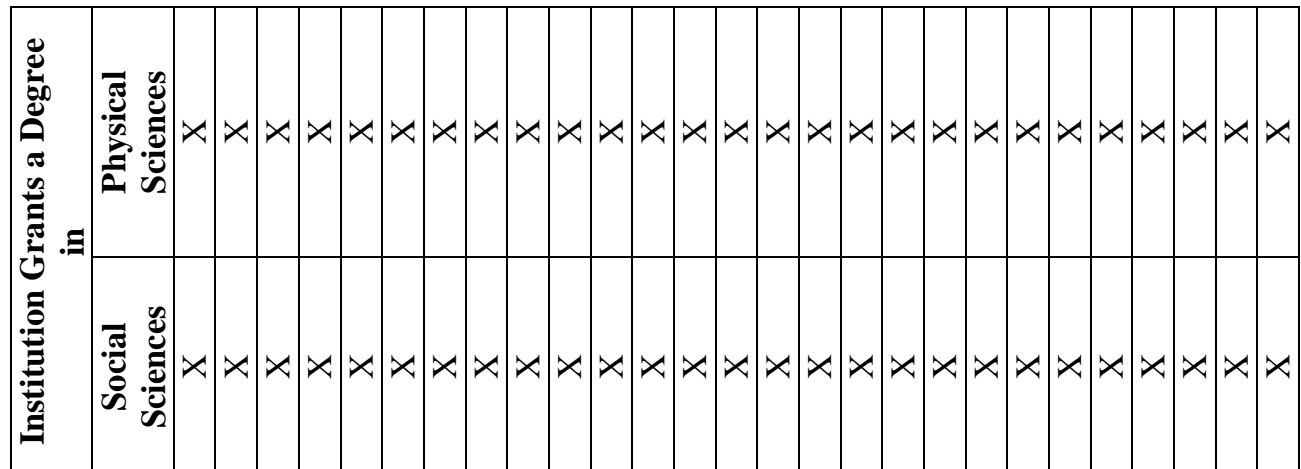

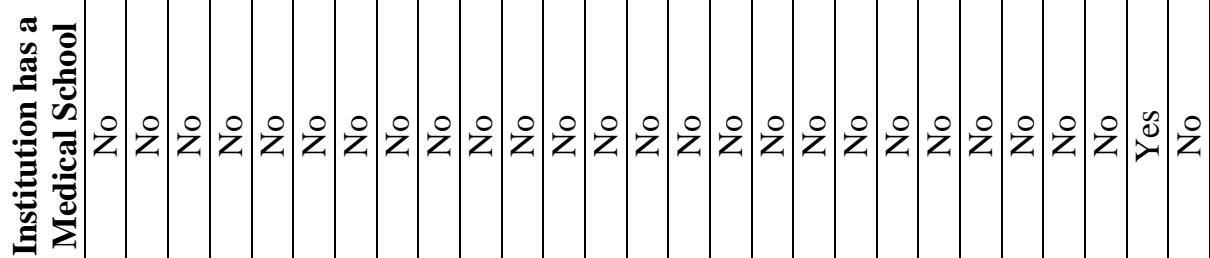

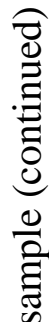

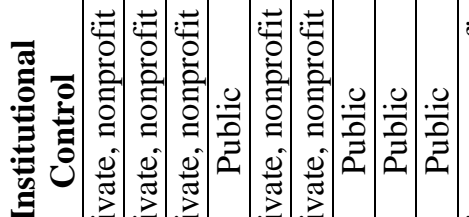

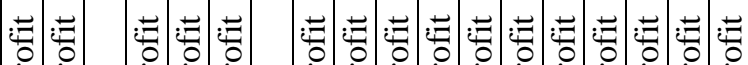

ธ

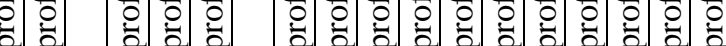

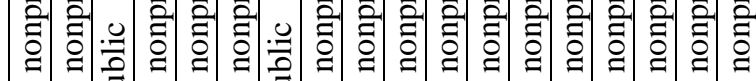

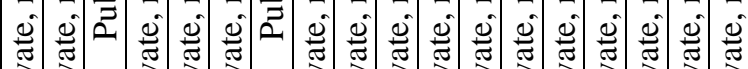

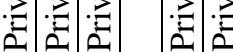
$\cdot \vec{a} \cdot \vec{z} \cdot \vec{z} \cdot \overrightarrow{2} \cdot \overrightarrow{2}$

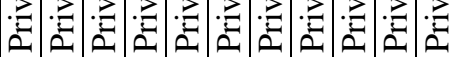

(

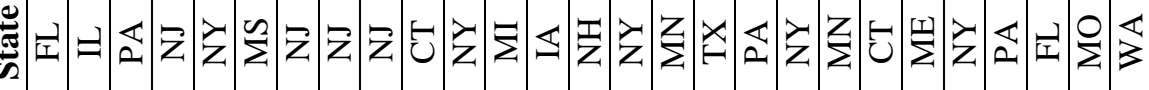

$\frac{\substack{0 \\ 0}}{0}$

$>$

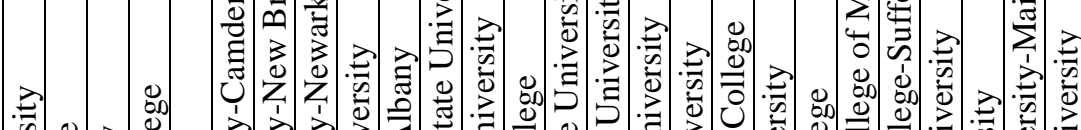

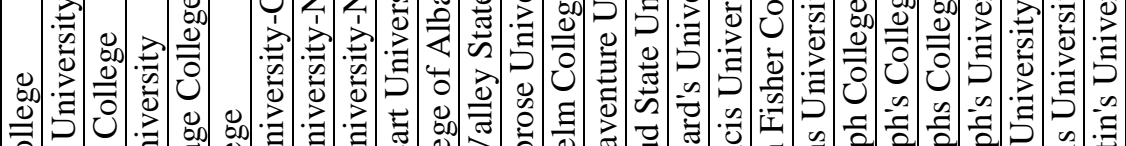
=

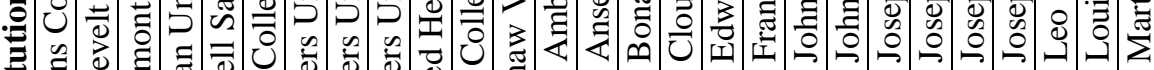

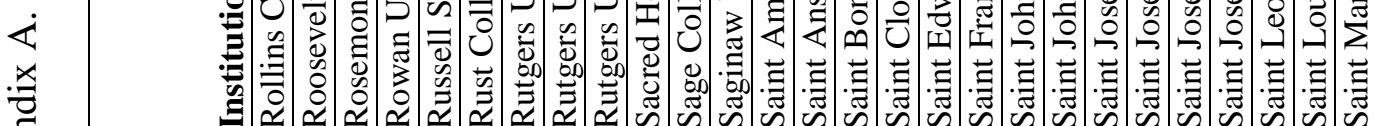
这 


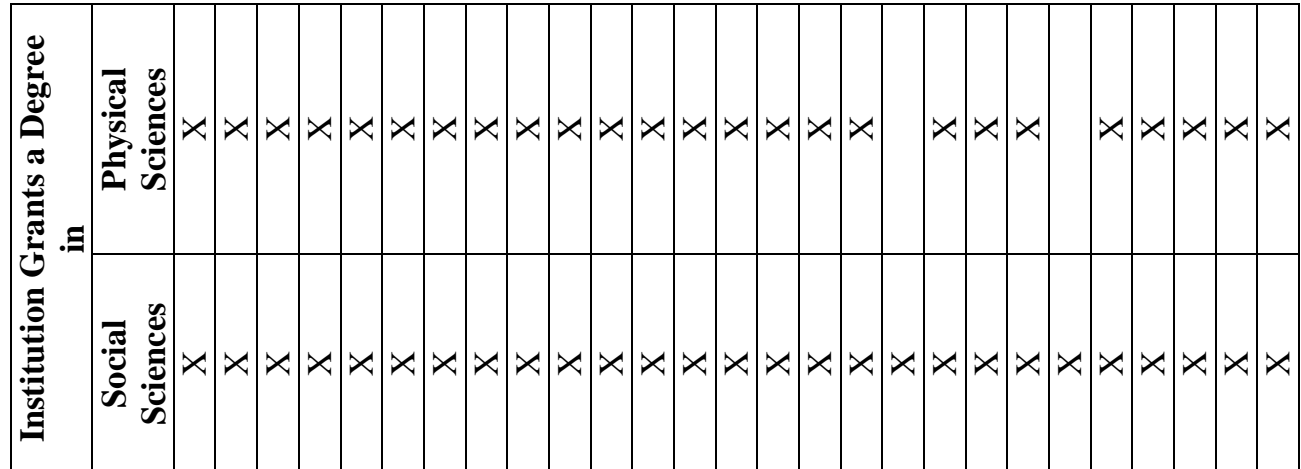

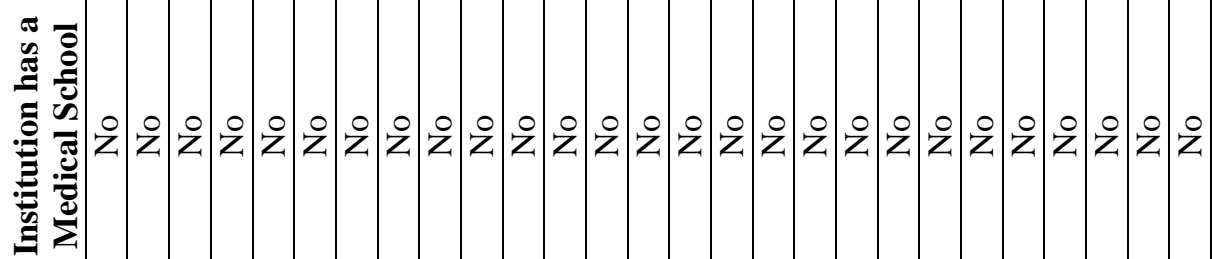

흘

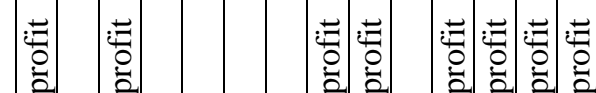

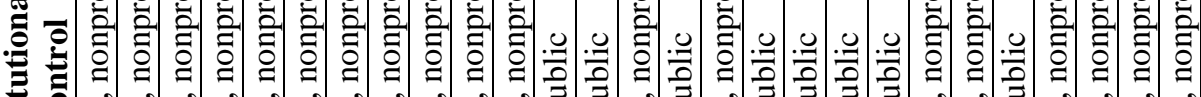

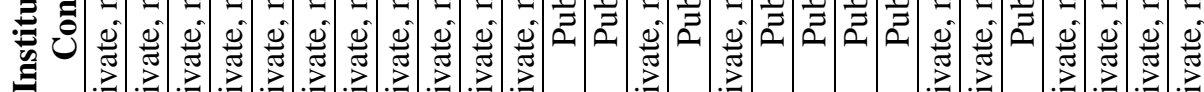
를

高

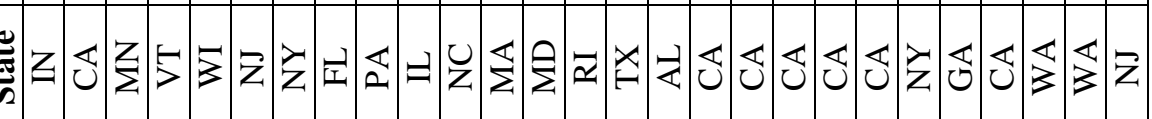

$\stackrel{\oplus}{\Xi}$

$\Xi$

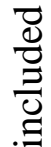

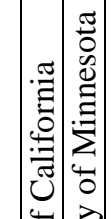

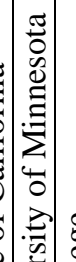

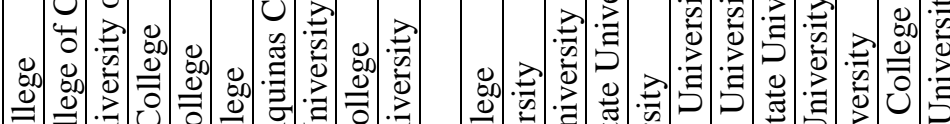

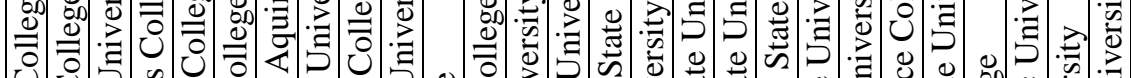

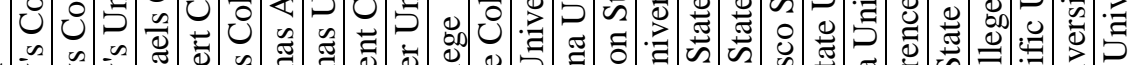

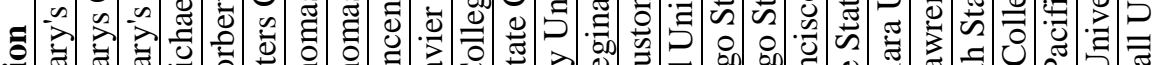

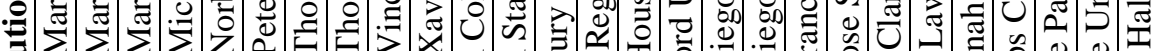

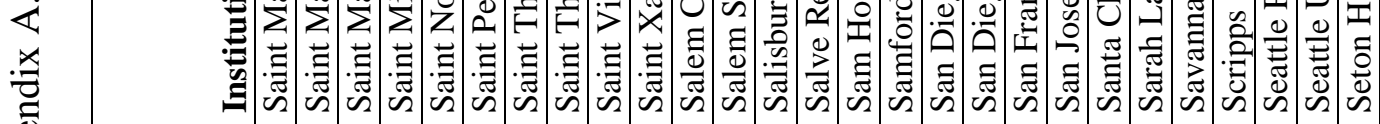

这 


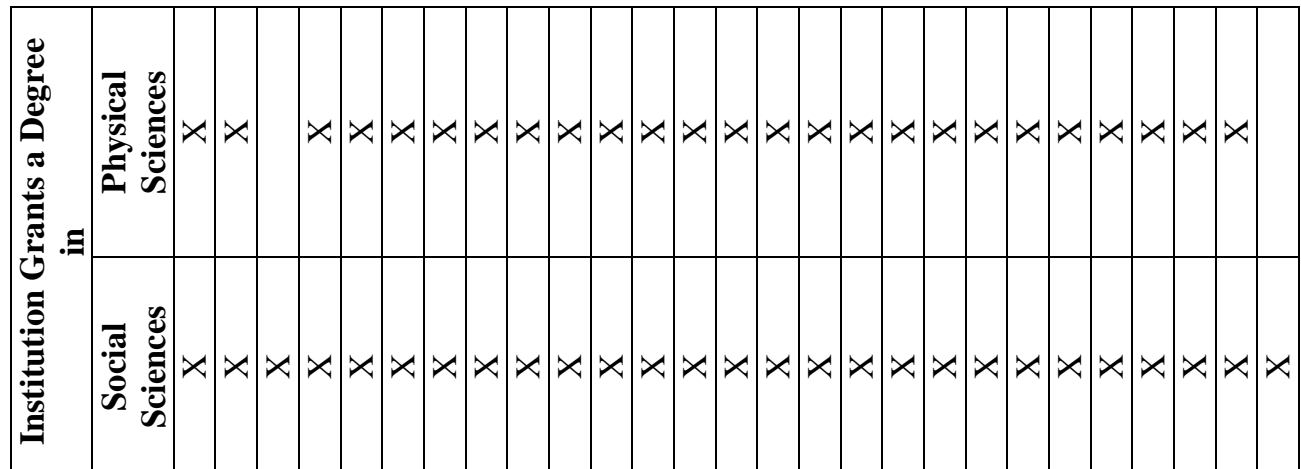

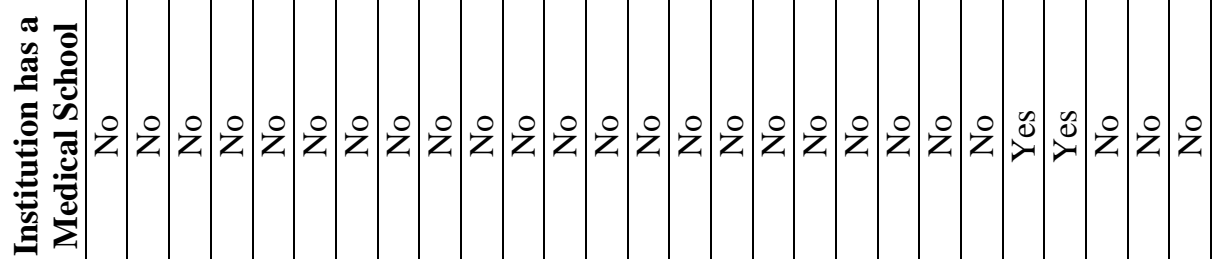

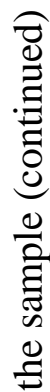

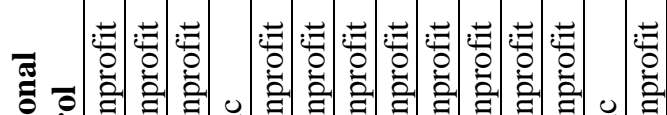

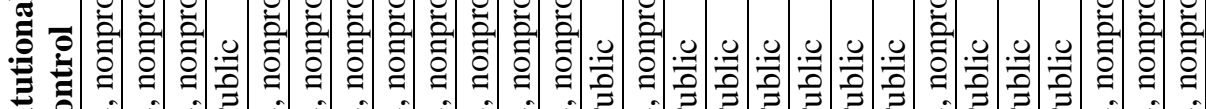

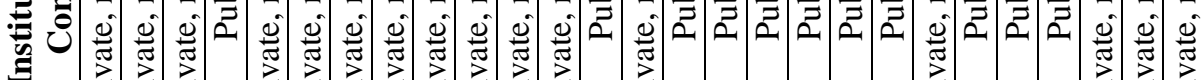

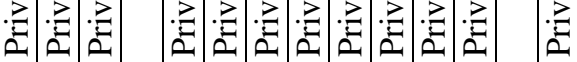

?

¿

站 Z゙

है

.

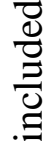

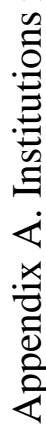




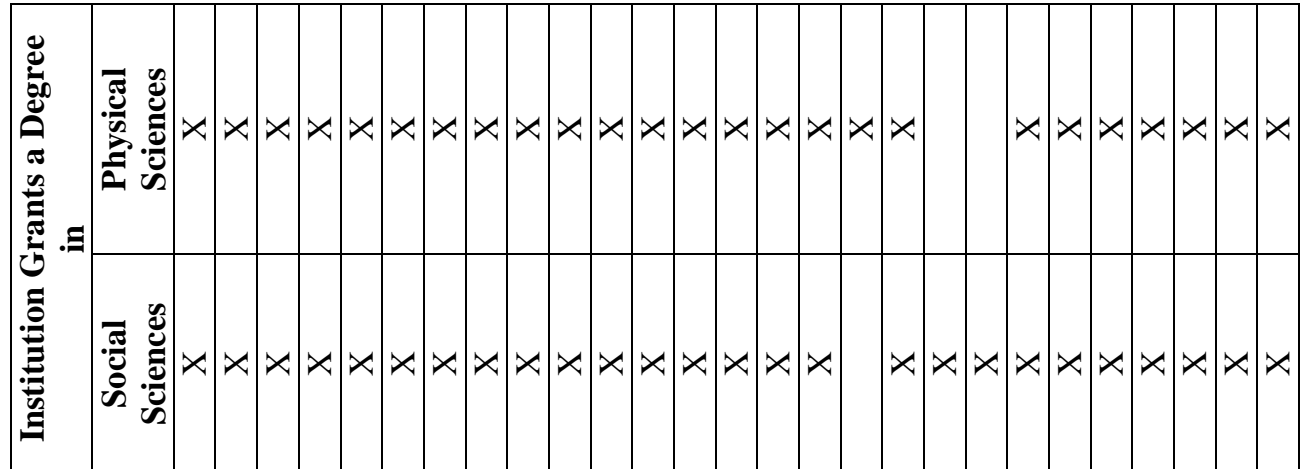

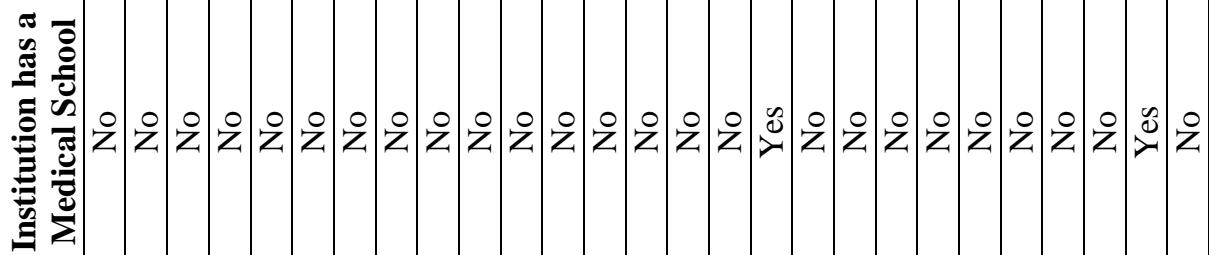

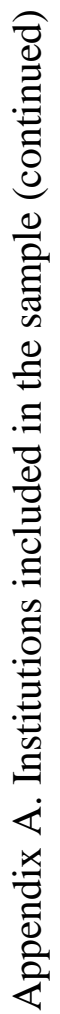

들.

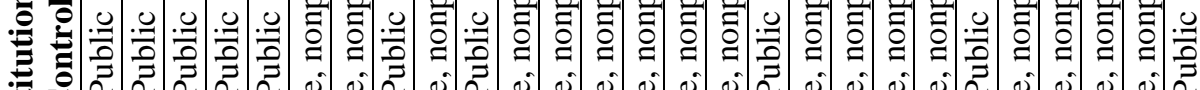

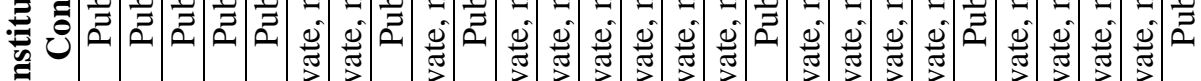

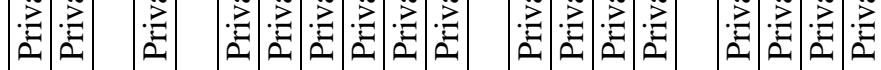

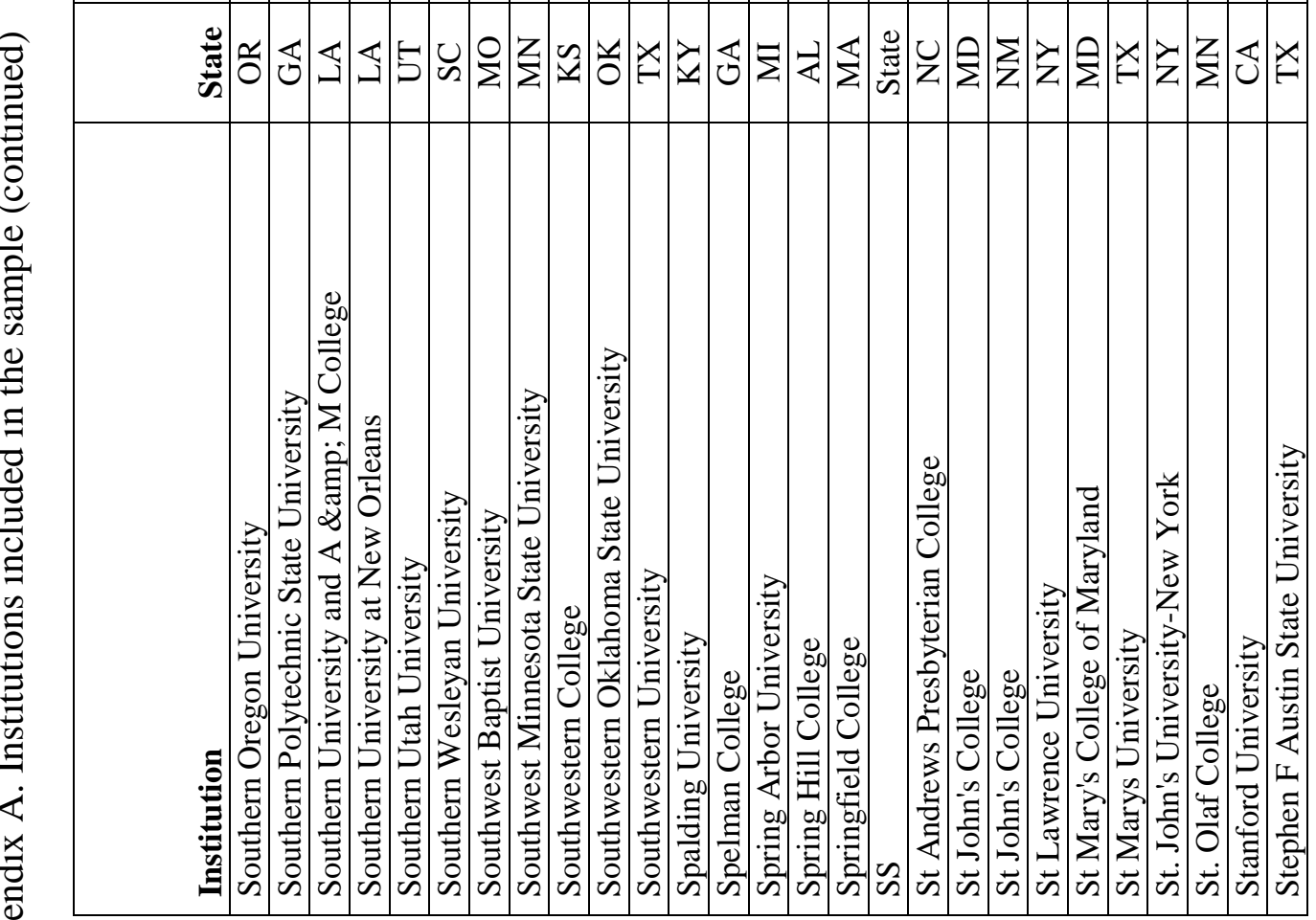




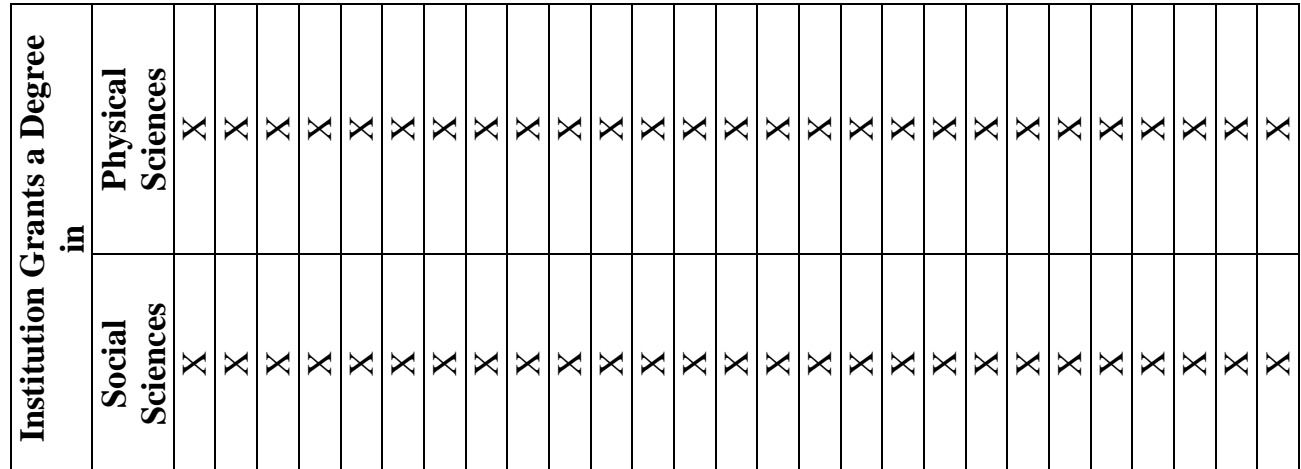

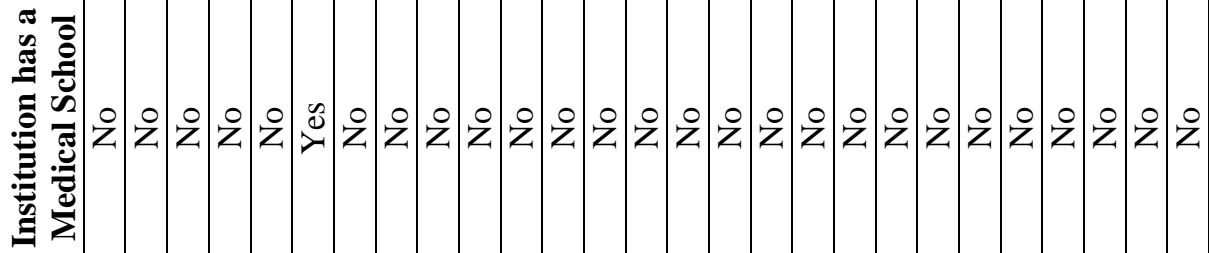

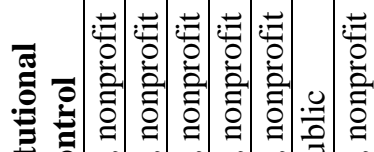

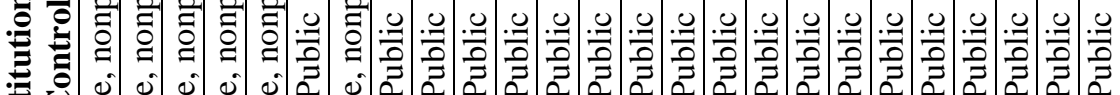

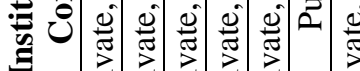

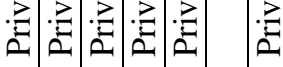

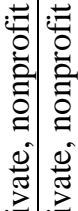
ב

己

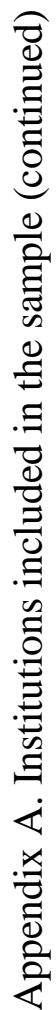

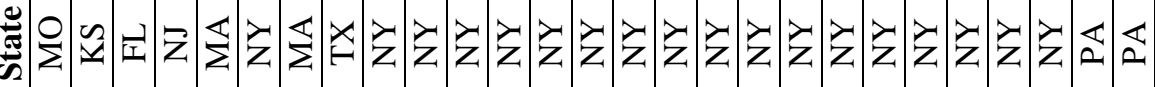

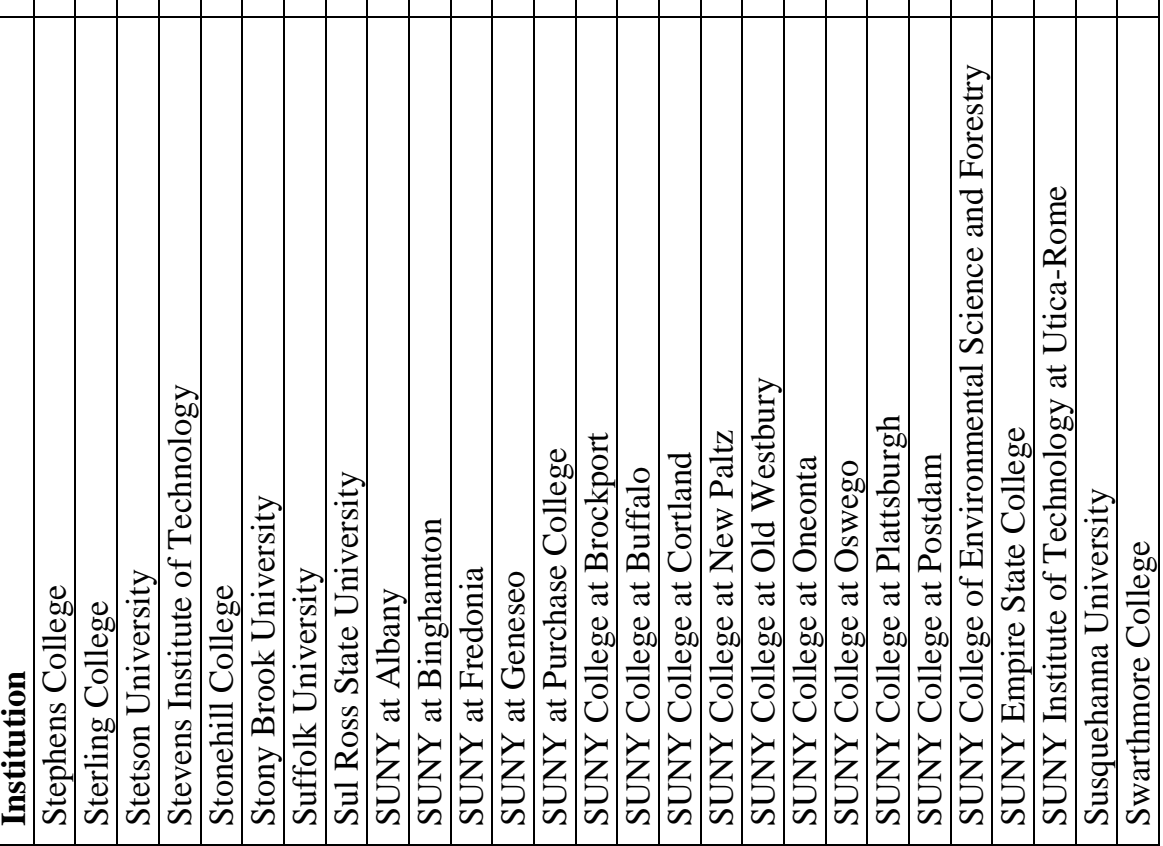




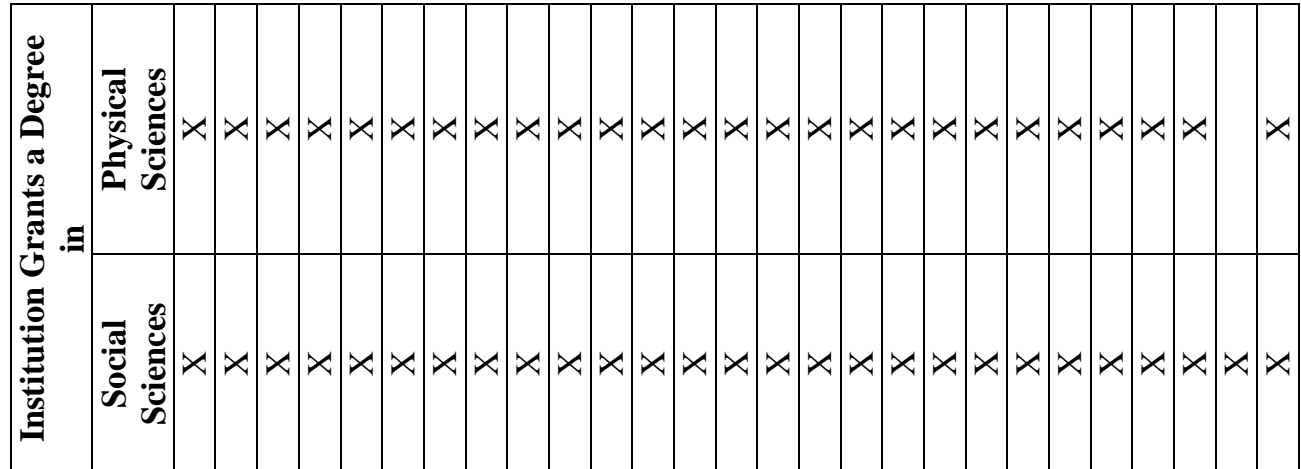

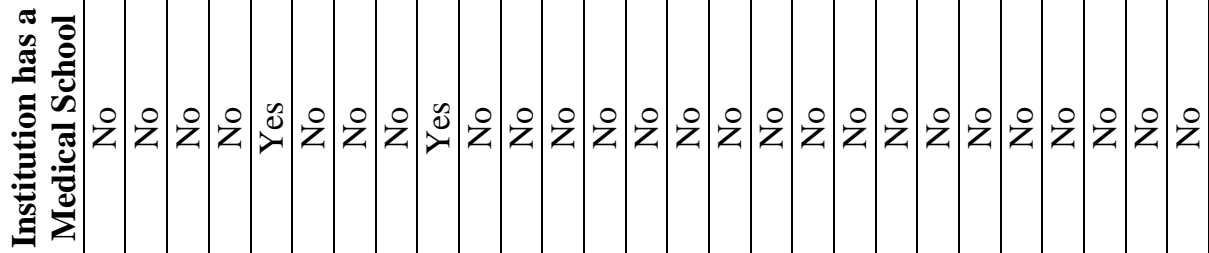

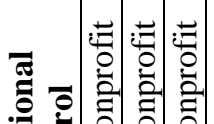

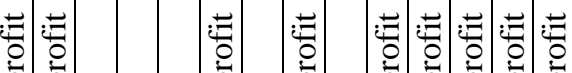

을 홉

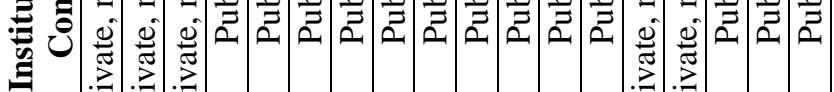
$\cdot \overrightarrow{2} \cdot \vec{\Xi}$

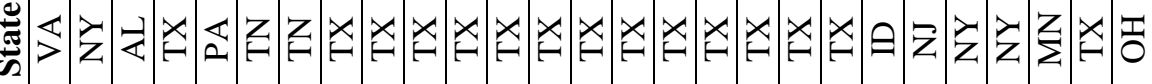




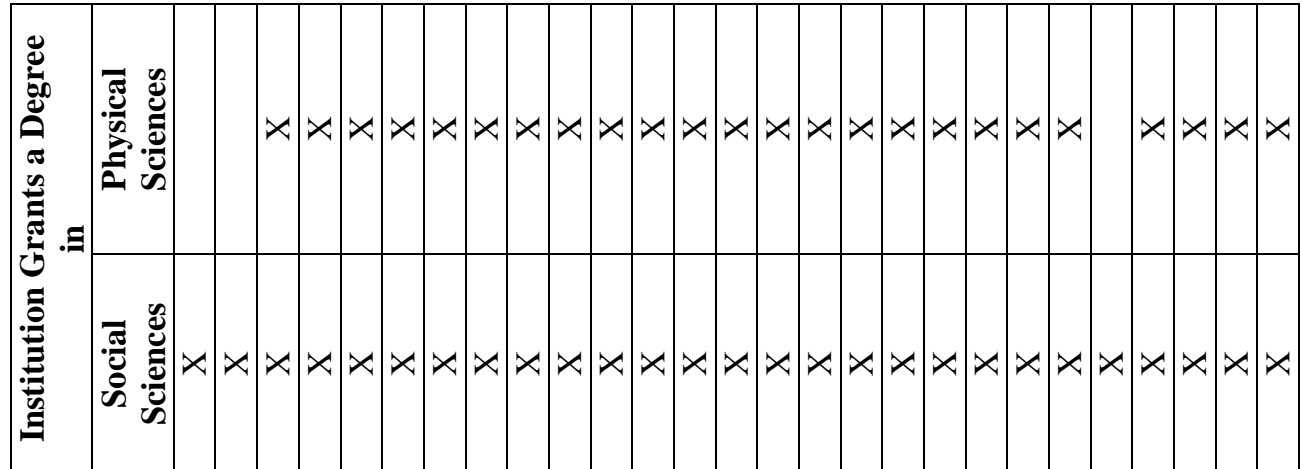

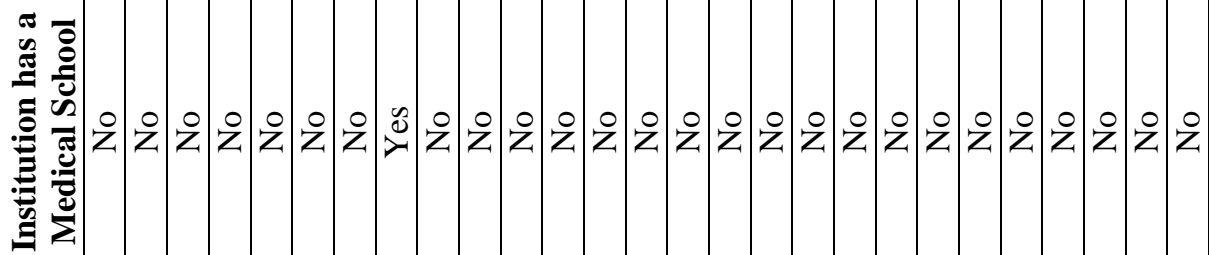

ฮิฮ

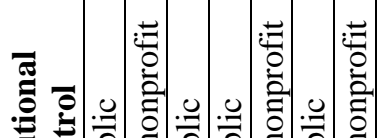

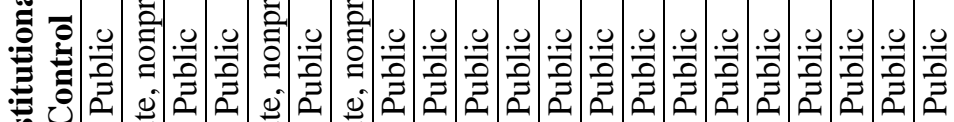

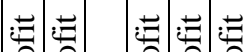

政

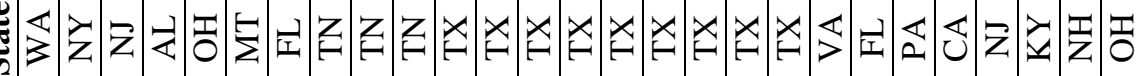




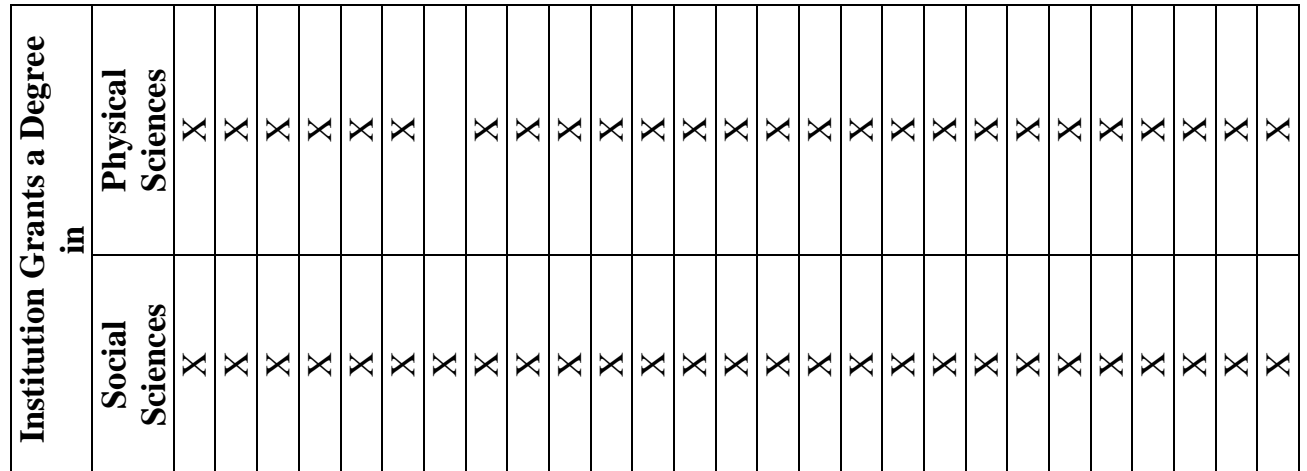

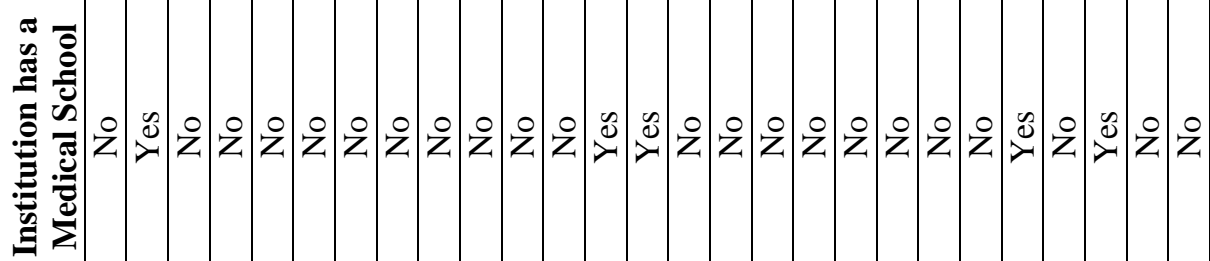

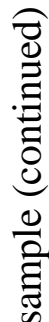

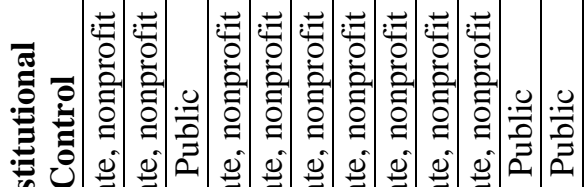

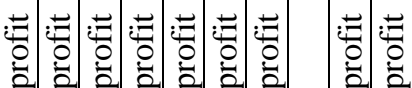

‡

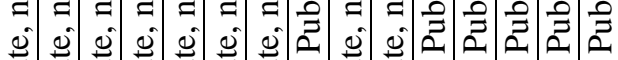

窝

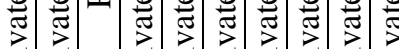

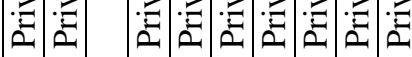

.

$\vec{z} \cdot \vec{z}$

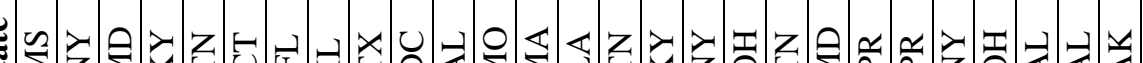

,

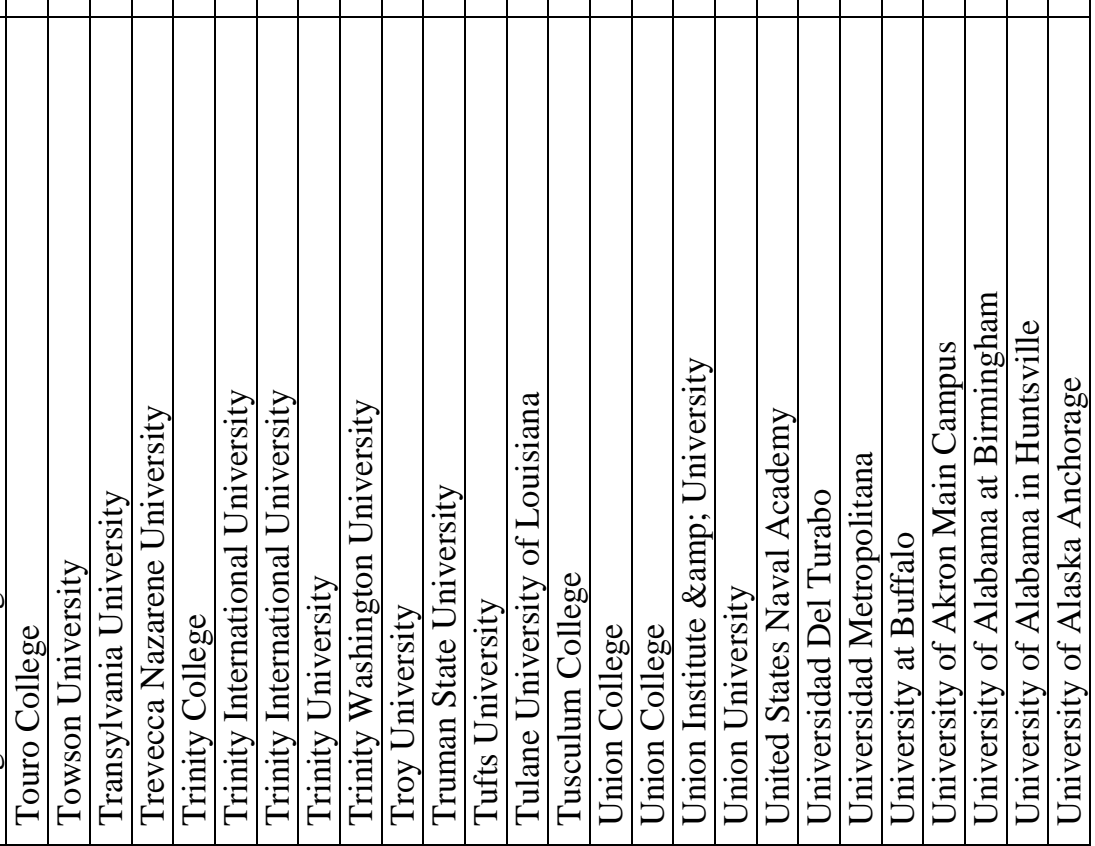

这 


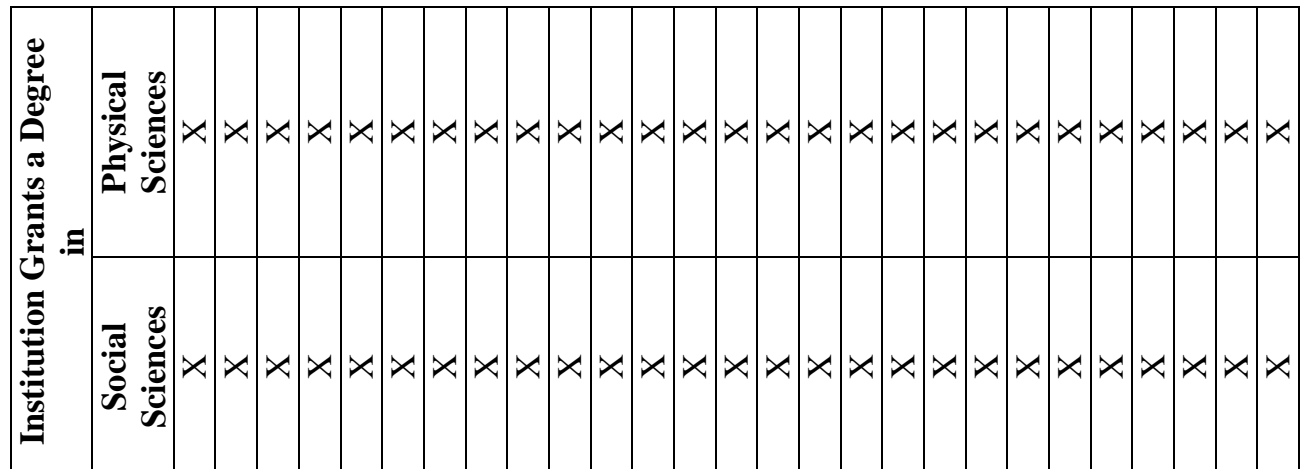

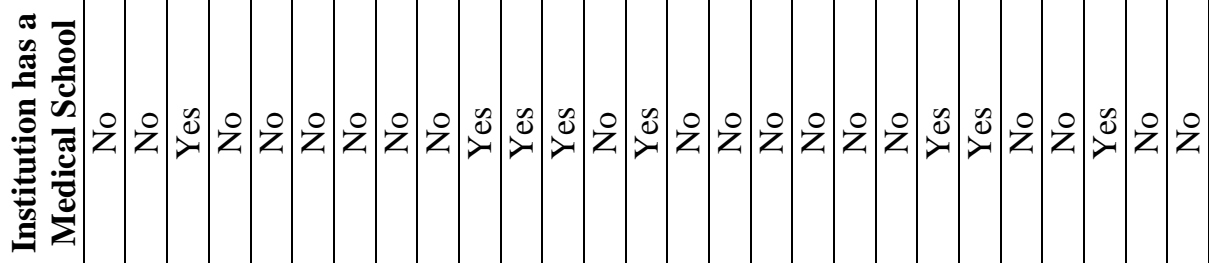

胥

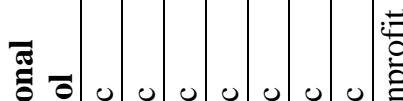

률

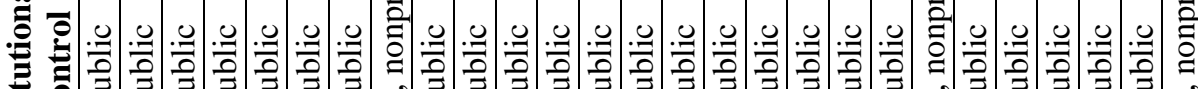

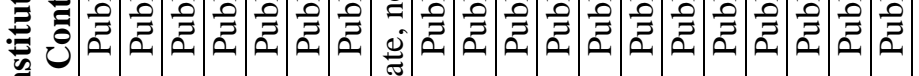

章

ב.

:

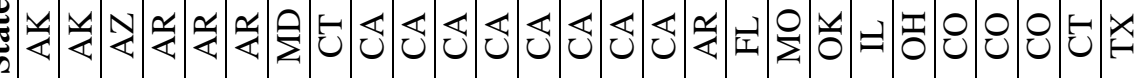

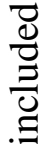

藏

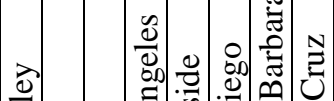

:

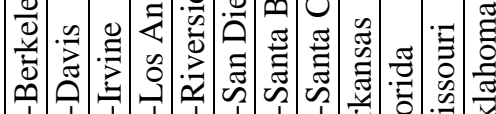

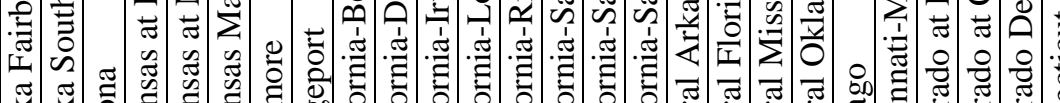

:

前

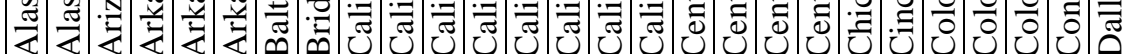

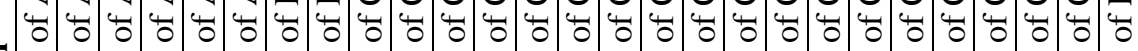

¿

.

$\frac{\mathscr{2}}{2}$

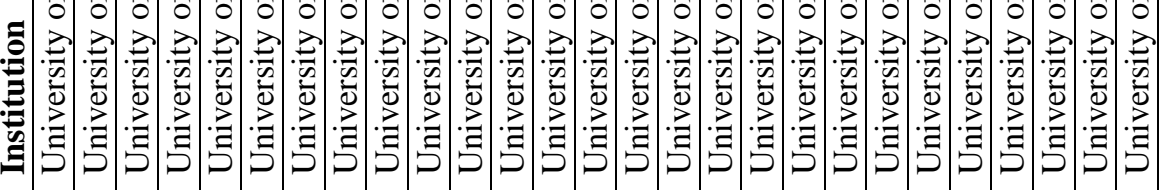




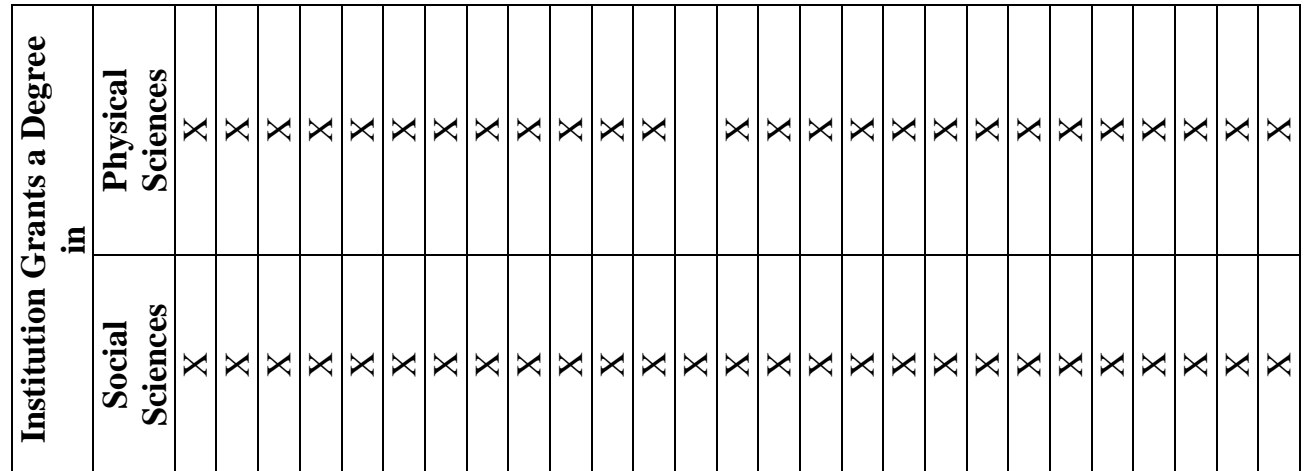

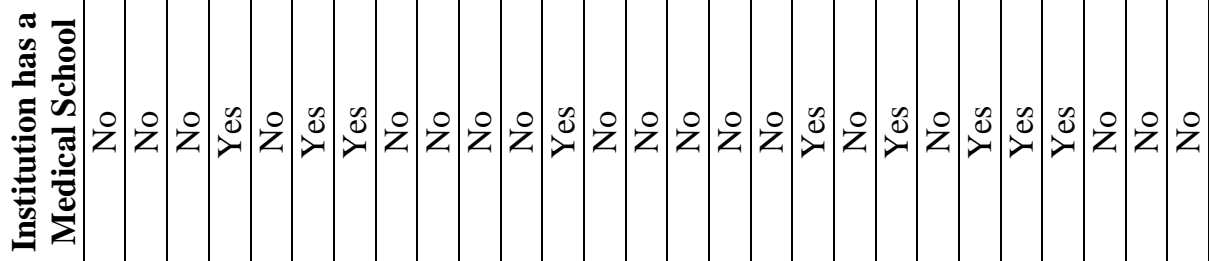

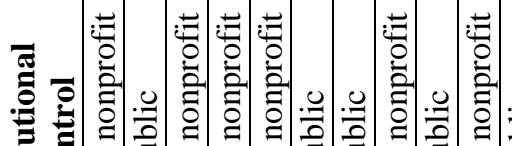

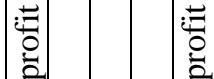

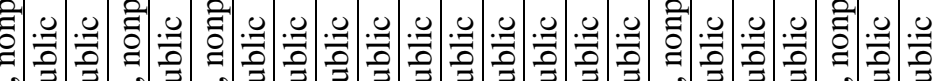

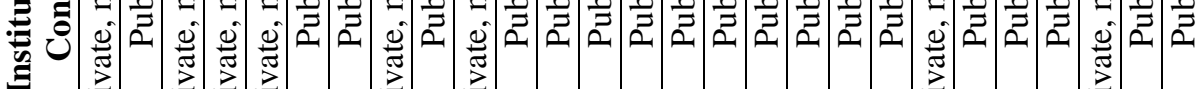

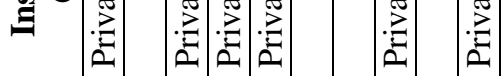

ב

$\Xi$

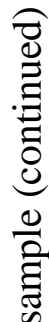

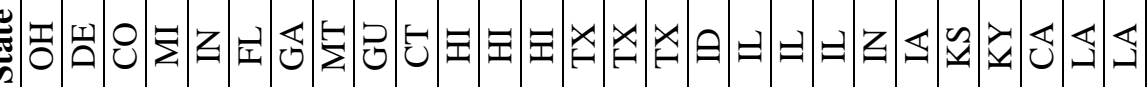

$\frac{7}{\frac{0}{0}}$

:

ธ

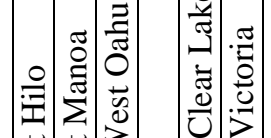

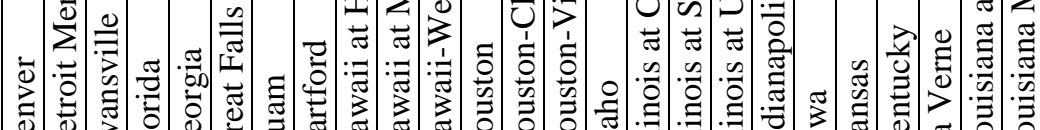

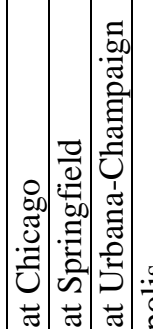

:

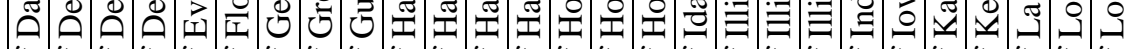

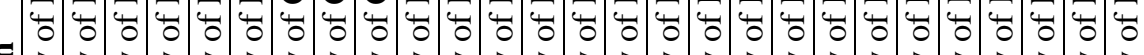

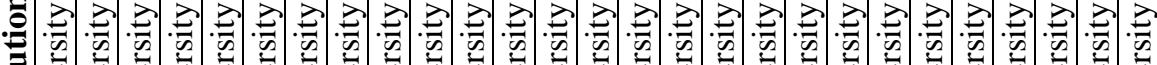

$\varangle$

$\stackrel{x}{g}$

$\frac{2}{2}$ 


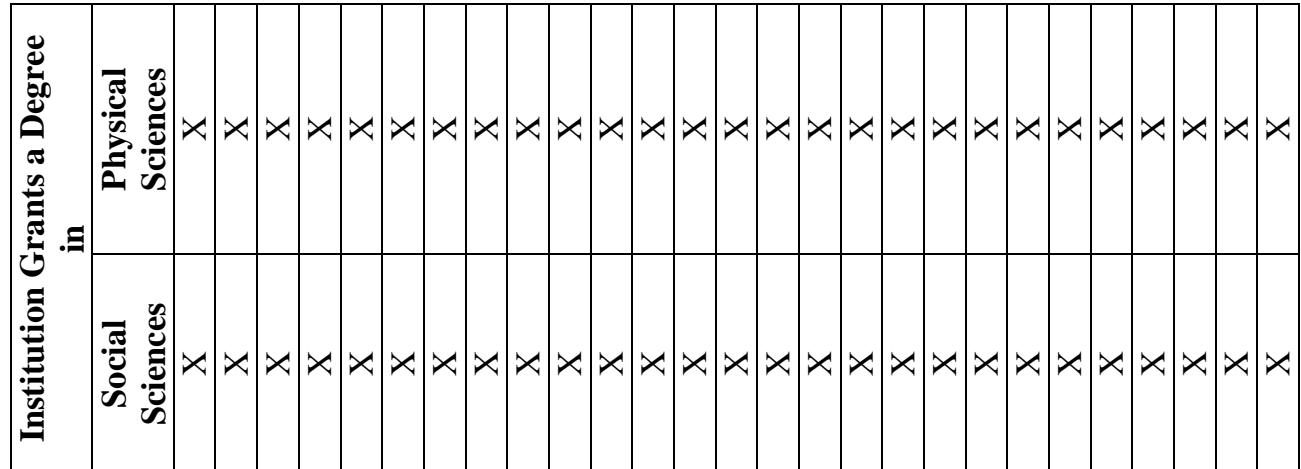

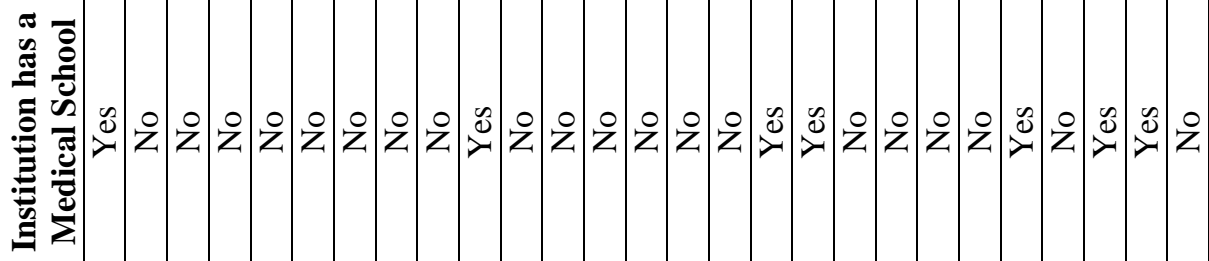

苞

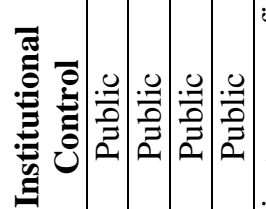

응

릉

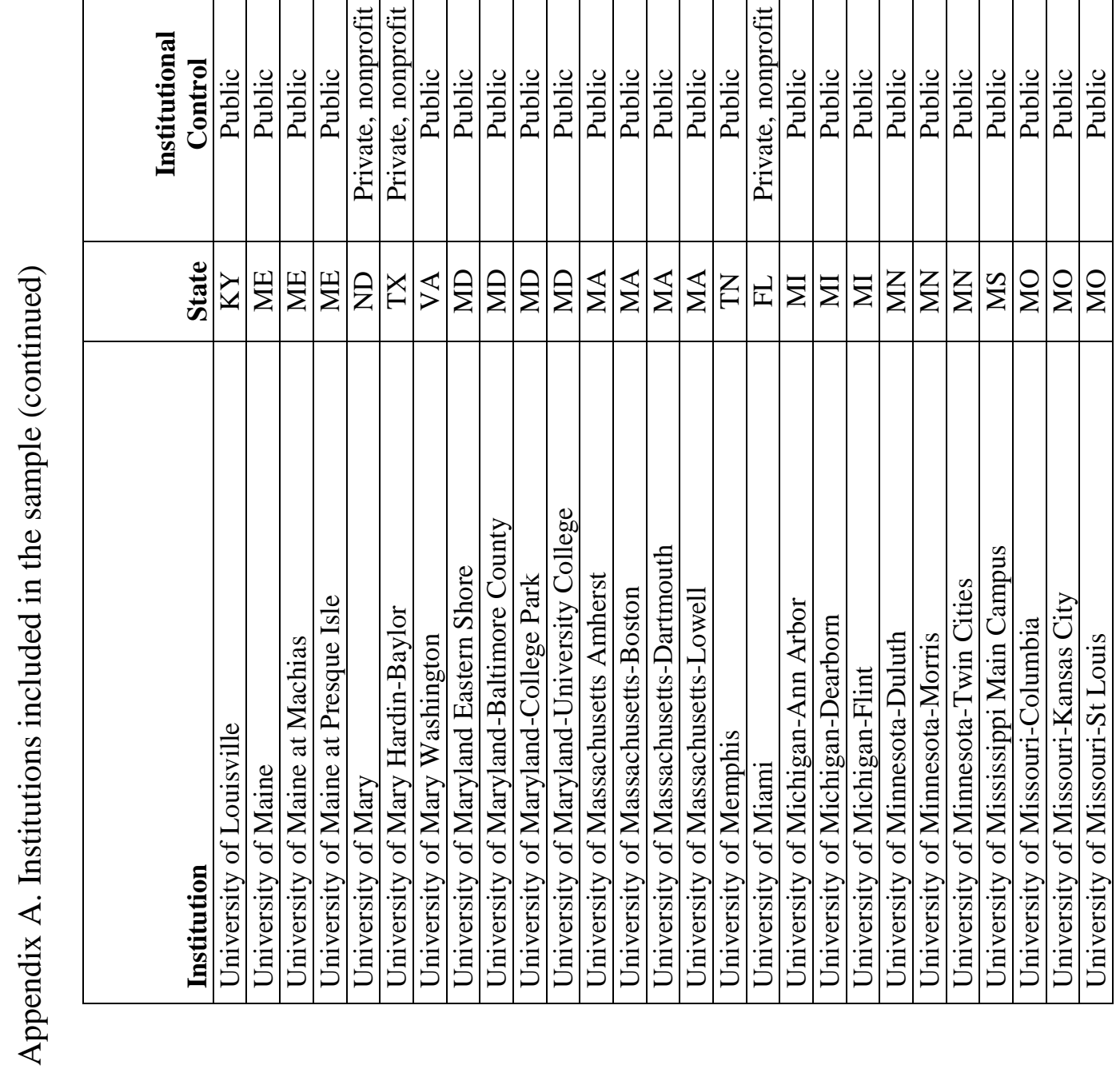




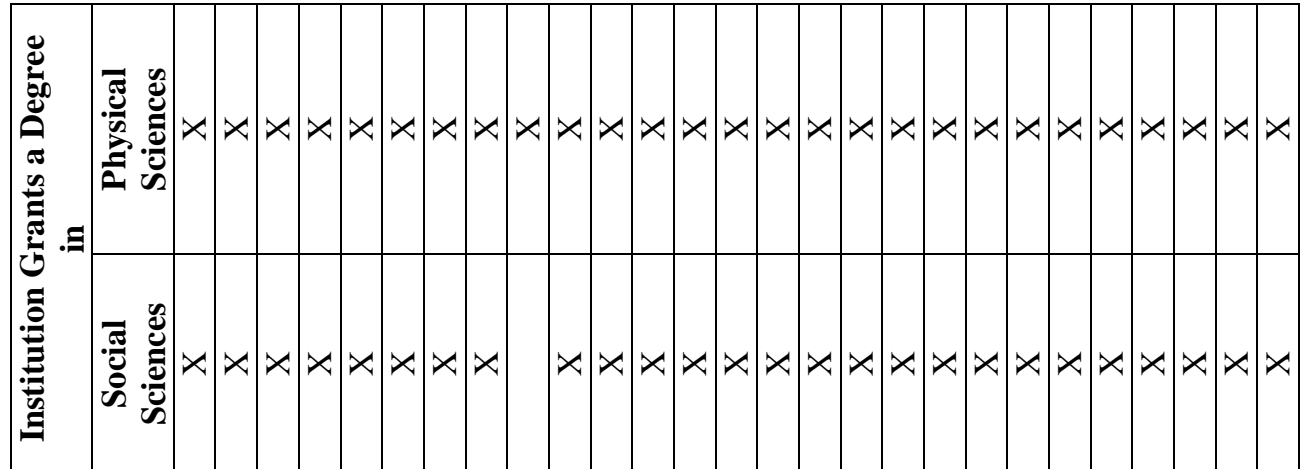

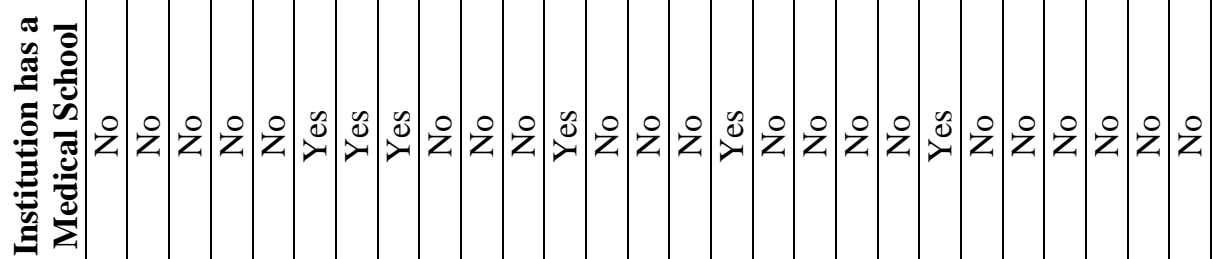

可

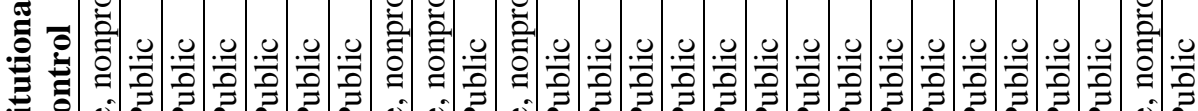

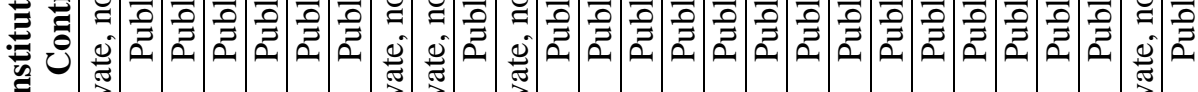

$\Xi$ $\stackrel{2}{2}$

$\cdot \vec{\Xi} \cdot \vec{z} \cdot \vec{z}$

$\stackrel{\vec{Z}}{2}$

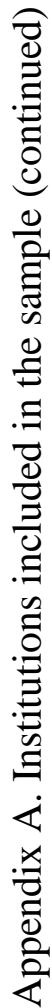

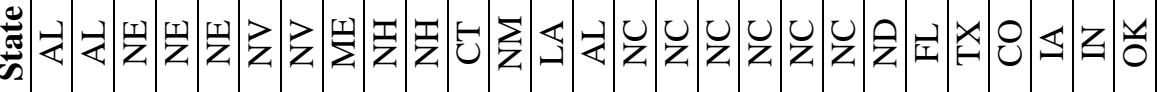




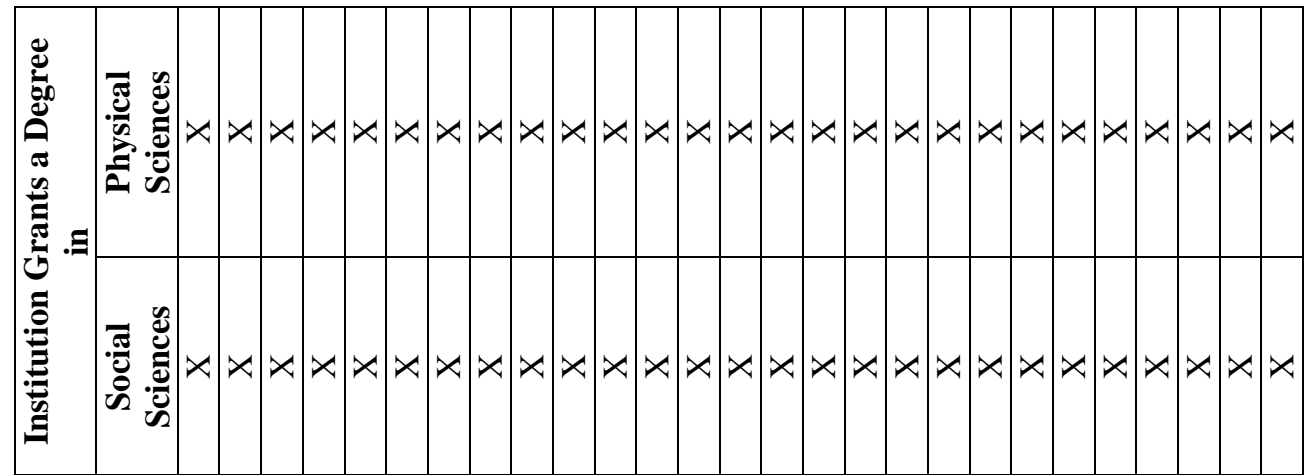

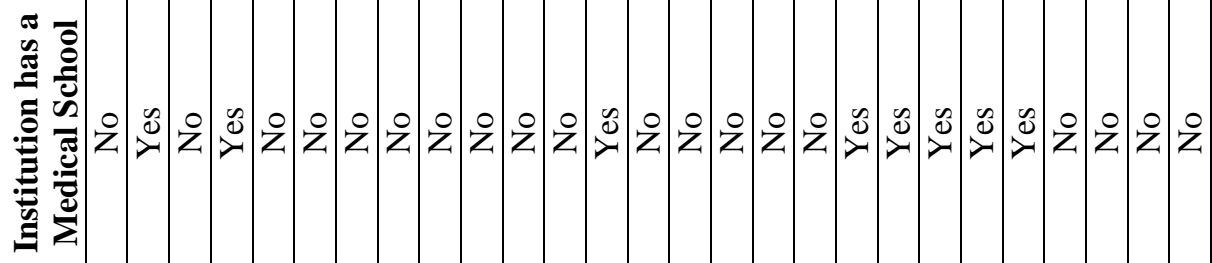

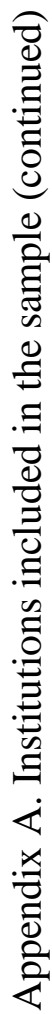

无

进

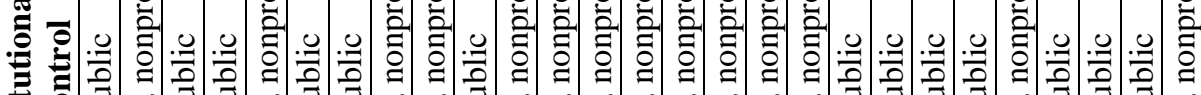

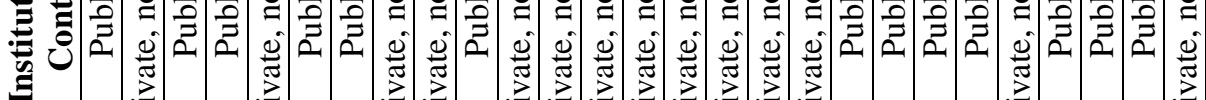

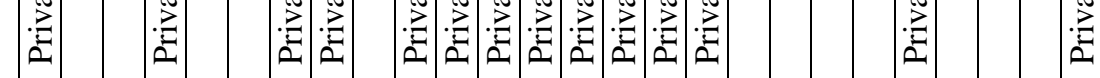

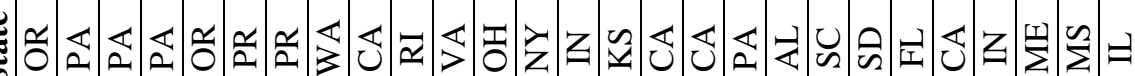

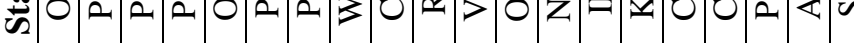




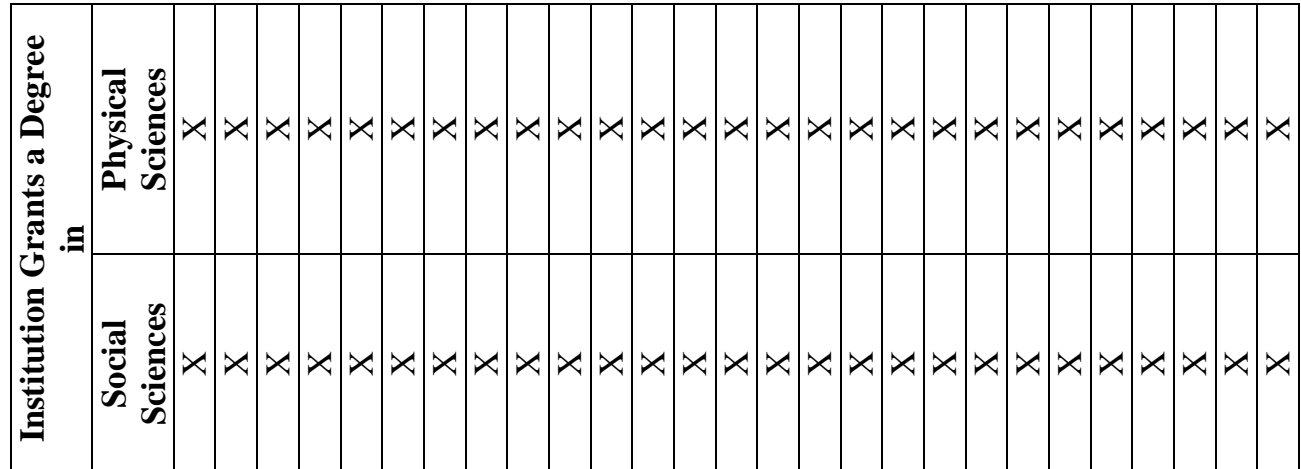

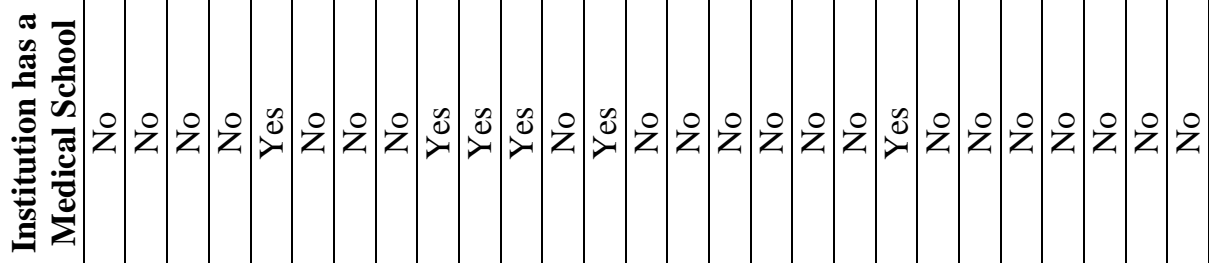

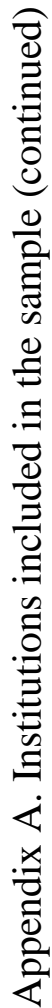

西

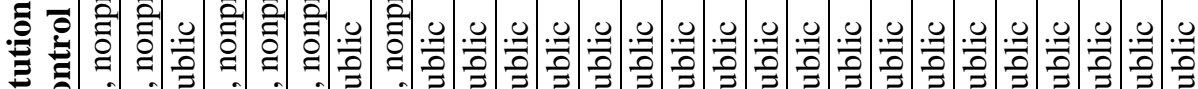

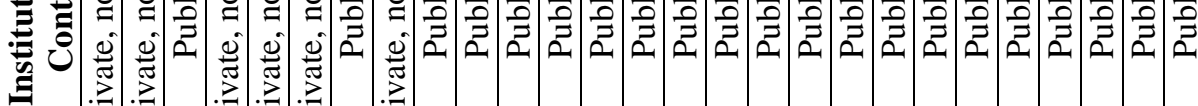

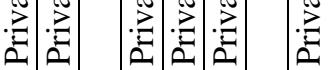

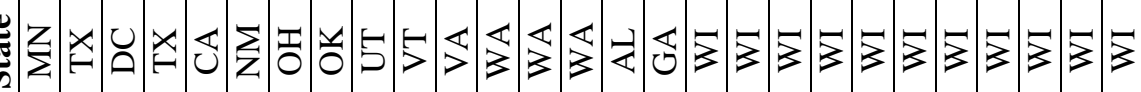

$\pi$

ถู)

ะ ปี

है

音

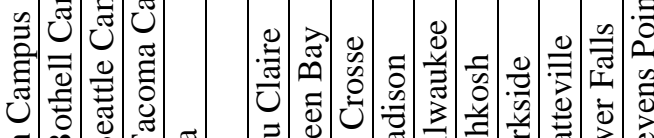

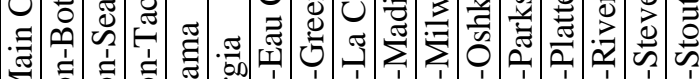

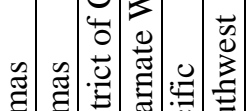

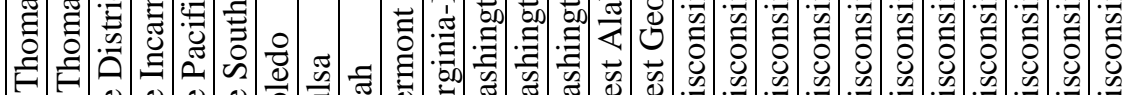

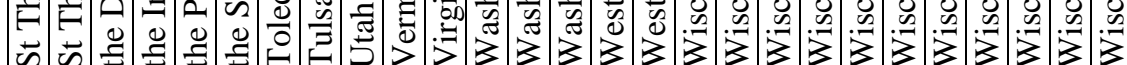

类

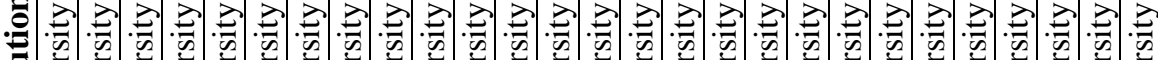




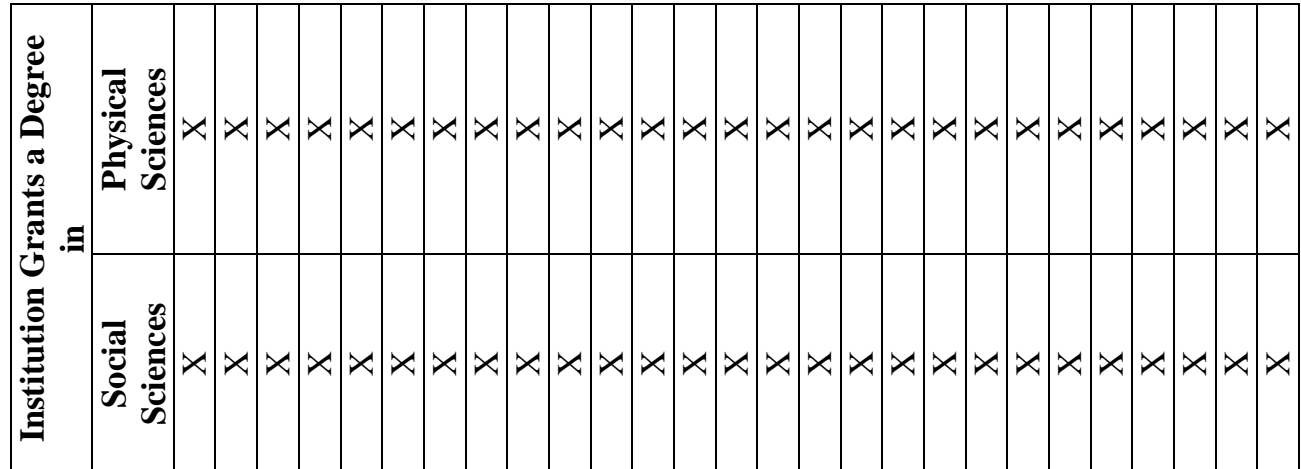

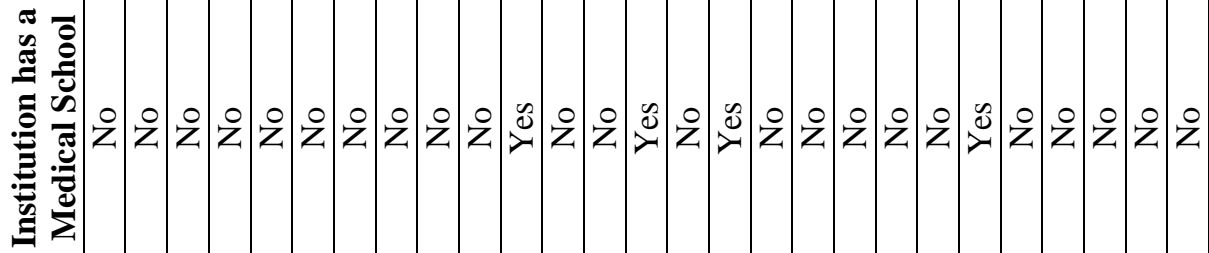

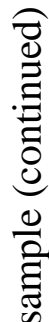

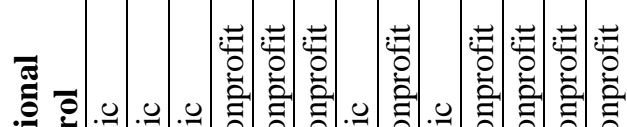

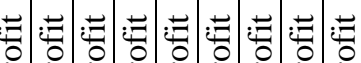

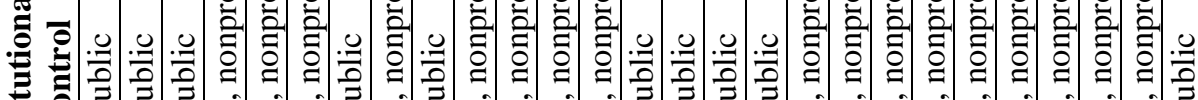

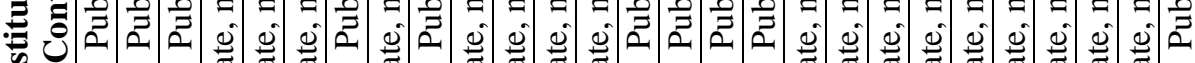
⿹弋工

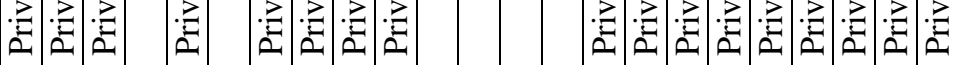

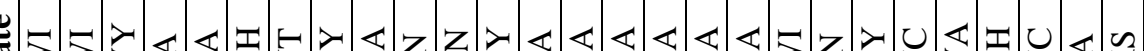

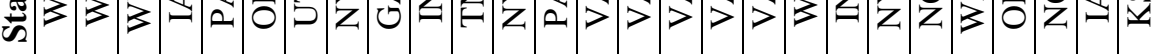

:

离

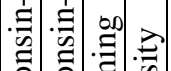




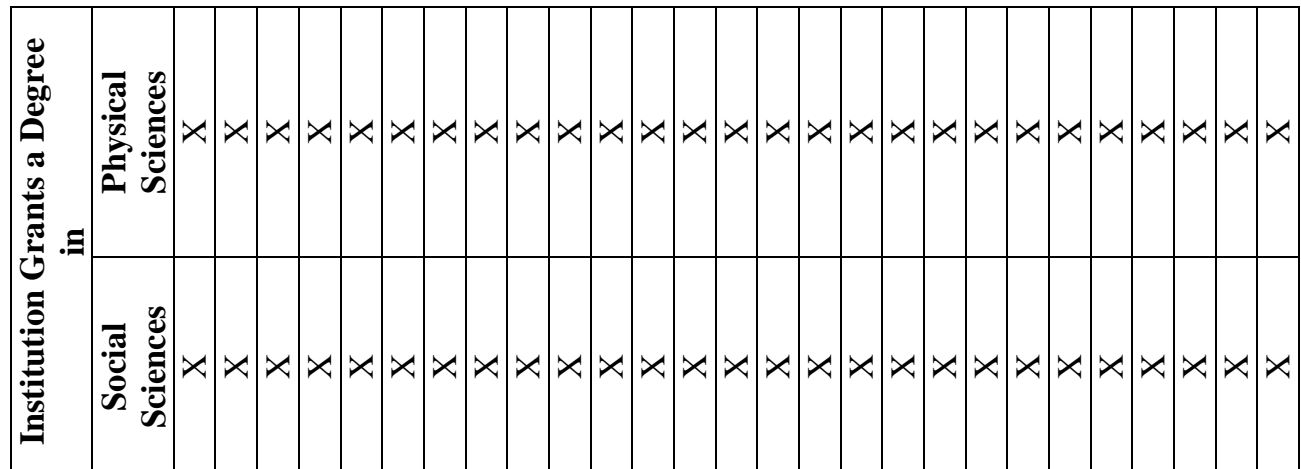

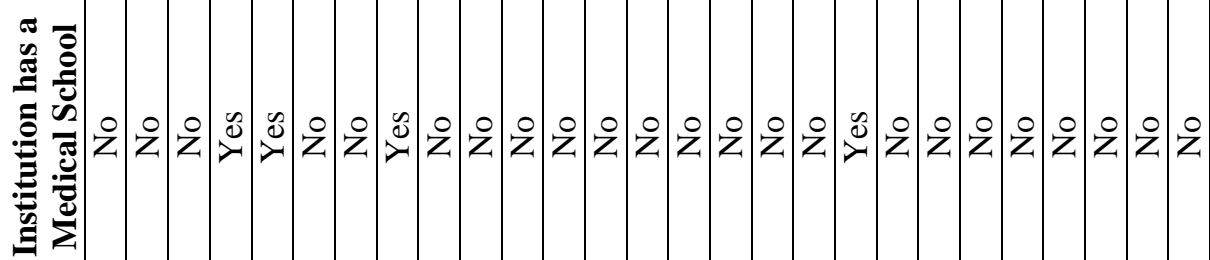

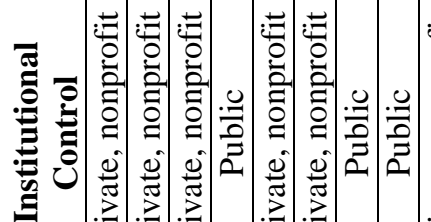

들

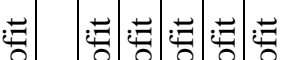

은 은

$:=$ 흐응

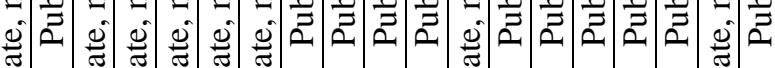

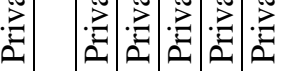

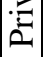

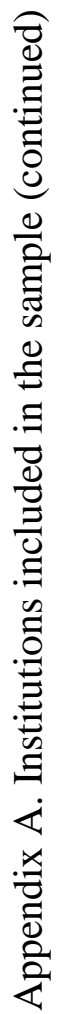

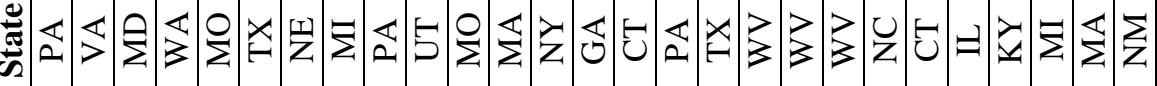

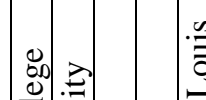

U

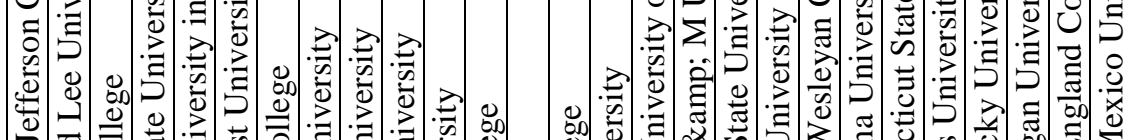
\&

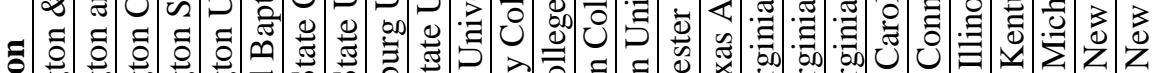
.0 to

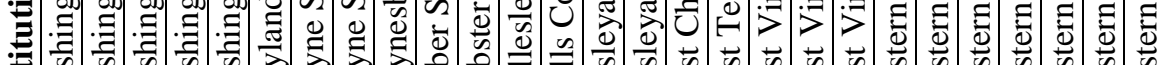

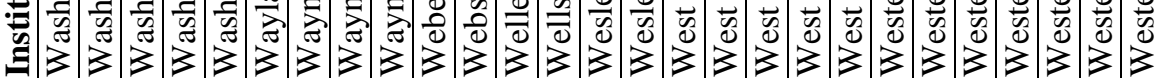

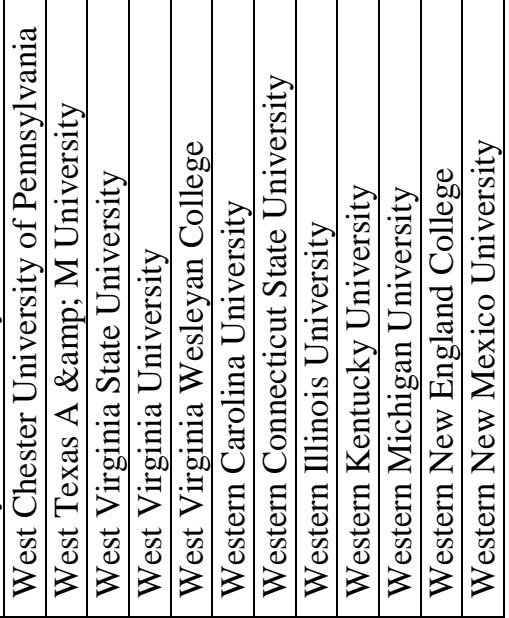




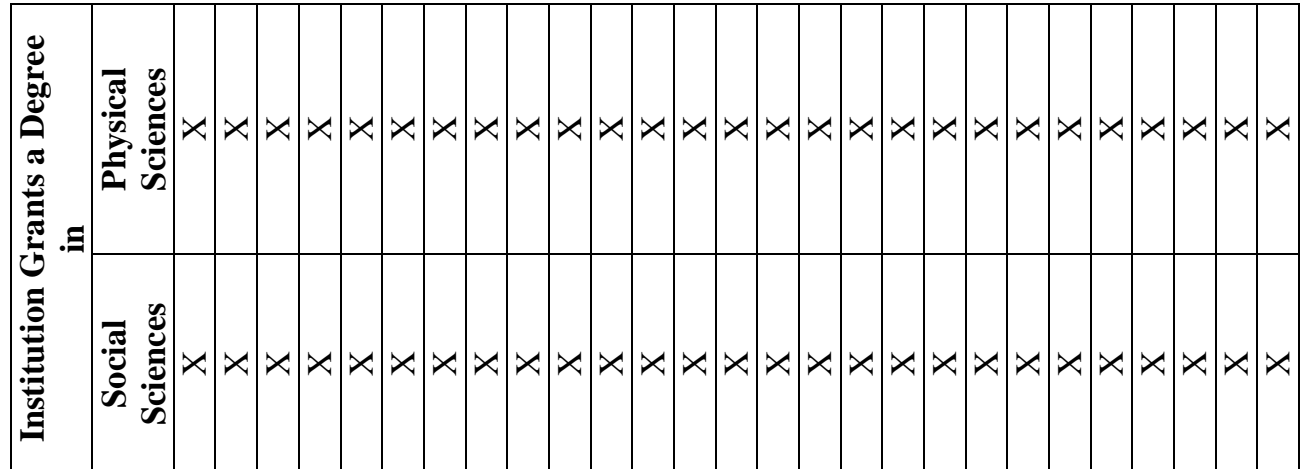

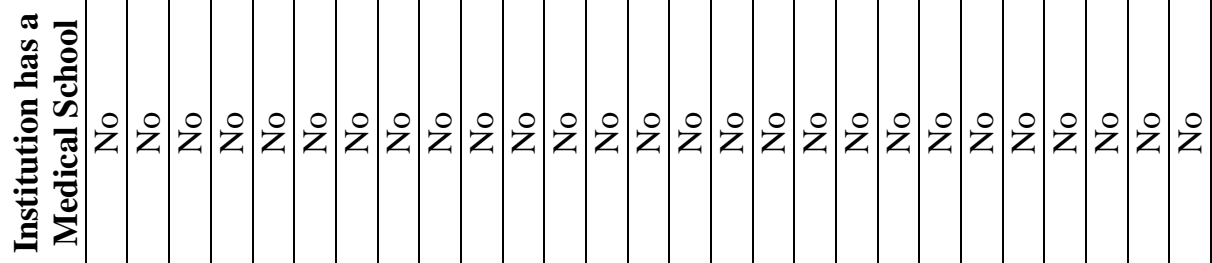

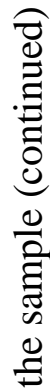

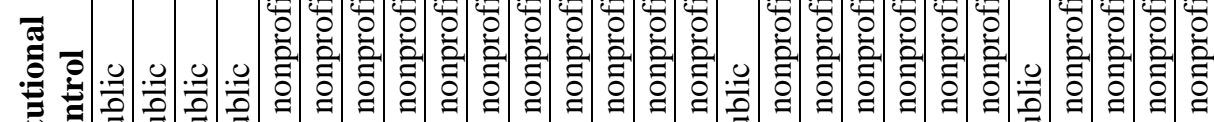

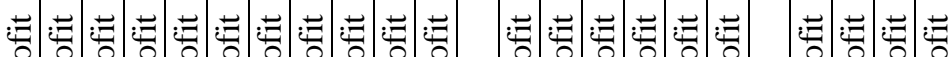

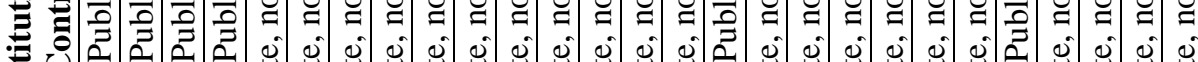

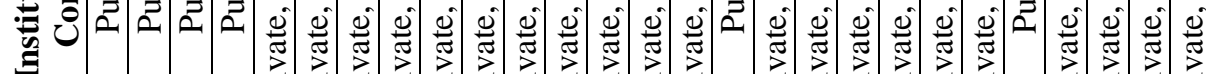

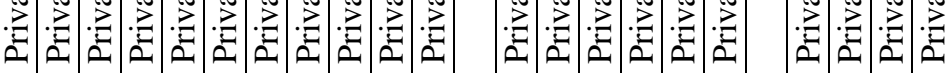

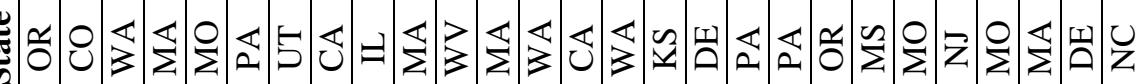




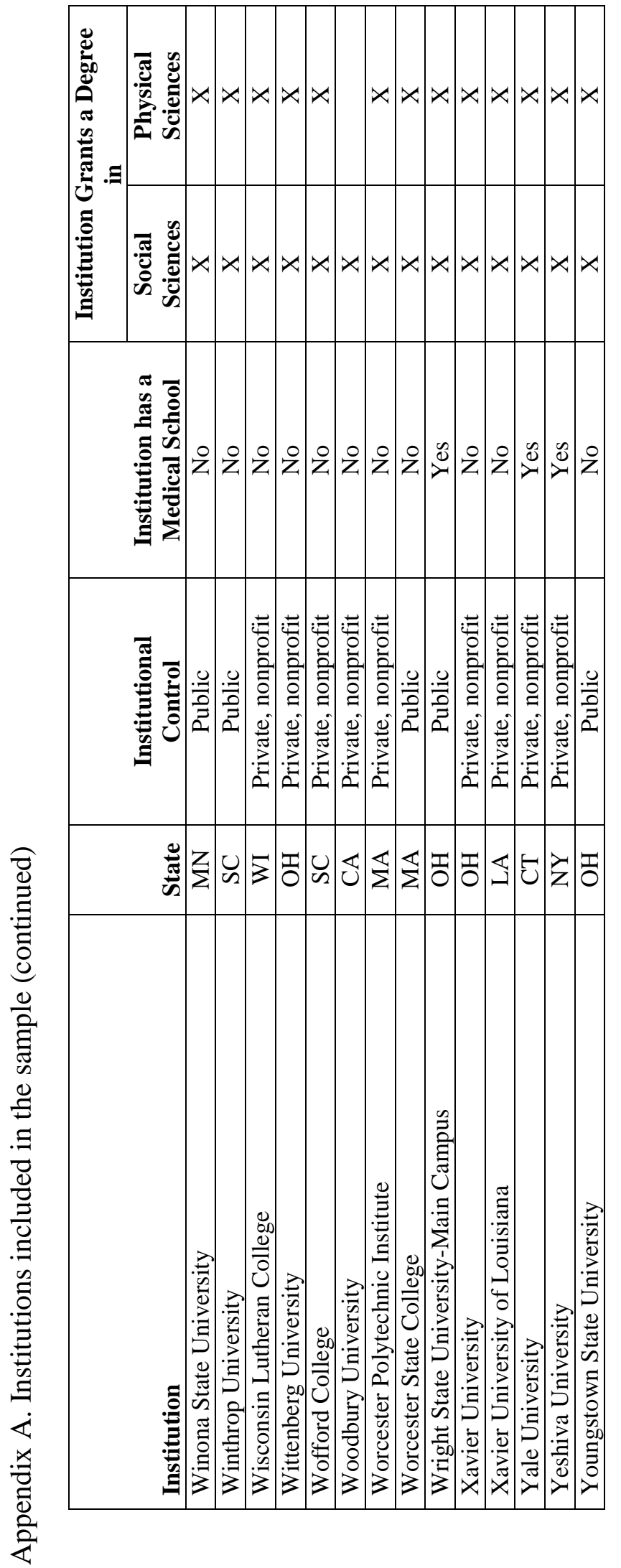


Appendix B. IPEDS program disciplines grouped as social sciences and physical sciences

\begin{tabular}{|c|c|}
\hline Social Sciences & Physical Sciences \\
\hline 04-Architecture and Related Programs & 01-Agricultural Business and Production \\
\hline 05-Area, Ethnic and Cultural Studies & 02-Agricultural Sciences \\
\hline $\begin{array}{l}\text { 08-Marketing Operations/Marketing and } \\
\text { Distribution }\end{array}$ & $\begin{array}{l}\text { 03-Conservation and Renewable Natural } \\
\text { Resources }\end{array}$ \\
\hline 09-Communications & 14-Engineering \\
\hline 10-Communications Technologies & 15-Engineering-Related Technologies \\
\hline 11-Computer and Information Sciences & 26-Biological Science/Life Sciences \\
\hline 12-Personal and Miscellaneous Services & 29-Military Technologies \\
\hline 13-Education & 40-Physical Sciences \\
\hline 16-Foreign Languages and Literatures & 41-Science Technologies \\
\hline 19-Home Economics, General & 46-Construction Trades \\
\hline 20-Vocational Home & 47-Mechanics and Repairers \\
\hline 22-Law and Legal Studies & 48-Precision Production Trades \\
\hline 23-English Language and Literature/Letters & $\begin{array}{l}\text { 49-Transportation and Material Moving } \\
\text { Workers }\end{array}$ \\
\hline $\begin{array}{l}\text { 24-Liberal Arts and Studies, General } \\
\text { Sciences and Humanities }\end{array}$ & $\begin{array}{l}\text { 51-Health Professions and Related } \\
\text { Sciences }\end{array}$ \\
\hline \multicolumn{2}{|l|}{ 25-Library Science } \\
\hline \multicolumn{2}{|l|}{ 27-Mathematics } \\
\hline \multicolumn{2}{|l|}{ 30-Multi/Interdisciplinary Studies } \\
\hline \multicolumn{2}{|l|}{$\begin{array}{l}\text { 31-Parks, Recreation, Leisure and Fitness } \\
\text { Studies }\end{array}$} \\
\hline \multicolumn{2}{|l|}{ 38-Philosophy and Religion } \\
\hline \multicolumn{2}{|l|}{$\begin{array}{l}\text { 39-Theological Studies and Religious } \\
\text { Vocations }\end{array}$} \\
\hline \multicolumn{2}{|l|}{ 42-Psychology } \\
\hline \multicolumn{2}{|l|}{ 43-Protective Services } \\
\hline \multicolumn{2}{|l|}{ 44-Public Administration and Services } \\
\hline \multicolumn{2}{|l|}{ 45-Social Sciences and History } \\
\hline 50-Visual and Performing Arts & \\
\hline $\begin{array}{l}\text { 52-Business Management and } \\
\text { Administrative Services }\end{array}$ & \\
\hline
\end{tabular}

